University of Nebraska - Lincoln

DigitalCommons@University of Nebraska - Lincoln

2008

Hydrogeology, Chemical Characteristics, and Transport Processes in the Zone of Contribution of a Public-Supply Well in York, Nebraska

\author{
Matthew K. Landon \\ Brian R. Clark \\ USGS, brclark@usgs.gov \\ Peter B. McMahon \\ USGS, pmcmahon@usgs.gov \\ Michael J. Turco \\ Virginia L. McGuire
}

Follow this and additional works at: https://digitalcommons.unl.edu/usgspubs

Part of the Earth Sciences Commons

Landon, Matthew K.; Clark, Brian R.; McMahon, Peter B.; Turco, Michael J.; and McGuire, Virginia L., "Hydrogeology, Chemical Characteristics, and Transport Processes in the Zone of Contribution of a Public-Supply Well in York, Nebraska" (2008). Publications of the US Geological Survey. 37.

https://digitalcommons.unl.edu/usgspubs/37

This Article is brought to you for free and open access by the US Geological Survey at DigitalCommons@University of Nebraska - Lincoln. It has been accepted for inclusion in Publications of the US Geological Survey by an authorized administrator of DigitalCommons@University of Nebraska - Lincoln. 


\section{Hydrogeology, Chemical Characteristics, and Transport Processes in the Zone of Contribution of a Public-Supply Well in York, Nebraska}

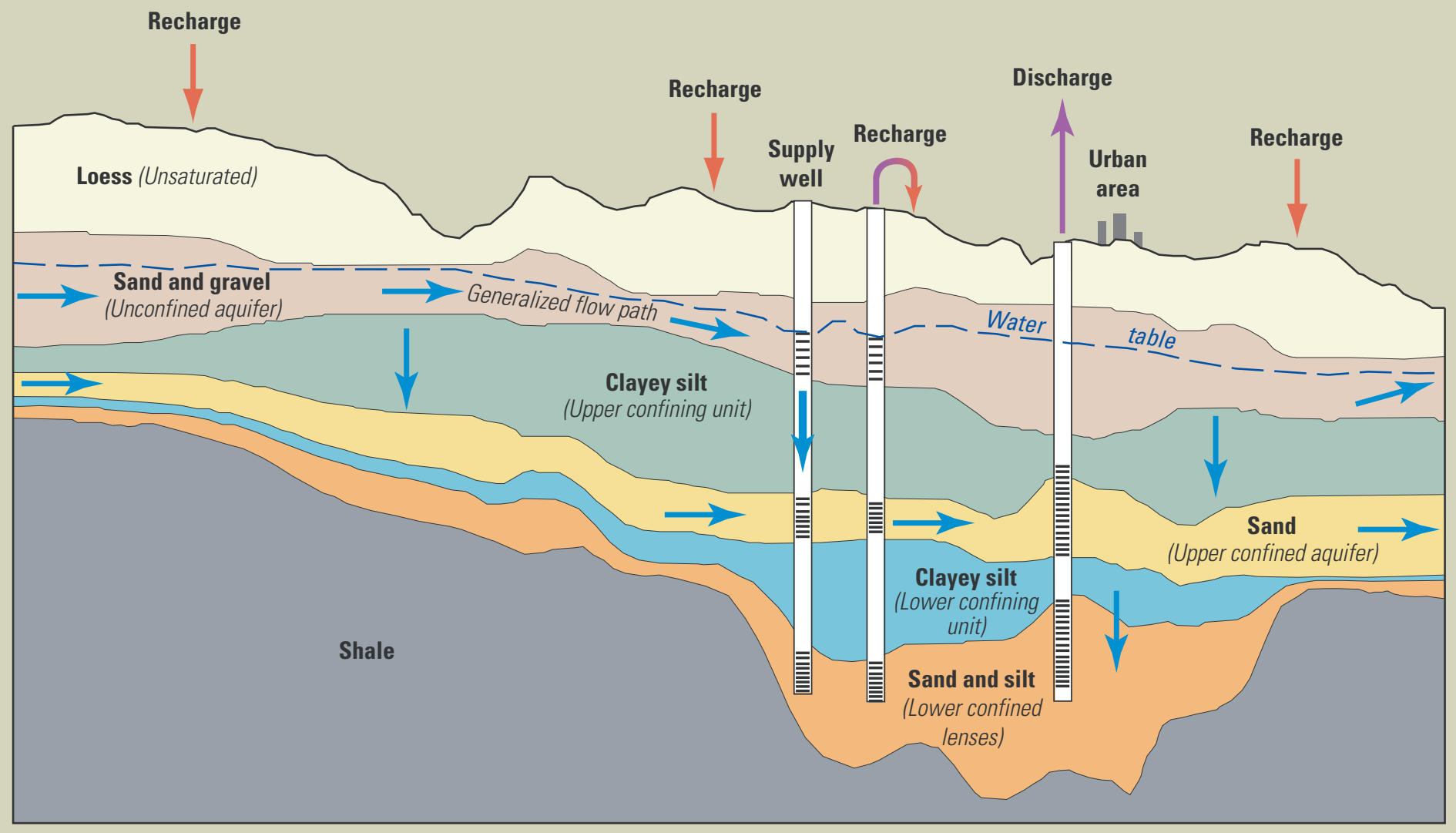

Scientific Investigations Report 2008-5050 



\section{Hydrogeology, Chemical Characteristics, and Transport Processes in the Zone of Contribution of a Public-Supply Well in York, Nebraska}

By Matthew K. Landon, Brian R. Clark, Peter B. McMahon, Virginia L. McGuire, and Michael J. Turco

National Water-Quality Assessment Program

Transport of Anthropogenic and Natural Contaminants (TANC)

to Public-Supply Wells

Scientific Investigations Report 2008-5050 


\section{U.S. Department of the Interior DIRK KEMPTHORNE, Secretary}

\section{U.S. Geological Survey \\ Mark D. Myers, Director}

\section{U.S. Geological Survey, Reston, Virginia: 2008}

For product and ordering information:

World Wide Web: http://www.usgs.gov/pubprod

Telephone: 1-888-ASK-USGS

For more information on the USGS--the Federal source for science about the Earth, its natural and living resources, natural hazards, and the environment:

World Wide Web: http://www.usgs.gov

Telephone: 1-888-ASK-USGS

Any use of trade, product, or firm names is for descriptive purposes only and does not imply endorsement by the U.S. Government.

Although this report is in the public domain, permission must be secured from the individual copyright owners to reproduce any copyrighted materials contained within this report.

Suggested citation:

Landon, M.K., Clark, B.R., McMahon, P.B., McGuire, V.L., and Turco, M.J., 2008, Hydrogeology, chemical characteristics, and transport processes in the zone of contribution of a public-supply well in York, Nebraska: U.S. Geological Survey Scientific Investigations Report 2008-5050, 149 p. 


\section{FOREWORD}

The U.S. Geological Survey (USGS) is committed to providing the Nation with credible scientific information that helps to enhance and protect the overall quality of life and that facilitates effective management of water, biological, energy, and mineral resources (http://www.usgs.gov//). Information on the Nation's water resources is critical to ensuring long-term availability of water that is safe for drinking and recreation and is suitable for industry, irrigation, and fish and wild life. Population growth and increasing demands for water make the availability of that water, now measured in terms of quantity and quality, even more essential to the long-term sustainability of our communities and ecosystems.

The USGS implemented the National Water-Quality Assessment (NAWQA) Program in 1991 to support national, regional, State, and local information needs and decisions related to water-quality management and policy (http:// water.usgs.gov/nawqa). The NAWQA Program is designed to answer: What is the condition of our Nation's streams and ground water? How are conditions changing over time? How do natural features and human activities affect the quality of streams and ground water, and where are those effects most pronounced? By combining information on water chemistry, physical characteristics, stream habitat, and aquatic life, the NAWQA Program aims to provide science-based insights for current and emerging water issues and priorities. From 1991-2001, the NAWQA Program completed interdisciplinary assessments and established a baseline understanding of water-quality conditions in 51 of the Nation's river basins and aquifers, referred to as Study Units (http://water.usgs.gov/nawqa/studyu.html).

Multiple national and regional assessments are ongoing in the second decade (2001-2012) of the NAWQA Program as 42 of the 51 Study Units are reassessed. These assessments extend the findings in the Study Units by determining status and trends at sites that have been consistently monitored for more than a decade, and filling critical gaps in characterizing the quality of surface water and ground water. For example, increased emphasis has been placed on assessing the quality of source water and finished water associated with many of the Nation's largest community water systems. During the second decade, NAWQA is addressing five national priority topics that build an understanding of how natural features and human activities affect water quality, and establish links between sources of contaminants, the transport of those contaminants through the hydrologic system, and the potential effects of contaminants on humans and aquatic ecosystems. Included are topics on the fate of agricultural chemicals, effects of urbanization on stream ecosystems, bioaccumulation of mercury in stream ecosystems, effects of nutrient enrichment on aquatic ecosystems, and transport of contaminants to public-supply wells. These topical studies are conducted in those Study Units most affected by these issues; they comprise a set of multi-Study-Unit designs for systematic national assessment. In addition, national syntheses of information on pesticides, volatile organic compounds (VOCs), nutrients, selected trace elements, and aquatic ecology are continuing.

The USGS aims to disseminate credible, timely, and relevant science information to address practical and effective water-resource management and strategies that protect and restore water quality. We hope this NAWQA publication will provide you with insights and information to meet your needs, and will foster increased citizen awareness and involvement in the protection and restoration of our Nation's waters.

The USGS recognizes that a national assessment by a single program cannot address all water-resource issues of interest. External coordination at all levels is critical for cost-effective management, regulation, and conservation of our Nation's water resources. The NAWQA Program, therefore, depends on advice and information from other agenciesFederal, State, regional, interstate, Tribal, and local—as well as nongovernmental organizations, industry, academia, and other stakeholder groups. Your assistance and suggestions are greatly appreciated.

Matthew C. Larsen

Acting Associate Director for Water 
This page has been intentionally left blank. 


\section{Contents}

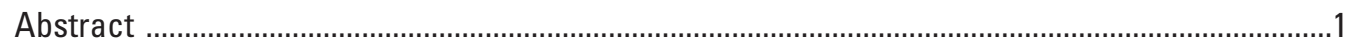

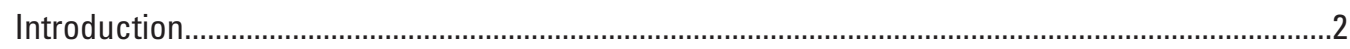

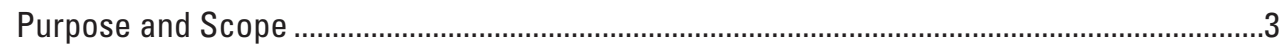

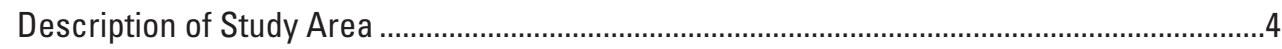

Previous Investigations...................................................................................................

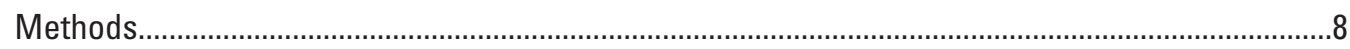

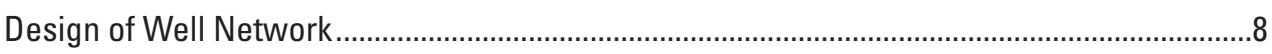

Drilling, Well Installation, Coring, and Core Analysis .............................................................11

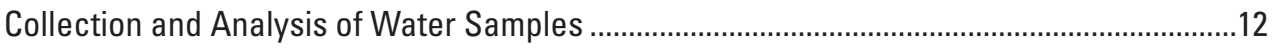

Collecting Depth-Dependent Flow and Chemistry Data.........................................................14

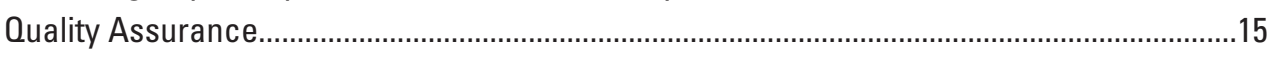

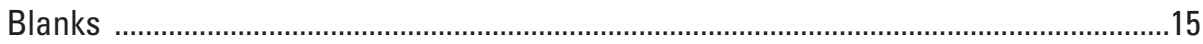

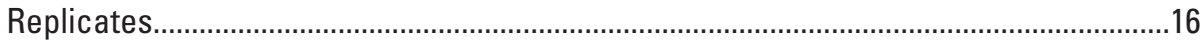

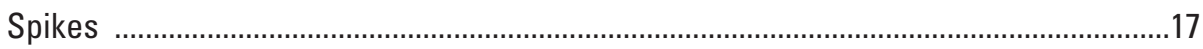

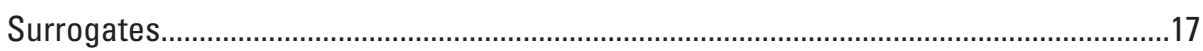

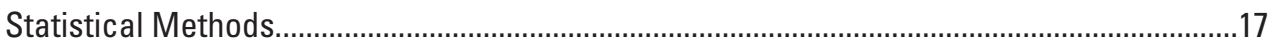

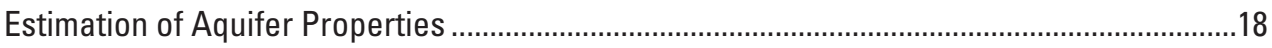

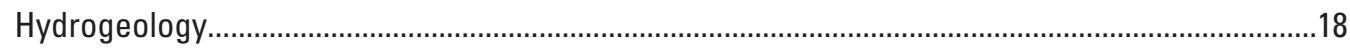

Geology, Mineralogy, and Sediment Chemistry............................................................. 18

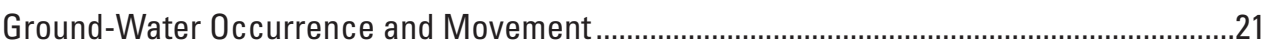

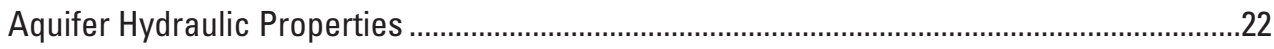

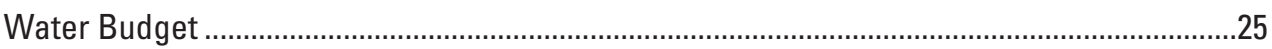

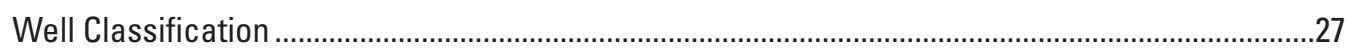

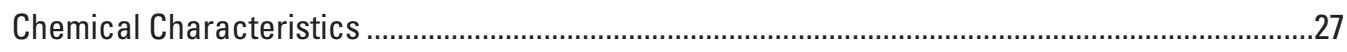

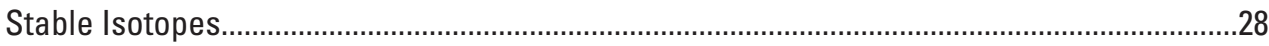

Precipitation and Return Flow Fractions in the Shallow Unconfined Aquifer .................30

Fractions of Water from the Unconfined Aquifer in Wells with Mixed Waters

in the Confined Aquifers......................................................................................

Isotopic Differences between Unconfined and Confined Aquifers ................................31

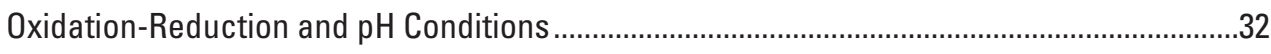

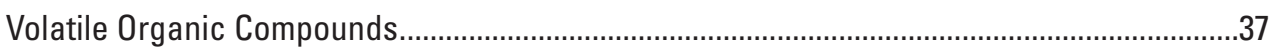

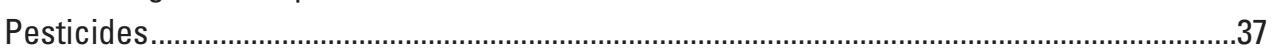

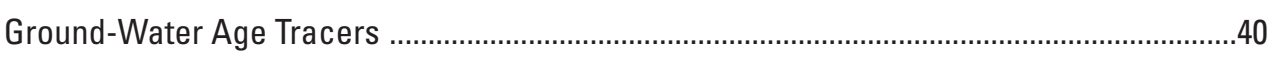

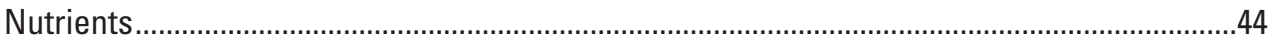

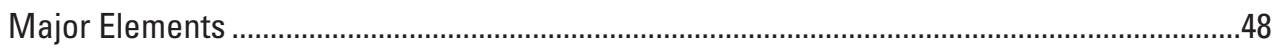

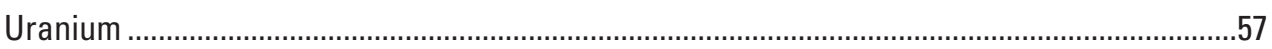

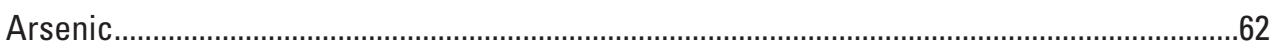

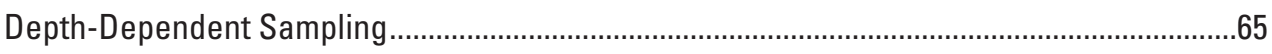

Flow and Chemistry Profile Checks ..........................................................................65

Depth Intervals Contributing Solutes to the Study Public-Supply Well..........................69 
Processes Affecting Transport of Anthropogenic and Natural Contaminants to

Public-Supply Wells..........................................................................................................70

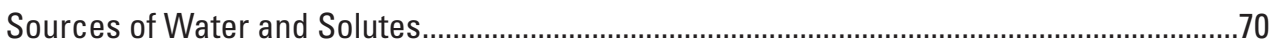

Movement of Water and Solutes to Supply Wells ..............................................................72

Evidence for Well-Bore Leakage ............................................................................73

Effects of Attenuation Reactions ...............................................................................78

Supply-Well Effects on Transport of Water and Solutes....................................................79

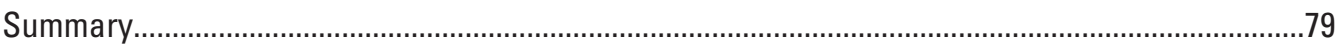

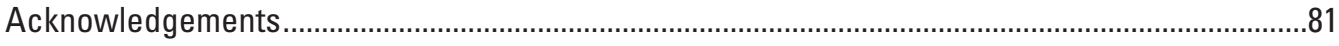

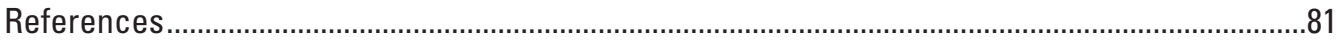

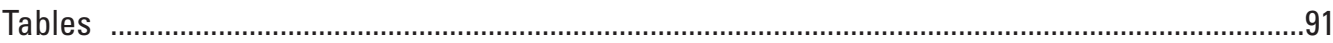

\section{Figures}

Figure 1. Map showing topographic and hydrogeologic features of the regional- and local-scale TANC study areas near York, Nebraska, and principal geologic units of the High Plains aquifer

Figure 2. Conceptual model of ground-water flow in the local-scale TANC study area near York, Nebraska

Figure 3. Map showing location of wells installed for the local-scale TANC study near York, Nebraska

Figure 4. Distribution of potential contaminant sources compiled from various sources in the local-scale TANC study area near York, Nebraska

Figure 5. Cross sections showing hydrogeologic units and geophysical logs from selected test holes drilled for the local-scale TANC study near York, Nebraska

Figure 6. Graphs showing water-level elevations in selected monitorng wells in the local-scale TANC study area near York, Nebraska, 2003-2005

Figure 7. Oxygen and hydrogen isotope values for ground water in the local-scale TANC study area near York, Nebraska

Figure 8. Graphs showing relation of oxidation-reduction indicators to depth of top of screen below the water table in the local-scale TANC study area near York, Nebraska

Figure 9. Graph showing sum of dissolved oxygen and nitrate (as nitrogen) and sum of manganese and iron in wells in the local-scale TANC study area near York, Nebraska

Figure 10. Graphs showing concentrations of selected constituents for unconfined shallow wells and depth to water below land surface for the local-scale TANC study area near York, Nebraska

Figure 11. Graph showing relation of $\mathrm{pH}$ to depth of top of screen below the water table in the local-scale TANC study area near York, Nebraska

Figure 12. Graphs showing relation of depth of top of screen below water table to concentrations of selected volatile organic chemicals in the local-scale TANC study area near York, Nebraska

Figure 13. Cross section showing sums of concentrations of pesticides in ground water in the local-scale TANC study area near York, Nebraska 
Figure 14. Graphs showing concentrations of age-dating tracers in samples and historical atmospheric curves corrected for radioactive decay for piston, exponential, and exponential binary mixing models, local-scale TANC study area near York,

Nebraska

Figure 15. Graphs showing relations in ground water in the local-scale TANC study area near York, Nebraska: $A$. measured nitrogen and oxygen isotopic values of nitrate, $B$. measured nitrogen isotopic values of nitrate and concentrations of nitrate, C. calculated initial nitrogen isotopic composition of nitrate and concentrations of nitrate prior to denitrification, and $D$. calculated initial nitrogen isotopic composition of nitrate prior to denitrification and concentration of orthophosphate .............. 46

Figure 16. Piper diagram showing general types of ground water in the local-scale TANC study area near York, Nebraska

Figure 17. Graphs showing relations between chloride and $A$. initial $\delta^{15} \mathrm{~N}$-nitrate, $B$. potassium, and $C$. orthophosphate and between sulfate and $D$. calculated initial $\delta^{15} \mathrm{~N}$-nitrate and $E$. boron in ground water from the local-scale TANC study area near York, Nebraska

Figure 18. Graph showing chloride and chloride/bromide in ground-water samples from the local-scale TANC study area near York, Nebraska

Figure 19. Graphs showing relations between tracers in ground-water samples from the local-scale TANC study area near York, Nebraska: $\delta^{18} 0$ and $A$. chloride, $B$. sulfate; chloride and $C$. sulfate, $D$. bromide, and $E$. PCE (tetrachloroethylene)

Figure 20. Graphs showing relations in ground-water samples from the TANC local-scale study area near York, Nebraska: $A$. pH and bicarbonate, $B$. chloride and bicarbonate, C. chloride and calcium.

Figure 21. Graphs showing the relation of uranium to $A$. depth below water table and $B$. uranium isotope ratios for samples collected from the local-scale TANC study area in York, Nebraska.

Figure 22. Graphs showing relation of concentrations of uranium to $A$. bicarbonate, $B$. chloride, $C$. $\delta^{15} \mathrm{~N}$-nitrate, $D$. orthophosphate, $E$. calcium, and, $F$. iron in samples from the local-scale TANC study area near York, Nebraska...

Figure 23. Graphs showing arsenic speciation in ground water in the local-scale TANC study area near York, Nebraska

Figure 24. Graphs showing arsenic and $A$. chloride and $B$. orthophosphate, and $C$. arsenate and iron concentrations in ground water in the local-scale TANC study near York, Nebraska

Figure 25. Graphs showing the vertical distribution of flow and concentrations of selected constituents in samples from different depths in the study supply well and adjacent monitoring wells in the local-scale TANC study area near York, Nebraska

Figure 26. Graphs showing the vertical distribution of unconfined mixing fractions in samples from different depths in the confined layer in the local-scale TANC study area near York, Nebraska

Figure 27. Scenarios for movement of unconfined water into the confined aquifer in the local-scale TANC study area near York, Nebraska 


\section{Tables}

Table 1. Well construction information for monitoring wells installed for the local-scale TANC study near York, Nebraska

Table 2. Analytes and methods of analyses for water samples collected from wells during October 2003-April 2005 for the local-scale TANC study near York, Nebraska

Table 3. Quality-control summary for constituents detected in field blanks and groundwater samples collected for the local-scale TANC study near York, Nebraska $\quad \ldots 96$

Table 4. Quality-control summary of replicate analytes with relative standard deviations greater than zero, collected for the local-scale TANC study near York, Nebraska

Table 5A. Quality-control summary of matrix spike recoveries for volatile organic compounds and gasoline additives and oxygenates in samples collected for the local-scale TANC study near York, Nebraska

Table 5B. Quality-control summary of matrix spike recoveries for pesticides and pesticide degradates in samples collected for the local-scale TANC study near York, Nebraska

Table 6. Hydrogeologic units in the local-scale TANC study area near York, Nebraska ...... 102

Table 7. Grain-size analyses of selected core samples collected for the local-scale TANC study near York, Nebraska.

Table 8. Mineralogy of selected core samples collected for the local-scale TANC study near York, Nebraska

Table 9. Elemental and isotopic analyses of selected core samples collected for the local-scale TANC study near York, Nebraska

Table 10. Values of hydraulic conductivity determined from slug tests in monitoring wells and from historical aquifer tests in the local-scale TANC study area near York, Nebraska

Table 11. Wells classified by degree of confinement, depth, land use, well type, and mixing, in and near York, Nebraska

Table 12. Hydrogen and oxygen stable isotopic values and mixing calculations for the local-scale TANC study near York, Nebraska

Table 13. Concentrations of constituents used to classify oxidation-reduction (redox) conditions in ground-water samples collected for the local-scale TANC study near York, Nebraska

Table 14. Results of analyses of volatile organic compounds and gasoline oxygenates in samples, and analytes detected in ground-water samples during October 2003 through April 2005 in the local-scale TANC study area near York, Nebraska

Table 15. Results of analyses of pesticides and pesticide degradates in ground-water samples in which analytes were detected during October 2003 through April 2005 in the local-scale TANC study area near York, Nebraska ....

Table 16. Age tracer and supporting data for ground-water samples collected from the local-scale TANC study area near York, Nebraska

Table 17. Age and mixing interpretations for ground-water samples from the local-scale TANC study area in York, Nebraska

Table 18. Results of analyses of nutrients in ground-water samples collected during October 2003 through April 2005 in the local-scale TANC study area near York, Nebraska 
Table 19. Results of analyses of selected isotopes of nitrogen, sulfur, uranium, and radon in ground-water samples collected during October 2003 through April 2005 in the local-scale TANC study area near York, Nebraska

Table 20. Results of analyses of selected field parameters and major and minor elements in ground-water samples collected during October 2003 through April 2005 in the local-scale TANC study area near York, Nebraska

Table 21. Results of analyses of trace elements in ground-water samples collected during October 2003 through April 2005 in the local-scale TANC study area near York, Nebraska 


\section{Conversion Factors, Notes, Acronyms, and Abbreviations}

\begin{tabular}{|c|c|c|}
\hline Multiply & By & To obtain \\
\hline \multicolumn{3}{|c|}{ Length } \\
\hline centimeter $(\mathrm{cm})$ & 0.3937 & inch (in.) \\
\hline millimeter (mm) & 0.03937 & inch (in.) \\
\hline meter $(\mathrm{m})$ & 3.281 & foot $(\mathrm{ft})$ \\
\hline kilometer (km) & 0.6214 & mile (mi) \\
\hline \multicolumn{3}{|c|}{ Area } \\
\hline square meter $\left(\mathrm{m}^{2}\right)$ & 0.0002471 & acre \\
\hline hectare (ha) & 2.471 & acre \\
\hline square kilometer $\left(\mathrm{km}^{2}\right)$ & 247.1 & acre \\
\hline square centimeter $\left(\mathrm{cm}^{2}\right)$ & 0.001076 & square foot $\left(\mathrm{ft}^{2}\right)$ \\
\hline square meter $\left(\mathrm{m}^{2}\right)$ & 10.76 & square foot $\left(\mathrm{ft}^{2}\right)$ \\
\hline hectare (ha) & 0.003861 & square mile $\left(\mathrm{mi}^{2}\right)$ \\
\hline square kilometer $\left(\mathrm{km}^{2}\right)$ & 0.3861 & square mile $\left(\mathrm{mi}^{2}\right)$ \\
\hline \multicolumn{3}{|c|}{ Volume } \\
\hline liter (L) & 33.82 & ounce, fluid (fl. oz) \\
\hline liter (L) & 0.2642 & gallon (gal) \\
\hline cubic meter $\left(\mathrm{m}^{3}\right)$ & 264.2 & gallon (gal) \\
\hline cubic centimeter $\left(\mathrm{cm}^{3}\right)$ & 0.06102 & cubic inch $\left(\mathrm{in}^{3}\right)$ \\
\hline liter (L) & 61.02 & cubic inch $\left(\mathrm{in}^{3}\right)$ \\
\hline cubic meter $\left(\mathrm{m}^{3}\right)$ & 35.31 & cubic foot $\left(\mathrm{ft}^{3}\right)$ \\
\hline cubic meter $\left(\mathrm{m}^{3}\right)$ & 0.0008107 & acre-foot (acre-ft) \\
\hline \multicolumn{3}{|c|}{ Flow rate } \\
\hline cubic meter per second $\left(\mathrm{m}^{3} / \mathrm{s}\right)$ & 70.07 & acre-foot per day (acre-ft/d) \\
\hline cubic meter per year $\left(\mathrm{m}^{3} / \mathrm{yr}\right)$ & 0.000811 & acre-foot per year (acre-ft/yr) \\
\hline meter per second $(\mathrm{m} / \mathrm{s})$ & 3.281 & foot per second $(\mathrm{ft} / \mathrm{s})$ \\
\hline meter per day $(\mathrm{m} / \mathrm{d})$ & 3.281 & foot per day $(\mathrm{ft} / \mathrm{d})$ \\
\hline cubic meter per second $\left(\mathrm{m}^{3} / \mathrm{s}\right)$ & 35.31 & cubic foot per second $\left(\mathrm{ft}^{3} / \mathrm{s}\right)$ \\
\hline cubic meter per day $\left(\mathrm{m}^{3} / \mathrm{d}\right)$ & 35.31 & cubic foot per day $\left(\mathrm{ft}^{3} / \mathrm{d}\right)$ \\
\hline liter per second $(\mathrm{L} / \mathrm{s})$ & 15.85 & gallon per minute (gal/min) \\
\hline cubic meter per day $\left(\mathrm{m}^{3} / \mathrm{d}\right)$ & 264.2 & gallon per day $(\mathrm{gal} / \mathrm{d})$ \\
\hline cubic meter per second $\left(\mathrm{m}^{3} / \mathrm{s}\right)$ & 22.83 & million gallons per day (Mgal/d) \\
\hline millimeter per year $(\mathrm{mm} / \mathrm{yr})$ & 0.03937 & inch per year (in/yr) \\
\hline \multicolumn{3}{|c|}{ Mass } \\
\hline gram $(\mathrm{g})$ & 0.03527 & ounce, avoirdupois (oz) \\
\hline kilogram $(\mathrm{kg})$ & 2.205 & pound avoirdupois (lb) \\
\hline megagram per year $(\mathrm{Mg} / \mathrm{yr})$ & 1.102 & ton per year (ton/yr) \\
\hline metric ton per year & 1.102 & ton per year (ton/yr) \\
\hline \multicolumn{3}{|c|}{ Pressure } \\
\hline kilopascal (kPa) & 0.2961 & inch of mercury at $60^{\circ} \mathrm{F}$ (in $\mathrm{Hg}$ ) \\
\hline kilopascal $(\mathrm{kPa})$ & 0.1450 & pound per square inch $\left(\mathrm{lb} / \mathrm{ft}^{2}\right)$ \\
\hline \multicolumn{3}{|c|}{ Density } \\
\hline gram per cubic centimeter $\left(\mathrm{g} / \mathrm{cm}^{3}\right)$ & 62.4220 & pound per cubic foot $\left(\mathrm{lb} / \mathrm{ft}^{3}\right)$ \\
\hline \multicolumn{3}{|c|}{ Radioactivity } \\
\hline becquerel per liter $(\mathrm{Bq} / \mathrm{L})$ & 27.027 & picocurie per liter $(\mathrm{pCi} / \mathrm{L})$ \\
\hline \multicolumn{3}{|c|}{ Specific capacity } \\
\hline liter per second per meter $[(\mathrm{L} / \mathrm{s}) / \mathrm{m}]$ & 4.831 & gallon per minute per foot $[(\mathrm{gal} / \mathrm{min}) / \mathrm{ft}]$ \\
\hline \multicolumn{3}{|c|}{ Hydraulic conductivity } \\
\hline meter per day $(\mathrm{m} / \mathrm{d})$ & 3.281 & foot per day $(\mathrm{ft} / \mathrm{d})$ \\
\hline \multicolumn{3}{|c|}{ Hydraulic gradient } \\
\hline meter per kilometer $(\mathrm{m} / \mathrm{km})$ & 5.27983 & foot per mile ( $\mathrm{ft} / \mathrm{mi})$ \\
\hline \multicolumn{3}{|c|}{ Application rate } \\
\hline kilograms per hectare per year $[(\mathrm{kg} / \mathrm{ha}) / \mathrm{yr}]$ & 0.8921 & pounds per acre per year $[(\mathrm{lb} / \mathrm{acre}) / \mathrm{yr}]$ \\
\hline
\end{tabular}


Temperature in degrees Celsius $\left({ }^{\circ} \mathrm{C}\right)$ may be converted to degrees Fahrenheit $\left({ }^{\circ} \mathrm{F}\right)$ as follows:

$$
{ }^{\circ} \mathrm{F}=\left(1.8 \times^{\circ} \mathrm{C}\right)+32
$$

Temperature in degrees Fahrenheit $\left({ }^{\circ} \mathrm{F}\right)$ may be converted to degrees Celsius $\left({ }^{\circ} \mathrm{C}\right)$ as follows:

$$
{ }^{\circ} \mathrm{C}=\left({ }^{\circ} \mathrm{F}-32\right) / 1.8
$$

Vertical coordinate information is referenced to the North American Vertical Datum of 1988 (NAVD 88).

Horizontal coordinate information is referenced to the North American Datum of 1983

(NAD 83).

Altitude, as used in this report, refers to distance above the vertical datum.

Specific conductance is given in microsiemens per centimeter at 25 degrees Celsius ( $\mu \mathrm{S} / \mathrm{cm}$ at $\left.25^{\circ} \mathrm{C}\right)$.

Concentrations of chemical constituents in water are given either in milligrams per liter (mg/L) or micrograms per liter $(\mu \mathrm{g} / \mathrm{L})$.

\section{Acronyms and Abbreviations}

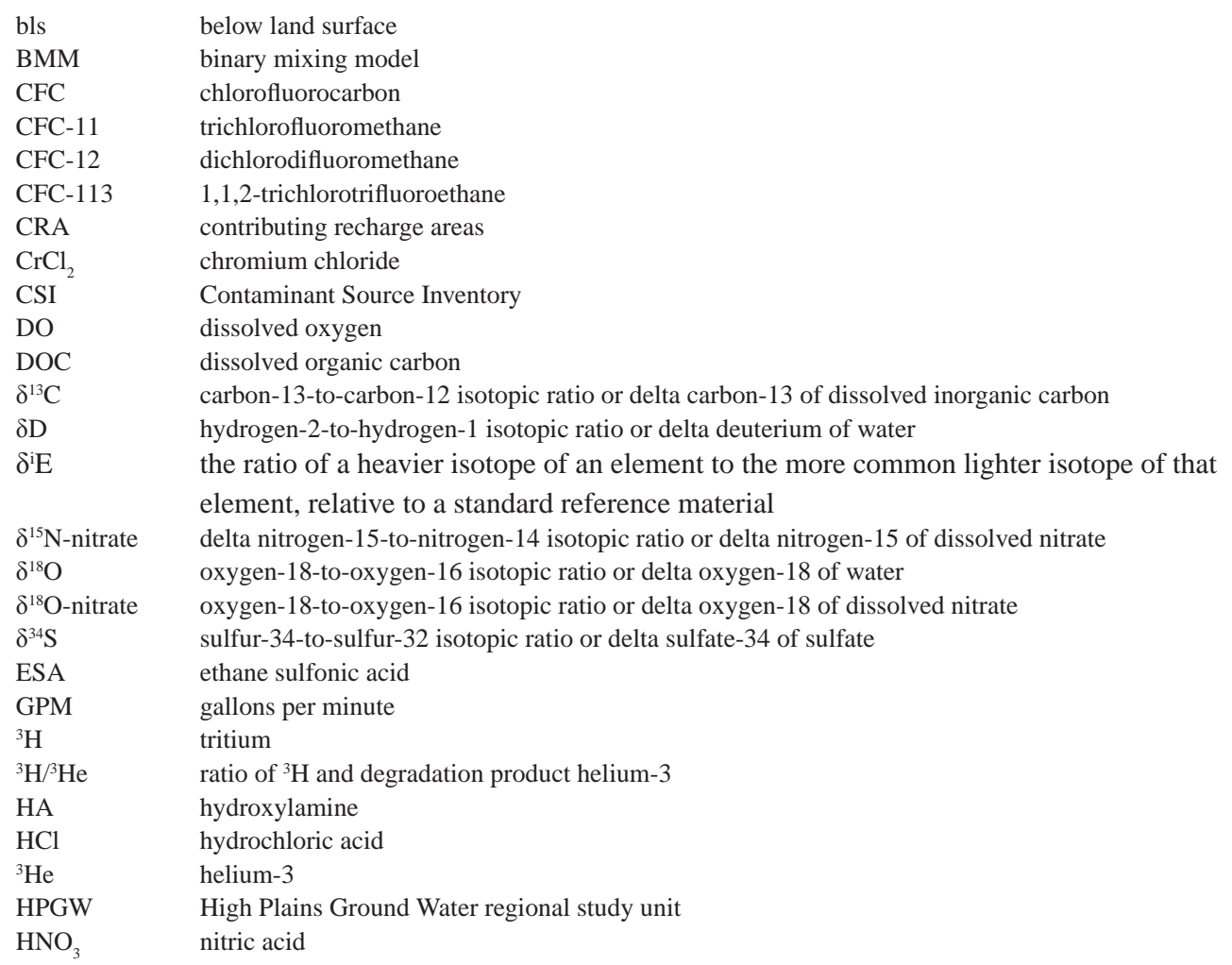




\begin{tabular}{ll}
$\mathrm{H}_{2} \mathrm{~S}$ & hydrogen sulfide \\
ICP-MS & inductively-coupled plasma/mass spectrometry \\
ICP-OES & inductively-coupled plasma/optical emission spectroscopy \\
$K_{h}$ & horizontal hydraulic conductivity \\
$K_{v}$ & vertical hydraulic conductivity \\
LRL & laboratory reporting level \\
LT-MDL & long-term method detection level \\
M & molar \\
MCL & Maximum Contaminant Level \\
MWL & Meteoric Water Line \\
N & normal \\
NaOH & sodium oxide \\
NAWQA & National Water Quality Assessment \\
nitrate-N & nitrate as nitrogen \\
NWQL & National Water Quality Laboratory \\
PCE & tetrachloroethylene \\
PFM & piston flow model \\
ppb & parts per billion \\
PSW & public-supply well \\
PVC & polyvinyl chloride \\
r & the Pearson or linear correlation coefficient \\
r $^{2}$ & coefficient of determination \\
RCRA & Resource Conservation and Recovery Act \\
RSD & relative standard deviation \\
S & second \\
SF & sulfur hexafluoride \\
SnCl & stannous (tin) chloride \\
SWQA & Source Water Quality Assessment \\
$\sigma$ & standard deviation \\
TANC & Transport of Anthropogenic and Natural Contaminants \\
TCE & trichloroethylene \\
TDS & total dissolved solids \\
TEAP & Terminal Electron Acceptor Process \\
UBBNRD & Upper Big Blue Natural Resources District \\
USEPA & U.S. Environmental Protection Agency \\
USGS & U.S. Geological Survey \\
VCDT & Vienna Canyon Diablo Troilite \\
VOC & volatile organic compound \\
VPDB & Vienna Pee Dee belemnite \\
VSMOW & Vienna Standard Mean Ocean Water \\
ZOC & zones of contribution \\
\hline greater than \\
\hline less than \\
\hline
\end{tabular}




\title{
Hydrogeology, Chemical Characteristics, and Transport Processes in the Zone of Contribution of a Public-Supply Well in York, Nebraska
}

\author{
By Matthew K. Landon, Brian R. Clark, Peter B. McMahon, Virginia L. McGuire, and Michael J. Turco
}

\section{Abstract}

In 2001, the U.S. Geological Survey, as part of the National Water Quality Assessment (NAWQA) Program, initiated a topical study of Transport of Anthropogenic and Natural Contaminants (TANC) to PSW (public-supply wells). Local-scale and regional-scale TANC study areas were delineated within selected NAWQA study units for intensive study of processes effecting transport of contaminants to PSWs. This report describes results from a local-scale TANC study area at York, Nebraska, within the High Plains aquifer, including the hydrogeology and geochemistry of a 108-squarekilometer study area that contains the zone of contribution to a PSW selected for study (study PSW), and describes factors controlling the transport of selected anthropogenic and natural contaminants to PSWs.

Within the local-scale TANC study area, the High Plains aquifer is approximately $75 \mathrm{~m}$ (meter) thick, and includes an unconfined aquifer, an upper confining unit, an upper confined aquifer, and a lower confining unit with lower confined sand lenses (units below the upper confining unit are referred to as confined aquifers) in unconsolidated alluvial and glacial deposits overlain by loess and underlain by Cretaceous shale. From northwest to southeast, land use in the local-scale TANC study area changes from predominantly irrigated agricultural land to residential and commercial land in the small community of York (population approximately 8,100).

For the purposes of comparing water chemistry, wells were classified by degree of aquifer confinement (unconfined and confined), depth in the unconfined aquifer (shallow and deep), land use (urban and agricultural), and extent of mixing in wells in the confined aquifer with water from the unconfined aquifer (mixed and unmixed). Oxygen $\left(\delta^{18} \mathrm{O}\right)$ and hydrogen $(\delta \mathrm{D})$ stable isotopic values indicated a clear isotopic contrast between shallow wells in the unconfined aquifer (hereinafter, unconfined shallow wells) and most monitoring wells in the confined aquifers (hereinafter, confined unmixed wells). $\delta^{18} \mathrm{O}$ and $\delta \mathrm{D}$ values for a minority of wells in the confined aquifers were intermediate between those for the unconfined shallow wells and those for the confined unmixed wells. These intermediate values were consistent with mixing of water from unconfined and confined aquifers (hereinafter, confined mixed wells). Oxidation-reduction conditions were primarily oxic in the unconfined aquifer and variably reducing in the confined aquifers.

Trace amounts of volatile organic compounds (VOC), particularly tetrachloroethylene (PCE) and trichloroethylene (TCE), were widely detected in unconfined shallow urban wells and indicated the presence of young urban recharge waters in most confined mixed wells. The presence of degradation products of agricultural pesticides (acetochlor and alachlor) in some confined mixed wells suggests that some fraction of the water in these wells also was the result of recharge in agricultural areas. In the unconfined aquifer, age-tracer data (chlorofluorocarbon and sulfur hexafluoride data, and tritium to helium-3 ratios) fit a piston-flow model, with apparent recharge ages ranging from 7 to 48 years and generally increasing with depth. Age-tracer data for the confined aquifers were consistent with mixing of "old" water, not containing modern tracers recharged in the last 60 years, and exponentially-mixed "young" water with modern tracers. Confined unmixed wells contained less than $(<) 3$ percent (\%) young water mixed with a much larger fraction greater than or equal to $(\geq) 97 \%$ of old water. Confined mixed wells contained $>30 \%$ young water and mean ages ranged from 12 to 14 years. Median concentrations of nitrate (as nitrogen, hereinafter, nitrate-N) were 17.3 and $16.0 \mathrm{mg} / \mathrm{L}$ (milligram per liter) in unconfined shallow urban and agricultural wells, respectively, indicating a range of likely nitrate sources. Septic systems are most numerous near the edge of the urban area and appear to be a major anthropogenic source of solutesincluding nitrate- $\mathrm{N}$, orthophosphate, chloride, sulfate, calcium, potassium, and boron-to unconfined shallow urban wells. 
In oxic unconfined shallow urban and agricultural wells with uranium concentrations of 5 to $40 \mu \mathrm{g} / \mathrm{L}$ (microgram per liter), the predominant source of uranium was probably desorption or dissolution from sediment under oxic conditions and the formation of soluble complexes of uranium with calcium and bicarbonate. Although septic systems are not likely to be a source of uranium, concentrations of uranium in oxic unconfined shallow urban wells were greatest where tracers of septic-system effects occurred, perhaps because of greater calcium concentrations than in wells not affected by septic systems. The highest uranium concentrations (44 to $184 \mu \mathrm{g} / \mathrm{L}$ ) in the study area were where water from the unconfined aquifer, inferred to have leaked downward in multi-layer wells that penetrate the upper confining unit, mixed with iron-reducing water in the upper confined aquifer. The geochemical mechanism producing these high uranium concentrations is not known but may involve dissolution of iron oxides transported with colloids from the unconfined aquifer by well-bore leakage under iron-reducing conditions in the upper confined aquifer, releasing uranium. Relatively uniform arsenic concentrations of 2 to $9 \mu \mathrm{g} / \mathrm{L}$ coupled with changes in arsenic speciation with increasing depth suggest that multiple processes influence arsenic concentrations, including competitive desorption of arsenate from sediments in the unconfined aquifer in the presence of orthophosphate derived from septic-system effluent, long-term reductive dissolution and oxidation-reduction reactions in the upper confined aquifer and lower confined lenses, and mixing of waters from the unconfined and confined aquifers.

Samples collected from the surface discharge of the study PSW, which integrated water from the entire screened interval in the upper confined aquifer, contained concentrations of PCE, TCE, and uranium that were below drinking-water standards but of concern as indicators of low-level contamination. However, these contaminants were not detected in monitoring wells $<30 \mathrm{~m}$ from the PSW that were screened in the same upper confined aquifer. Depthdependent samples were collected from the PSW under typical pumping conditions at five depths in the 18-m long screen; the depths were selected on the basis of flow profiling using the tracer pulse method. The samples from the bottom half of the screen had $\delta^{18} \mathrm{O}$ and $\delta \mathrm{D}$ values and concentrations of PCE, TCE, major ions, excess nitrogen gas, and uranium that were consistent with those in water derived from the shallow unconfined aquifer in the urban area mixed with water from the upper confined aquifer. The presence of the water from the unconfined aquifer only at the bottom of the study PSW screen implies that well-bore leakage in the PSW itself was not the pathway for vertical movement. Similar mixtures of unconfined and confined aquifer water signatures were detected in a few monitoring wells screened in the confined aquifers. This nonuniform distribution of mixed waters implies that there were preferential flow paths permitting water and contaminants from the unconfined aquifer to move through the upper and lower confining units. The primary pathway was probably downward leakage of water through well bores or annular spaces of irrigation, commercial, or older supply wells that penetrated the upper and lower confining units.

In the PSW studied, concentrations of constituents of concern were primarily limited by dilution with "old" water from the upper confined aquifer (all constituents, particularly uranium), and chemical transformation (denitrification of nitrate, reductive dechlorination of PCE and TCE). Historical data indicate that nitrate concentrations in some PSWs in the regional-scale TANC study area screened in both the upper confined aquifer and lower confined lenses were sometimes higher than drinking-water standards, indicating that shortcircuit pathways and pumping stress can overcome dilution and reaction processes under some circumstances. It is likely that concentrations of nitrate and other constituents moving with water from the unconfined aquifer to PSWs were influenced by pumping stress and the number and distance of well-bore leakage points from the PSWs.

\section{Introduction}

Contamination of public-supply wells (PSW) is a potential threat to the health of people consuming the water, and has had negative economic effects on communities that need to treat contaminated water or find alternative water supplies. Investigations at multiple spatial scales across the United States have indicated that shallow ground-water quality is affected by land-use activities in many locations, but that water quality is less frequently affected at the greater depths where PSWs typically are screened (Nolan and Stoner, 2000; Gilliom and others, 2006; Zogorski and others, 2006). In addition, constituents such as arsenic and uranium that are often derived from natural sources (hereinafter, natural contaminants) are becoming of increasing concern as measurements of these constituents have become increasingly sensitive, harmful health effects have been identified, and drinking-water standards have been lowered (Focazio and others, 1999; Welch and others, 2000). Concentrations of anthropogenic or natural constituents can change along ground-water flow paths from recharge or source areas to PSWs as a result of many processes. These processes can be broadly grouped into those concerning sources, including contaminant loading or mobilization; transport, including migration and reaction; and receptors (wells), including PSW operations (Franke and others, 1998; Focazio and others, 2002). The U.S. Geological Survey National Water Quality Assessment (NAWQA) Program began a topical study program in 2001 (Wilber and Couch, 2002), to address questions regarding factors controlling vulnerability of PSWs to anthropogenic and natural contaminants, by using consistent and systematic data collected in a variety of principal aquifer settings in the United States. The topical program is referred to as the study of Transport of Anthropogenic and Natural Contaminants (TANC) to PSWs. 
The goal of the TANC program is to understand the source, transport, and receptor factors that control the movement of contaminants to PSWs in representative aquifers of the United States (Eberts and others, 2005a). Studies were conducted at regional scales of up to thousands of square kilometers $\left(\mathrm{km}^{2}\right)$ in eight TANC study areas around the United States during 2002-2003 and at local-scales of less than $(<)$ $200 \mathrm{~km}^{2}$ in four of the TANC study areas during 2003-2006. One of the TANC study areas where local-scale studies were done is at York, Nebraska, within the High Plains Ground Water (HPGW) regional study unit of the NAWQA program (Dennehy, 2000).

As part of the regional-scale TANC investigations, existing information on hydrogeology, land use, and water chemistry was compiled, and existing or new ground-water flow models were used to simulate zones of contribution (ZOC) and contributing recharge areas (CRA) to PSWs. The $\mathrm{ZOC}$ is the three-dimensional volumetric part of the aquifer through which ground water flows from the CRA to the discharging well (Morrissey, 1989). The CRA is defined as the surface area on the three-dimensional boundary of the groundwater system that delineates the location of water entering the ground-water system that eventually flows to the well and is discharged from the aquifer (Reilly and Pollock, 1993). This regional-scale analysis was done to identify statistical relations between explanatory hydrogeologic and land-use variables and water quality in PSWs at regional scales using mostly existing information (Eberts and others, 2005a). The multi-scale design of the overall study was designed to facilitate extrapolation of results from detailed local-scale TANC studies to larger areas. Regional-scale TANC study areas are described by Paschke (2007). The hydrogeologic setting, water chemistry, and simulation of ground-water flow in the regional-scale HPGW TANC study area of $388.5 \mathrm{~km}^{2}$ is described by Landon and Turco (2007). This report describes the hydrogeology and geochemistry of the local-scale HPGW TANC study area of $108 \mathrm{~km}^{2}$ and discusses factors controlling transport of selected anthropogenic and natural contaminants to PSWs.

York, Nebraska, was selected for the HPGW TANC study for several reasons. Historical data indicated that PSWs in York were vulnerable to contamination from several sources. The possible sources of contamination and the layered hydrogeologic conditions at York are typical of conditions in many communities across the Midwest and other predominantly rural areas in the Nation. Potential contamination threats include chlorinated organic solvents from historical chemical use at small commercial facilities typically found in Midwestern communities, nitrate and pesticides from intensive irrigated cultivated agricultural land use, arsenic from natural deposits of shale and glacial till, and uranium from alluvial sediments. Movement of these contaminants through the aquifer system may be enhanced by increased ground-water flow velocities caused by intensive ground-water pumping for irrigation and increased recharge from irrigation return flows and cultivation. Moreover, the common practice of screening irrigation and supply wells across large intervals of an aquifer to improve well yields can contribute to more rapid vertical movement of contaminants than would naturally occur, as a result of penetration of confining units by well bores. Because these factors affect many other places, a topical study of the transport and fate of contaminants at York, Nebraska, was considered to be broadly transferable to many communities, particularly in the High Plains, and Midwest.

\section{Purpose and Scope}

The purposes of this report are to document the hydrogeologic setting, and occurrence and distribution of selected chemical characteristics, and discuss factors controlling transport of selected anthropogenic and natural contaminants to PSWs in the local-scale TANC study area at York, Nebraska. This report includes a brief description of the design of the local-scale monitoring well network and methods of data collection and analysis. The hydrogeologic setting of the local-scale study area is described, including the geology as determined from drilling and geophysical logging for the study, the results of tests of aquifer hydraulic properties, and historical and seasonal ground-water levels and their implications for ground-water flow patterns. A brief description of the water budget is given, but a more detailed analysis of the water budget and a model constructed and calibrated to simulate ground-water flow and age distribution in the local-scale TANC study area is described in a separate report by Clark and others (2008).

This report describes the interpretative steps in estimating ground-water ages using atmospheric tracers, and describes the distribution of the interpreted ground-water ages. General water-chemistry characteristics such as oxidation-reduction conditions, $\mathrm{pH}$, and water types are described. The occurrence and distribution of selected constituents that are useful for developing interpretations of patterns and pathways of groundwater recharge and discharge are described. Isotopic and geochemical data used in interpreting processes influencing nitrate, VOC, uranium, and arsenic distributions are described. Factors influencing transport of these anthropogenic and natural contaminants to PSWs in the local-scale TANC study area are discussed. This report is intended to serve as a foundation for analyses comparing results of studies in the local-scale TANC study area and others in California, Connecticut, and Florida. 


\section{Description of Study Area}

The local-scale TANC study area at York, Nebraska, was nested within a larger regional-scale TANC study area. Although this report focuses on the results of the local-scale TANC study, a summary of characteristics of the regionalscale TANC study area is presented here to illustrate the features of the system that are most relevant to understanding movement of water and solutes along ground-water flow paths to PSWs at the local scale. Characteristics of the regionalscale TANC study area around York have been previously described by Landon and Turco (2007) (fig. 1). Characteristics of the High Plains aquifer influencing water quality have been described in publications from the HPGW NAWQA study unit (Dennehy and others, 2002).

The regional-scale TANC study area encompasses $388.5 \mathrm{~km}^{2}$. The orientation of the rectangular study area coincides with regional ground-water flow from northwest to southeast. The regional-scale TANC study area was selected to facilitate ground-water-flow modeling of the region upgradient of and around York. The local-scale TANC study area (fig. 1) is a smaller rectangular area of $108 \mathrm{~km}^{2}$ selected for study of processes influencing contaminant distribution along an apparent ground-water flow path to a PSW in southeastern York.

The regional- and local-scale TANC study areas are located in east-central Nebraska within the High Plains aquifer, which consists of Quaternary-age alluvial deposits in eastern Nebraska and Kansas (fig. 1) (Gutentag and others, 1984; Dennehy and others, 2002). In the local-scale TANC study area, the layered sediments are approximately $75 \mathrm{~m}$ thick and consist of (with increasing depth) unsaturated loess overlying a heterogeneous unconfined coarse sand and gravel (hereinafter, unconfined aquifer), a clayey silt glacial till (hereinafter, upper confining unit), a confined fine sand (hereinafter, upper confined aquifer), and deeper clayey silt (hereinafter, lower confining unit) intermixed with discontinuous fine sand (hereinafter, lower confined lenses) (Keech and others, 1967; Gottula and Link, 1992). Depth to water ranges from 3 to $24 \mathrm{~m}$ across the local-scale TANC study area. The water table is usually near the top of the unconfined aquifer but in a few locations is located in the overlying loess. A conceptual model of the local-scale TANC study area is shown in figure 2 .

York is located within the Central Loess Plains Ecoregion, a mostly flat-lying region of windblown silt with relatively little dissection by streams (ig. 1) (Bailey, 1980). Most of the soils in the area are classified as well drained (Verstraeten and others, 1998).
Mean annual precipitation is $71.1 \mathrm{~cm} / \mathrm{yr}$ (centimeter per year) (High Plains Climate Center, 2003); most of the precipitation falls during thunderstorms in the spring and fall (Verstraeten and others, 1998). There are no naturally perennial streams in the study area other than the lower reaches of Beaver Creek near the southeastern edge of the regional-scale TANC study area (fig. 1) (Landon and Turco, 2007). Flows in Beaver Creek through and just to the east of York are maintained by discharges from the York wastewater plant and industrial return flows. Consequently, Beaver Creek loses water to the aquifer downstream from York to near the southeastern edge of the regional-scale TANC study area (Landon and Turco, 2007).

Irrigated agriculture is the primary land use. Irrigated corn, soybeans, sorghum, alfalfa, and small grains account for 54 percent (\%) of the land area in the local-scale TANC study area (Center for Advanced Land Management Information Technologies, 2000). Other minor land uses include dryland cropland (20\%), urban (13\%), rangeland (9\%), and natural land uses (woodland, wetland, open water, 4\%). The population of York is approximately 8,100 (U.S. Census Bureau, 2003). Within York, urban land use is roughly equally divided between commercial/transportation and low density residential/urban and recreational grass areas (U.S. Geological Survey, 1999-2000).

Ground water is the sole source of irrigation water. Irrigation-well density in the regional-scale TANC study area was 2.0 wells per $\mathrm{km}^{2}$. Ground water from the High Plains aquifer supplies $100 \%$ of the drinking water to York. There are no alternative drinking-water sources in the region. The Cretaceous-age Dakota sandstone, located more than a hundred $\mathrm{m}$ below the High Plains aquifer beneath Cretaceous shale, is generally too saline for public supply.

Unconfined and confined ground-water conditions occur in the local-scale TANC study area. Many irrigation, commercial, and some older PSWs are screened in the unconfined aquifer, the upper confined aquifer, and the lower confined lenses (fig. 2). Most York PSWs are screened in the upper confined aquifer and the lower confined lenses.

The local-scale TANC study area differs from the regional-scale TANC study area in that it is focused on an apparent ground-water flow path to a PSW in southeastern York selected for study, and therefore, has a larger fraction of urban area (13\%) than the regional-scale TANC study area (4\%) (fig. 1]). The local-scale TANC study area extends from mostly irrigated agricultural areas to the west and northwest of York, through a transitional area from rural to urban land use along the western edge of York, to residential and commercial areas of York (fig. 3). 


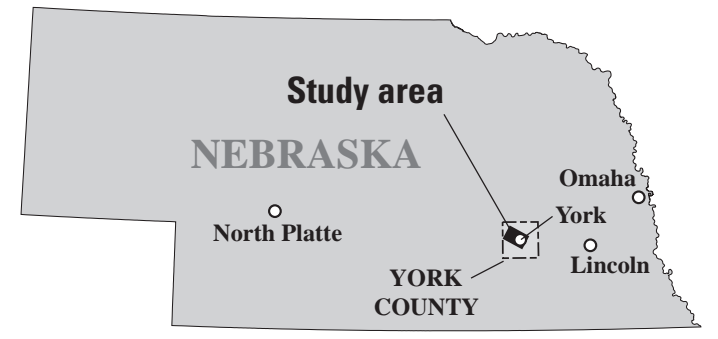

\section{EXPLANATION}
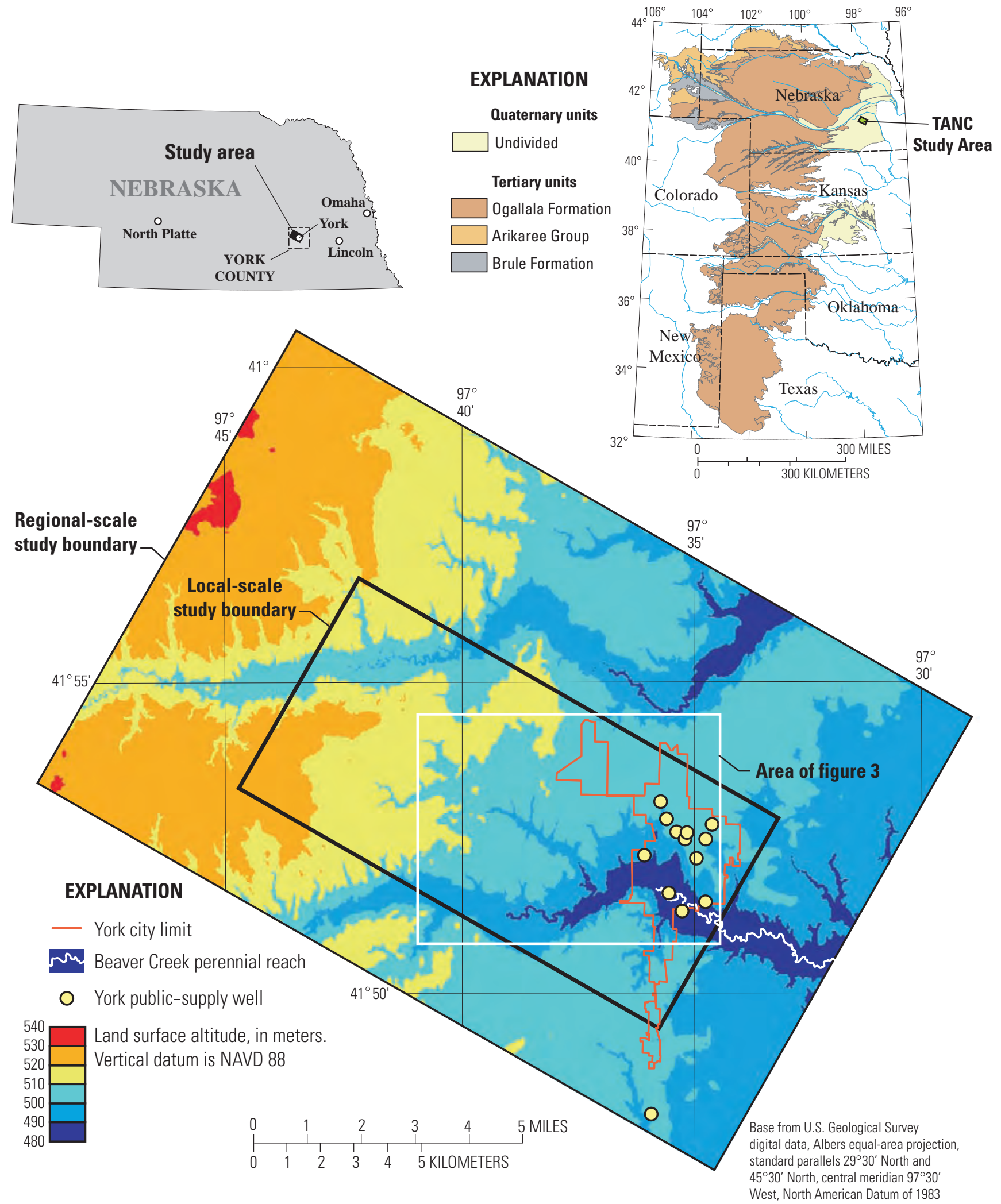

Figure 1. Topographic and hydrogeologic features of the regional- and local-scale TANC study areas near York, Nebraska, and principal geologic units of the High Plains aquifer (modified from Gutentag and others, 1984; Landon and Turco, 2007). 

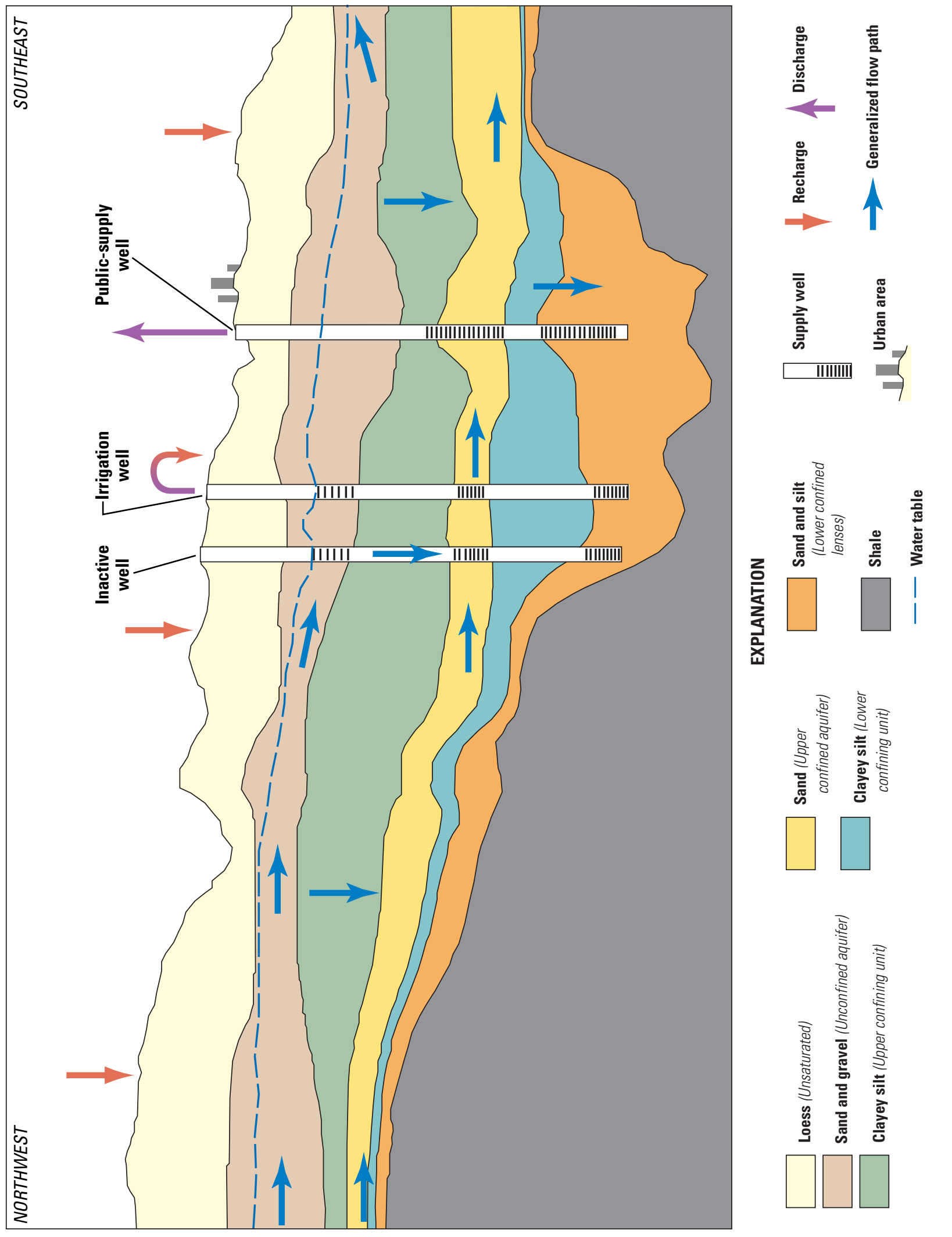

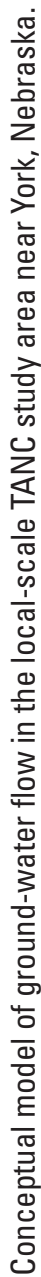




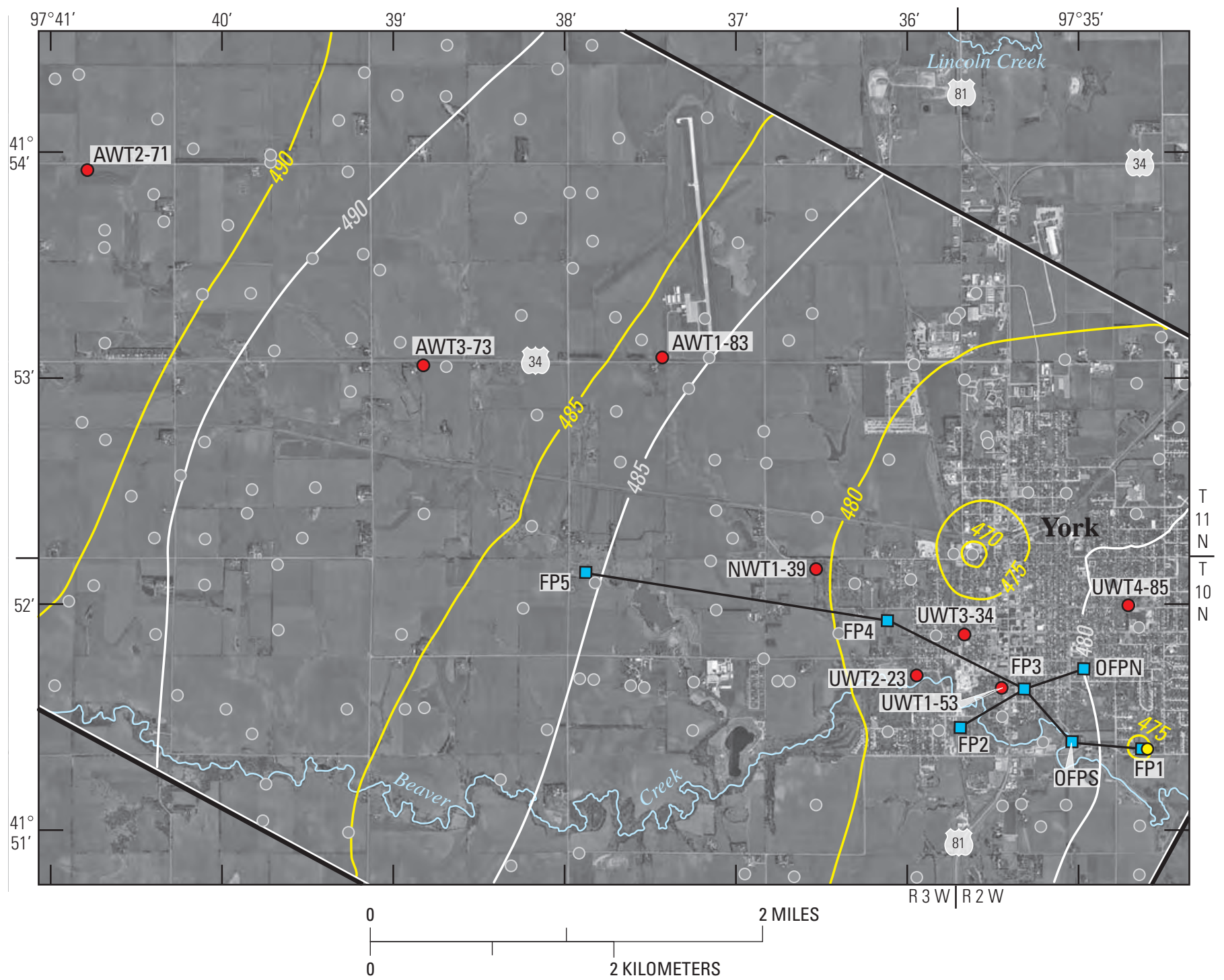

\section{EXPLANATION}

Simulated hydraulic head contour - Shows altitude of simulated hydraulic head April 2003. Contour interval 5 feet. Datum is NAVD 88. Closed contours with diameter of less than 175 meters are not shown. (From Clark and others, 2008)

$\begin{array}{ll}-485 & \text { Unconfined aquifer } \\ -475-\quad \text { Upper confined aquifer }\end{array}$

Local-scale study area and ground-water flow model boundary (From Clark and others, 2008)

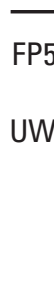

FP5

Line of geologic section (shown in figure 5)

Multiple monitoring well site -7 total sites

UWT2-23 Single monitoring well-Screened near water table (8 total sites)

O Study public-supply well (Study PSW)

Other well, not used in this study, primarily used for irrigation, commercial, or public-supply purposes

Figure 3. Location of wells installed for the local-scale TANC study near York, Nebraska. 
Additional information on land-use activity potentially relevant to ground-water quality was obtained from State and local sources. Information on the distribution of potential locations where hazardous chemicals may be used or generated was collected as part of a Contaminant Source Inventory (CSI) obtained from the Nebraska Department of Environmental Quality (Deanna Kelley, Nebraska Department of Environmental Quality, written commun., April 10, 2003). The CSI is a qualitative inventory of potential sites where hazardous materials are used, stored, or generated, or where regulatory investigations of toxic releases to air, water, or soil have been conducted (Resource Conservation and Recovery Act (RCRA) or Superfund sites). These locations are plotted on figure 4. The CSI data indicate a clustering of potential urban contaminant sources along a north-south strip along Highway 81 in York. Most of these sites are fuel storage tanks. There also are a few storage tanks or RCRA sites in western York near the apparent ground-water flow path investigated (figs. 3 and 4).

The approximate distribution of known septic systems within or near the boundaries of York was obtained from the city of York (Orville Davidson, Public Utilities Superintendent, York, Nebraska, written. commun., February $15,2003)$ and is shown on figure 4 . This information is intended to illustrate approximately where septic systems are relatively numerous and could therefore be potential sources of solutes to shallow ground water. Most of the septic systems are in east-west swaths along major roads or in neighborhoods along the western and southwestern edge of York.

A map of the approximate distribution of current or historical livestock facilities or livestock waste disposal was obtained from the Upper Big Blue Natural Resources District (UBBNRD) (Rod DeBuhr, Water Department Manager, written commun., September 1, 2005) and the city of York (Orville Davidson, Public Utilities Superintendent, York, Nebraska, oral commun., October 3, 2005). Several livestock areas were to the west of York (fig. 4).

\section{Previous Investigations}

The hydrogeology of York County was described by Keech and others (1967). Regional hydrogeologic investigations including the study area were conducted by Johnson and Keech (1959) and Gutentag and others (1984). Several ground-water modeling investigations of study areas ranging from three to several thousand square kilometers around York have contributed to the understanding of the ground-water hydrology in the area (Emery, 1966; Huntoon, 1974; Cady and Ginsburg, 1979; Nebraska Natural Resources Commission, 1983; Luckey and others, 1986; Alley and Emery, 1986; Argonne National Laboratory, 1995a,b; Upper
Big Blue Natural Resources District, 1999). The Nebraska Cooperative Hydrology Study Group (2001) constructed and calibrated a regional transient multi-layer ground-water flow model of an area that included York County.

Gottula and Link (1992) described the hydrogeology and ground-water quality of the western portion of the UBBNRD, which encompasses the study area. The spatial and temporal distribution of water quality in the High Plains aquifer in the UBBNRD was described by Verstraeten and others (1998). Relations between nitrate and atrazine concentrations in ground water and explanatory variables in York County were investigated by Druliner and others (1996). Herbicide transport and degradation in the aquifer about $3 \mathrm{~km}$ west of York were studied by Ma (1996) and Ma and Spalding (1997) to evaluate the effects of local artificial recharge with impounded surface water on ground-water quality. Argonne National Laboratory $(1993,1994,1995 a, b)$ investigated a ground-water carbon tetrachloride plume from a former grain storage facility in northern York. Landon and Turco (2007) described the hydrogeologic setting, the ambient geochemical characteristics, and simulations of ground-water flow, including ZOCs and CRAs for York PSW in the regional-scale TANC study area.

\section{Methods}

Methods used for the local-scale TANC study at York, Nebraska, are described in the section below, and include the design of the well network, drilling, well installation, coring, core analysis, collection and analysis of water samples, collection of depth-dependent flow and chemistry data, quality-assurance of water-quality data, statistical analysis of water-quality data, and estimation of aquifer properties.

\section{Design of Well Network}

The well network was designed so that an existing PSW would be the focus of the study, and additional wells were installed to allow monitoring of ground water from potential source areas along a likely flow path to the PSW. A PSW in York (hereinafter, study PSW) was selected for the study because of constituents of concern in the well, a ZOC that included both urban and agricultural land-use areas, its importance as a heavily-utilized PSW for water supply, and its distance from other pumping wells that would minimize the effect of pumpage from these wells on the ground-water flow paths to the study PSW. These selection criteria are explained further in the following paragraph. 

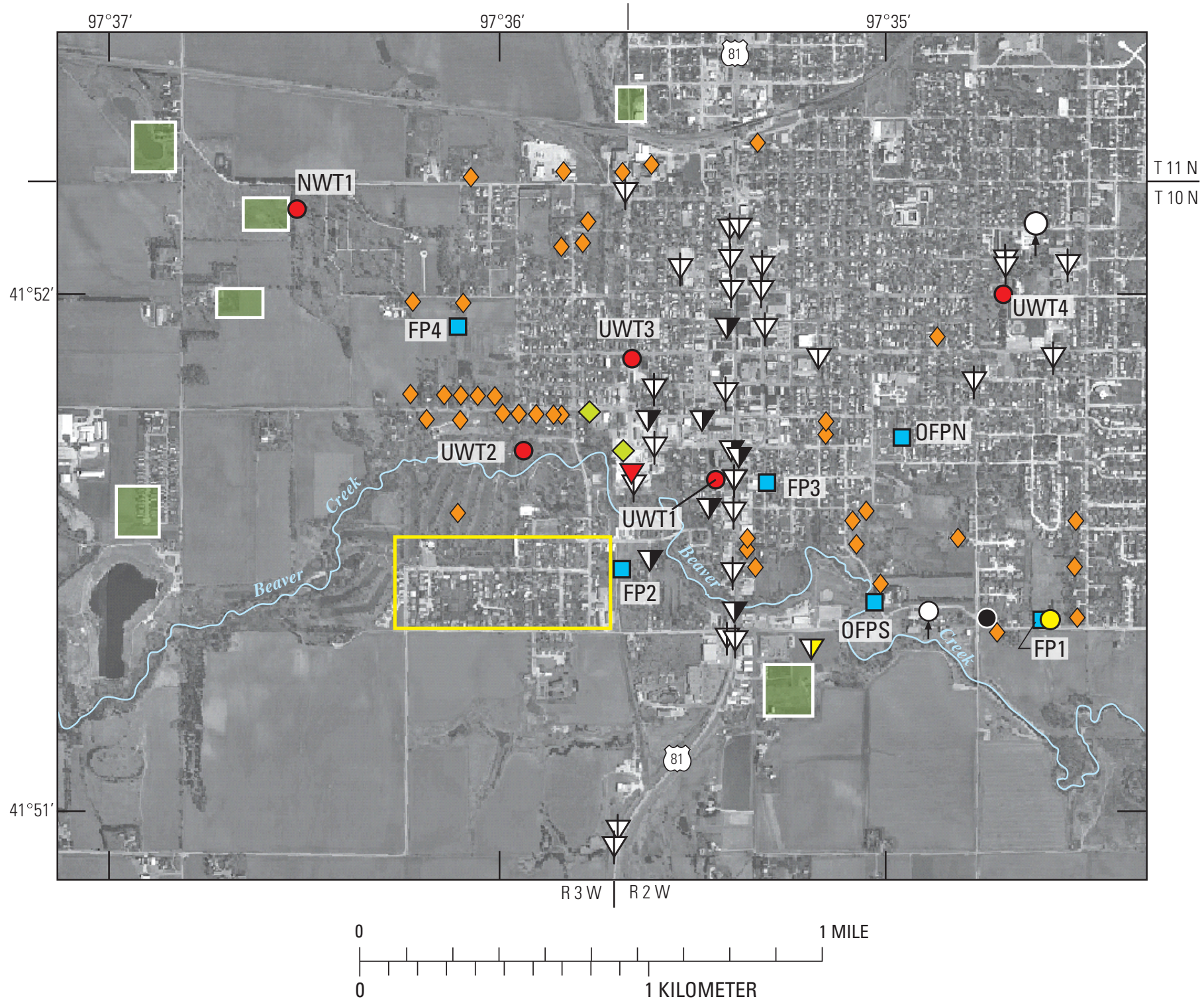

\section{EXPLANATION}

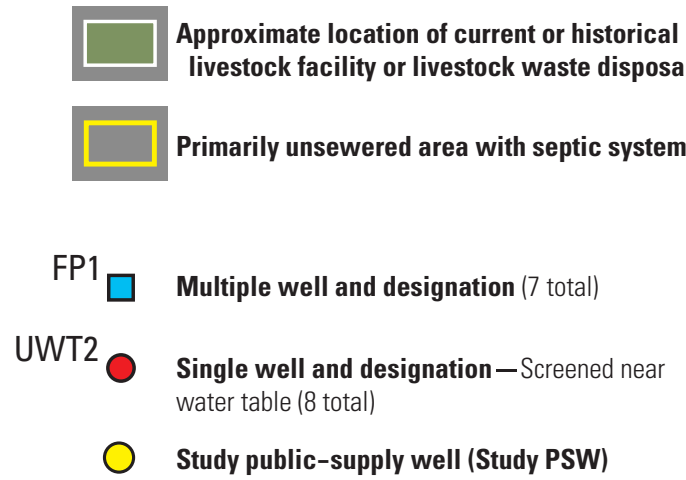

$\diamond$ Approximate location of septic systems

Potential urban contaminant sources (from contaminant source inventory classified by regulatory category)

$\begin{array}{lc}\nabla \text { Leaking storage tank } & \nabla \begin{array}{l}\text { Superfund Amendment } \\ \text { and Reauthorization } \\ \text { Act Title III }\end{array} \\ \begin{array}{l}\text { National Pollution } \\ \text { Discharge Elimination } \\ \text { System }\end{array} & \bigcirc \text { Wastewater } \\ \nabla \begin{array}{l}\text { Resource Conservation } \\ \text { and Recovery Act }\end{array} & \nabla \text { Superfund }\end{array}$

Figure 4. Distribution of potential contaminant sources compiled from various sources in the local-scale TANC study area near York, Nebraska. 
Samples were collected from the study PSW and from seven other York PSWs for the NAWQA Source Water Quality Assessment (SWQA) program in October-December 2002. At that time, trichloroethylene (TCE), tetrachloroethylene (PCE), and their degradation products were detected in the study PSW, along with uranium concentrations that were below drinking-water standards but of concern $(17 \mu \mathrm{g} / \mathrm{L}$ [microgram per liter]), and moderate arsenic concentrations of about $6 \mu \mathrm{g} / \mathrm{L}$. The concentration of nitrate (as nitrogen, hereinafter, nitrate-N) was low $(0.09 \mathrm{mg} / \mathrm{L}$ [milligram per liter]), but reconnaissance sampling indicated nitrogen gas concentrations of 1-2 mg/L larger (hereinafter, excess nitrogen gas) than concentrations that would be expected from atmospheric equilibrium at the recharge temperature. The excess nitrogen gas was consistent with denitrification of nitrate- $\mathrm{N}$, that is, more nitrate- $\mathrm{N}$ could reach the well if denitrification was not occurring. Thus, a variety of anthropogenic and natural contaminants of interest could be investigated at the study PSW. The simulated ZOC of the study PSW (Landon and Turco, 2007) indicated that urban and agricultural land use could influence ground water captured by the well. Most of the seven other wells sampled for the SWQA program and considered as candidate study PSWs had smaller areas of upgradient urban land use because they were located closer to the western, or upgradient, edge of town, or were used less frequently and had smaller withdrawal rates. As the second most heavily pumped York PSW during 2000-2004, the study PSW provided opportunities to investigate receptor (pumping well) effects on contaminant movement. Most of the other candidate wells considered were closer to other pumping wells than the study PSW, and in some cases, the simulated ZOC for the other wells was very complicated (Landon and Turco, 2007) because of withdrawals from nearby supply wells. Such flow fields would have made attempts to monitor an apparent ground-water flow path to a PSW complex and uncertain. In comparison, the simulated ZOC for the study PSW was relatively simple, making it possible to install monitoring wells along an apparent ground-water flow path leading to the well.

The study PSW was installed in 1977. The diameter of the well casing is 40.6 centimeters $(\mathrm{cm})$. The layered geology at the study PSW is characteristic of that throughout the study area (fig. 2). The study PSW was screened only in the upper confined aquifer, with an 18.3-m-long screen from 42.7 to $61.0 \mathrm{~m}$ below land surface (bls). The study PSW originally also had a deeper screen in a sand lens (lower confined lenses) from 72.8 to $75.9 \mathrm{~m}$. However, the well bore was filled with concrete below the screen in the upper confined aquifer in the 1990s to reduce sand inflow (Orville Davidson, Public Utilities Director, city of York, Nebraska, oral commun, September 10, 2003).
A network of short-screened monitoring wells was installed in or near the simulated ZOC of the study PSW (fig. 3; table 1 [see back of report]) to allow ground-water flow and geochemistry data to be collected along apparent ground-water flow paths from locations within the estimated CRAs to the study PSW. A total of 36 wells were installed in two phases; 18 wells were installed during April-May 2003, and an additional 18 wells were installed during April 2004. In the first phase, wells were installed in 5 well nests (FP1, FP3, FP4, OFPS [2 of 4 wells], and OFPN) along or adjacent to the estimated main axis of ground-water flow to the study PSW. Well nest FP1 was installed less than $30 \mathrm{~m}$ from the study PSW to characterize ground-water hydraulic heads, and to compare water chemistry in the study PSW with that in the adjacent unconfined aquifer (one well), upper confined aquifer (two wells, where the study PSW was screened), and lower confined lenses (one well). Well nests FP3 and FP4 were installed along the axis of highest probability of being within the ZOC to the study PSW, determined by using a regionalscale TANC steady-state model (Landon and Turco, 2007; Jeffrey Starn, Hydrologist, U.S. Geological Survey, written commun., March 15, 2003). Well nests OFPS and OFPN were installed to the south and north, respectively, of the main axis of the estimated ZOC to bracket the studied ground-waterflow path to the study PSW. Subsequently, local-scale transient ground-water flow modeling and particle tracking indicated that the OFPS and OFPN well nests also were located within the ZOC to the study PSW (Clark and others, 2008). In the second phase, two additional well nests were installed-FP2, south of the main axis of the ZOC, and FP5, extending the flow path farther upgradient into the agricultural area (fig. 3). In addition, eight single-completion wells with depths to the bottom of the screen ranging from 7 to $27 \mathrm{~m}$ were installed near the water table to characterize ground-water quality in potential recharge source areas of the unconfined aquifer. Refined simulations of the ZOC were used to select the locations of these wells. Of the eight water-table wells, four were installed in urban areas (UWT1-53, UWT2-23, UWT3-34, UWT4-85), three were installed in cultivated agricultural areas (AWT1-83, AWT2-71, AWT3-73), and one was installed at the downgradient end of one of the largest pasture areas that could be located within the local-scale TANC study area (NWT1-39). Since, in addition to these eight single wells, each of the seven well nests also included a monitoring well screened near the water table, there were a total of fifteen near-water table wells. 


\section{Drilling, Well Installation, Coring, and Core Analysis}

All drilling and well installation was done by the U.S. Geological Survey (USGS) Rocky Mountain Drilling Unit (Denver, Colorado) using techniques that conformed to USGS NAWQA protocols (Lapham and others, 1995; Lapham and others, 1996). Hollow-stem augering methods were used to drill all 19 of the wells installed in the unconfined aquifer and five of the 10 wells installed in the upper confined aquifer (table 1). The diameter of the resulting boreholes was $16.5 \mathrm{~cm}$. Mud-rotary methods were used to install five of the 10 wells completed in the upper confined aquifer, all six of the wells completed in the lower confined lenses, and one well installed in the underlying Carlile Shale (table 1). The diameter of these boreholes was $22.2 \mathrm{~cm}$. All drilling equipment was steamcleaned between drill sites to prevent cross-contamination of boreholes.

Nearly all monitoring wells were constructed of threaded 5.1-cm-diameter, schedule 40 polyvinyl chloride (PVC) with 1.5-m long screens. One 5.1-cm-diameter monitoring well had a 3-m-long screen (table 1). A sand pack consisting of clean silica sand typically extended from $3 \mathrm{~m}$ or less below the bottom of the screen to $1.5 \mathrm{~m}$ above the top of the screen. The wells were sealed by filling the borehole above the sand pack with a bentonite slurry and a cement cap above the bentonite near the land surface. Most wells were completed at grade with the land surface. Protective enclosures and locking caps were installed.

Water levels in all 36 monitoring wells were measured approximately monthly. Hourly water-levels were recorded using Design Analysis DH21 pressure transducers and data loggers in 11 monitoring wells and Beaver Creek during April 2003 through September 2005 and in two additional monitoring wells during August 2004 through September 2005.

One multilayer well, FP5-LS, was constructed of 10-cm-diameter, schedule 80 PVC, and had a 18.3-m long screen across the entire unconfined aquifer and a $21.3-\mathrm{m}$ long screen across the entire upper confined aquifer; the screens were separated by a 15.2-m-long cased interval across the upper confining unit (table 1). The multilayer well was installed to directly measure the effects of downward leakage of water from the unconfined aquifer to the upper confined aquifer through the well bore since well-bore leakage was hypothesized to be an important process influencing water chemistry in the upper confined aquifer and lower confined lenses. This temporary well was similar to many irrigation wells in the local-scale TANC study area that have long screens in the unconfined aquifer, upper confined aquifer, and lower confined lenses to maximize well yields. Water chemistry and hydraulic heads in FP5-LS were compared with those in adjacent short-screened monitoring wells screened in the shallow unconfined aquifer, near the bottom of the unconfined aquifer, and the upper confined aquifer. The adjacent monitoring wells were located 15 to $30 \mathrm{~m}$ upgradient of the multilayer well. This temporary well was abandoned in August 2005.

Lithology was determined using drill cuttings collected, described, and archived over 1.5-m intervals. Geophysical logs were collected in the deepest borehole drilled at each well nest site; the deepest borehole was drilled first and the geophysical logs were used to plan the placement of all monitoring well screens in each nest. Then additional boreholes located about $3 \mathrm{~m}$ apart were drilled to the target depths, and a single monitoring well was installed in each borehole. Geophysical logs collected included natural gamma, resistivity, and spontaneous potential at all sites; temperature, specific conductance, caliper, neutron, and electromagnetic induction logs were collected at some sites.

Core samples were collected and analyzed to characterize the chemical, mineralogical, and physical properties of the major vertical layers in the hydrogeologic system. In April-May 2003, four cores and one drill-cuttings sample were collected and analyzed. In April 2004, eight cores were collected and analyzed. Four cores from above the water table were collected with the hollow-stem auger using a 1-m-long 7.6-cm-diameter wire-line piston split-barrel sampler lined with an acrylic sleeve. Eight cores were collected from the bottom of the unconfined aquifer to the shale underlying the High Plains aquifer using the mud-rotary drilling rig and a variety of coring devices. In fine-textured confining units, a 3-m-long core tube was driven into the sediments below the bottom of the mud-rotary borehole. This method was unsuccessful for recovering coarse-textured sediments. For cores of sand near the bottom of the unconfined aquifer, upper confined aquifer or lower confined lenses, coring was begun in the sand using a 1.5-m-long core barrel, and the barrel was driven into an underlying clay to seal the end of the core barrel, allowing recovery of the overlying sands. Core samples for laboratory analysis were immediately transferred to a nitrogen-filled processing chamber, subsampled, and sealed in jars or core tubes to minimize exposure to the atmosphere.

Selected core samples were analyzed by USGS laboratories for mineralogy by x-ray diffraction, heavy mineral separation, and mass spectrometry. Selected core samples also were analyzed for percent organic carbon (loss on ignition), total organic carbon, carbon-13/carbon-12 isotopic ratios $\left(\delta^{13} \mathrm{C}\right)$ for total carbon, organic carbon, and calcite (USGS National Water Quality Laboratory [NWQL]). Particle-size distribution of core subsamples ranging from 0.04 micron to $2 \mathrm{~mm}$ (millimeter) was analyzed using a commercially built apparatus (K.S. Perkins, USGS, written commun. 2005).

The abundance of elements in grain coatings or other mineral phases from core samples was evaluated in USGS laboratories using different acids and reagents for extraction, including (1) 10\% nitric acid $\left(\mathrm{HNO}_{3}\right)$, (2) 6-normal (N) hydrochloric acid $(\mathrm{HCl}),(3)$ 0.5-N HCl-hydroxylamine (HA)-extractable iron, and (4) acid-volatile and chromiumreducible sulfides (Craig Brown, Hydrologist, U.S. Geological Survey, written commun., July 6, 2006). All extractions were performed on an "as received" wet basis, but the moisture 
content was determined from a separate subsample and used to correct the analytical concentrations to dry weight.

The coating extraction ( $\mathrm{HCl}$ and nitric acid) methods were primarily intended to target ferric oxyhydroxides and their associated trace elements, but they can also extract various amounts of other oxides and clay, carbonate, and sulfide phases. The sample-to-solution ratio was $5 \pm 1 \mathrm{~g}$ (gram) wet sediment to $15 \mathrm{ml}$ (milliliter) of acid solution for the $6 \mathrm{~N} \mathrm{HCl}$ and $10 \% \mathrm{HNO}_{3}$ extractions and 4-10 g wet sediment to $75 \mathrm{ml}$ of reagent for the $0.5-\mathrm{N} \mathrm{HCl}-\mathrm{HA}$ extractions. The sediment-acid aliquots were set on a shaker table for 6 hours, then centrifuged, filtered with 0.45 micronpore filters, and analyzed for several minor elements. Leachate derived from the $10 \% \mathrm{HNO}_{3}$ extractions was analyzed using inductively-coupled plasma/optical emission spectroscopy (ICP-OES). Further dilution to 5\% HNO3 was required for analysis of arsenic, cadmium, lead, and uranium by inductively-coupled plasma/mass spectrometry (ICP-MS). Analysis of the 6-N HCl extracts required dilution to 1.6- $\mathrm{N} \mathrm{HCl}$ before analysis by ICP-MS. The 0.5-N HCl-HA extractions were done following methods described by Lovley and Phillips (1987) and analyzed by ICP-MS and the ferrozine method with a Hach DR/2400 Spectrometer (Hach Company, 2002).

Sulfide phases in sediments or rock were extracted using the method described by Allen and others $(1991,1993)$ and summarized in EPA Method 9030B. The method was modified (to avoid oxidizing hydrogen sulfide by soluble ferric iron) by adding $\mathrm{SnCl}_{2}$ (Michelle Tuttle, USGS, Research Chemist, personal commun., 2003) and further modified by adding $\mathrm{CrCl}_{2}$ (Canfield and others, 1986, Bowles and others, 2003) to include pyrite-bound sulfide. Sulfide phases that are extracted by this method include pyrite, elemental sulfur, and acid volatile monosulfides. Samples of 5-20 g of wet sediment were transferred to a 250-ml round-bottomed flask (under nitrogen) with $10 \mathrm{~g} \mathrm{SnCl}_{2}$. The flask was attached to a nitrogen stream on a heating mantle and $75 \mathrm{ml}$ of deaerated $6 \mathrm{~N} \mathrm{HCl}$ and $50 \mathrm{ml}$ of $\mathrm{CrCl}_{2}$ were added. The samples were heated and kept at a sub-boiling temperature for 1 hour. Hydrogen sulfide $\left(\mathrm{H}_{2} \mathrm{~S}\right)$ was collected in 2 sequential aliquots of $100 \mathrm{ml}$ of 0.5-molar (M) NaOH. Sulfide was analyzed colorimetrically using a Hach Spectrometer DR/2400 using the methylene blue method specified by the manufacturer (Hach Company, 2002).

\section{Collection and Analysis of Water Samples}

Water samples were collected from wells during October 2003 through April 2005; analytes from different groups of wells varied slightly. Samples were collected during five sampling periods: October-November 2003, June 2004, July-August 2004, October 2004, and March-April 2005. For sampling purposes, monitoring wells were classified into 3 groups: flow-path wells, off-path wells, and source wells (table 1). Flow-path wells were deeper than wells screened near the water table in well nests along the main axis of the apparent ground-water flow path to and less than $3 \mathrm{~km}$ from the study PSW (FP1, FP3, OFPS, and FP4 well nests [fig. 3]). Off-path wells were deeper than wells screened near the water table in well nests located in or near the ZOC to the study PSW, but not along the main axis of the apparent ground-water flow path to the study PSW (OFPN, FP2) or more than $3 \mathrm{~km}$ from the study PSW (FP5). These wells were sampled for fewer analytes than flow-path wells. Source wells included the shallowest monitoring wells in each nest (seven wells) and eight single completion wells screened near the water table in various land use settings. Source wells were sampled once for an extensive list of analytes. The analytes in this sampling depended upon whether the well was part of a well nest that was flow-path (FP1, FP3, OFPS, FP4) or off-path (OFPN, FP2, FP5). Source wells also were sampled 2 or 3 more times for a more limited number of analytes. The surface discharge of the study PSW was sampled according to a source-well sampling plan. "Surface-discharge sample," the terminology of Izbicki and others (2005a,b), is used hereinafter to describe samples collected from the flow of the entire PSW at the wellhead near land surface, integrating flow from all screened depths. Shallow wells were sampled more frequently than wells screened deeper in the system because shallow water chemistry is typically more temporally variable than water chemistry deeper in the system. The surface discharge of the study PSW was sampled four times to detect temporal changes in water chemistry. Analytes measured for each well category are listed in table 2 (see back of report).

Ground-water samples were collected from wells using procedures described by Koterba and others (1995) and the USGS National Field Manual (U.S. Geological Survey, variously dated) (table 2). Water samples were processed on-site in a mobile laboratory using methods designed to minimize changes to the water-sample chemistry. Water was pumped from wells using a submersible pump and delivered to the mobile laboratory through polytetrafluoroethylene (PTFE, hereinafter referred to as Teflon) tubing with stainlesssteel connections to minimize sample contamination. Before samples were collected, stagnant water was flushed from the well by purging at least three casing volumes. While the well was being purged, water temperature, specific conductance, $\mathrm{pH}$, dissolved oxygen, and turbidity were measured in a chamber filled with flowing ground water until readings were stable. Once readings had stabilized, water samples were collected in precleaned bottles within a plastic-enclosed space to prevent sample contamination by airborne particles. To prevent degradation of water samples and maintain the initial concentration of compounds between the time of sample collection and laboratory analyses, sample bottles were preserved according to the requirements of the various laboratory methods. For some analytes, samples were filtered and the resulting laboratory-reported values only represent concentrations of dissolved species (table 2). For other analytes, samples were not filtered and the concentrations represent those in whole water (including particulate fractions); however, most of these unfiltered 
samples were collected for analytes present as dissolved gases or isotopic ratios of oxygen and hydrogen in water molecules, so concentrations associated with particulate phases were expected to be minor. Preservation practices differ among analytes and may include chilling, filtration, and (or) chemical treatment (U.S. Geological Survey, variously dated). Sampling equipment was cleaned after samples were collected at each well using standard NAWQA procedures to prevent cross-contamination between wells (U.S. Geological Survey, variously dated).

Samples were collected and analyzed for a broad suite of analytes, including water temperature, specific conductance, $\mathrm{pH}$, dissolved oxygen, major ions, trace elements, arsenic species, nutrients, 85 volatile organic compounds (VOC), eight gasoline oxygenates, 64 pesticides and degradation products, 22 acetamide herbicides and degradation products, dissolved organic carbon (DOC), dissolved gases, radium isotopes, radon, gross alpha and beta radiation, and isotopes of oxygen, hydrogen, nitrogen, sulfur, carbon, and uranium. Selected ground-water samples were analyzed for age-dating tracers including chlorofluorocarbons (CFC), sulfur hexafluoride $\left(\mathrm{SF}_{6}\right)$, tritium $\left({ }^{3} \mathrm{H}\right)$, and ratios of ${ }^{3} \mathrm{H}$ and degradation product helium-3 $\left({ }^{3} \mathrm{He}\right)$ (hereinafter referred to as ${ }^{3} \mathrm{H} /{ }^{3} \mathrm{He}$ technique). The ${ }^{3} \mathrm{H} /{ }^{3} \mathrm{He}$ technique includes analysis of additional noble gases $\left({ }^{4} \mathrm{He}\right.$ and neon). Dissolved hydrogen gas was measured in selected wells having dissolved oxygen concentrations below $1 \mathrm{mg} / \mathrm{L}$ following the method developed by Chapelle and Lovely (1990). A list of constituent groups analyses and references describing the methods is provided in table 2. Additional details of nutrient, isotopic, and age-tracer techniques are described below.

The USGS NWQL uses the laboratory reporting level (LRL) as a threshold for reporting analytical results. The LRL is set to minimize the reporting of false negatives (not detecting a compound when it is actually present in a sample) to less than 1\% (Childress, and others, 1999). The LRL is usually set at two-times the long-term method detection level (LT-MDL), which is the average (long-term) MDL calculated from multiple analytical measurements (more than 50). The MDL is the minimum concentration of a substance that can be measured and reported with $99 \%$ confidence that the concentration is greater than zero (at the MDL there is less than $1 \%$ chance of a false positive) (U.S. Environmental Protection Agency, 2002). Concentrations below the LRL are reported as estimated concentrations (designated with an "E" before the value).

Nitrogen species analyzed included ammonia, nitrite, and nitrite plus nitrate. Concentrations were reported in $\mathrm{mg} / \mathrm{L}$ as nitrogen.

Stable isotopes of oxygen, hydrogen, sulfur, carbon, and nitrogen were analyzed in an attempt to improve understanding of sources of water and reactions affecting the chemical composition of ground water (Clark and Fritz,
1997). Samples for stable isotopes of hydrogen, oxygen, sulfur and nitrogen were analyzed by the USGS Stable Isotope Laboratory in Reston, Virginia. Isotope data are presented in delta $(\delta)$ notation as the ratio of the heavy to the light isotope, in units of per mil (\%o), normalized to a standard (equation 1).

$$
\delta^{\mathrm{i}} \mathrm{E}=\left[\left(\mathrm{R}_{\text {sample }} / \mathrm{R}_{\text {standard }}\right)-1\right] \times 1,000 \text { per mil }
$$

where

$\mathrm{R}_{\text {sample }}$ and $\mathrm{R}_{\text {standard }}$ are the ratios of the heavy to the light isotope in the sample and in the standard, respectively.

Positive values of $\delta^{\mathrm{i}} \mathrm{E}$ indicate enrichment of the heavier isotope, and negative values indicate depletion of the heavier isotope, compared to the ratios observed in the standard reference material. ( $\delta^{\mathrm{i}} \mathrm{E}$ is the ratio of a heavier isotope of an element $\left[{ }^{i} \mathrm{E}\right]$ to the more common lighter isotope of that element, relative to a standard reference material.) Delta deuterium $(\delta \mathrm{D})$ and delta oxygen-18 $\left(\delta^{18} \mathrm{O}\right)$ were analyzed using an isotope ratio-mass spectrometer by hydrogen gas/ water equilibration and carbon dioxide gas/water equilibration techniques respectively and reported relative to Vienna Standard Mean Ocean Water (VSMOW) (Coplen and others, 1991; Epstein and Mayeda, 1953). Dissolved sulfate was analyzed for delta sulfur-34 ( $\delta^{34} \mathrm{~S}$-sulfate) using methods of Carmody and others (1997) and reported relative to the Vienna Canyon Diablo Troilite (VCDT) standard. Isotopes of nitrogen and oxygen of nitrate (hereinafter, $\delta^{15} \mathrm{~N}$-nitrate and $\delta^{18} \mathrm{O}$ nitrate, respectively) were analyzed by bacterial conversion of nitrate to nitrous oxide and reported relative to nitrogen gas in air and VSMOW, respectively (Sigman and others, 2001; Casciotti and others, 2002). Water samples were analyzed for delta carbon-13 $\left(\delta^{13} \mathrm{C}\right)$ using mass-spectrometry techniques at the University of Waterloo Environmental Isotope Laboratory and reported relative to the Vienna Pee Dee belemnite (VPDB) standard (Coplen, 1993).

A Rayleigh distillation calculation of expected changes in $\delta^{18} \mathrm{O}$ and $\delta \mathrm{D}$ in water while it underwent evaporation during evaporation of water was made using the methods of Clark and Fritz (1997, p. 55); the results were compared with groundwater values. An equation by Gonfiantini (1986) was used to calculate the kinetic fractionation factor, which includes kinetic effects on the isotopic fractionation during evaporation as a function of humidity. The equilibrium fractionation factor as a function of temperature was calculated using the coefficients of Kakiuchi and Matsuo (1979). The average annual atmospheric relative humidity of $70 \%$ and temperature of $11^{\circ} \mathrm{C}$ for York, Nebraska, were used in the calculations (High Plains Climate Center, 2003). 
The $\mathrm{CFC}$ and $\mathrm{SF}_{6}$ age-tracer methods are based upon the increase in concentrations of these trace gases in the atmosphere since the 1940s and 1950s as a result of industrial use of these compounds (Busenberg and Plummer, 1992, 2000). Concentrations of these gases in the atmosphere increased from the 1940s to the mid-1990s. Significant production of $\mathrm{SF}_{6}$ began in the 1960s for use in high voltage electrical switches, and atmospheric concentrations of $\mathrm{SF}_{6}$ have continued to increase. The concentrations of CFCs and $\mathrm{SF}_{6}$ in the atmosphere are proportional to their concentrations in recharge water entering an aquifer at that time; the proportionality is determined by the recharge temperature. Recharge temperatures were estimated from concentrations of dissolved nitrogen and argon gas (Busenberg and others, 1993). If there are no other sources or sinks for $\mathrm{CFCs}$ and $\mathrm{SF}_{6}$ in the aquifer and the effects of dispersion are minimal, the concentrations of these compounds in the ground-water at the time of recharge are preserved and indicate the approximate date that the water entered the aquifer. The three individual CFC compounds $(12,11,113)$, each having a different historical atmospheric concentration trend, provide three independent age estimates. Because each age tracer technique has uncertainties and is affected in different ways by aquifer processes, ages estimated using these techniques are referred to as "apparent ages."

The ${ }^{3} \mathrm{H} /{ }^{3} \mathrm{He}$ method is based upon the increase in ${ }^{3} \mathrm{H}$ concentrations in precipitation after atmospheric hydrogen bomb testing in the 1950s and 1960s (Schlosser and others, 1988, 1989; Solomon and others, 1992). ${ }^{3} \mathrm{H}$ concentrations peaked in 1963 and have declined substantially since then. ${ }^{3} \mathrm{H}$ has a half-life of 12.43 years and radioactively decays to form ${ }^{3} \mathrm{He}$. By determining the ratio of ${ }^{3} \mathrm{H}$ to ${ }^{3} \mathrm{He}$ resulting from the decay of ${ }^{3} \mathrm{H}$, the time that the water has resided in the aquifer can be calculated. Helium can be produced naturally also by sediments; the amount of ${ }^{3} \mathrm{He}$ derived from ${ }^{3} \mathrm{H}$ decay rather than geologic sources is estimated using ${ }^{3} \mathrm{He} /{ }^{4} \mathrm{He}$ ratios and neon gas concentrations.

Water samples for $\mathrm{CFCs}, \mathrm{SF}_{6}$, noble gases, and other dissolved gases were collected directly from copper tubing attached to the submersible pump and did not flow through Teflon sample lines; these samples were prevented from coming into contact with the atmosphere, in accordance with protocols for sampling for these trace gases (Busenberg and Plummer, 1992, 2000; Schlosser and others, 1989). Concentrations of two tracers of modern waters $\left(\mathrm{CFCs}, \mathrm{SF}_{6}\right.$, or ${ }^{3} \mathrm{H} /{ }^{3} \mathrm{He}$ ) and ${ }^{3} \mathrm{H}$ were collected in 13 wells in OctoberNovember 2003, and the surface discharge and four depths in the well screen of the study PSW in June 2004. The wells for which ground-water ages were calculated were located along an apparent flow path to the study PSW (flow-path wells; table 2). Concentrations of ${ }^{3} \mathrm{H}$ were measured in all wells in which other age tracers were analyzed.

\section{Collecting Depth-Dependent Flow and Chemistry Data}

Depth-dependent flow information was collected in the study PSW under pumping conditions using the "tracer pulse" method of Izbicki and others (1999). The method involves use of a high-pressure hose equipped with valves for dye injection. The hose is mounted on a trailer mounted reel. The apparatus used for this study was designed and constructed by Allen H. Christensen, USGS, San Diego, California. The approach is suitable for use in supply wells having limited access; it can be used where clearance between the pump bowls and well casing is $2.5 \mathrm{~cm}$ or more. To reduce the chances that down-hole equipment would become stuck or come in contact with moving pump parts, a $3.17-\mathrm{cm}$ insidediameter PVC access pipe extending from the wellhead about $0.6 \mathrm{~m}$ above land surface to a depth of $41.8 \mathrm{~m}$ bls was installed by a city contractor. The access pipe ended just above the top of the screen at $42.7 \mathrm{~m}$ bls but below the pump intake at about $39.6 \mathrm{~m}$ bls. The access pipe was installed by lifting the wellhead and installing the pipe between the casing and pump bowls and attaching the pipe to a threaded access port already in the casing.

Measurements were made on June 15, 2004, under typical pumping conditions of about 1,940 liters per minute ( $\mathrm{L} / \mathrm{min})$ (510 gallons per minute [GPM]). The well ran continuously during the measurement period. To obtain vertical profiles of flow in the supply well, the $1.27-\mathrm{cm}$ diameter hose was filled with rhodamine WT dye, and the end of the hose was lowered to a known depth in the well (Izbicki and others, 1999). A pulse of the dye tracer was injected into the water column. The maximum instantaneous concentration of rhodamine WT dye in the surface discharge of the study PSW during any onesecond measurement interval was 6.5 parts per billion (ppb), less than the U.S. Environmental Protection Agency (USEPA) maximum of $10 \mathrm{ppb}$ for rhodamine WT for water entering a drinking water plant (before treatment and distribution) over periods of hours to days. Average concentrations in the surface discharge of the study PSW during the injection tests were $<0.1 \mathrm{ppb}$, a factor of less than one-hundredth of the regulatory limit. The water from the study PSW was then mixed with water from wells elsewhere in the distribution system so that concentrations in water delivered to customers would have been diluted to concentrations lower than those in the surface discharge of the study PSW. Dye was never visible in the water in the surface discharge of the study PSW, and so would not have affected the aesthetic properties of the water delivered. The timing of the injection was controlled and recorded electronically by an IZ-Mobile 2 injection timer. The fluorescence of the surface discharge of the well was measured using an inline fluorometer. The calibrated fluorometer transferred dye concentration data in $\mathrm{ppb}$ to a laptop computer in real-time. The travel-time of the tracer from the point of injection to the fluorometer was recorded. Either the travel time of the first arrival or the center of mass of the tracer pulse from the injection point to the fluorometer 
can be used to calculate the velocity, as long as the same approach is employed at all depths. For this study, the first arrival was always used to calculate velocity. Multiple tests were conducted at each depth. The hose was then lowered to the next measurement depth and another series of tracer pulse tests were conducted. Measurements were made every $3.0 \mathrm{~m}$. On the basis of the estimated velocity of the water and the fact that the timing of the injection was only known to the nearest second, measurements at intervals of $<3.0 \mathrm{~m}$ were considered unwarranted because of resulting uncertainties. Using an equation of Izbicki and others (1999), the flow rate (Q) for a known well radius (r) was calculated, assuming piston flow:

$$
\mathrm{Q}=\left(\mathrm{V} \pi \mathrm{r}_{\mathrm{w}}{ }^{2}\right)
$$

where

$$
\mathrm{V}=\left(\mathrm{d}_{2}-\mathrm{d}_{1}\right) /\left(\mathrm{t}_{2}-\mathrm{t}_{1}\right)
$$

where

$$
\begin{aligned}
\mathrm{Q}= & \text { flow rate, } \mathrm{m}^{3} / \mathrm{s} ; \\
\mathrm{V}= & \text { velocity of water in measurement interval, } \mathrm{m} / \mathrm{s} ; \\
\mathrm{r}_{\mathrm{w}}= & \text { well radius, } \mathrm{m} ; \\
\mathrm{d}= & \text { depth of measurement, } 1 \text { - top of interval, } \\
& 2 \text { - bottom of interval, } \mathrm{m} \text {; and } \\
\mathrm{t}= & \text { travel time of dye pulse from injection point } \\
& \text { to fluorometer, } \mathrm{s} .
\end{aligned}
$$

Three to eight tracer pulse tests were done every $3 \mathrm{~m}$ along the study PSW screen from 42.7 to $61.0 \mathrm{~m}$ bls. Two partial profiles were measured: profile 1 consisted of measurements at 42.7, 45.7, 48.8, 51.8, 54.9, 57.9, and 61.0 $\mathrm{m}$ bls; profile 2 consisted of measurements at 44.2, 47.2, 50.3, $53.3,56.4$, and $59.4 \mathrm{~m}$ bls. The pump intake was situated above the well screen so that all water within the screened interval would flow vertically upward during pumping, and samples collected at selected depths were presumed to represent a composite of all of the water entering the well below each sampling point.

A 50.8 -cm-long by 2.22 -cm-diameter Solinist Model 407 Integra stainless-steel portable bladder pump was lowered down the access pipe to collect water samples. Sampling depths were selected on the basis of the flow profile, which indicated approximately $75 \%$ of the flow came from the upper half of the screen. In order to collect more samples from the intervals where most of the flow occurred, five samples were collected from depths of 42.7, 45.7, 48.8, 51.8, and $61.0 \mathrm{~m}$ bls, along the screen, which extended from 42.7 to $61.0 \mathrm{~m}$ bls. Flow rates with the bladder pump were 200 to $400 \mathrm{~mL} / \mathrm{min}$. The low flow rate permitted the extensive list of analytes to be collected from a maximum of only 2 depths per day. The bladder pump was cleaned after samples were collected at each depth. The pump was removed from the well and a peristaltic pump was used to push cleaning solutions through the pump and tubing. The same approach was used to drive nitrogen-purged universal blank water through the system to collect field blanks. Otherwise, the same sampling procedures and analytical methods were used to collect the depthdependent samples as were used to collect the monitoring-well samples. A sample was collected from the surface discharge of the study PSW also on June 18, 2004, to compare with depthdependent samples; the surface-discharge sample integrates all of the water flowing into the well from the range of depths along the screened interval.

\section{Quality Assurance}

Additional samples were collected to evaluate the reliability of sample collection and analysis procedures. About $14 \%$ of the total samples analyzed were quality(3) control samples; these included field blanks, source-solution blanks, sequential replicates, and spikes. In addition, 100\% of the samples for organic constituents were analyzed using surrogate compounds to monitor laboratory method performance. Additional laboratory quality-control analyses were done by the analytical laboratories, as specified by the respective analytical methods, and are not described here. The quality-management system for the USGS NWQL is described in Maloney, T.J., ed. (2005).

\section{Blanks}

Field blanks were collected at about $10 \%$ of the wells to determine if a sample was biased when collected, transported, or analyzed. All field blanks were collected using nitrogenpurged blank water that was certified by NWQL to be free of environmental sample analytes above their reporting levels. Field blanks were processed using the same procedures and equipment as those used for the environmental samples. Field blanks were analyzed for major ions, trace elements, nutrients, DOC, pesticides, VOCs, and gasoline oxygenates. It is not possible to obtain meaningful blank solutions for dissolved gases or isotopic species and no blanks for age tracers, dissolved gases, radon, or isotopic species were collected.

Source-solution blanks were collected to verify that the blank water used for the associated field blanks had no detectable concentrations of VOCs or gasoline oxygenates. Source-solution blanks were collected at the sampling site by pouring blank water (source solution) into sample containers that were then stored, shipped, and analyzed in the , same manner as the field blank and ground-water samples. If both the field blank and its associated source-solution blank contained a constituent, the source-solution water was assumed to be the origin of the detected analyte in the field blanks. The only constituent for which this was the case was acetone (table 3 [see back of report]). However, acetone was not detected in environmental samples, so this limited contamination of the source-solution water had no effect on the data interpreted for the study. 
Sample bias with respect to an analyte was of potential concern on the basis of data from blanks if the following criteria were met: (1) a constituent was detected in one or more field blanks and in ground-water samples, (2) the concentration detected in the field blank was greater than the concentration in the associated source-solution blank, and (3) the minimum concentration detected in ground-water samples was less than the sum of the maximum concentration detected in field blanks and the average long-term method detection level (LT-MDL), or half of the LRL, (hereinafter, this sum is referred to as the censoring threshold). The LT-MDL was used as a measure of analytical uncertainty, which is appropriate for concentrations within a factor of less than about 10 of the LT-MDL. Nearly all concentrations detected in blanks were less than 10 times the LT-MDL. This method of censoring follows that of Wright and others (2005), and is based on the assumption that the amount of contamination in the field blank and the associated ground-water sample are comparable. If the results for a constituent met the above criteria, the chronological pattern of detections in blanks and ground-water samples for each sampling period was evaluated. If a constituent was detected in at least one associated blank and ground-water sample at similar concentrations during a sampling period, all detections in ground-water samples at concentrations below the censoring threshold were removed from the environmental sample data set for the sampling period and flagged as being potentially biased by sample collection and analysis procedures (hereinafter, referred to as censored). If a constituent was detected in the field blanks, but not in the associated ground-water samples, the groundwater data were not censored. If a constituent was detected in ground-water samples below the censoring threshold for a sampling period different than that for which the constituent was detected in field blanks and the constituent was detected in fewer than $50 \%$ of blanks, ground-water values were not censored. In addition, when constituents were detected in 50\% or more of field blanks, the possibility that environmental concentrations were higher than they would have been because of biased sample collection was assessed by determining the number of ground-water samples in which the maximum concentration was more than $10 \%$ of environmental concentrations. The $50 \%$ blank detection threshold was used to separate constituents suspected to be affected by systematic bias of the sampling from constituents affected by random bias from the sampling. Constituents for which the maximum blank concentration was $<10 \%$ of the environmental concentration were considered to be unaffected by systematic bias.

Table 3 lists the constituents that had detections in field blanks. For 10 of the 22 constituents detected in field blanks, no environmental data were censored because environmental concentrations were greater than the censoring threshold. One constituent, acetone, was detected in 2 or 7 field blanks and in associated source-solution blanks but was not detected in ground-water samples; consequently, no data were censored. For 3 constituents - carbon disulfide, tetrahydrofuran, and vanadium - minimum concentrations detected in ground-water samples were less than the censoring threshold but no groundwater data were censored because (1) the detection in a single field blank occurred during a sampling period different than when ground-water sample concentrations below the censoring threshold occurred, and (2) field blanks collected during the sampling periods when ground-water concentrations were below the censoring threshold showed no detection. For eight constituents, the concentrations for at least 1 environmental sample were censored. Constituents were censored within only a certain sampling period if the analysis of blank data from only that sampling period showed contamination. This was the case for the VOCs chloroform and 1,2,4-trimethylbenzene, which were only detected in blanks during the first one or two sampling periods of the study. Although 23 environmental concentrations for iron were censored, this did not affect the interpretative results of the study because only low concentrations that were not significant for interpretation of oxidation-reduction conditions needed to be censored. The low iron concentrations that were censored were in oxic ground waters, where low concentrations were expected and iron concentrations have little interpretative use. Concentrations of chromium, copper, manganese, and zinc were censored in 1 to 33 environmental samples per constituent, out of 56 samples collected. Detections of trace concentrations of these constituents in blanks were noted in other waterquality investigations (Apodaca and others, 2006). Only two constituents, copper and nickel, were detected in more than $50 \%$ of the blanks and maximum concentrations in blanks that were more than $10 \%$ of concentrations in some environmental samples. For copper, 23 samples met these criteria; for nickel, 36 samples met these criteria. For these samples and constituents, environmental concentrations may have been biased by sampling processes and the data were not used in the analyses. The primary trace elements of interpretative interest for this study were uranium and arsenic, which were not censored; therefore, censoring low concentrations of chromium, manganese, and zinc and a substantial number of copper and nickel analyses had no effect on the interpretations of this study. Concentrations of DOC at or near the LRL of $0.3 \mathrm{mg} / \mathrm{L}$ were censored in 7 environmental samples, indicating low DOC concentrations in some environmental samples could not be distinguished from DOC concentrations in blanks.

\section{Replicates}

Replicate samples were collected to assess the variability resulting from collecting and analyzing samples. All replicates were sequential; the replicate sample was collected after the ground-water sample and both were analyzed using the same method. The relative standard deviation (RSD) was used to express differences between replicate pairs. The RSD is defined as the standard deviation divided by the mean concentration for each replicate pair of samples, multiplied by 100. If one value for a sample was reported as a nondetect and the value for the replicate was reported below the 
reporting level, the RSD was set to zero because the values are analytically identical. If one value for a sample was reported as a non-detect and the replicate value was greater than the LRL, the non-detection value was set equal to one-quarter of the LRL, and the RSD was calculated. Values of RSD $<20 \%$ are considered acceptable in this study.

Generally, the replicate results indicated low variability of the analytical results. The median relative standard deviation was $<5 \%$ for all constituents (table 4 [see back of report]). The maximum relative standard deviation was $<20 \%$ for all constituents except manganese. Concentrations of manganese measured in one replicate pair were 1.5 and $2.9 \mu \mathrm{g} / \mathrm{L}$, resulting in an RSD of $46 \%$. These concentrations were about 10 times greater than the laboratory reporting level of $0.2 \mu \mathrm{g} / \mathrm{L}$ for manganese. However, these manganese concentrations were $<10 \%$ of the value of manganese used as an indicator of manganese reducing conditions of $50 \mu \mathrm{g} / \mathrm{L}$; manganese was primarily used in this study as one of the indicators of oxidation-reduction conditions that affect many constituents. Thus, uncertainty in analytical concentrations of manganese at concentrations of <about $5 \mu \mathrm{g} / \mathrm{L}$ was of no practical consequence to the interpretations of this study.

Replicates of all dissolved gas, $\mathrm{CFC}$, and $\mathrm{SF}_{6}$ samples were analyzed. Most of these analytes had a RSD <5\% (not shown).

\section{Spikes}

Laboratory matrix spikes are quality-control samples used to evaluate the bias and variability of analytical results caused by interferences from the chemistry of the ground water sampled (matrix interferences). Two spike samples each were prepared and analyzed for VOCs (86 analytes), gasoline oxygenates ( 8 analytes), and pesticides (62 analytes). Laboratory matrix spikes were prepared by adding solutions containing known concentrations of target analytes to replicate ground-water samples before sample preparation and analysis. The constituents added were the same as those analyzed in the environmental samples. Acceptable ranges for spike recoveries for this study (after subtracting any detections in the corresponding environmental sample) were between 70 and $130 \%$ for VOCs and gasoline oxygenates (Connor and others, 1998; Rose and Sandstrom, 2003) and 60 to 120\% for pesticides (Zaugg and others, 1995; Sandstrom and others, 2001).

Recoveries for spiked VOCs and gasoline oxygenates were within the acceptable range for all compounds except for tetrachloroethylene (PCE) (166\%), trichlorofluoromethane (CFC-11) (131\%), and vinyl chloride (135\%), which had one spike each outside the acceptable range (table 5A [see back of report]). PCE was the most frequently detected VOC in ground water, and the slightly higher than optimal recoveries may imply that concentrations in ground-water samples were slightly over-estimated. The high spike recoveries for CFC-11 and vinyl chloride were inconsequential, as these analytes were not detected in ground-water samples.
Of the 62 pesticides in spiked samples, $23 \mathrm{had}$ recoveries $<60 \%$ in one or both spikes (table $5 \mathrm{~B}$ [see back of report]). Included in these pesticides having low recoveries was 2-chloro-4-isopropylamino-6-amino-s-triazine (de-ethylatrazine), which is a pesticide degradation product of atrazine that is frequently detected in ground-water and was detected in this study. De-ethylatrazine had spike recoveries of 47 to $58 \%$. Such a low recovery suggests that de-ethylatrazine may be more prevalent than was detected and (or) at higher concentrations than reported. It also is possible that the number of detections and the concentrations of the other 22 pesticides having at least one spike recovery $<60 \%$ may be underestimated. The only other pesticide detected in groundwater samples for which spikes were collected, atrazine, had acceptable recoveries.

\section{Surrogates}

At the NWQL, surrogate compounds were added to all ground-water, surface-water, and quality-control samples that were analyzed for pesticides, VOCs, and gasoline oxygenates. Surrogate compounds are constituents that behave like pesticide or VOC analytes but are not normally found in the environment. Surrogates are added to the sample just prior to analysis. Surrogates are used to evaluate the ability of the sampling and analysis methods to detect like compounds in each sample and to determine whether the chemistry of each sample would interfere with the pesticide or VOC analysis (referred to as matrix interference). A 70 to $130 \%$ recovery is generally considered acceptable, and values outside this range indicate possible problems with the processing and analysis of samples.

The surrogate recoveries were nearly always within the acceptable range. Two surrogates, $\alpha-\mathrm{HCH}-\mathrm{d} 6$ and diazinon-d10, were added to each of the 21 pesticide samples collected for this study. The mean recovery was 91\% (standard deviation $(\sigma)=1.3 \%)$ for $\alpha-\mathrm{HCH}-\mathrm{d} 6$ and $95 \%(\sigma=1.6 \%)$ for diazinon-d10. Three surrogates were added to 86 VOC samples at the NWQL and one surrogate was added to 43 gasoline oxygenate samples. Mean VOC surrogate recoveries for 1,2-dichloroethane-d4, 1-bromo-4-fluorobenzene, and toluene-d8 were $112 \%(\sigma=7.1 \%), 95 \%(\sigma=5.6 \%)$, and $99 \%(\sigma=2.7 \%)$ respectively. The mean gasoline oxygenate recovery for isobutyl alcohol-d6 was $108 \%(\sigma=24.2 \%)$.

\section{Statistical Methods}

Nonparametric methods were used to identify statistically significant correlations between potential explanatory variables and concentrations of constituents of particular interest. Potential explanatory variables included concentrations of other constituents or physical parameters such as depth to water or depth below water table. Nonparametric statistics were used for the analyses; these are robust techniques that are generally not affected by 
outliers and do not require that the data follow any particular distribution (Helsel and Hirsch, 1992). Use of nonparametric analyses was necessary as many of the data sets investigated did not appear to follow a normal distribution, as would be required for parametric techniques to be used. The significance level (p) used for hypothesis testing for this report was compared to a threshold value $(\alpha)$ of $5 \%(\alpha=0.05)$ to evaluate whether the relation was statistically significant $(\mathrm{p}<\alpha)$. Correlations were investigated using Spearman's method to calculate the rank-order correlation coefficient $(\rho)$. Values of $\rho$ range from +1.0 (perfect positive correlation), through 0.0 (no correlation), to -1.0 (perfect negative correlation). In limited cases when the relation between two variables was clearly linear, the Pearson or linear correlation coefficient (r) was calculated using the data values rather than the data ranks. The value of the coefficient of determination $\left(\mathrm{r}^{2}\right)$ also was calculated in these cases and represents the fraction of the variance explained by the linear regression (Helsel and Hirsch, 1992). All statistical analysis was done using S-PLUS for Windows, version 6.1, Professional Edition.

\section{Estimation of Aquifer Properties}

Slug tests were completed in 33 monitoring wells to determine horizontal hydraulic conductivity $\left(K_{h}\right)$ of the aquifer near the screened interval. Slug tests were conducted using pneumatic (air) slugs in 29 wells, solid slugs in 3 wells, and a combination of slug types in 1 well. The water-level responses were recorded using a Druck pressure transducer attached to a Campbell Scientific CR10X data logger. Normalized (recorded water-level - static)/initial displacement $\left[\mathrm{y}_{0}\right]$ ) plots of the water-level response data were used to determine whether the response depended on $\mathrm{y}_{0}$; if so, the response from the smallest displacement was analyzed. The normalized plots were visually reviewed to determine if the water-level response was over-damped, critically damped, or under damped (Butler, 1998). For overdamped responses, an Excel workbook template of Halford and Kuniansky (2002) applying the Bouwer and Rice (1976) method was used to calculate $K_{h}$. For underdamped and critically damped responses, a spreadsheet template of Butler and others (2003) that is based on models described by Springer and Gelhar (1991) and Butler (1998) was used that solves the damped spring equation to determine the damping factor, and calculates $K_{h}$ using the Bouwer and Rice shape factor (Butler and others, 2003). For each of the slug tests conducted for this study, there was a substantial linear segment in the response curves, indicating that the theoretical conditions of the Bouwer and Rice (1976) method were generally met for the tests. Recommended field guidelines were followed, including initiating the tests very rapidly relative to the formation response, doing a series of tests at more than one $\mathrm{y}_{0}$ to determine if the response depends on $\mathrm{y}_{0}$, and ensuring that the pressure transducer was as close to the static-water level as possible (Butler and others, 2003).
The saturated hydraulic conductivity (vertical) of core samples were analyzed using the methods of Nimmo and Mello (1991) and Nimmo and others (2002) in a USGS laboratory in Menlo Park, California (Kim Perkins, U.S. Geological Survey, written, commun., October 20, 2004). One core of unsaturated loess, two cores of the upper confining clayey silt till, and one core of a lower confining clayey silt were submitted for analysis.

\section{Hydrogeology}

The hydrogeologic setting of the local-scale TANC study area is described below. Particular emphasis was placed upon the new understanding of the hydrogeology of the localscale TANC study area gained from lithologic, geophysical, ground-water level, and aquifer property data collected for this investigation.

\section{Geology, Mineralogy, and Sediment Chemistry}

The local-scale TANC study area lies within the High Plains aquifer, which consists of Quaternary-age unconsolidated deposits in eastern Nebraska (fig. 1) (Gutentag and others, 1984). The sediments consist of sand, gravel, silt, and clay that form a layered sequence of aquifers separated by intervening aquitards (fig. 5). Landon and Turco (2007) interpreted available lithologic logs to conceptualize the geology of the regional-scale TANC study area as a sixlayer system. This conceptualization was slightly refined to describe geologic heterogeneity influencing water and solute transport within the $108-\mathrm{km}^{2}$ local-scale TANC study area using lithologic descriptions and geophysical logging of seven test holes drilled through the aquifer into the underlying shale. The additional test holes indicated the presence of the upper four units or aquifers at all sites with some additional heterogeneity identified within the units. The hydrogeologic units in the local-scale TANC study area are described below and summarized in table 6 (see back of report).

The High Plains aquifer in the local-scale TANC study area is underlain by the Carlile Shale of Late Cretaceous age (Keech and others, 1967). Unweathered Carlile Shale is black or dark-grey, fossil-rich consolidated rock with traces of sand and white limestone or calcite fragments. At some locations, the upper few meters of the shale has been weathered and consists of light brown and light gray silty clay with increasing amounts of more consolidated black shale with depth.

Generally, the thickness of the upper four hydrogeologic units does not vary greatly across the study area (fig. 5). Total thickness of the aquifer is primarily controlled by variations in the bedrock surface. The depth to the top of the shale and the thickness of the lower confining unit and lower confined lenses vary more than the thickness of the units in the upper part of the aquifer. 

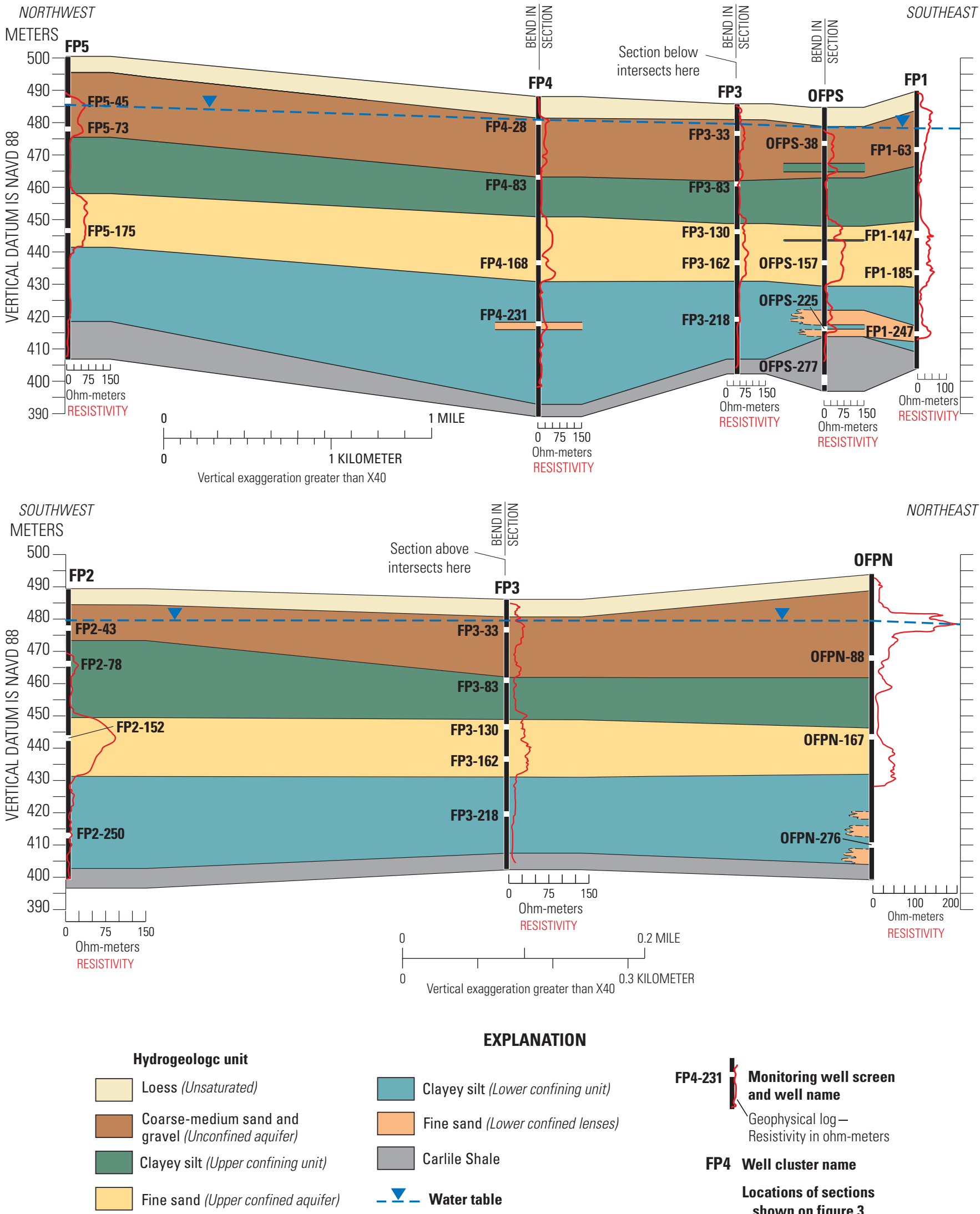

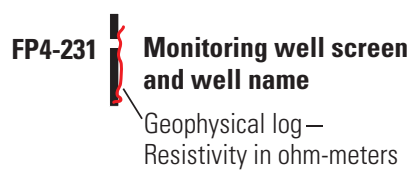

FP4 Well cluster name

Locations of sections shown on figure 3

Figure 5. Cross sections showing hydrogeologic units and geophysical logs from selected test holes drilled for the local-scale TANC study near York, Nebraska. 
The silt, clay, sand, and gravel that make up the High Plains aquifer were deposited during the Pleistocene epoch ( 0.01 to 2 million years ago). Sediments of the lower confining unit and lower confined lenses, the upper confined aquifer, and the upper confining unit (table 6) were deposited during the early part of the Pleistocene, when continental glaciers moved into the study area from the north (Gottula and Link, 1992). The advance and retreat of continental glaciers in the region created barriers to western streams and source sediments. Glacial drainage resulted in deposition of silt, clay, and sand in stream valleys. The uppermost glacially derived sediment is the upper confining unit, a mixture of silt, clay, and stones derived from source materials to the north. During glacial retreat to the north, sand and gravel from streams draining from the west was deposited with interbedded silt and clay of eolian and fluvial origin. These deposits form the unconfined aquifer (table 6). The source of the sediments may have included both reworked Ogallala Formation, the principal hydrogeologic unit of the High Plains aquifer west of the study area, and materials from the Rocky Mountains (Swinehart and others, 1994; Snow and Spalding, 1994). Finally, wind-blown silt, or loess, was deposited across the landscape during the late Pleistocene.

The uppermost geologic layer is loess, which is continuous across the local-scale TANC study area and unsaturated in most locations. In a few locations, the water table extends into the bottom part of the loess, particularly where the depth-to-water is shallow, such as along Beaver Creek (fig. 1) or Lincoln Creek (topographic valley north of York shown on figure 1). Sediment particle-size analysis of a sample of unsaturated loess indicated mostly silt-sized particles (80.3\%), with lesser amounts of clay (17.3\%; table 7 [see back of report]). The loess is the parent material for the fertile silt and clay loam soils that cover most of the study area. Heterogeneities such as cracks, root casts, and animal burrows can allow water to move more rapidly through the loess under some circumstances.

Deposits of sand and gravel with discontinuous silt and clay lenses underlie the loess and form the unconfined aquifer, which is continuous across the local-scale TANC study area. The water table is near the top of the unconfined aquifer at most locations. Lithologic descriptions and geophysical logs (induction and (or) resistivity) indicated sediment texture generally became finer downward through the unconfined aquifer, with the gravel and coarse sand grading into more fine-textured sand, grading into heterogeneous thinly interbedded sand, silt, and clay (fig. 5; tables 6 and 7 ). Crosssections by Keech and others (1967) indicate that thin silt layers at the bottom of the unconfined aquifer are common.

A clayey silt that forms the upper confining unit underlies the unconfined layer and is continuous across the local-scale TANC study area. The upper confining unit contains stones of different sizes and is poorly sorted. These sediments have been interpreted as a glacial till deposited by continental glaciers that advanced southward into eastern
Nebraska; the western extent of the glacial till is about $20 \mathrm{~km}$ west of the regional-scale study area (Swinehart and others, 1994). A sediment particle-size analysis of a core sample of the upper confining unit indicated that it consists mostly of silt-sized particles and lesser amounts of clay (table 7).

A moderately well-sorted fine-to-medium sand underlies the upper confining unit and forms the upper confined aquifer. The upper confined aquifer contains only minor amounts of gravel, silt, and clay (table 7) and is more homogeneous than the unconfined aquifer. Nearly all PSWs and many irrigation and commercial wells are fully screened across the upper confined aquifer, which is continuous across the local-scale TANC study area and is the principal water-supply unit.

Underlying the upper confined aquifer is a heterogeneous mixture of silt, clay, and fine-to-medium sand. Silt and clay are more abundant than the poorly-sorted fine-to-medium sand lenses (table 6). Sand lenses, when present, are 1- to $5-\mathrm{m}$ thick and are discontinuous between test holes. Some PSWs and irrigation wells have multiple screens that intersect the thin sand lenses. Landon and Turco (2007) divided the silt, clay, and sand deposits in the lower part of the confined aquifer system into two layers for the regional-scale TANC study: a lower confining unit consisting of more silt and clay than sand and an underlying lower confined layer consisting of more sand than silt and clay. The drilling and geophysical logging done for the local-scale TANC study indicated that the deposits in the bottom part of the confined aquifer system were heterogeneous and did not always conform with the regional-scale TANC conceptualization. Rather, the sediments in the lower part of the confined aquifer system mostly consisted of silt and clay deposits, described as the lower confining unit in this report, and discontinuous thin sand lenses within silt and clay, described in this report as the lower confined lenses. Sediment particle-size analysis of a core sample from the lower confining unit indicated that the sample consisted mostly of silt-sized particles with lesser amounts of clay (table 7).

Quartz is the most abundant mineral in core samples from all hydrogeologic units, followed by plagioclase and potassium feldspar in most units (table 8 [see back of report]). Although the x-ray diffraction (XRD) results are qualitative, they indicate the relative abundance of different minerals in the solid phase. Calcite was detected in most core samples, except those from the loess and upper confining unit. Small quantities of gypsum and halite were detected in the shale underlying the High Plains aquifer. Gypsum and halite also were detected in a sample from FP3 (depth 38.1 to $41.1 \mathrm{~m}$ ) in the upper confined aquifer; however, these detections were considered spurious because the water chemistry was not consistent with the presence of these minerals. Furthermore, these minerals were not detected in other aquifer samples. This sample was collected by sieving drill cuttings from mud-rotary drilling and washing the drilling mud off with de-ionized water. It is suspected that the traces of gypsum and halite in this sample represent contamination from the drilling mud. 
Pyrite was identified in heavy mineral separates in 3 samples from near the water table in the unconfined aquifer, in the upper confined aquifer, and in the lower confining unit (table 8). Fractions of heavy mineral separates comprised of pyrite were greatest in the upper confined aquifer and the lower confining unit samples. Although the pyrite was present only in very small amounts (unquantifiable since XRD and heavy mineral separates results are qualitative), the presence of pyrite indicates that it is potentially available as a reactant affecting ground-water iron, sulfate, and oxidation-reduction patterns. Sulfide concentrations measured using the acidvolatile and chromium-reducible sulfides extraction process ranged from 0.18 to $3.2 \mathrm{mg} / \mathrm{kg}$ in the loess, unconfined aquifer, upper confining unit, and upper part of the upper confined aquifer (table 9 [see back of report]). Sulfide concentrations were 1 to 3 orders of magnitude greater than these values near the bottom of the upper confined aquifer $(75 \mathrm{mg} / \mathrm{kg})$ and in the lower confining units $(1,800 \mathrm{mg} / \mathrm{kg})$, consistent with larger fractions of pyrite in heavy mineral separates.

Results of sequential extractions of core samples indicate that iron, manganese, uranium, and arsenic were present in the aquifer sediments and underlying shale, and concentrations of these elements in ground water were not limited by source sediments. Total iron concentrations from $0.5-\mathrm{N} \mathrm{HCl}-\mathrm{HA}$ extractions represented poorly crystalline, microbially reducible fractions of iron oxides in the sediment phase (Craig Brown, U.S. Geological Survey, written commun., July 5, 2006). Total iron concentrations in these extractions were greatest in core samples from the loess, unconfined aquifer near the water table, and lower confining unit (table 9). No sample of shale was analyzed using the $0.5-\mathrm{N} \mathrm{HCl}-\mathrm{HA}$ extraction; however, extractions using stronger acids mobilizing more of the total solid-phase chemistry indicated that the shale core had the highest concentration of iron (table 9). Extractions using 6- $\mathrm{N} \mathrm{HCl}$ and $10 \% \mathrm{HNO}_{3}$ indicated that manganese concentrations were (1) higher in fine-textured than in coarse-textured sediments, (2) detected in all but one core sample, (3) lowest in the unconfined aquifer, and (4) present in much lower concentrations than iron. Uranium was detected in all samples analyzed, but the highest concentrations were in samples from the lower confining unit and shale (table 9). Arsenic was detected in all samples analyzed from $10 \%-\mathrm{HNO}_{3}$ extractions, but were highest in fine-textured upper confining and lower confining units and the Carlile Shale.

Organic carbon contents in fine-textured sediments including the Carlile Shale (3.2\%), lower confining unit $(0.07$ and $0.26 \%)$, and loess $(0.13 \%)$ were greater than those in core samples from the unconfined and upper confined aquifers, which ranged from 0.03 to $0.05 \%$ (table 9). The upper confining unit not analyzed for organic carbon. The similarity of total carbon and organic carbon content indicate that total carbon consisted nearly entirely of organic carbon in the loess and unconfined aquifer, and Carlile Shale. In the upper confined aquifer and lower confining unit, the difference between total carbon and organic carbon suggested that most of the carbon is present in inorganic forms, most likely as calcite. This observation is supported by $\delta^{13} \mathrm{C}$ values of total carbon, organic carbon, and calcite. Total carbon $\delta^{13} \mathrm{C}$ values approached those of organic carbon for the loess, unconfined aquifer, and Carlile Shale, where organic carbon dominates. Values of $\delta^{13} \mathrm{C}$ for total carbon in 3 samples from the upper confined aquifer and lower confining unit approached those of calcite, indicating that inorganic carbon is the dominant form in these units. These results suggest that calcite is abundant in and below the upper confined aquifer. The small offset between total carbon and organic carbon $\delta^{13} \mathrm{C}$ values and XRD results for relative abundances of calcite described earlier imply that calcite is present only in small quantities in the loess, unconfined aquifer, and upper confining unit. However, the presence of even a small amount of calcite in these units can have a great effect on inorganic ground-water chemistry (see Major Elements).

\section{Ground-Water Occurrence and Movement}

Both unconfined and confined conditions exist within the TANC local-scale study area. Ground water predominantly flows from the northwest and west to the southeast and east (fig. 3); the average gradient was about 0.001326 in the unconfined aquifer (Keech and others, 1967). Regional watertable maps were available for several periods, including the late 1950s (Johnson and Keech, 1959), the mid-1960s (Keech and others, 1967), 1979 (Nebraska Conservation and Survey Division, 1980), 1995 (Dreeszen, 2001), and 1996 (Verstraeten and others, 1998). The maps indicate consistent regional flow directions and gradients, even as heads in the entire aquifer have risen and fallen over the last 5 decades. Ground water passing beneath York that is not withdrawn by pumping probably discharges into the West Fork of the Big Blue River about 24 to $32 \mathrm{~km}$ southeast of York (Landon and Turco, 2007).

There are no naturally perennial streams in the immediate vicinity of York. Flow in Beaver Creek is primarily maintained by return flow of ground water pumped for commercial purposes or by discharge of treated wastewater effluent (Landon and Turco, 2007). Leakage from Beaver Creek to the aquifer over the stream reach extending downstream from near the southwestern edge of York to the edge of the regionalscale study area (fig. 1) was estimated to be about $0.042 \mathrm{~m}^{3} / \mathrm{s}$; this estimate was based on average return flows and low-flow streamflows measured on Beaver Creek downstream of York during the late 1980s and early 1990s (Landon and Turco, 2007).

The depth to water ranged from 3 to $24 \mathrm{~m}$ below land surface in 15 shallow monitoring wells installed for this study. Depth to water was less within the Beaver Creek alluvial valley and in the eastern part of the local-scale TANC study area than in the rest of the study area. 
Water levels decreased from 1 to $2 \mathrm{~m}$ in wells in the shallow unconfined aquifer during April 2003-September 2005 in response to drought conditions during 2003-2004. Ground-water levels in the shallow unconfined aquifer fluctuated slowly over weeks to months and did not change quickly in response to individual precipitation events or seasons. Rather, the thickness and properties of the unsaturated loess and the storage properties of the unconfined aquifer apparently serve to smooth out wetting fronts from precipitation and irrigation events such that recharge events do not produce a short-term rise in the water table.

There are large downward vertical hydraulic head gradients from the unconfined aquifer to the upper confined aquifer and lower confined lenses, particularly during the summer irrigation season (fig. 6). Large hydraulic head differences occur across the upper confining unit at all sites. Hydraulic heads in the unconfined aquifer were greater than those in the upper confined aquifer by 1 to $3 \mathrm{~m}$ during the fall, winter, and spring when irrigation wells were not pumping; during the summer irrigation season, hydraulic heads in the upper confined aquifer declined 7 to $13 \mathrm{~m}$ in response to withdrawals while hydraulic heads in the unconfined aquifer declined by less than $1 \mathrm{~m}$. Hydraulic heads in the upper confined aquifer decrease more because of the much lower storage of water per volume of aquifer in confined than in unconfined aquifers (Freeze and Cherry, 1979). Downward vertical hydraulic head gradients across the upper confining unit during the summer were as much as $0.75 \mathrm{~m} / \mathrm{m}$. Hydraulic head gradients within the unconfined aquifer were generally downward but small $(0.001 \mathrm{~m} / \mathrm{m})$. Hydraulic head gradients within the upper confined aquifer at FP3, away from pumping wells, were small and not consistent in direction. At FP1, $<30 \mathrm{~m}$ from the study PSW, the hydraulic head in the upper part of the upper confined aquifer (FP1-147) was 1 to $3 \mathrm{~m}$ lower than the hydraulic head in the lower part (FP1-185). The probable cause of the upward hydraulic head gradient is that the water intake for the study PSW pump is above the top of the upper confined aquifer. At most locations and times, the downward hydraulic head gradients of 0.03 to $0.33 \mathrm{~m} / \mathrm{m}$ from the upper confined aquifer to the lower confined lenses were relatively small (fig. 6). In the lower confined lenses, hydraulic heads were closest to, or sometimes greater than, those in the upper confined aquifer during June-July, likely because hydraulic heads declined more rapidly in the upper confined aquifer at the beginning of the irrigation season. Thereafter, hydraulic heads in the lower confined lenses dropped below those in the upper confined aquifer for the rest of the irrigation and non-irrigation periods.

Hydraulic heads observed in well nest FP1, within $30 \mathrm{~m}$ of the study PSW, showed more short-term variability than those at other sites because of the on and off cycles of the supply well pump. Hydraulic heads in the unconfined aquifer (FP1-63) did not change in response to study PSW pumping cycles, indicating that pumping stress in the upper confined aquifer did not propagate into the unconfined aquifer. This lack of a response is consistent with the absence of local short-circuit pathways across the upper confining unit at this location. Withdrawals from the study PSW in the upper confined aquifer caused hydraulic heads in the lower confined lenses (FP1-247) to decline by $<2 \mathrm{~m}$, considerably less than the 6-m decline in the upper confined aquifer.

Exchange of water between the High Plains aquifer and the underlying Cretaceous Carlile Shale is likely to be volumetrically negligible compared to other aquifer fluxes because the permeability of the shale is much lower than that of the High Plains aquifer (Luckey and others, 1986). Limited data indicate that there have been small upward hydraulichead gradients from the shale to the lower confined lenses, implying that small upward fluxes of water into the aquifer may occur. McMahon (2001a) found upward hydraulic head gradients from underlying bedrock layers in the central High Plains aquifer in response to withdrawals from the aquifer. In a monitoring well completed in the Carlile Shale (OFPS-277), hydraulic heads during the spring and early summer in 2004 and winter in 2004 and 2005 were consistently slightly higher than those in the lower confined layer (OFPS-225). Hydraulic head data for well OFPS-277 are more uncertain than data for other wells because this well could not be properly developed due to very low yield from the well. Because the well had a long time to equilibrate to hydraulic heads in the shale, measurements during the periods listed above probably reflect actual hydraulic heads in the shale even though the well could never be fully developed. Hydraulic heads during the late summer and early fall in 2004 may have been affected by attempts to develop the well.

\section{Aquifer Hydraulic Properties}

Slug tests were done to determine $K_{h}$ at many locations and depths in the aquifer for the purpose of developing a conceptual model for the spatial distribution of $K_{h}$ that could be used as initial input into a numerical model (Clark and others, 2008). Previous studies often found that effective $K_{h}$ is greater for large-volume tests such as aquifer or tracer tests than for relatively small-volume tests like slug tests (discussed by Butler, 1998). However, it was not possible to conduct large-volume aquifer tests at enough locations to characterize spatial variability in $K_{h}$. 


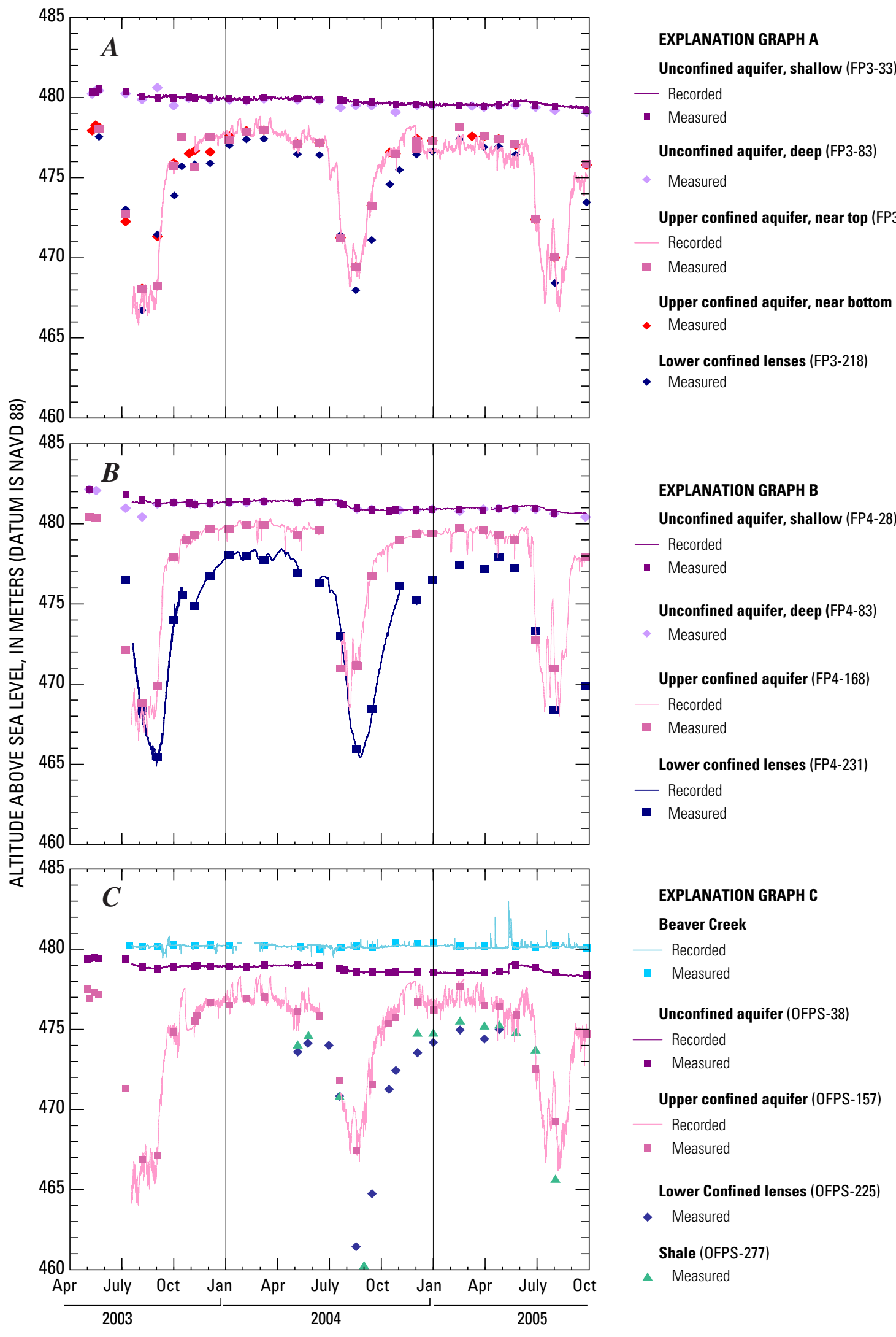

Figure 6. Water-level elevations in selected monitorng wells in the local-scale TANC study area near York, Nebraska, 2003-2005. 


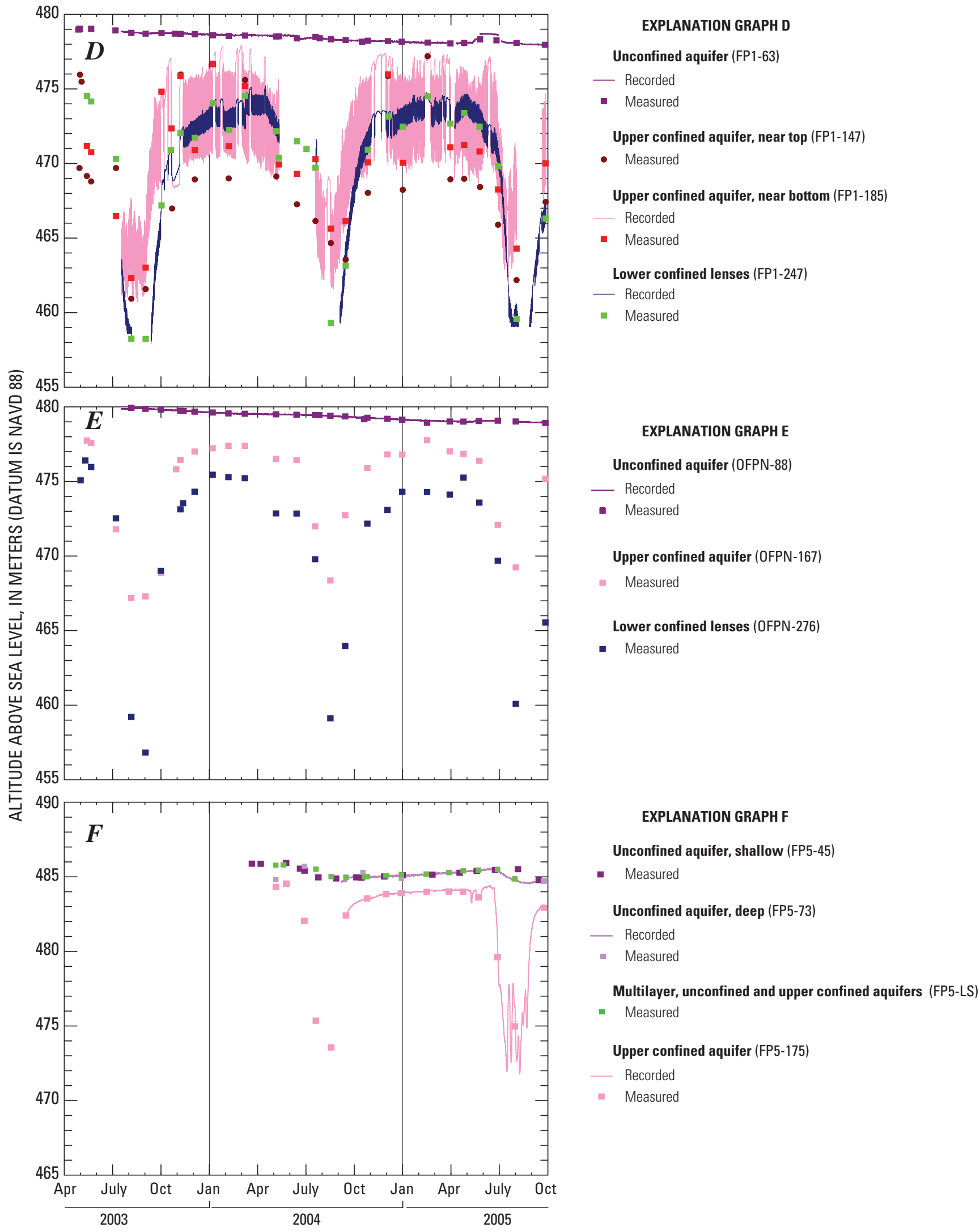

Figure 6.-Continued. 


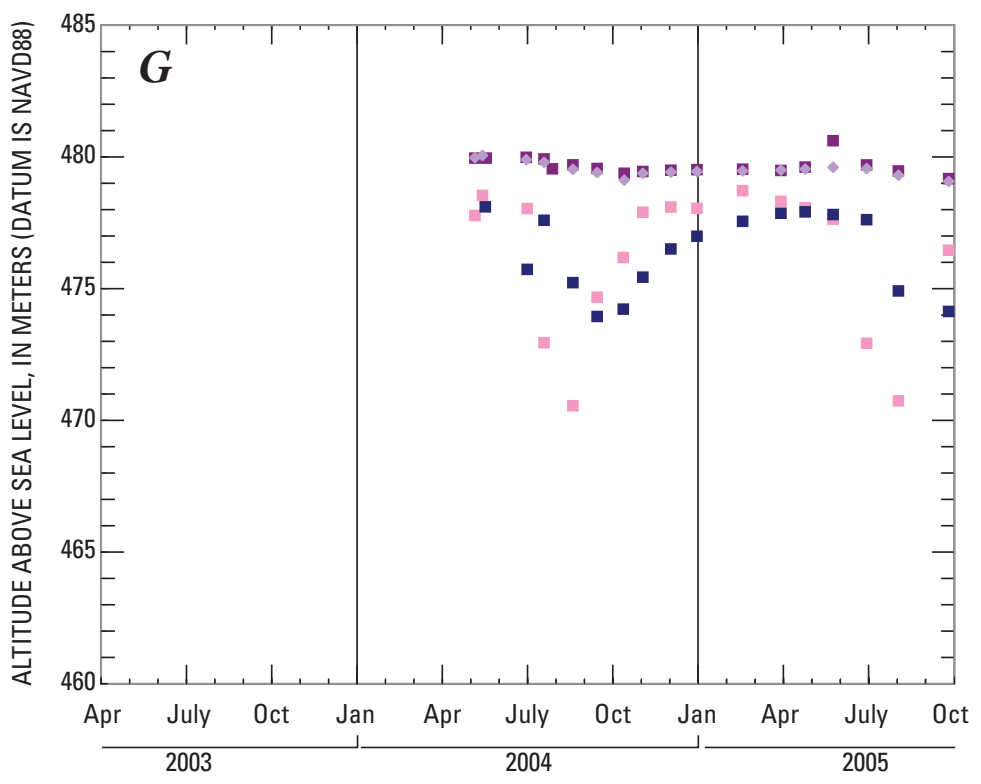

\section{EXPLANATION GRAPH G}

Unconfined aquifer, shallow (FP2-43)

- Recorded

Unconfined aquifer, deep (FP2-78)

- Measured

Upper confined aquifer (FP2-152)

- Measured

Lower confined lenses (FP2-250)

- Measured

Figure 6.-Continued.

Results of slug tests in 34 monitoring wells indicated vertical variations in $K_{h}$ consistent with lithologic and geophysical data. $K_{h}$ was highest in the upper and middle depths of the unconfined aquifer where the layers have the coarsest texture (table 10 [see back of report]). Values of $K_{h}$ varied more in the unconfined aquifer than in the deeper units, probably reflecting the poor sorting and heterogeneity of the deposits, and ranged from 3 to $32 \mathrm{~m} / \mathrm{d}$. $K_{h}$ near the bottom of the unconfined aquifer was generally lower than at shallower depths, reflecting the finer texture of the sediments in the lower part of the unconfined aquifer. $K_{h}$ in the upper confined aquifer was less than $K_{h}$ in the unconfined aquifer, reflecting the generally finer texture of the upper confined aquifer. There did not appear to be any consistent vertical differences in $K_{h}$ with depth through the upper confined aquifer. $K_{h}$ in the lower confined lenses was mostly $<3 \mathrm{~m} / \mathrm{d}$ and smaller than $K_{h}$ in the upper confined aquifer; most of the monitoring wells in the lower confined lenses were screened in silty sand, sandy silt, or clayey silt.

A few aquifer tests to measure $K_{h}$ values of larger volumes have been conducted in the past (table 10) and results generally support the conceptual model of greater $K_{h}$ in the unconfined aquifer than in the upper confined aquifer or lower confined sand lenses. Two aquifer tests in the unconfined aquifer yielded values of $K_{h}$ that ranged from 41 to $120 \mathrm{~m} / \mathrm{d}$ (Argonne National Laboratory, 1995a; Ma, 1996). One aquifer test in the upper confined aquifer yielded a $K_{h}$ of $20 \mathrm{~m} / \mathrm{d}$ and two tests in the lower confined lenses yielded 4.8 and $6.9 \mathrm{~m} / \mathrm{d}$ (Layne Geosciences, written commun., 1997).

Laboratory tests of saturated vertical hydraulic conductivity $\left(K_{v}\right)$ of core samples indicated that three samples from confining units (two from the upper confining unit and one from the lower confining unit) had $K_{v}$ ranging from
$6.4 \times 10^{-6}$ to $1.5 \times 10^{-5} \mathrm{~m} / \mathrm{d}$; one sample of loess had a $K_{v}$ of $1.5 \times 10^{-5} \mathrm{~m} / \mathrm{d}$ (table 10 ). These laboratory values derived from measuring small core samples probably represent minimum values because the small volume measured did not incorporate preferential flow paths present in larger volumes that could facilitate more rapid movement of water than implied by these laboratory $K_{v}$ values. Nevertheless, these laboratory values provide minimum bounding estimates of the $K_{v}$ of the loess and confining units.

\section{Water Budget}

A steady-state conceptual and simulated water budget for the regional-scale TANC study area for 1997-2001 was described by Landon and Turco (2007). More comprehensive analyses of the transient simulated water budget of the local-scale TANC study area, changes in ground-water-levels since the 1950s, and interpretations of historical changes in the water balance are described by Clark and others (2008). Water-budget information is presented in this report for the purpose of characterizing the hydrogeologic setting.

Ground-water withdrawals for irrigation were the largest outflow, accounting for $73 \%$ of total outflows; withdrawals for commercial and municipal supply accounted for 3 and $2 \%$, respectively (Landon and Turco, 2007). Withdrawals for selfsupplied domestic or livestock purposes were not quantified because they are probably negligible compared with other withdrawals (Upper Big Blue Natural Resources District, 1999). The remaining $22 \%$ of outflow from the regional-scale TANC study area was ground-water flow out of the study area at the southeastern boundary. 
Most ground-water inflows were from recharge, accounting for $89 \%$ of inflows (Landon and Turco, 2007). Regional ground-water inflows from the northwestern boundary accounted for $7 \%$ of inflows and seepage of water from Beaver Creek into the aquifer accounted for $4 \%$ of the inflows.

Average withdrawal rates for irrigation were estimated at $25 \mathrm{~cm} / \mathrm{yr}$ for 1998 through 2002 on the basis of metered pumpage in 50 to 150 wells per year reported to the UBBNRD (Rod DeBuhr, UBBNRD, Water Department Manager, written commun., April 15, 2003). These average values included both sprinkler and gravity irrigation systems. Sprinkler irrigated lands accounted for about $46 \%$ of the irrigated area in the regional-scale TANC study area; gravity irrigated lands account for about $54 \%$. Metered pumpage data for earlier periods and attempts to estimate historical metered pumpage are discussed by Clark and others (2008).

Initial values of recharge rates for the regional-scale TANC study were estimated from the difference between other sources of inflow and outflow in the conceptual ground-water budget. Estimates of lateral boundary fluxes and groundwater withdrawals were considered to be better constrained than ground-water recharge, which can vary greatly because of many hydrologic, geologic, and land-use factors. Total recharge of about $2.3 \mathrm{~m}^{3} / \mathrm{s}$ was needed to satisfy the water balance. Recharge from precipitation was initially estimated as $14.2 \mathrm{~cm} / \mathrm{yr}, 20 \%$ of average annual precipitation. Recharge on irrigated land was initially estimated as $20.6 \mathrm{~cm} / \mathrm{yr}$, the sum of recharge from precipitation plus $6.4 \mathrm{~cm} / \mathrm{yr}$, representing $25 \%$ return flow from irrigation $(25.4 \mathrm{~cm} / \mathrm{yr})$. These initial values were slightly adjusted during calibration of the regional-scale model so that final recharge values were

\begin{tabular}{|c|c|c|}
\hline Land Use & Recharge rate $(\mathrm{cm} / \mathrm{yr})$ & $\%$ of annual average \\
\hline $\begin{array}{c}\text { Non-irrigated } \\
\text { non-urban }\end{array}$ & 17.1 & $24.1 \%$ of precipitation \\
\hline Sprinkler irrigated & $\begin{array}{l}20.6 \text { (17.1 from } \\
\text { precipitation, } 3.5 \text { from } \\
\text { irrigation return flow) }\end{array}$ & $\begin{array}{l}\text { Irrigation return flow } \\
\text { recharge is } 13.8 \% \text { of } \\
\text { applied irrigation of } \\
25.4 \mathrm{~cm} / \mathrm{yr}\end{array}$ \\
\hline Gravity irrigated & $\begin{array}{l}22.8 \text { (17.1 from } \\
\text { precipitation, } 5.7 \text { from } \\
\text { irrigation return flow) }\end{array}$ & $\begin{array}{l}\text { Irrigation return flow } \\
\text { recharge is } 22.4 \% \text { of } \\
\text { applied irrigation of } \\
25.4 \mathrm{~cm} / \mathrm{yr}\end{array}$ \\
\hline
\end{tabular}

The irrigation-return flow percentages are within historical ranges of values reported for irrigation systems within the High Plains region (Mustick and Stewart, 1992).
Annual withdrawals for public supply from the city of York averaged $2.07 \times 10^{6} \mathrm{~m}^{3}$ during 1981-2004. Annual withdrawals varied from year to year and were within about $20 \%$ of the average during 1981-2004. However, average annual withdrawals gradually increased and were $2.35 \times 10^{6} \mathrm{~m}^{3}$ during $2000-2004$, about $17 \%$ greater than during 1981-84. Withdrawals are projected to increase by about 12\% in the next 20 years (Kirkam Michael Consulting Engineers, 2003). Withdrawals vary seasonally; MaySeptember withdrawals during 1999-2004 were about 67\% greater than October-April withdrawals, probably primarily reflecting outdoor water use.

Annual withdrawal data since 1981 show that withdrawals from the study PSW were intermediate and variable from the time of installation in 1977 through the 1980 s, relatively low during the 1990s, and greatly increased during 2000-2004. During 2001-2004, the study PSW had the highest annual average withdrawal rate of any York supply well in the system. Monthly withdrawals from the study PSW during 1999-2004 varied considerably, reflecting the operation of the York supply system, which cycled specific wells on and off in response to demand and maintenance schedules. Average withdrawals from the study PSW during MaySeptember were only $29 \%$ greater than during October-April during 1999-2004, which is less than the average seasonal variation in withdrawals for the entire system.

Higher hydraulic heads in Beaver Creek than in adjacent shallow unconfined well OFPS-38 during 2003-2005 were consistent with loss of water from Beaver Creek to the aquifer, but fluxes may be small. There was a consistently downward vertical hydraulic head gradient from Beaver Creek to the unconfined aquifer (fig. 6C). However, hydraulic head fluctuations in OFPS-38 did not mimic those in the creek, except during a large runoff event in the spring of 2005 that produced a 2-m rise in Beaver Creek and a 50-cm rise in OFPS-38. The lack of a close relation between surfacewater and ground-water hydraulic heads may be caused by the sediments beneath Beaver Creek not being completely saturated. The hydraulic head in OFPS-38 was usually about $1.5 \mathrm{~m}$ below that in Beaver Creek (fig. 6C) although this well was located about $10 \mathrm{~m}$ from the stream. A lack of saturation, except during high water-levels during large storm events, would limit the temporal response of ground-water hydraulic heads to stream hydraulic heads. In addition, the stream sediments are comprised of organic-rich clay and silt and are expected to have low permeability. These observations suggest that fluxes from Beaver Creek are limited but uncertain. 


\section{Well Classification}

In the sections that follow, water chemistry is compared among different groups of wells. Monitoring wells were initially classified according to their degree of confinement (unconfined or confined), depth in the unconfined aquifer (shallow or deep, defined below), and land-use setting (urban or agricultural) (table 11 [see back of report]). Samples from the study PSW, screened in the upper confined aquifer, including samples of surface discharge collected at 3 different times and depth-dependent samples collected from 5 depths during June 2004, were lumped into one category, study PSW, for plotting purposes (table 11). Initial analysis indicated that waters from most monitoring wells screened in the upper confined aquifer and lower confined lenses had similar chemistry; therefore, most of these wells were lumped under the combined category "confined aquifers" (used hereinafter in the report), which are compared to wells in the unconfined aquifer. In the unconfined aquifer, wells having a depth to the top of the screen of $<7.5 \mathrm{~m}$ below the water table were operationally defined as "shallow." Wells in the unconfined aquifer having a depth to the top of the screen greater than (>) $7.5 \mathrm{~m}$ (up to $20 \mathrm{~m}$ ) below the water table were operationally defined as "deep." Land-use was classified as predominantly agricultural or urban for wells based upon observations at the well, aerial photographs, and land-use coverages (Center for Advanced Land Management Information Technologies, 2000; U.S. Geological Survey, 1999-2000).

Initial analysis with this physical hydrogeologic classification indicated that (1) most monitoring wells screened in the confined aquifers had oxygen $\left(\delta^{18} \mathrm{O}\right)$ and hydrogen $(\delta \mathrm{D})$ stable-isotopic values that were very similar, and (2) some samples from the study PSW and some monitoring wells screened in the confined aquifers had $\delta^{18} \mathrm{O}$ and $\delta \mathrm{D}$ values consistent with mixtures of water from the unconfined aquifer and the confined aquifers. Values of $\delta^{18} \mathrm{O}$ and $\delta \mathrm{D}$ are particularly useful for identifying waters from different recharge sources and mixing because they are tracers of the water molecules themselves and are not affected by anthropogenic or natural sources or reactions that influence concentrations of many dissolved solutes. Mixing water from the unconfined aquifer in the confined aquifers was expected to affect concentrations of most dissolved solutes in the affected wells. Consequently, it was essential to incorporate the extent of mixing in wells in the confined aquifers into the well classification scheme to relate chemical characteristics to explanatory processes. Wells in the confined aquifer that were mixtures of water from the unconfined aquifer and confined aquifers on the basis of $\delta^{18} \mathrm{O}$ and $\delta \mathrm{D}$ values were classified as confined urban or agricultural mixed wells; wells in the confined aquifer with the isotopically uniform $\delta^{18} \mathrm{O}$ and $\delta \mathrm{D}$ values consistent with those of most confined waters were classified as confined urban or agricultural unmixed wells.

Because $\delta^{18} \mathrm{O}$ and $\delta \mathrm{D}$ data were useful for distinguishing mixed waters, which was critical for refining the classification of wells, the first section of "Chemical Characteristics," which follows this section, describes interpretations of $\delta^{18} \mathrm{O}$ and $\delta \mathrm{D}$ results. Then, the physical/isotopic scheme used for classifying the wells described above is used for the remainder of the report to interpret the distribution of oxidation-reduction and $\mathrm{pH}$ conditions, VOCs, pesticides, ground-water age, nutrients, major elements, uranium, and arsenic within a framework for well classification that includes degree of confinement, depth, land use, well type, and mixing of unconfined and confined waters. The well classification scheme results in 9 categories, shown in table 11 (also in table 1), and are used hereinafter in this report. The categories are (number of wells shown in parentheses) unconfined shallow urban (9), unconfined shallow agricultural (6), unconfined deep urban (2), unconfined deep agricultural (2), confined urban unmixed (8), confined urban mixed (4), confined agricultural unmixed (2), and confined agricultural mixed (2) monitoring wells, and the study PSW (1).

\section{Chemical Characteristics}

Chemical characteristics of the ground water within the local-scale TANC study area are best understood within the context of recharge and mixing patterns, as described in "Stable Isotopes." Following the discussion of "Stable Isotopes," constituent groups are presented in an order whereby the most complex subjects, most dependent on earlier topics, are presented last: "Oxidation-Reduction and pH Conditions" are presented first, as these geochemical characteristics affect many constituents. Thereafter, sections on "Volatile Organic Compounds" and "Pesticides" are presented, as these constituent groups were primarily used in this study as tracers of urban and agricultural land uses, respectively. Some of the pesticides also serve as approximate indicators of ground-water age, based on history of use. Following these sections, "Ground-Water Age Tracers" and interpreted age distributions are presented. These first five sections provide information on sources and travel times of water, as well as geochemical characteristics of the aquifer system. Thereafter, "Nutrients" are discussed, including nitrate, an anthropogenic constituent of principal interest to all local-scale TANC study units. As the nitrate and associated isotopic data are useful for interpreting major element distributions, the "Major Elements" section follows "Nutrients." Major elements are valuable tracers of water sources and pathways, which influence "Uranium" and "Arsenic," the next constituent groups presented; uranium and arsenic are natural constituents of interest to all localscale TANC study units. Finally, results from all constituent groups are discussed in the final section, "Depth-Dependent Sampling," to illuminate the processes and factors affecting the water quality of the study PSW. 
Temporal variations in water chemistry were generally minor in water at most wells. Consequently, temporal variations are not discussed except in those few cases when temporal variations indicated important processes occurring in the aquifer. The emphasis of the report is on describing spatial variations in water chemistry that indicate processes controlling water quality in different parts of the aquifer.

Interpretations that consider all constituents and tracers will be discussed in "Processes Affecting Transport of Anthropogenic and Natural Contaminants to Public-Supply Wells." that follows this section of the report. The data will be discussed to highlight chemical signatures of waters in different portions of the aquifer and source zones, pathways for different waters, and possible effects of pumping wells on chemical transport. The predominant controlling processes for the primary constituents of concern will be discussed based on these interpretations.

\section{Stable Isotopes}

Values of $\delta^{18} \mathrm{O}$ and $\delta \mathrm{D}$ differed between the unconfined and confined aquifers and between agricultural and urban land-use areas in the shallow unconfined aquifer (table 12 [see back of report]). Values of $\delta^{18} \mathrm{O}$ and $\delta \mathrm{D}$ have been widely used to identify ground-water recharge sources and areas (Darling and Bath, 1988; Stewart and McDonnell, 1991; Coplen, 1993; Mathieu and Bariac, 1996). In the local-scale TANC study area, wells were assigned to four groups on the basis of $\delta^{18} \mathrm{O}$ and $\delta \mathrm{D}$ values (i. .7 ), as described in the following paragraphs.

Group 1 includes most wells in the confined aquifers (confined urban unmixed and confined agricultural unmixed wells, referred to as confined unmixed wells for the remainder of this section, table 12), which had the most negative isotopic values (lightest). Values of $\delta^{18} \mathrm{O}$ and $\delta \mathrm{D}$ in confined unmixed wells (group 1) were very similar and varied little in individual wells through time (fig. 7; table 12).

Group 2 includes unconfined shallow agricultural wells, which had the least negative isotopic values (heaviest).

Group 3 includes unconfined shallow urban wells, which had more negative values than unconfined shallow agricultural wells, apart from the similarity of values between the most negative unconfined shallow agricultural well, FP4-28, and the least negative unconfined shallow urban wells, UWT3-34 and UWT4-85 (table 12). Isotopic values for unconfined shallow urban and agricultural wells varied more spatially and through time than values for confined unmixed wells.

Group 4 includes wells having intermediate values of $\delta^{18} \mathrm{O}$ and $\delta \mathrm{D}$ between unconfined shallow urban and agricultural wells and confined unmixed wells. Included in this group are a minority of monitoring wells (FP5-175, FP5-LS, FP3-162, OFPS-157, FP3-218, FP2-250; table 12) screened in the confined aquifers (including confined urban mixed and confined agricultural mixed wells, referred to as confined mixed wells for the remainder of this section; table 11). These intermediate $\delta^{18} \mathrm{O}$ and $\delta \mathrm{D}$ values are consistent with these wells containing mixtures of water from the shallow unconfined aquifer and water from the confined aquifers. Calculations of mixing fractions are described later in this section. Similarly, depth-dependent samples from the study PSW, particularly those from 61.0- and 51.8-m bls, had $\delta^{18} \mathrm{O}$ and $\delta \mathrm{D}$ values intermediate between those of unconfined shallow urban and agricultural wells and confined unmixed wells. Isotopic values of samples collected from the study $P S W$ surface discharge were similar to those of confined unmixed wells.

Finally, unconfined deep urban and unconfined deep agricultural wells (referred to as unconfined deep wells for the remainder of this section, table 11) also had intermediate isotopic values and are included in group 4. In the case of confined mixed well OFPS- $157, \delta^{18} \mathrm{O}$ and $\delta \mathrm{D}$ values were more variable through time than in any other well, with the $\delta^{18} \mathrm{O}$ decreasing from -8.84 to $-9.56 \%$ between November 2003 and April 2005 (table 12). Comparing ground-water $\delta^{18} \mathrm{O}$ and $\delta$ D values with the Meteoric Water Line (MWL) can indicate whether samples primarily follow a distribution reflecting variations in the isotopic composition of precipitation or whether secondary processes such as evaporation or mixing have shifted ground-water sample values off of the MWL (Coplen, 1993). Globally, meteoric waters plot along a MWL $\left(\delta \mathrm{D}=8.0 \delta^{18} \mathrm{O}+10\right.$, shown on fig. 7), which is often used in the absence of locally measured MWLs; less negative values reflect higher temperature environments and more negative values reflect lower temperature environments as affected by latitude, elevation, or season (Craig, 1961). Local MWLs provide additional information on input waters for groundwater recharge because the slope and intercept of local MWLs vary by geographic position and climatic factors (Kendall and Coplen, 2001). The isotopic values for local precipitation in York were not known, but published local MWLs for two nearby cities were used to estimate the MWL for York. There is a gradient in the isotopic composition of precipitation across Nebraska as a result of changes in moisture sources and precipitation (Harvey, 2001). Consequently, MWLs for Mead, Nebraska ( $\delta \mathrm{D}=7.40 \delta^{18} \mathrm{O}+7.32$; Harvey, 2001), approximately $100 \mathrm{~km}$ east of York, and North Platte, Nebraska $\left(\delta \mathrm{D}=7.66 \delta^{18} \mathrm{O}+4.66\right.$; Harvey and Welker, 2000), approximately $270 \mathrm{~km}$ west of York, have slightly different slopes and substantially different intercepts with the global MLW. The MWL of York (not plotted), given its intermediate geographic location, should lie between those of Mead and North Platte but should be closer to that of Mead because of the closer proximity and greater climatic similarity (annual precipitation: Mead, $70.4 \mathrm{~cm}$, York, $71.1 \mathrm{~cm}$, North Platte $50.5 \mathrm{~cm}$ ). However, both local MWLs and the global MWL are shown on fig. 7 for reference because the position of the York MWL cannot be known with certainty. 


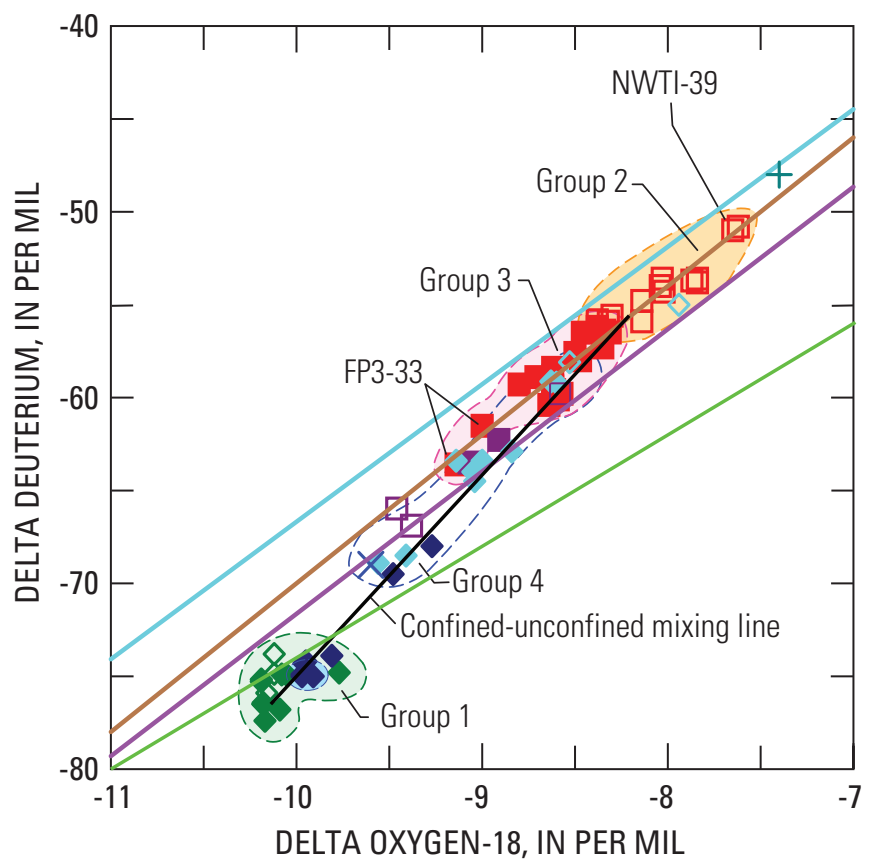

\title{
EXPLANATION
}

\author{
Meteoric Water Lines (MWL's) \\ Global MWL (Craig, 1961) \\ _ Local Mead, Nebraska MWL (Harvey, 2001) \\ — Local North Platte, Nebraska MWL \\ (Harvey and Welker, 2000)

\section{Unconfined wells \\ - Urban shallow \\ - Urban deep \\ $\square$ Agricultural shallow \\ $\square$ Agricultural deep}

$\begin{aligned} & \text { Confined wells } \\ & \text { Urban unmixed } \\ & \text { Urban mixed } \\ & \text { - Study public supply well (Study PSW) } \\ & \diamond \text { Agricultural unmixed } \\ & \diamond \text { Agricultural mixed }\end{aligned}$

\section{Mean precipitation}

+ Mead annual weighted

$\times$ North Platte annual weighted

_ Evaporation line (slope $=6.1$ ) calculated from Rayleigh distillation at average annual humidity and temperature

Figure 7. Oxygen and hydrogen isotope values for ground water in the local-scale TANC study area near York, Nebraska.

Ground-water samples from the local-scale TANC study area generally plot near the MWLs shown on figure 7, indicating that most of the isotopic variation in ground water can be attributed to variation in the isotopic composition of precipitation. $\delta^{18} \mathrm{O}$ and $\delta \mathrm{D}$ in precipitation vary seasonally in Nebraska as a result of seasonal changes in moisture sources and temperature (Harvey, 2001). Isotopic values are the most negative in the winter. These seasonal changes in precipitation $\delta^{18} \mathrm{O}$ and $\delta \mathrm{D}$ can result in isotopic values of winter, spring, or fall recharge being more negative than those of summer recharge. Samples from confined unmixed wells (group 1) plot to the right of the local and global MWLs (fig. 7). Evaporation shifts the isotopic composition of residual water to the right of a MWL along a line that typically has a slope between 3 and 6.5 (Coplen, 1993). The evaporation line shown on fig. 7 was calculated using a Rayleigh distillation equation for the average annual humidity and temperature at York (see Methods, Collection and Analysis of Water Samples) and has a slope of 6.1. The position of confined water samples to the right of the MWLs implies that these samples may have been affected by evaporation. Samples from unconfined wells plotted closer to the MWLs, which indicates that the water in these wells has been affected less by evaporation than water from the confined wells. These results imply that evaporation modified the composition of "old" recharge that resides in the confined aquifers more than that of "young" recharge residing in shallow depths of the unconfined aquifer.

The variations in $\delta^{18} \mathrm{O}$ and $\delta \mathrm{D}$ for ground water at different depths and beneath different land-use areas in the local-scale TANC study area reflect several factors. First, the differences between unconfined shallow agricultural and unconfined shallow urban wells, presumably representing recently recharged ground water, primarily reflect differing proportions of recharge derived from precipitation and recharge derived from return flow consisting of groundwater pumped for irrigation or urban supply. Second, values of confined mixed wells and the study PSW reflect mixing of waters from the unconfined aquifer with water from the confined aquifers. Third, the isotopic differences between unconfined shallow urban and agricultural wells and confined unmixed wells reflect historical changes in recharge compositions. These factors are discussed below. 


\section{Precipitation and Return Flow Fractions in the Shallow Unconfined Aquifer}

Isotopic values for unconfined shallow urban and agricultural wells reflected different proportions of recharge from precipitation and recharge from return flow of ground water pumped for irrigation or urban supply (hereinafter referred to as "return flow"). A well representing an unmixed water source is referred to in this report as an "end-member"; mixing two end-members produces waters that plot along a mixing line between the two end-member positions on plots comparing two or more constituents. The identification of end-members and mixing calculations are described below.

The end-member well for precipitation recharge was NWT1-39, located at the downgradient edge of a pasture that extends about $400 \mathrm{~m}$ northwest, a site deliberately selected to be as far from irrigated lands as possible. Samples from NWT1-39 had the least negative isotopic values of any ground-water samples (fig. 7; table 12). The annual weighted-mean-isotopic value of Mead precipitation $(\delta \mathrm{D}=-48 \%$ ) was only slightly less negative than that of NWT1-39 $(\delta \mathrm{D}=-50.8 \%$ ) (fig. 7); the $\delta \mathrm{D}$ of precipitation in York was expected to be more negative than precipitation at Mead because of east-west isotopic gradients. Ground water recharged by precipitation often has the value of the annualmean-weighted isotopic value of precipitation (Clark and Fritz, 1997). The similarity between NWT1-39 and Mead annual mean-weighted precipitation values is consistent with the interpretation that recharge at NWT1-39 is primarily or entirely derived from precipitation.

In contrast to NWT1-39, the most negative isotopic values in unconfined shallow urban wells were in wells suspected of being influenced by recharge of return flow. The most negative isotopic values for unconfined shallow wells were for FP3-33 (table 12), which has a relatively shallow depth to water of about $6 \mathrm{~m}$ and underlies a heavily-irrigated urban lawn. Wells having the next most negative isotopic values were OFPN-88, OFPS-38, FP2-43, and UWT2-23 (table 12). Well OFPN-88 is located at the downgradient edge of a well-landscaped and watered city park. Well OFPS-38 is located adjacent to Beaver Creek, whose flow was primarily from ground water pumped for cooling purposes and discharged to the Creek. FP2-43 is in an area just downgradient of a neighborhood served by septic systems (fig. 4). Because ground water was the source of domestic and municipal supply in the local-scale TANC study area, the water source to septic systems would have been ground water. Likewise, well UWT2-23 had chemical characteristics suggesting that it was influenced by septic-system discharge (see Major Elements).

The fractions of precipitation recharge and return-flow recharge were calculated for $\delta \mathrm{D}$ and $\delta^{18} \mathrm{O}$. Mixing fractions based on values of $\delta \mathrm{D}$ were used as the primary estimate because values of $\delta^{18} \mathrm{O}$ can be more strongly affected by evaporation (Clark and Fritz, 1997), but both sets of values are shown in table 12 for comparison. The fraction of samples from unconfined shallow urban and agricultural wells consisting of precipitation recharge rather than return-flow recharge was calculated as

$$
\mathrm{F}_{\mathrm{pr}}=\left[\left(\delta \mathrm{D}_{\mathrm{s}}-\delta \mathrm{D}_{\mathrm{rf}}\right) /\left(\delta \mathrm{D}_{\mathrm{pr}}-\delta \mathrm{D}_{\mathrm{rf}}\right)\right] \times 100
$$

where

$\mathrm{F}_{\mathrm{pr}}$ is fraction of precipitation recharge, percent;

$\delta D_{s}$ is the $\delta \mathrm{D}$ of the sample, per mil;

$\delta D_{\text {rf }}$ is the $\delta D$ of the return flow recharge end-member, per mil; and

$\delta D_{p r}$ is the $\delta \mathrm{D}$ of the precipitation recharge end-member, per mil.

For unconfined shallow urban wells, the return flow end-member was assumed to be the study PSW surface discharge, which during the time of this study represented the mix of water from unconfined and confined aquifers in the city's municipal water supply as a whole. The annual average pumping rates from 2000-04 and simulated fractions of water from the unconfined aquifer and confined aquifers withdrawn from individual city supply wells represented in the local-scale TANC ground-water flow model (Clark and others, 2008) were used to estimate the fraction of the municipal supply withdrawn from the confined aquifers at $89 \%$; this fraction was very close to the fraction of water in the study PSW derived from the upper confined aquifer (88\%) calculated using $\delta \mathrm{D}$ data (table 12). For unconfined shallow agricultural wells, the amount of irrigation water from the unconfined aquifer and confined aquifers applied to upgradient fields was expected to vary. Given field-scale uncertainties and mixing of irrigation waters from different sources, an average fraction of irrigation water derived from the unconfined aquifer was calculated for the entire local-scale TANC study area using model results of Clark and others (2008). These calculations indicated that an average of $65 \%$ of irrigation water was derived from the unconfined aquifer and $35 \%$ derived from the confined aquifers (table 12). The composition of unconfined aquifer water in agricultural areas was calculated as the average of compositions from 2 vertical well profiles through the unconfined aquifer at FP4 and FP5 (table 12).

The results of the mixing calculations are shown in table 12. Fractions of precipitation recharge were found to vary from 47\% for FP3-33 to 78\% for UWT3-34 for unconfined shallow urban wells. For unconfined shallow agricultural wells, fractions of precipitation recharge were found to range from 65 to $100 \%$. 
Fractions of Water from the Unconfined Aquifer in Wells with Mixed Waters in the Confined Aquifers

Samples from confined mixed and unconfined deep wells, and depth-dependent samples from the study PSW, had intermediate isotopic values between unconfined shallow urban and agricultural wells and confined unmixed wells (table 12), and mostly plotted along an apparent mixing line (fig. 7). Mixing fractions of unconfined shallow water in the confined mixed wells having intermediate values were calculated and are shown in table 12. The unconfined shallow end-member composition was different for confined mixed wells in urban and agricultural areas, as shown near the bottom of table 12 .

Using $\delta \mathrm{D}$ values, calculated fractions of unconfined shallow water in confined mixed wells ranged from 41 to $94 \%$ (table 12). In depth-dependent samples from the study PSW, unconfined shallow mixing fractions ranged from 15 to $46 \%$. In the study PSW surface discharge, the unconfined shallow mixing fraction was $12 \%$ in 3 samples collected at different times during October 2003 to April 2005. Unconfined shallow mixing fractions in confined unmixed wells ranged from 0 to $15 \%$. However, the mixing values probably represent maximum fractions of unconfined shallow water, as the minimum $\delta \mathrm{D}$ value for confined unmixed wells was used as the end-member. If the minimum value was an outlier rather than the best representation of confined unmixed water, then unconfined shallow mixing fractions would be smaller. The unconfined shallow mixing fractions can probably only be estimated with confidence within a margin of $\pm 10 \%$.

The introduction of substantial amounts (41 to 94\%) of water from the unconfined aquifer to the confined aquifers in a minority (6 of 16) of monitoring wells screened in the confined aquifers suggests that the mixing is the result of movement of water from the unconfined aquifer to the confined aquifers along preferential flow paths that are only present locally. The most likely preferential flow paths through the upper confining unit and lower confining unit are multi-layer wells screened in the unconfined and confined aquifers, which might permit water to move downward through well bores due to the substantial downward hydraulic head gradients present. Physical, chemical, and modeling results (Clark and others, 2008) that support the interpretation of well-bore leakage as a dominant transport process are discussed in "Movement of Water and Solutes to Supply Wells."

\section{Isotopic Differences between Unconfined and Confined Aquifers}

The differences between the isotopic values of samples from unconfined shallow and confined unmixed wells indicate that historical changes in the isotopic composition of recharge have occurred. Shallow unconfined waters have primarily recharged in the last decade, whereas confined waters recharged 60 years to several thousand years ago (see "Ground-Water Age Tracers"). The change in the isotopic composition of ground-water recharge could not be explained on the basis of available information but may result from the mechanisms listed below or some combination of them. More negative $\delta^{18} \mathrm{O}$ and $\delta \mathrm{D}$ values for "old" confined unmixed wells compared with those for "young" unconfined shallow wells could indicate

(1) a predominance of winter recharge during the pre-settlement period when the land cover was primarily grassland compared to recent decades when the land cover was predominantly cropland. Darling and Bath (1988) observed more negative isotopic values for recharge under grassland than under cropland in a humid temperate setting, consistent with winter recharge comprising a larger fraction of total recharge under grassland than under cropland. Water use by continuous cover grassland could diminish deep percolation and recharge from summer rainfall more than crops such as corn and soybeans; the lower vegetation density of these crops could allow deep percolation from summer rains on bare soils between plants. Consequently, a greater fraction of total annual recharge would occur during winter on grasslands when water use by grass was low and deep percolation could occur;

(2) changes in the isotopic composition of recharge reflecting climate change. Paleowaters recharged under cooler climatic conditions more than 9,000 years before present having more negative isotopic values than modern recharge have been reported in the Central and Southern High Plains Aquifer (Dutton, 1995; McMahon and others, 2004). Uncorrected carbon-14 ages of ground water from the bottom of the confined aquifer in the local-scale TANC study area are $<7,500$ years before present; corrected ages, having substantial uncertainties, indicate ages of $<2,000$ years before present (see "Ground-Water Age Tracers"). If confined unmixed waters are at the young end of this range, they probably do not span a long enough time period to indicate a change in climate. However, the substantial uncertainties in the age of confined unmixed ground water allow for the possibility that these waters reflect recharge under a cooler paleoclimatic condition;

(3) recharge areas for confined unmixed waters located far to the west of the local-scale TANC study area. Areas currently likely to have modern ground-water recharge that has $\delta \mathrm{D}$ values of $-74 \%$ (the least negative value for confined unmixed wells, table 12) or lower (because confined unmixed waters may have been modified by evaporation) lie several hundred kilometers to the west in western and central Nebraska (Kendall and Coplen, 2001). Regional ground-water flow patterns indicate that these areas are unlikely to be the recharge areas for ground water in the confined aquifers near York (Luckey and others, 1986). However, simulations and understanding of the pre-ground-water development condition of the High Plains aquifer are poorly constrained, so it is possible that confined unmixed waters may have recharged far to the west where isotopic values of recharge are currently more negative than in the local-scale TANC study area. 
For the purpose of this study, the most important result of the $\delta^{18} \mathrm{O}$ and $\delta \mathrm{D}$ analyses is that there is an isotopic contrast between unconfined shallow and confined unmixed waters that can be used to trace the downward movement of water from the unconfined aquifer into parts of the confined aquifers. The causes of the isotopic contrast between unconfined shallow and confined unmixed waters are of interest but less important than the fact that the isotopic contrast exists and that $\delta^{18} \mathrm{O}$ and $\delta \mathrm{D}$ values can be used as tracers of unconfined shallow waters.

\section{Oxidation-Reduction and pH Conditions}

Oxidation-reduction (redox) conditions influence the transport of many organic and inorganic constituents (Chapelle and others, 1995). Redox conditions along ground-water flow paths commonly change because of biological utilization of dissolved oxygen (DO), nitrate, manganese, iron, and sulfate, as electron acceptors in microbially mediated reactions with organic carbon or reduced sulfide commonly serving as electron donors (Champ and others, 1979; Chapelle and others, 1995; Chapelle, 2001). These redox conditions proceed along a well-documented sequence of Terminal Electron Acceptor Processes (TEAP), in which a single TEAP typically dominates at a particular time and aquifer location (Chapelle and others, 1995). The predominant TEAPs, from more oxidizing to reducing are oxygen-reducing (also referred to as oxic in this report), nitrate-reducing, manganese-reducing, iron-reducing, sulfate-reducing, and methanogenic.

Threshold values for classifying the redox conditions and interpreted redox conditions for the study area are listed in table 13 (see back of report). This classification scheme developed for the TANC study is described by Paschke (2007). The presence of redox species indicating more than one TEAP may indicate mixing of waters from different redox zones upgradient of the well, that the well is screened across more than one redox zone, or spatial heterogeneity in microbial activity in the aquifer. In addition, different redox couples often are not consistent, indicating electrochemical disequilibrium in ground water (Lindburg and Runnels, 1984). Thus, the redox classification was used as a general set of guidelines for interpreting redox condition. Interpretations were sometimes complicated by mixing and (or) disequilibrium and did not always indicate an unambiguous redox state for every well.
Water in most of the unconfined aquifer was oxic, as indicated by DO values of 2.5 to $9.0 \mathrm{mg} / \mathrm{L}$ (fig. 8A). Water in most of the confined aquifers was nitrate-reducing to methanogenic. The generally reducing conditions in the confined aquifers were indicated by DO and nitrate- $\mathrm{N}$ concentrations mostly $<0.5 \mathrm{mg} / \mathrm{L}$ (fig. 8A,B), manganese concentrations $\geq 50 \mu \mathrm{g} / \mathrm{L}$ (fig. 8C) and iron concentrations $\geq 100 \mu \mathrm{g} / \mathrm{L}$ (fig. 8D). Some wells in confined aquifers also had $\geq 0.005 \mathrm{mg} / \mathrm{L}$ hydrogen sulfide, consistent with sulfatereducing conditions (fig. 8E), and detectable methane, consistent with methanogenic conditions (fig. 8F). Zones having both high iron and detectable hydrogen sulfide were classified as having redox conditions ranging from iron- to sulfate-reducing (table 13); these waters may be mixtures of waters from these redox zones or zones where both processes occur simultaneously. Of the 16 wells screened in the confined aquifers, 8 had redox indicators spanning a range from less reducing conditions such as nitrate-, manganese-, or ironreducing conditions to more highly reducing conditions such as sulfate-reducing and methanogenic conditions. Such a range of conditions may indicate mixing of different waters from different redox zones or disequilibrium between redox indicators. Generally, DO and nitrate-N decreased with depth from the unconfined aquifer to the confined aquifers, and manganese, iron, hydrogen sulfide, and methane increased.

Exceptions to the generally oxic conditions in the unconfined aquifer occurred in monitoring wells UWT2-23, UWT1-53, FP3-33, and OFPS-38 (table 13; figs. 8 and 9), which were variably reducing. All of these wells had DO $<1.0 \mathrm{mg} / \mathrm{L}$ (fig. 10A) . UWT1-53, FP3-33, and OFPS-38 had manganese $>400 \mu \mathrm{g} / \mathrm{L}$ (fig. $8 \mathrm{C}$ ), and OFPS-38 had iron $>650 \mu \mathrm{g} / \mathrm{L}$, detectable hydrogen sulfide, and the highest methane concentration measured in the local-scale TANC study area, $297 \mu \mathrm{g} / \mathrm{L}$. Redox conditions at OFPS-38 may represent a mixture of nitrate-reducing, iron-reducing, sulfatereducing, and methanogenic waters because of its proximity to Beaver Creek sediments, which are likely organic-rich. The different redox zones may narrow near Beaver Creek, and water from these zones could mix within the 1.52-m-long screen of OFPS-38. Wells UWT1-53 and FP3-33 were mixtures of nitrate- and manganese-reducing waters, although traces of methane may imply mixing with minor amounts of water that had been methanogenic. All of these wells had depths to water of less than about $7 \mathrm{~m}$ (fig 10). 

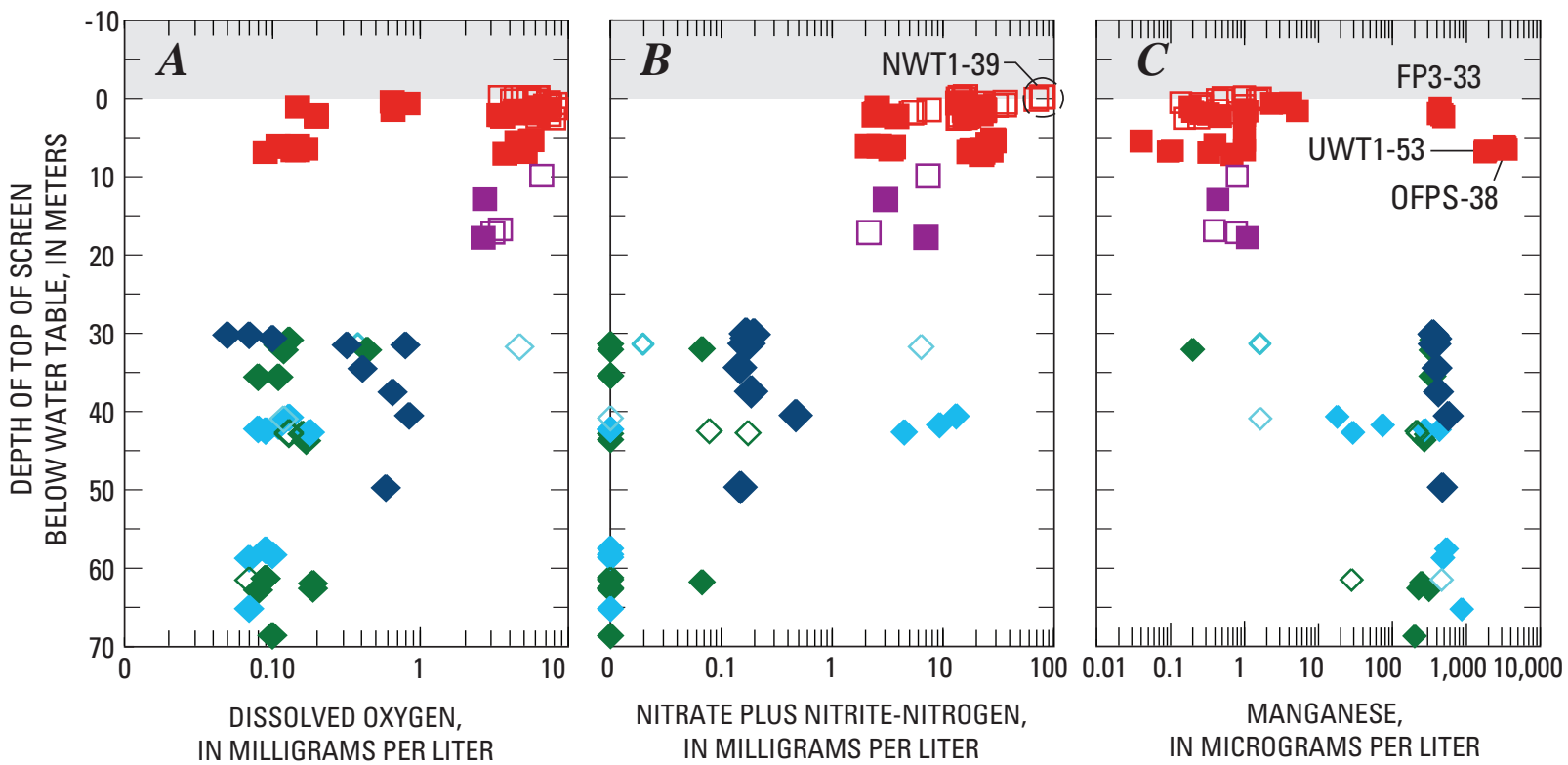

IN MILLIGRAMS PER LITER
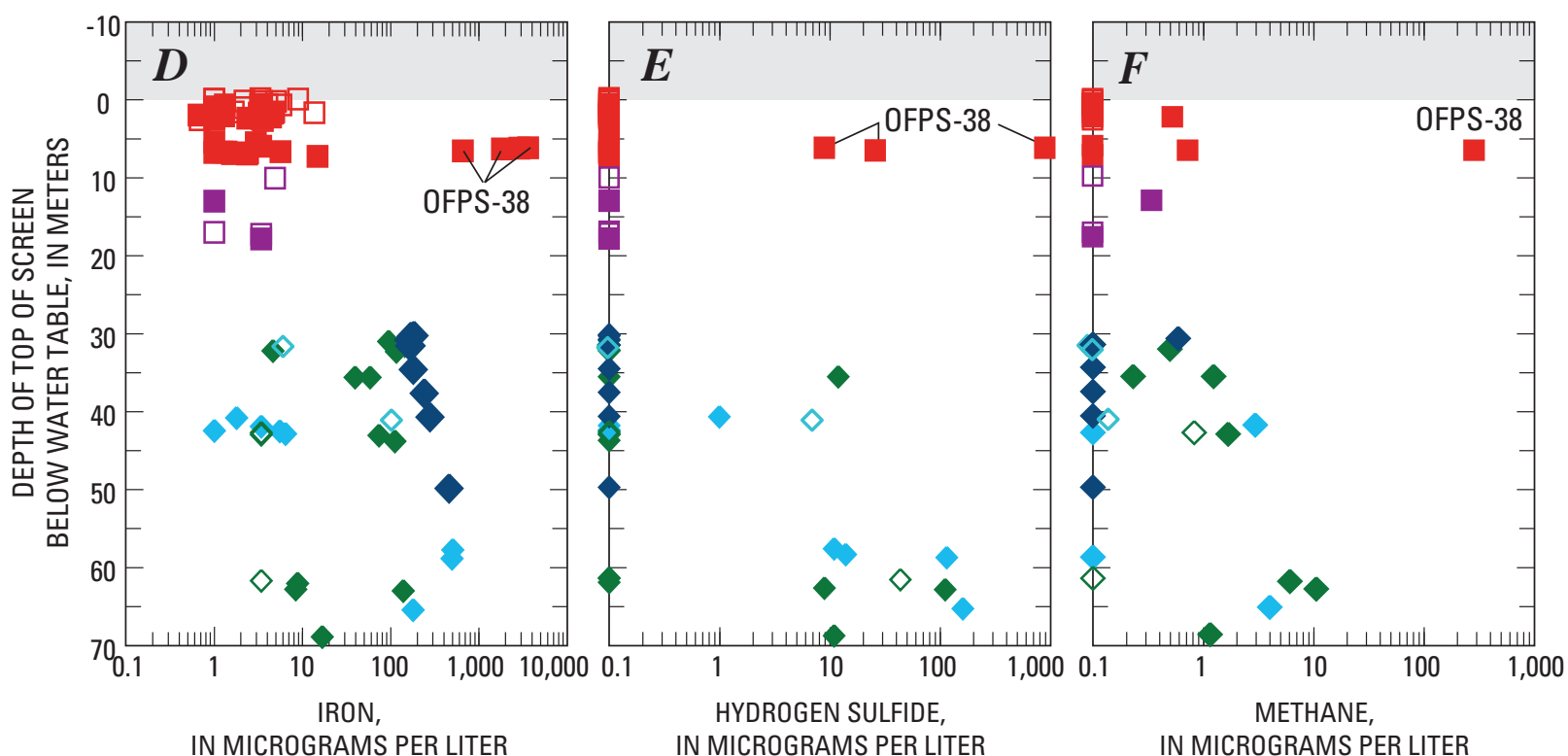

IN MICROGRAMS PER LITER

IN MICROGRAMS PER LITER

IN MICROGRAMS PER LITER

\section{EXPLANATION}

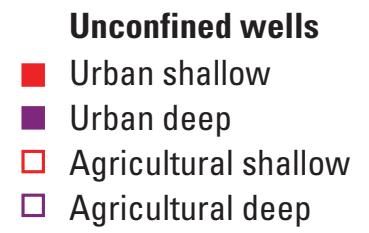

Unconfined wells

Confined wells

- Urban unmixed

$\checkmark$ Urban mixed

- Study public supply well (Study PSW)

$\diamond$ Agricultural unmixed

$\diamond$ Agricultural mixed

Figure 8. Relation of oxidation-reduction indicators to depth of top of screen below the water table in the local-scale TANC study area near York, Nebraska. 


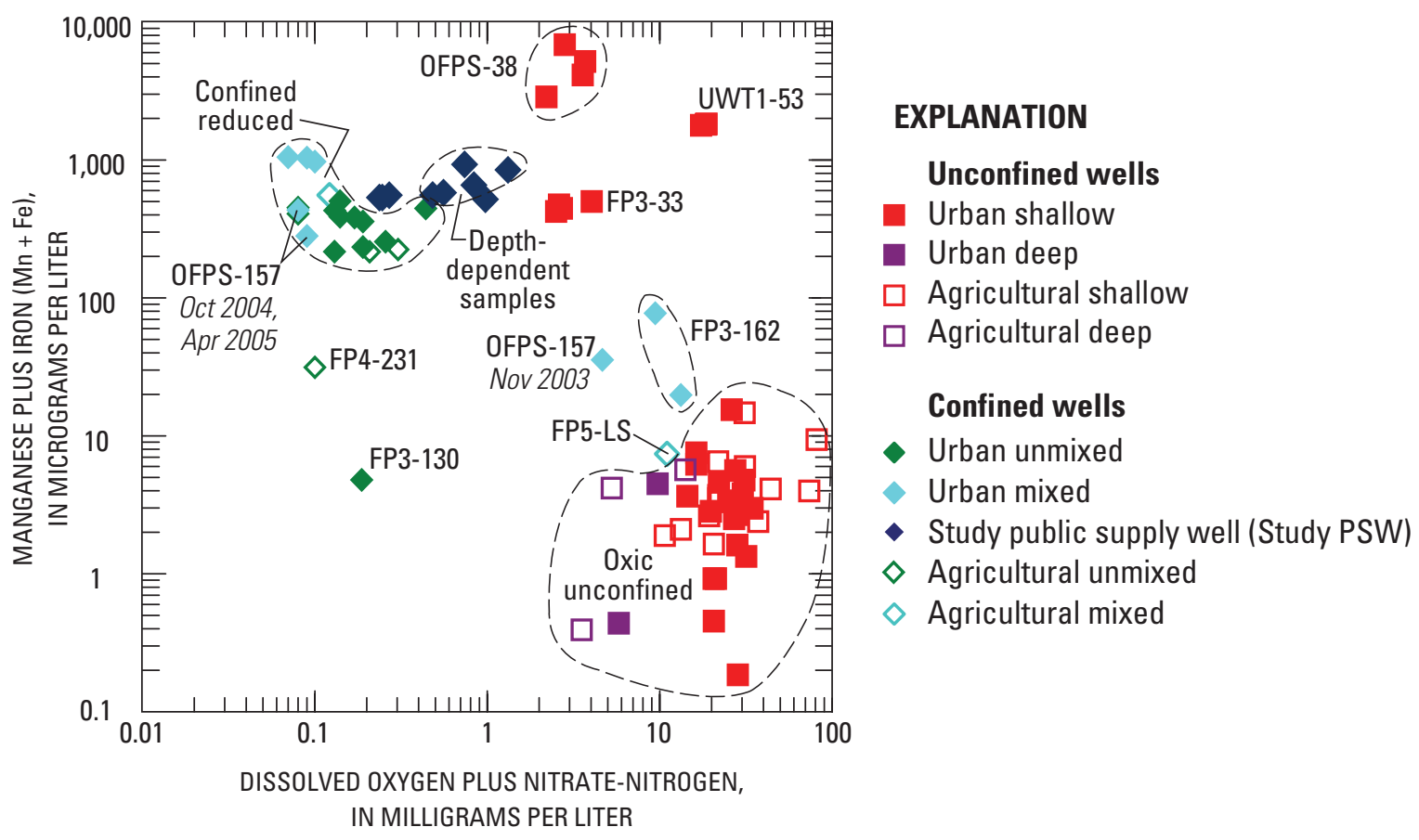

Figure 9. Sum of dissolved oxygen and nitrate (as nitrogen) and sum of manganese and iron in wells in the localscale TANC study area near York, Nebraska.

Ground water in the shallow parts of the unconfined aquifer is probably more reducing where depth to water is small because dissolved organic carbon (DOC) leached from natural organic matter in soils is more likely to reach the water table where the depth to water is small (Starr and Gillham, 1993). Concentrations of DO in unconfined shallow urban and agricultural wells were strongly correlated $(\rho=0.80$; $\mathrm{p} \leq 0.001$ ) with depth of the water table below land surface. Under shallow water-table conditions, the shallowest groundwater flow paths can interact with newly generated DOC from soil processes before the microbially labile component has been fully consumed, permitting more DOC to reach ground water and serve as electron donors for redox reactions (Starr and Gilham, 1993; Eberts and others, 2005b). DOC concentrations in reducing unconfined shallow urban wells OFPS-38, UWT2-23, and FP3-33 were generally $\geq 2.5 \mathrm{mg} / \mathrm{L}$, more than DOC concentrations in most oxic unconfined shallow urban and agricultural wells (fig. 10B). Exceptions to this relation occurred in oxic wells FP1-63 and NWT1-39, which appear to be influenced by anthropogenic sources (see "Volatile Organic Compounds," and "Nutrients"). The leaching of DOC from soils is likely to be strongly affected by variations in recharge rates, soil properties, soil organic matter content (Starr and Gilham, 1993), and depth of the screen below the water table. Two other unconfined shallow urban (UWT3-34) and agricultural (FP4-28) wells had depths to water of 6.8 to $7.3 \mathrm{~m}$, similar to UWT1-53 and FP3-33, but were oxic, indicating that factors other than depth to water may contribute to DOC, DO, and redox conditions in the shallow unconfined aquifer. Some of the unconfined shallow urban wells having reducing conditions (OFPS-38, UWT2-23, and UWT1-53) also may be influenced by the proximity to stream sediments in Beaver Creek.

In general, the upper confined aquifer can be classified as manganese- to iron-reducing. Sulfate-reducing and mixed methanogenic conditions occur locally, but their distribution is varied and cannot be reliably mapped. Water from 8 of the 9 monitoring wells screened in the upper confined aquifer had $\geq 50 \mu \mathrm{g} / \mathrm{L}$ of manganese. Water from 3 of the wells had $\geq 100$ $\mu \mathrm{g} / \mathrm{L}$ of iron and water from 2 had detectable $(\geq 0.01 \mathrm{mg} / \mathrm{L})$ hydrogen sulfide. Traces of methane were detected in 5 of the wells. $\mathrm{H}_{2}$ concentrations measured in a few wells ranged from about 0.3 to $0.8 \mathrm{nM}$ (nanomole), consistent with iron-reducing conditions (Chapelle and others, 1995).

The lower confined lenses can be classified as iron- to sulfate-reducing. Iron concentrations were $\geq 100 \mu \mathrm{g} / \mathrm{L}$ in 3 of the 6 wells screened in the lower confined lenses, and hydrogen sulfide was detected $(\geq 0.01 \mathrm{mg} / \mathrm{L})$ in all 6 wells. However, hydrogen sulfide was detected only in 1 of 3 samples collected from FP1-247. Methane was detected in 4 of the 6 wells, possibly indicating mixing of water affected by methanogenic conditions with less reducing waters. 

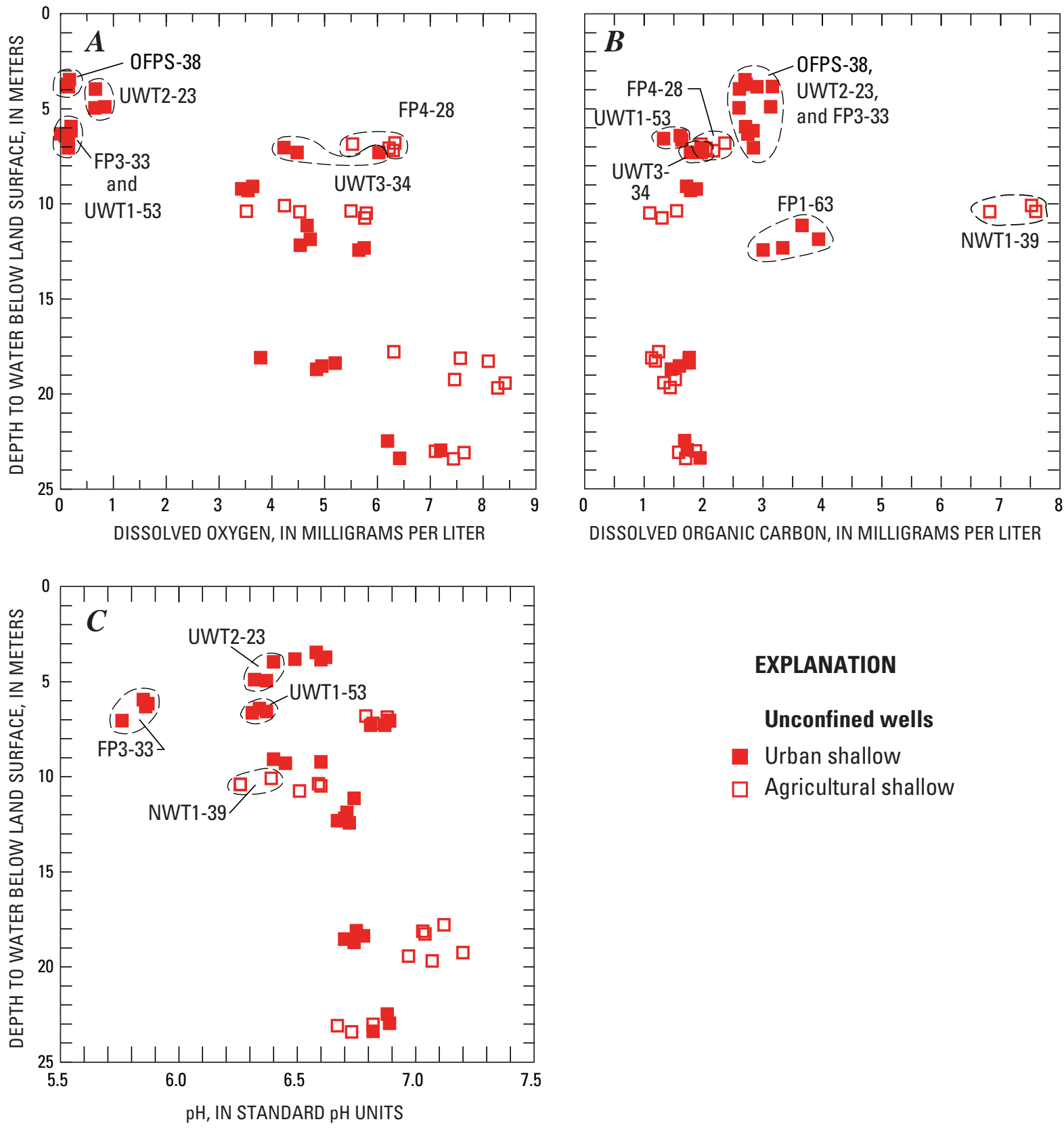

\section{EXPLANATION}

Unconfined wells

Urban shallow

Agricultural shallow

Figure 10. Concentrations of selected constituents for unconfined shallow wells and depth to water below land surface for the local-scale TANC study area near York, Nebraska.

Confined mixed wells were sometimes less reducing than confined unmixed wells (figs. 8 and 9; table 13). Confined mixed wells FP3-162, OFPS-157, and FP5-LS had higher nitrate-N and lower manganese and iron than confined unmixed wells and were generally classified as nitrate-reducing as compared with confined unmixed wells, which were generally manganese- to sulfate-reducing (table 13). Redox conditions at well OFPS-157 changed from November 2003 to October 2004 from less reducing to more reducing conditions, with decreases in nitrate- $\mathrm{N}$ and increases in manganese and iron concentrations (fig. 9). Redox conditions at this well were similar in October 2004 and April 2005. Nearly all other wells had consistent redox conditions through time. Not all confined mixed wells had less reducing water than confined unmixed wells; well FP3-218 had sulfate-reducing conditions similar to those in confined unmixed wells. Because chemistry in these confined mixed wells is interpreted as being influenced by well-bore leakage (see "Movement of Water and Solutes to Supply Wells") and the distribution of this leakage is inherently uncertain, the distribution of nitrate-reducing waters within the confined aquifers is unknown. The study PSW had constant redox conditions, classified as iron-reducing conditions, throughout the study period (figs. 8, 9; table 13). 
Generally, $\mathrm{pH}$ ranged from about 6.3 to 7.6 for most samples but increased with depth (fig. 11). Values of $\mathrm{pH}$ were lower in the unconfined aquifer, mostly 6.3 to 7.2 , than confined unmixed wells, mostly 7.3 to 7.6. Exceptions to the general trend of increasing $\mathrm{pH}$ with depth are discussed in the paragraphs below.

Most unconfined shallow urban and agricultural wells with depths to water less than about $7 \mathrm{~m} \mathrm{had} \mathrm{pH}$ $<6.6$ (fig. 10C). The lowest $\mathrm{pH}$ values, 5.8 to 5.9, were for well FP3-33. These are the same wells that also had nitrate-reducing to methanogenic conditions rather than the oxic conditions in most of the unconfined aquifer. The $\mathrm{pH}$ of unconfined shallow urban and agricultural wells was correlated with depth to water below land surface $(\rho=0.59$; $\rho<0.001)$ and DO $(\rho=0.79 ; \rho<0.001)$. The low DO and $\mathrm{pH}$ in areas with depth to water less than about $7 \mathrm{~m}$ below land surface probably resulted from oxidation of DOC leaching to the water table.

Most confined mixed wells had pHs from 6.7 to 7.4, lower than confined unmixed wells, which generally had $\mathrm{pHs}$ of 7.0 to 7.6 (fig. 11). The distribution of these relatively low-pH confined mixed waters is likely complex and temporally variable because these mixed waters are interpreted to be primarily related to leakage of water from the unconfined aquifer down well bores crossing the confining units (see "Movement of Water and Solutes to Supply Wells").

Two confined unmixed wells, FP3-130 and FP4-231, had $\mathrm{pHs}$ of 8.5 and 8.7. Because waters having a high $\mathrm{pH}$ were unusual, the distribution and processes producing these waters are not well understood.

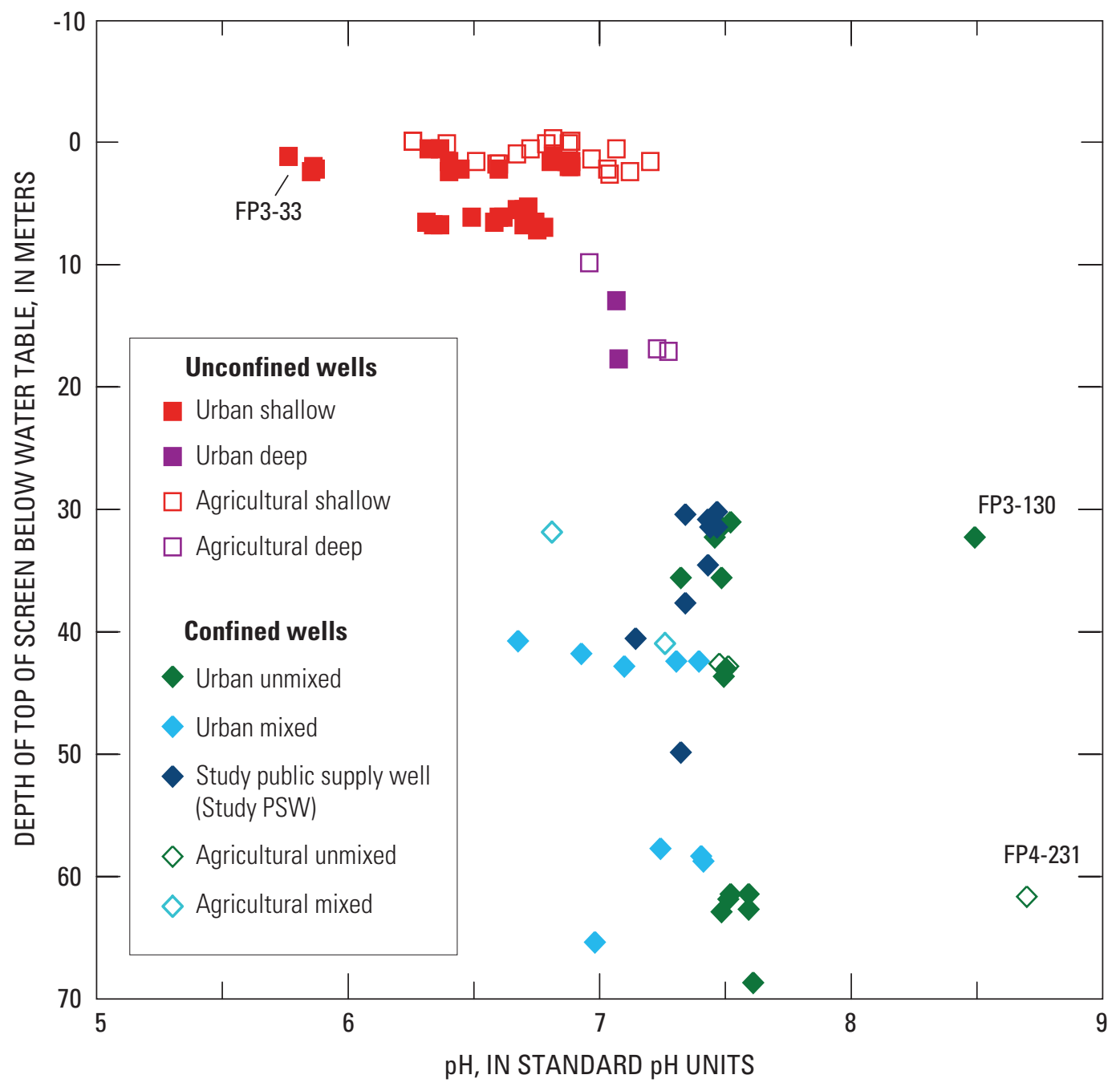

Figure 11. Relation of $\mathrm{pH}$ to depth of top of screen below the water table in the local-scale TANC study area near York, Nebraska. 


\section{Volatile Organic Compounds}

VOCs were detected in most unconfined shallow urban wells, some confined mixed urban wells, and in the study PSW (fig. 12). Because VOCs were detected in most unconfined shallow urban wells but detected in very few unconfined shallow agricultural wells, the presence of VOCs in confined urban mixed wells indicates that some fraction of water was affected by urban land use.

Twenty-five VOCs were detected in ground-water samples (table 14 [see back of report]). Fourteen of these VOCs were detected in only one well each. Seven of these VOCs detected in a single well were detected within a single sample from well FP2-250. Most VOCs were detected at low concentrations within a factor of 10 of the laboratory reporting level and in fewer than $10 \%$ of wells. VOCs were detected in 21 of 36 wells sampled and in 7 of 9 unconfined shallow urban wells. The number of VOCs detected in these wells ranged from one to eight.

Concentrations of VOCs were larger than those allowed by the U.S. Environmental Protection Agency (USEPA) Maximum Contaminant Level (MCL) in 3 wells. Two unconfined shallow urban wells, had tetrachloroethylene (PCE) concentrations approximately equal to the MCL of $5 \mu \mathrm{g} / \mathrm{L}$ or higher: well FP1-63, about 6 to $12 \mu \mathrm{g} / \mathrm{L}$ and well OFPN-88, about $5 \mu \mathrm{g} / \mathrm{L}$ (table 14). In addition, concentrations of 1,2-dichloroethane (1,2-DCA) of 5.0 to $5.8 \mu \mathrm{g} / \mathrm{L}$ in confined urban mixed well FP3-162 were greater than or approximately equal to the USEPA MCL of $5 \mu \mathrm{g} / \mathrm{L}$. None of the monitoring wells containing concentrations of VOCs larger than MCLs are used as a drinking-water source. The MCL pertains to drinking-water supplies only. Nonetheless, the MCLs provide a benchmark for comparison with measured concentrations in ground water.

The most frequently detected VOCs were the chlorinated solvents PCE, trichloroethylene (TCE), cis-1,2dichlorethylene (cis-1,2 DCE), and trans-1,2-dichlorethylene (trans-1,2 DCE) (table 14). PCE and TCE were detected in four of nine unconfined shallow urban wells and in the study $P S W$. In three of nine unconfined shallow urban wells, PCE was detected but TCE was not. The remaining two unconfined shallow urban wells (FP3-33, FP2-43) had no detections of PCE or TCE. Trichloromethane (chloroform) was detected in 10 of 82 samples and seven wells, although only three of the samples and wells had concentrations greater than the LRL of $0.024 \mu \mathrm{g} / \mathrm{L}$. Twenty other VOCs besides PCE, TCE, their degradation products cis- and trans-1,2 DCE, and chloroform were detected; other compounds were detected less frequently, usually in only a few wells, and usually in relatively low concentrations (table 14).

There are multiple possible sources for the VOCs in unconfined shallow urban wells. Because the seven unconfined shallow urban wells where PCE was detected (FP1-63, OFPN-88, OFPS-38, UWT1-53, UWT2-23, UWT3-34, and UWT4-85) were likely not along the same ground-water flow path (fig. 4), it is likely that there were widespread, low-level, inputs of PCE to the aquifer from multiple sources in the urban area. In addition, different urban unconfined wells had different VOCs (table 14), implying different sources.

PCE, TCE, and cis- and trans-1,2 DCE were detected in the surface discharge and the depth-dependent samples collected from the study PSW (table 14). Other VOCs were detected in the confined urban mixed well FP3-162, about $1 \mathrm{~km}$ upgradient of the study PSW. As VOCs are derived from anthropogenic activity at the land surface, primarily if not entirely in the urban area, the presence of VOCs in confined mixed urban wells indicates that some water from the unconfined aquifer in the urban area reached these wells. Water from these confined mixed urban wells and the study $P S W$, particularly depth-dependent samples, containing VOCs also had stable isotopic compositions indicating that these wells contained a mixture of water from the unconfined and the confined aquifers.

The iron-reducing conditions present in the study $P S W$ may permit anaerobic degradation of PCE and TCE. Constituents cis-1,2 DCE and trans-1,2 DCE are degradation products from reductive dechlorination of PCE and TCE, a reaction facilitated by microorganisms under reducing conditions (Vogel and McCarty, 1985; Bradley, 2000). In addition, TCE can be formed from degradation of PCE. Concentrations of cis-1,2 DCE were greater than concentrations of trans-1,2 DCE, consistent with expected abundances of these degradation products from reductive dechlorination (Vogel and McCarty, 1985). Complicating interpretations of the importance of reductive dechlorination is the fact that cis-1,2 DCE and sometimes trans-1,2 DCE also were detected in unconfined shallow urban wells FP1-63, OFPN-88, and UWT1-53 (table 14). The presence of cis- and trans-1,2 DCE in unconfined shallow urban wells could be the result of reductive dechlorination of PCE and TCE in reducing parts of the unconfined aquifer upgradient of the monitoring wells where these compounds are detected.

\section{Pesticides}

Selected pesticides were analyzed in four well nests (FP1, OFPS, FP3, and FP4; fig. 3) located along the main well transect and the study PSW in October 2003 and in depthdependent samples from the study PSW in June 2004 (fig. 13; table 15 [see back of report]). Pesticides or degradates were detected in 7 of 16 wells. Pesticides were detected in 3 of 4 unconfined shallow urban and agricultural wells sampled. Pesticides were detected in all 3 confined urban mixed wells (FP3-162, FP3-218, OFPS-157) sampled for pesticides. A pesticide degradation product, acetochlor ESA, was detected at a concentration of $0.02 \mu \mathrm{g} / \mathrm{L}$ in a depth-dependent sample collected from the top of the screen in the study PSW; the study PSW also shows evidence of mixing with unconfined waters based on stable isotopes, VOCs, and major elements. Pesticides were not detected in 6 confined unmixed wells. 

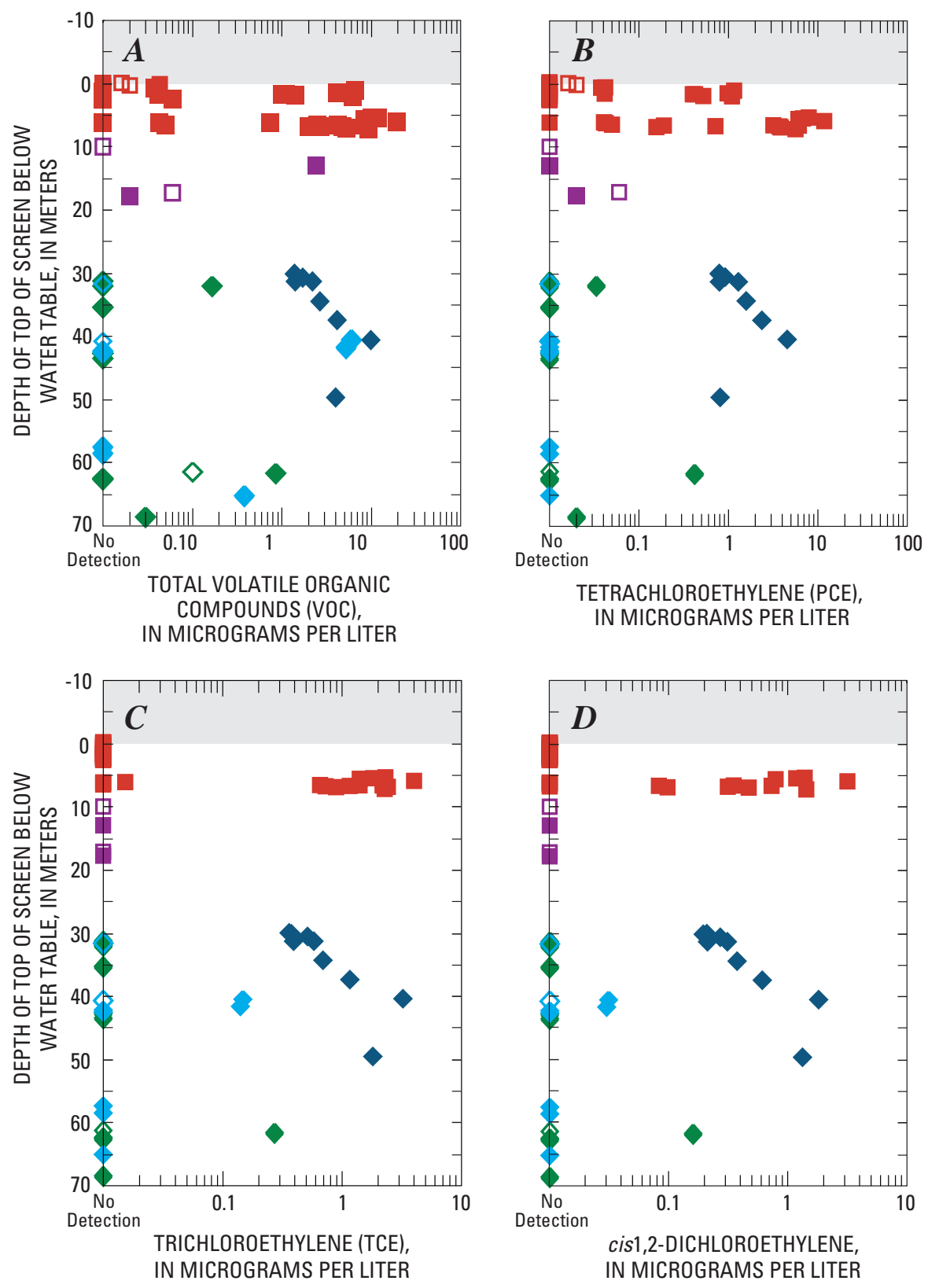

\section{EXPLANATION}

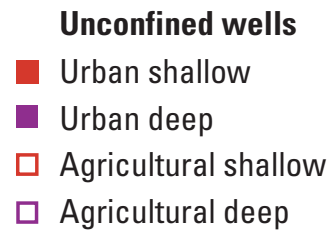
Confined wells
$\checkmark$ Urban unmixed
$\checkmark$ Urban mixed
- Study public supply well (Study PSW)
$\diamond$ Agricultural unmixed
$\diamond$ Agricultural mixed

Figure 12. Relation of depth of top of screen below water table to concentrations of selected volatile organic chemicals in the local-scale TANC study area near York, Nebraska. 


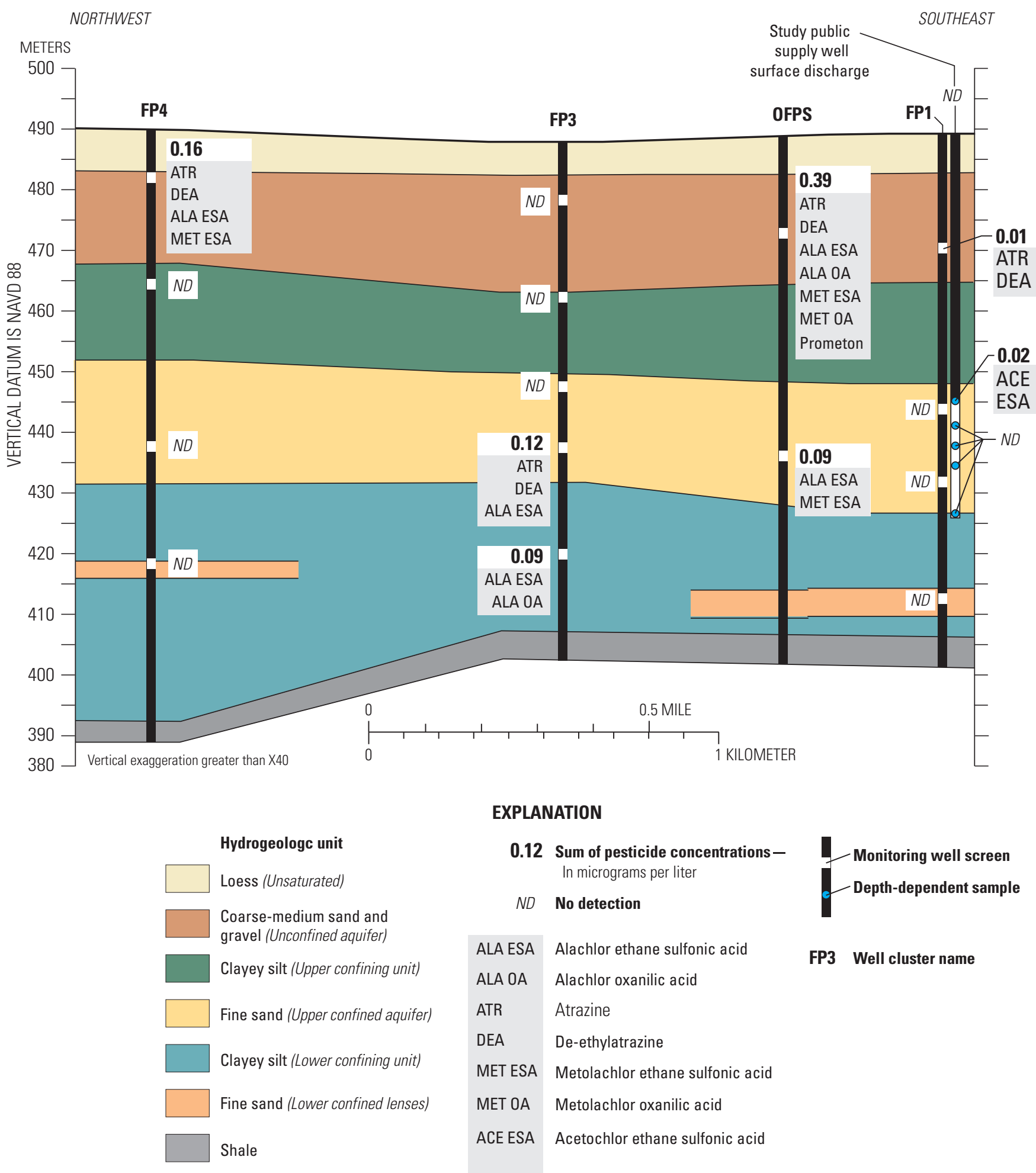

Figure 13. Cross section showing sums of concentrations of pesticides in ground water in the local-scale TANC study area near York, Nebraska. 
Atrazine was detected in 4 wells at concentrations of 0.006 to $0.062 \mu \mathrm{g} / \mathrm{L}$ (fig. 13 ; table 15 ). The atrazine degradation product 2-chloro-4-isopropylamino-6-amino$s$-triazine (de-ethylatrazine) was detected in 3 unconfined shallow urban and agricultural wells at concentrations of 0.005 to 0.042 ; de-ethylatrazine-to-atrazine ratios ranged from 0.7 to 0.8 . The alachlor degradation product alachlor ethane sulfonic acid (ESA) was detected in 5 wells at concentrations of 0.02 to $0.11 \mu \mathrm{g} / \mathrm{L}$. The alachlor degradation product alachlor oxanilic acid (OA) was detected in 2 wells at concentrations of 0.02 to $0.09 \mu \mathrm{g} / \mathrm{L}$. The metolachlor degradation product metolachlor ESA was detected in 3 wells in concentrations of 0.03 to $0.04 \mu \mathrm{g} / \mathrm{L}$. There were no detections of the parent herbicides alachlor, acetochlor, or metolachlor.

The presence of pesticides can be used to constrain the age of the young fraction of ground-water mixtures (Plummer and others, 1993) and to indicate contributions from agricultural recharge areas of pesticides used exclusively on agricultural crops. The estimated age of the young fraction was constrained by the presence of pesticides in confined mixed wells showing evidence of mixing with water from the unconfined aquifer. Acetochlor has been registered for use on corn since 1994 (U.S. Environmental Protection Agency, 2006). The detection of acetochlor ESA in the depth-dependent sample at the top of the screen of the study $P S W$ indicated that a fraction of the sample was recharged after 1994 from agricultural land on which corn was grown. Metolachlor was first registered in 1976 and is used on turfgrass and crops such as corn, sorghum, and soybeans (U.S. Environmental Protection Agency, 1995). The presence of metolachlor ESA in confined urban mixed well OFPS-157 (fig. 13; table 15) implies a fraction of the water was recharged after 1976. Alachlor was first registered in 1969, and is used for weed control in corn, soybean, and sorghum fields (U.S. Environmental Protection Agency, 1998). The detection of alachlor ESA in 3 confined urban mixed wells (FP3-162, FP3-218, and OFPS-157) implies that a fraction of the water in these wells was recharged after 1969 from agricultural land. Atrazine was first registered for use in the United States in 1958, and is used for weed control in corn and sorghum fields and for non-agricultural weed control (U.S. Environmental Protection Agency, 2003). The presence of atrazine or de-ethylatrazine in confined urban mixed well FP3-162 indicated that some fraction of the water sample was recharged after 1958. Although alachlor and acetochlor are used exclusively on agricultural crops, it is possible that spills during storage or distribution could have resulted in these chemicals entering ground water in non-agricultural areas.

\section{Ground-Water Age Tracers}

Ground-water age tracers analyzed in ground-water samples collected for this study included CFC-12, CFC-11, $\mathrm{CFC}-113, \mathrm{SF}_{6},{ }^{3} \mathrm{H} /{ }^{3} \mathrm{He}$, and ${ }^{3} \mathrm{H}$. Interpretations of ground-water age tracers were complicated by mixing of waters of different ages, possible natural ( $\left.{ }^{3} \mathrm{He}, \mathrm{SF}_{6}\right)$ and anthropogenic (CFCs) contamination of ground water, and degradation of CFCs under reducing conditions in a few samples. The effect of these processes was to add uncertainty to age interpretations.

Two age-tracer methods, in addition to ${ }^{3} \mathrm{H}$, were used in each well sampled for ground-water age to facilitate comparison of results between tracers (see "Collection and Analysis of Water Samples"). Because of the relatively high cost of the age tracer methods, only two of the three available methods were used in each well. Results of reconnaissance sampling of five wells in September 2003 for CFCs suggested that contamination of the ground-water system with CFCs from local sources was minimal. CFCs are easy to collect and provide three independent age tracers (CFC-12, CFC-11, and CFC-113). Thus, all ground-water age samples were analyzed for CFCs. Samples from five monitoring wells in the unconfined aquifer were collected and analyzed for concentrations of CFCs and ${ }^{3} \mathrm{H} /{ }^{3} \mathrm{He}$. Samples from seven monitoring wells and the study PSW in the upper confined aquifer and lower confined lenses were analyzed for concentrations of CFCs and $\mathrm{SF}_{6}$. Samples from different depths in the screen and the surface discharge of the study PSW collected in June 2004 were analyzed for ${ }^{3} \mathrm{H} /{ }^{3} \mathrm{He}$ and $\mathrm{SF}_{6}$. Depth-dependent samples could not be collected for CFCs since the submersible bladder pump used to collect these samples had Teflon tubing, which can contaminate CFC samples for age analysis (table 16 [see back of report]).

Because the same tracers were not analyzed in all wells and because of the effects of contamination, mixing, and degradation on tracer concentrations in waters collected from different wells, no single tracer could be used to interpret apparent age in all wells. Consequently, a diverse set of tracers and lumped parameter models was used in age interpretations (tables 16 and 17 [see back of report]). Multiple interpretations are possible using different models; the primary tracers and models considered are shown in table 17, although other age tracer data also were interpreted.

Tracer and ${ }^{3} \mathrm{H}$ concentrations were compared with results expected from different lumped parameter models including (1) a piston flow model (PFM), (2) an exponential mixing model (EMM), (3) binary mixing of "old" water containing no modern tracers with "young" water containing tracers whose distribution is defined by a PFM (binary mixing model, BMM), and (4) binary mixing of "old" and "young" water whose distribution is defined by an EMM (exponential binary mixing model, EBMM) (Cook and Böhlke, 2000). "Old" water was considered to be more than 40 to 60 years old, before the period when modern tracers $\mathrm{CFCs}, \mathrm{SF}_{6}$, and ${ }^{3} \mathrm{H}$ were in the atmosphere and precipitation. Excel workbooks for calculation and presentation of environmental tracer data for simple groundwater mixtures (Böhlke, 2006) were used to analyze the data. Example plots are shown in figure 14, and tracer data are given in table 16. Measured concentrations of particular tracers also were compared with those of other tracers to determine if the ratios, sometimes characteristic 

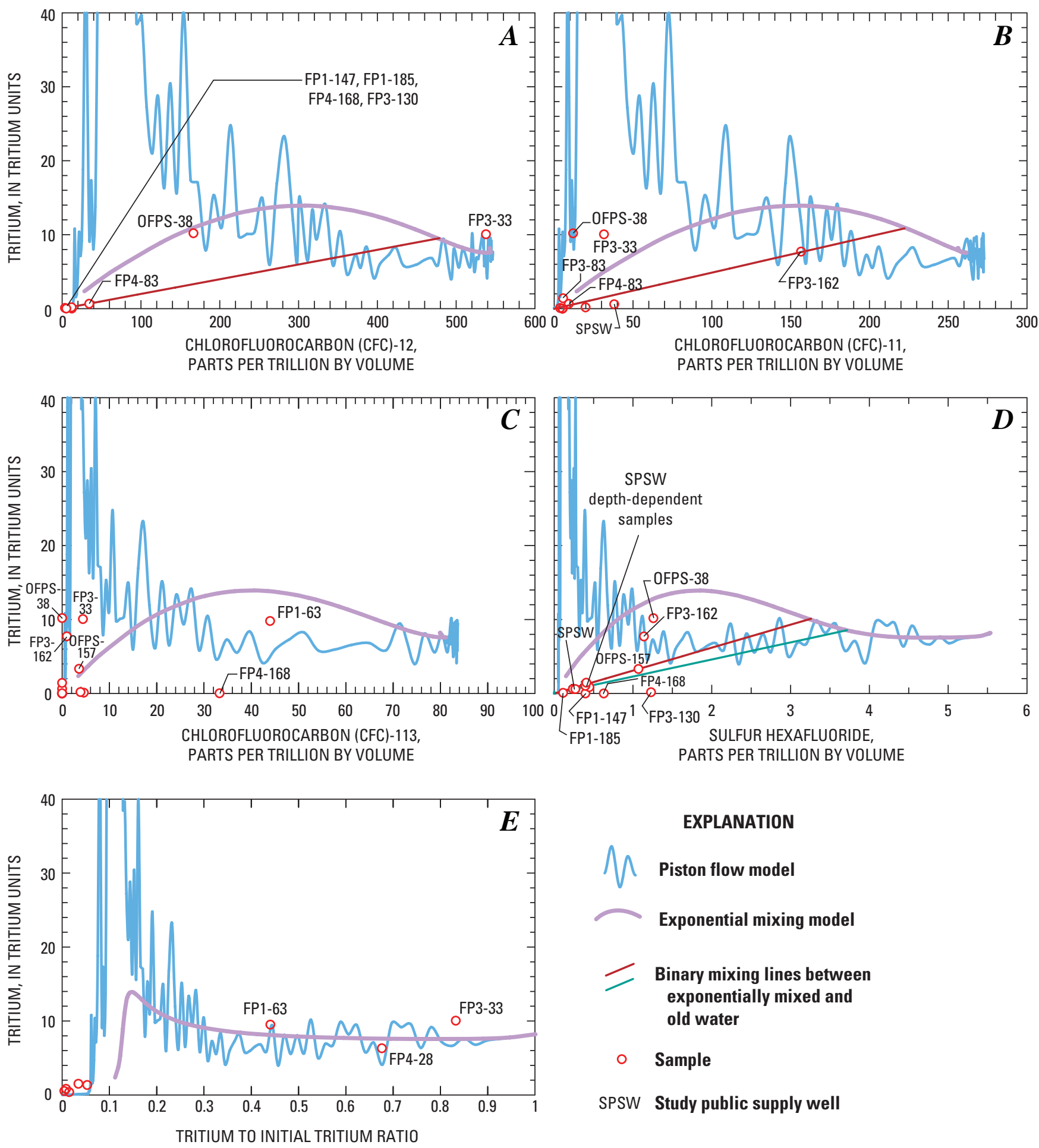

EXPLANATION

M Piston flow model

Exponential mixing model

Binary mixing lines between exponentially mixed and old water

\section{○ Sample}

SPSW Study public supply well

Figure 14. Concentrations of age-dating tracers in samples and historical atmospheric curves corrected for radioactive decay for piston, exponential, and exponential binary mixing models, local-scale TANC study area near York, Nebraska. 
of a particular time period, constrained the age of the young fraction of the water (Plummer and others, 1998). In nearly all cases, the use of tracer ratios did not better constrain the interpreted age of the young fraction, perhaps because some of the tracers in a given sample were affected by contamination and (or) degradation. This interpretive process was iterative, and refinements were made on the basis of multiple tracers and samples. Historical concentrations of tracers were obtained from the USGS Chlorofluorocarbon Laboratory. Monthly concentrations of tritium in precipitation in the study area since 1953 were estimated using a program that calculates tritium concentrations for a specified latitude-longitude by extrapolating results from stations where tritium in precipitation had been measured (Robert L. Michel, Research Hydrologist, U.S. Geological Survey, written commun., August 31, 2004). Tritium concentration data were then corrected for radioactive decay to the time of sampling in 2003 and 2004.

For wells in the unconfined aquifer (FP1-63, FP3-33, FP3-83, FP4-28, FP4-83) sampled for age tracers, concentrations generally usually plotted on or near PFM curves (fig. 14) and PFM apparent ages using different tracers generally corresponded reasonably well (table 17), indicating that ground-water ages can be reasonably interpreted using a PFM. Apparent ages increased with depth below water table, from 7 to 10 years at depths $<2.5 \mathrm{~m}, 15$ to 20 years at depths of 5 to $7 \mathrm{~m}$, and 44 to 48 years at depths of 17 to $18 \mathrm{~m}$, near the bottom of the unconfined aquifer (table 17). The PFM presumes that water entering the aquifer moves through the aquifer system without mixing and retains the original concentration of the water at the time of recharge (Cook and Böhlke, 2000). This theoretical ideal is a simplification, but can be a reasonable approximation in some simple aquifer systems for samples from wells with small screened intervals. For unconfined shallow urban and agricultural wells, the PFM fit CFC-12 at FP3-33 (fig. 14A), CFC-113 at FP1-63 (fig. 14C), $\mathrm{SF}_{6}$ at OFPS-38 (fig. 14D), and ${ }^{3} \mathrm{H} /{ }^{3} \mathrm{He}$ at FP3-33, FP1-63, and FP4-28 (fig. 14E) particularly well.

Age-tracer data for samples from the confined aquifers were consistent with mixing of "old" water, not containing modern tracers, and "young" water; the "young" water fraction was interpreted to be exponentially mixed. In the confined aquifers, results for different tracers often diverged and did not plot along PFM or EMM curves (fig. 14; table 17). However, samples plotting below these curves are along a linear mixing line drawn through the samples from the origin of the graph (zero concentration, old water recharge before tracers were in the atmosphere) to where this mixing line intersects the PFM or EMM curves. The mixing fraction is calculated from the distance that a sample plots along the mixing line between the two end-members. Binary (BMM) and exponential-binary (EBMM) mixing models were used to interpret the fraction of the sample consisting of young water having a particular mean age. With a BMM, the sample is a mixture of two subparcels, one which is young and contains measurable tracer and one which is too old to have measurable tracer. With an EMM, the sample consists of a number of sub-parcels, each having its own tracer concentration and age, which have an exponential age distribution and an overall mean age. The mean age will affect the weight that new recharge water mixing with existing ground water has on the composition of the mixture as a whole. The EMM represents a highly mixed sample consisting of waters having many different ages along a distribution. The EBMM model was a binary mixture of (1) a subparcel of water mixed according to the EMM and having a particular mean age, and (2) a subparcel too old to have measurable tracer. The primary mechanism for water from the unconfined aquifer to get into the confined aquifers was interpreted to be leakage down well bores connecting the aquifers. Because of the large hydraulic head gradient between the unconfined and confined aquifers, the leaky well bores were expected to result in mixing, within the well bores, of waters from the entire unconfined aquifer, which subsequently mixes with old water in the confined aquifer, an interpretation supported by simulation results (Clark and others, 2008). Of the lumped parameter models, the EMM most closely fit the expected highly mixed age distribution of well bore leakage waters from the unconfined aquifer. When these waters from the unconfined aquifer mix with water in the confined aquifers, the EBMM was the most appropriate lumped parameter model for interpreting the results. The BMM also yielded reasonable results for certain mixing scenarios. The mean ages and mixing fractions for these two models were fairly similar and both are presented in table 17. Implicit in the mixing calculations is that the remainder of the sample that is not young water consists of water that is more than 40 to 60 years old and contains no detectable quantities of modern atmospheric tracers.

Tracer results and mixing calculations indicated that confined unmixed wells (FP1-147, FP1-185, FP3-130, and FP4-168) contained $<3 \%$ young water mixed with a much larger fraction $(\geq 97 \%$ ) of old water with no modern tracers (table 17). Fractions of water from the unconfined aquifer in these same confined unmixed wells calculated using $\delta \mathrm{D}$ data ranged from 5 to $11 \%$ (table 12). Mixing fractions calculated using stable isotopic and age tracers could differ because of the sensitivity of the calculations to small changes in measured values and assumed end-members, simplifying assumptions made in the mixing calculations, and differences in the timing of historical changes in stable isotopic values compared to concentrations of atmospheric tracers. Considering uncertainties, the $\delta \mathrm{D}$ and CFC-12 mixing calculations compare reasonably well and both indicate only small quantities of young water $(<3$ to $11 \%)$ from the unconfined aquifer in confined unmixed wells. 
Mixing calculations for confined mixed wells FP3-162 and OFPS-157 indicated substantial young fractions of 70 and 32\%, respectively, and mean ages of 12 and 14 years. Corresponding mixing fractions calculated from $\delta \mathrm{D}$ values were 89 and $70 \%$, respectively (table 12). Although there were substantial differences in mixing fractions indicated by $\mathrm{SF}_{6}$ and $\delta \mathrm{D}$ at OFPS-157, both sets of mixing calculations indicated substantially larger fractions of young water in these monitoring wells than in confined unmixed wells.

The lumped parameter models and binary mixing calculations are inherently simplistic, considering the physical situation in which young water from the unconfined aquifer moves into the confined aquifers through leakage down well bores, which results in mixing of waters of different ages from the unconfined aquifer with tracer-free water in the confined aquifers. Because recharge and discharge have increased over several decades (Landon and Turco, 2007; Clark and others, 2008), the age distribution of waters in the unconfined aquifer was expected to become younger through time. This interpretation is supported by transient model simulations of ground-water age in the local-scale TANC study area (Clark and others, 2008), which indicate decreases in ground-water age from the 1940s into the 1980s. Moreover, water from the unconfined aquifer leaking down well bores could have a considerable range of ages, since this water would have been leaking continuously over decades. Given this situation, binary mixing calculations that assume a single mean age of a young fraction greatly simplify a complex problem. It is not possible to quantify more-complex mixing of more than two bodies of water having different ages, using lumped parameter models. Mixing calculations of greater complexity are implemented with the numerical flow and solute transport model described by Clark and others (2008).

Interpretation of ages was complicated by contamination and degradation of different tracers to different degrees. The CFC laboratory reported sample contamination when concentrations of CFCs and (or) $\mathrm{SF}_{6}$ were greater than could be derived from atmospheric input, indicating that there were local sources of a tracer that precluded its use as an age tracer (hereinafter, referred to as "contaminated for age dating purposes"). Potential degradation of CFCs was identified by (1) comparison of a single-tracer result with those for other tracers that are less susceptible to degradation or do not degrade and (2) literature review of the redox conditions under which different tracers degrade. CFC-12 is the most stable (least readily degraded) of the CFCs and is preferred for age interpretations if available (Busenberg and Plummer, 1992). However, CFC-12 data could be interpreted to indicate age in only 7 of 13 samples; the other 6 samples had CFC-12 concentrations that indicated contamination for age- dating purposes. CFC-12 appeared to have degraded at well OFPS-38 on the basis of (1) the observation that the apparent PFM age for CFC-12 (1971) was older than the apparent age for $\mathrm{SF}_{6}$ (1984) and (2) CFC-12 has sometimes been found to degrade under sulfate-reducing to methanogenic redox conditions (Oster and others, 1996; Plummer and Busenberg, 2000), such as those at OFPS-38. On the basis of these observations, the interpretation of ground-water age was based on $\mathrm{SF}_{6}$ at OFPS-38, as $\mathrm{SF}_{6}$ is not susceptible to degradation under reducing conditions (Busenberg and Plummer, 2000). Likewise, CFC-113 could only be used for age interpretations in 7 of 13 samples, because it was present in concentrations that indicated CFC-113 contamination for age-dating purposes in one well, was degraded in two wells (described in paragraph below), and was not detected in three additional wells (table 16). The most widespread available tracer was CFC-11; it was used to interpret age in 8 of 13 wells. CFC-11 concentrations indicated contamination for age-dating purposes in three wells and degradation in two wells.

For two wells, OFPS-38 and FP3-33, concentrations of CFC-11 and CFC-113 were substantially lower than expected in comparison with other tracers, probably indicating degradation of CFC-11 and -113 in these reducing waters. Concentrations of different tracers were compared with each other (for example, $\mathrm{CFC}-12$ against $\mathrm{CFC}-11$, not shown) and with curves from lumped parameter models on plots of tracers versus ${ }^{3} \mathrm{H}$ (fig. 14). On both kinds of plots, where concentrations of a particular tracer were lower than expected compared with the other tracer or lumped parameter curves, those concentrations were flagged as possibly being affected by processes that would affect one tracer but not another, such as degradation or contamination from non-atmospheric sources. CFC contamination from non-atmospheric sources usually causes concentrations to be in excess of those that could be derived from the atmosphere and is clearly identifiable from the reported concentrations (Busenberg and Plummer, 2000). The redox conditions for wells where concentrations of different CFCs were inconsistent were assessed to evaluate whether selective degradation of CFCs was consistent with the results. Concentrations of $\mathrm{SF}_{6}$ were slightly higher, or CFC-12 concentrations were slightly lower, for OPFS-38 than was expected according to lumped parameter models. Because it is reasonable that CFC- 12 degraded in this sample because of methanogenic conditions, $\mathrm{SF}_{6}$ was considered to provide a better estimate of the minimum age of the young fraction at OFPS-38. CFC-13 (not detected) and CFC-11 were similarly interpreted to be degraded at OFPS-38. Conditions at FP3-33 were nitrate- to manganese-reducing (but methane also was detected, so some methanogenic conditions also could occur). CFC-11 and $\mathrm{CFC}-113$ concentrations were less than expected on the basis of CFC- 12 and ${ }^{3} \mathrm{H} /{ }^{3} \mathrm{He}$ values, implying that these tracers degraded. On the basis of the reasonable agreement of apparent ages indicated by $\mathrm{CFC}-12$ and ${ }^{3} \mathrm{H} /{ }^{\beta} \mathrm{He}$, there was no evidence of CFC-12 degradation in water from FP3-33. 
CFC-11 concentrations were compared with other tracers in other wells. The results, particularly for wells in the confined aquifer having nitrate- to iron-reducing conditions, indicated that CFC-11 concentrations were similar to what would be expected from lumped parameter models if the CFC-11 wasn't degraded. CFC degradation is usually not detected under conditions less reducing than sulfate-reducing conditions (Plummer and Busenberg, 2000). If CFC-11 was degrading in the confined aquifer, $\mathrm{CFC}-12$ dates would have been consistently younger than $\mathrm{CFC}-11$ dates. However, CFC-11-based age results were generally similar to those for CFC-12. The very low tritium concentrations in most wells in the confined aquifers was consistent with the very low CFC-12 and CFC-11 concentrations, implying that low $\mathrm{CFC}$ concentrations in the confined aquifers indicated old water with very small fractions of young water rather than degradation of CFCs.

Concentrations of $\mathrm{SF}_{6}$ were greater than expected in comparison with apparent ages and mixing fractions indicated by CFCs in four confined unmixed wells (FP1-147, FP1-185, FP3-130, and FP4-168. Granitic rocks can contain $\mathrm{SF}_{6}$ in amounts significant enough to preclude using $\mathrm{SF}_{6}$ as a dating tool (Busenberg and Plummer, 2000). As sediments in the local-scale TANC study area were derived from granitic rocks of the Rocky Mountains, it is possible that $\mathrm{SF}_{6}$ concentrations could be biased high by geologic sources of $\mathrm{SF}_{6}$ in the confined aquifers. Whatever the source, ground-water ages based on $\mathrm{SF}_{6}$ are more uncertain because they may be affected by non-atmospheric sources.

Attempts to determine age using ${ }^{3} \mathrm{H} /{ }^{3} \mathrm{He}$ data were successful for four unconfined shallow urban and agricultural wells but were unsuccessful for one unconfined deep agricultural well (FP4-83) and for depth-dependent and surface-discharge samples collected from the study PSW because of the effects of elevated terrigenic helium (tables 16 and 17). Terrigenic He may be in aquifers where the rocks are enriched in uranium or thorium, or in ground-water samples in which young water mixed with relatively old water containing terrigenic, and in some cases, mantle He (Schlosser and others, 1989). This helium derived from geologic sources complicates interpretation of the helium isotope ratios. When combined with air contamination of some of these samples, ${ }^{3} \mathrm{H} /{ }^{3} \mathrm{He}$ could not be used to interpret ground-water age in these samples.

Age determinations in the study PSW were problematic. Calculations using $\mathrm{SF}_{6}$ EBMM indicated that the study PSW was a $7 \%$ mixture of water having a mean age of 1995 , and older, tracer-free water (table 17). Calculations using CFC-11 EBMM indicated a 14\% mixture of water having a mean age of 1990, and older, tracer-free water. These mixing fractions were approximately consistent with mixing fractions of unconfined layer water on the basis of $\delta \mathrm{D}$ of about $12 \%$ (table 12). Attempts to determine the age distribution of depthdependent samples from the study PSW collected in June 2004 were unsuccessful. Depth-dependent ${ }^{3} \mathrm{He}$ samples were compromised by high terrigenic helium and air contamination.
Values of $\mathrm{SF}_{6}$ in three depth-dependent samples from the upper half of the screen (42.7-, 45.7-, and 48.8-m bls samples) were nearly uniform along the vertical profile (table 16).

Samples for carbon-14 were collected from three monitoring wells screened near the bottom of the aquifer and two depth-dependent samples in the lower part of the screen of the study PSW (table 16). The results were not interpretable in three of the five samples (well FP3-218 and 2 depth-dependent samples from the study PSW) because substantial amounts of modern carbon and tritium indicated that the water contained too much young water to be dated using the carbon-14 technique. In wells FP1-247 and FP4-231, the carbon-14 method indicated uncorrected ages of 6,568 and 7,456 years before present, respectively. However, the uncorrected ages are too old-they do not consider the effects of carbonate dissolution on the initial carbon-14 activity of the groundwater at the time of recharge (Kalin, 2000). Simple corrections applied to account for these factors using the method of Tamers (1967) resulted in corrected ages of 1,368 and 1,767 years before present for wells FP1-247 and FP4-231, respectively. Although these corrected ages are considered to be more reasonable than uncorrected ages, uncertainties in the estimated initial carbon-14 activity of recharge water still cause uncertainties of hundreds to thousands of years in estimating the age of in these samples. The modern recharge composition is completely different from that which existed several thousand years ago because of changes in land use and water fluxes. Therefore, paleorecharge carbon-14 activities could not be measured directly and the carbon-14 dates should be regarded as poorly constrained estimates of the ages of old water near the bottom of the aquifer.

\section{Nutrients}

Concentrations of nitrite were negligible. Therefore, concentrations of nitrite plus nitrate were presumed to indicate concentrations of nitrate, measured as $\mathrm{N}$ (hereinafter, nitrate-N). Concentrations of nitrate-N were highest in unconfined shallow urban and agricultural wells, having median values of 17.3 and $16.0 \mathrm{mg} / \mathrm{L}$, respectively (fig. 8B). Concentrations of nitrate- $\mathrm{N}$ were $<0.2 \mathrm{mg} / \mathrm{L}$ in confined unmixed wells, were 2.2 to $7.4 \mathrm{mg} / \mathrm{L}$ in unconfined deep urban and agricultural wells, and ranged from less than the reporting level of 0.06 to $13.1 \mathrm{mg} / \mathrm{L}$ in confined mixed wells(fig. 8B; table 18 [see back of report]), indicating a general decrease in nitrate- $\mathrm{N}$ concentrations with increasing depth except in confined mixed wells. The decrease in nitrate- $\mathrm{N}$ concentrations with depth corresponds with increasingly reducing conditions (fig. 8). The lowest nitrate-N concentrations in unconfined shallow urban wells, $<5 \mathrm{mg} / \mathrm{L}$, were in wells OFPS-38 and FP3-33, which had nitrate-reducing to methanogenic conditions. Redox conditions more reducing than oxic conditions are hereinafter referred to as reducing conditions. 
Values of $\delta^{15} \mathrm{~N}$-nitrate and $\delta^{18} \mathrm{O}$-nitrate plot along a trend consistent with denitrification of nitrate in reducing ground water in the unconfined aquifer and confined aquifers (fig. 15A). Denitrification of nitrate to dissolved nitrogen gas and intermediate products in reducing ground water has been identified in numerous studies (review by Kendall, 1998). As denitrification occurs, the $\delta^{15} \mathrm{~N}$ and $\delta^{18} \mathrm{O}$ values of the residual nitrate increase. Across a range of field and laboratory studies, denitrification has been shown to enrich $\delta^{15} \mathrm{~N}$ and $\delta^{18} \mathrm{O}$ of nitrate; resulting values plot along a line having a slope between about 0.5 and 1.0 on a plot of $\delta^{15} \mathrm{~N}$ versus $\delta^{18} \mathrm{O}$ (Böttcher and others, 1990; Mengis and others, 1999). A linear best-fit line of the data shown in figure $15 \mathrm{~A}$ has a slope of $0.50\left(r^{2}=0.94\right)$, consistent with that expected for denitrification. The extent of denitrification was greater for confined urban unmixed wells and study PSW samples, having $\delta^{15} \mathrm{~N}$-nitrate values $>30 \%$ and $\delta^{18} \mathrm{O}$-nitrate values $>15 \%$, than for unconfined shallow urban wells and confined urban mixed wells having reducing conditions, which had intermediate values indicating partial denitrification (fig. 15A). Nitrate-N concentrations were $\geq 10 \mathrm{mg} / \mathrm{L}$ only when $\delta^{15} \mathrm{~N}$-nitrate values were less than about $13 \%$ (fig. 15B). Nitrate-N concentrations were smaller in samples when $\delta^{15} \mathrm{~N}$-nitrate values were larger, consistent with expected decreases in nitrate- $\mathrm{N}$ concentrations with denitrification.

Excess nitrogen gas $\left(\mathrm{N}_{2}\right)$ (table 16) in reducing water was consistent with the occurrence of denitrification. The excess $\mathrm{N}_{2}$ produced by denitrification was estimated by comparing measured concentrations of argon and $\mathrm{N}_{2}$ with those expected in water in equilibrium with the atmosphere (Vogel and others, 1981; Böhlke, 2002). Uncertainties in calculating the amount of excess $\mathrm{N}_{2}$ on the basis of argon and $\mathrm{N}_{2}$ concentrations include the recharge temperature and the amount of excess air. Therefore, the amount of excess $\mathrm{N}_{2}$ from denitrification cannot be uniquely determined from measuring $\mathrm{Ar}$ and $\mathrm{N}_{2}$ alone. Using a spreadsheet provided by the USGS Dissolved Gas laboratory, amounts of excess $\mathrm{N}_{2}$ were estimated by adjusting the values until the calculated recharge temperatures were close to the long-term mean annual air temperature at York, about $11^{\circ} \mathrm{C}$ (High Plains Climate Center, 2003). These analyses indicated that 1 to $7.5 \mathrm{mg} / \mathrm{L}$ of excess $\mathrm{N}_{2}$ was in reducing ground water, where denitrification would be suspected (table 16).

Additional calculations of the degree of reaction progress and initial nitrate- $\mathrm{N}$ concentrations and isotopic values, were determined from mass-balance calculations based on $\delta^{15} \mathrm{~N}$ values of excess $\mathrm{N}_{2}$ and residual nitrate- $\mathrm{N}$, and concentrations of nitrate- $\mathrm{N}$ and $\mathrm{N}_{2}$ using methods described by Böhlke (2002). Detailed description of these analyses is beyond the scope of this report, and is part of a synthesis effort to understand processes influencing nitrate- $\mathrm{N}$ concentrations in all TANC study areas (McMahon and others, 2008). Initial $\delta^{15} \mathrm{~N}$-nitrate values and concentrations of nitrate-N (at the time of ground-water recharge and before denitrification), corrected for denitrification effects on measured values, are reported here for the purpose of characterizing nitrate sources and comparing those results to other constituents to determine solute sources.

Initial $\delta^{15} \mathrm{~N}$-nitrate values for unconfined shallow urban and agricultural wells from the analyses described above suggested that there are multiple sources of nitrate, categorized as follows (fig. 15C; table 19 [see back of report]):

(1) 4.8 to $8.1 \%$ in unconfined shallow agricultural wells other than NWT1-39 and FP4-28;

(2) 11 to $19 \%$ in unconfined shallow urban wells other than UWT3-34;

(3) $10.5 \%$ o for well NWT1-39; and

(4) 8.6 and 9.3\%o for wells FP4-28 and UWT3-34, respectively.

The initial $\delta^{15} \mathrm{~N}$-nitrate values of most unconfined shallow agricultural wells (group 1 above) were consistent with fertilizer being an important source of ground-water nitrate-N. Nitrogen fertilizer has been the primary nitrogen source applied to crops for the last several decades; manure was not widely used as fertilizer in the study area (Rod DeBuhr, Water Department Manager, Upper Big Blue Natural Resources District, oral commun., March 15, 2003). Nitrogen fertilizer applied to crops in York County was estimated from countylevel data on historical fertilizer application rates (Alexander and Smith, 1990; David Lorenz, Hydrologist, USGS, written commun., 1999) and averaged about $100 \mathrm{~kg}$ nitrogen/ha for 1994-2003; the amount of manure applied averaged about $20 \mathrm{~kg}$ nitrogen/ha, according to estimates derived from data compiled from Census of Agriculture data for the same period (Sharon Qi, U.S. Geological Survey, Hydrologist, written commun., March 22, 2006). Values for $\delta^{15} \mathrm{~N}$-nitrate in ground water beneath fertilized fields are commonly 2 to $6 \%$ and are often slightly larger than fertilizer values and soil-water values because of nitrogen mixing, volatilization of ammonia fertilizer, or denitrification of nitrate in the unsaturated zone (Fogg and others, 1998; Kendall, 1998; Böhlke, 2003). Values of $\delta^{15} \mathrm{~N}$-nitrate for 4 soil-water samples from beneath irrigated fertilized fields (FP4 and AWT2 sites) were 2.6 to 9.8\%o, similar to values for unconfined shallow agricultural wells.

Values for $\delta^{15} \mathrm{~N}$-nitrate in most unconfined shallow urban wells were higher than for unconfined shallow agricultural wells and consistent with being derived from a animal waste source. Values for $\delta^{15} \mathrm{~N}$-nitrate in ground water affected by manure are typically 10 to 25 \%o (Fogg and others, 1998; Kendall, 1998; Böhlke, 2003), almost bracketing the range of unconfined shallow urban wells. Relatively high and variable $\delta^{15} \mathrm{~N}$-nitrate values derived from waste sources can result from isotopic fractionation during variable amounts of volatilization of ammonia from waste and other interactions with soils (Kreitler, 1975). At well FP3-33, a high initial $\delta^{15} \mathrm{~N}$-nitrate of $19 \%$ and a relatively low initial nitrate-N concentration of about $4.6 \mathrm{mg} / \mathrm{L}$ are consistent with this sample being more strongly affected by ammonia volatilization than samples from other unconfined shallow urban wells. Generally, different animal waste sources cannot be distinguished using $\delta^{15} \mathrm{~N}$ or $\delta^{18} \mathrm{O}$ of nitrate (Kendall, 1998). Within the local-scale TANC study area, possible animal waste sources that could contribute 

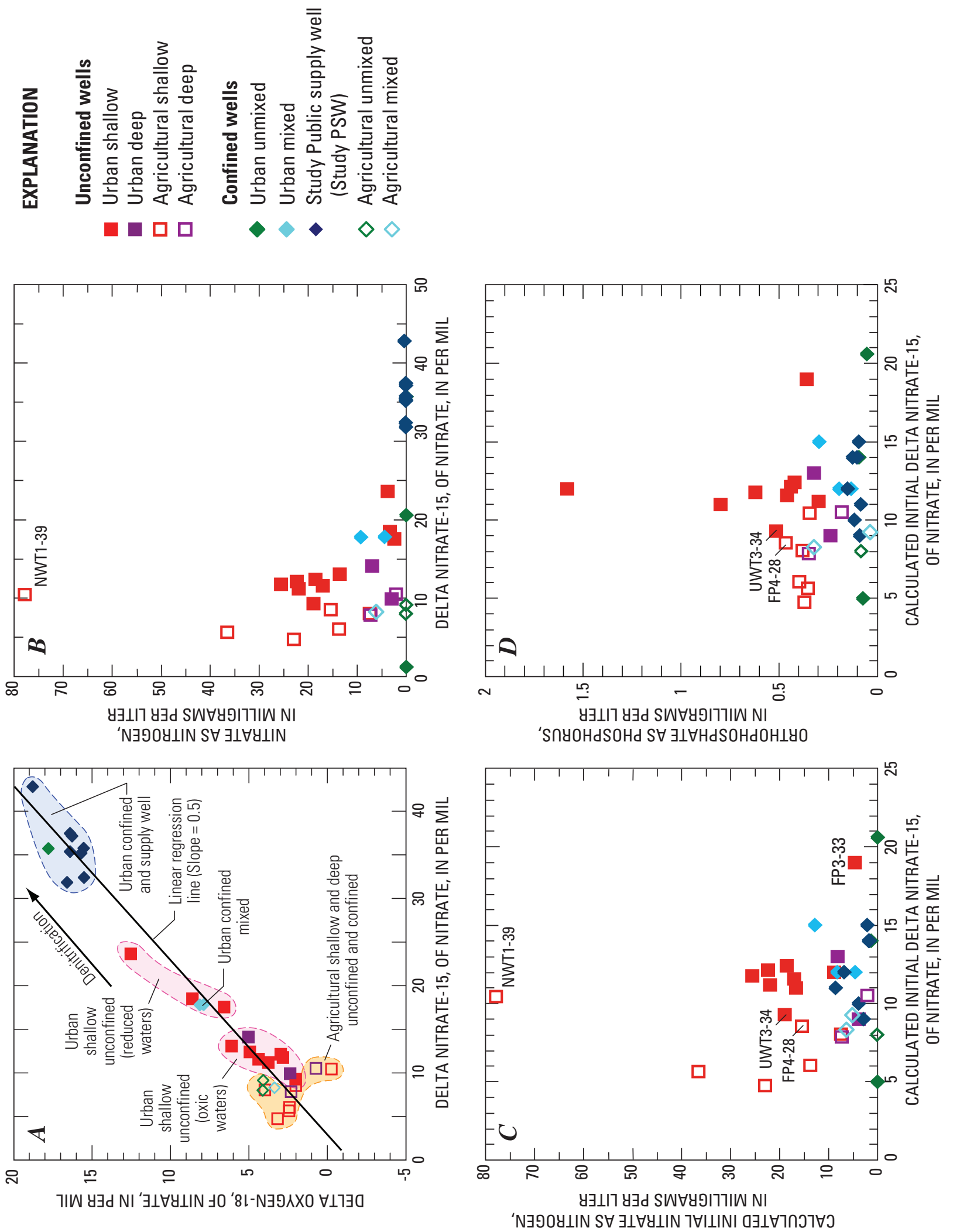

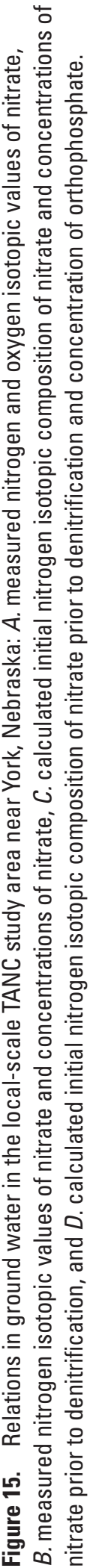


nitrate- $\mathrm{N}$ to shallow ground water are septic systems, leakage from the municipal wastewater sewer system, and livestock waste. Based upon the distribution of sources upgradient of the unconfined shallow urban wells and other chemistry (see Major Elements), septic systems or wastewater leakage sources were thought to be the primary sources of nitrate-N within the urban area.

Well NWT1-39 had the highest concentrations of nitrate-N, 69.5 to $80.3 \mathrm{mg} / \mathrm{L}$, measured in this study (fig. 8B; table 18). Well NWT1-39 is located at the downgradient end of a pasture (figs. 3 and 4 ) that was used for livestock manure disposal at times during the 1980s and 1990s. Leaching of the manure may have resulted in the high nitrate-N concentrations observed at this site. The $\delta^{15} \mathrm{~N}$-nitrate value of NWT1-39 was $10.5 \%$ o (table 19), within the range of $\delta^{15} \mathrm{~N}$-nitrate values expected for ground water affected by a manure source of nitrogen.

Intermediate $\delta^{15} \mathrm{~N}$ values of 8.6 to $9.3 \%$ at FP4-28 and UWT3-34 may indicate mixed sources of nitrate. These values were intermediate between lower ground-water values affected by fertilizer and higher values affected by animal waste. Well FP4-28 was near the western edge of York and would be primarily influenced by agricultural land use upgradient of the well. However, a garbage processing facility, a landfill, and residences with septic systems were identified upgradient of the well (fig. 4), so urban sources may have influenced this well. Well FP4-28 also was downgradient of several current or former livestock waste disposal areas and may have been affected by these sources (figs. 3 and 4), which would lead to a higher $\delta^{15} \mathrm{~N}$ value. Well UWT3-34 was located about $625 \mathrm{~m}$ east-by-southeast of FP4-28, about $400 \mathrm{~m}$ east of the western edge of York (fig. 4) and could have been affected by some of the same upgradient mixed sources as FP4-28.

Concentrations of orthophosphate as phosphorus (hereinafter orthophosphate) were largest in unconfined shallow urban wells, and ranged from 0.29 to $2.1 \mathrm{mg} / \mathrm{L}$ (table 18); the median was $0.46 \mathrm{mg} / \mathrm{L}$. Concentrations of orthophosphate in confined mixed wells were 0.021 to $0.320 \mathrm{mg} / \mathrm{L}$ compared with values of 0.027 to $0.186 \mathrm{mg} / \mathrm{L}$ in confined unmixed wells (table 18).

Elevated orthophosphate (operationally defined as $\geq 0.4 \mathrm{mg} / \mathrm{L}$ ) in unconfined shallow urban wells and FP4-28 may be associated with ground water affected by septic systems or leakage from the urban sanitary sewer system in addition to being affected by reducing conditions in the unconfined aquifer. Seven of nine unconfined shallow urban wells had elevated orthophosphate concentrations (fig. 15D). Of these seven wells, six had initial $\delta^{15} \mathrm{~N}$-nitrate values $\geq 10 \%$; the exception, UWT3-34, had initial $\delta^{15} \mathrm{~N}$-nitrate of $9.3 \%$ and may be affected by mixed nitrate sources. Likewise, the one agricultural well having elevated orthophosphate concentrations, FP4-28, had an intermediate $\delta^{15} \mathrm{~N}$-nitrate, $8.6 \%$, and may be affected by mixed nitrate sources. Of the 7 unconfined shallow urban wells and FP4-28 having elevated orthophosphate concentrations and initial $\delta^{15} \mathrm{~N}$ nitrate $\geq 8.6 \%$ o, 5 of these wells had oxic conditions and 3 had reducing conditions. Under reducing (anoxic) conditions, phosphorus is released from sediments (House, 2003). The highest orthophosphate concentrations in unconfined shallow urban wells were in wells OFPS-38 and UWT2-23, which have reducing ground water (table 13). In unconfined shallow urban wells having reducing conditions, it is likely that orthophosphate concentrations $\geq 0.4 \mathrm{mg} / \mathrm{L}$ primarily reflect the reducing redox conditions. In unconfined shallow wells having oxic conditions, the association of elevated orthophosphate with initial $\delta^{15} \mathrm{~N}$-nitrate values $\geq 10 \%$ in most unconfined shallow urban wells or $\geq 8.6 \%$ in FP4-28 and UWT3-34, indicating mixed sources (fig. 15D), suggests that the orthophosphate was associated with ground water affected by a manure source. This association is suggestive but does not prove a common source for the relatively high initial $\delta^{15} \mathrm{~N}$-nitrate and elevated orthophosphate concentrations.

Other possible sources of phosphorus to ground water are considered to be minor. Orthophosphate was relatively low, 0.3 to $0.4 \mathrm{mg} / \mathrm{L}$, in unconfined shallow agricultural wells, suggesting that phosphorus applied to agricultural crops did not result in elevated concentrations in ground water. A 1996 survey of fertilizer use in the Blue River Basin, which includes the local-scale TANC study area, showed that phosphate fertilizers were applied to about $75 \%$ of corn crops at an average rate of about $28 \mathrm{~kg} / \mathrm{ha}$ (Franti and Dorn, 1998). Leaching of phosphorus from fertilizer is typically minimal, as phosphorus is readily utilized by vegetation and affected by sorption and precipitation reactions in the soil (Sinaj and others, 2002). For these reasons, urban phosphorus fertilizer application was not considered to be a likely source of the relatively high orthophosphate concentrations in unconfined shallow urban wells.

Elevated concentrations of orthophosphate are commonly in wastewater and in ground water affected by septic systems in aquifer systems that are oxidizing and have calcareous sands that produce neutral pH (Robertson and others, 1998; Reay, 2004; McCray and others, 2005). In the local-scale TANC study area, near-neutral pHs, relatively high alkalinities and calcium concentrations, equilibrium of ground water with calcite (see "Major Elements"), and calcite in an unsaturated sand core samples suggest that calcite dissolution influences ground-water chemistry. Elevated orthophosphate concentrations in ground water affected by septic-system discharges would thus be expected. Therefore, it is likely that the elevated orthophosphate detected in unconfined shallow urban wells was associated with the same manure source that produced the $\delta^{15} \mathrm{~N}$-nitrate values $\geq 10 \%$. It cannot be determined whether the orthophosphate in unconfined shallow urban wells was derived from septic-systems or sanitarysewer system leakage, because the processes and geochemical signatures are similar. 
Concentrations of dissolved organic carbon (DOC) were generally greatest in unconfined shallow urban and agricultural wells. The highest concentrations of DOC of 6.8 to $7.6 \mathrm{mg} / \mathrm{L}$ were in well NWT1-39, interpreted as being affected by leaching of livestock manure (fig. 10). The relatively high DOC concentrations were consistent with leaching of organic material in the manure. Well FP1-63 had DOC of $3.4 \mathrm{mg} / \mathrm{L}$ (fig. 10), relatively high nitrate-N (25.6-28.8 $\mathrm{mg} / \mathrm{L}$ as $\mathrm{N}$ [table 18]), a $\delta^{15} \mathrm{~N}$-nitrate value of $11.8 \%$ o (table 19), consistent with a manure source, and the highest VOC concentrations of any well in the local-scale TANC study area (table 14). These characteristics suggest that well FP1-63 may have been affected by an anthropogenic point source contributing nutrients and VOCs to ground water. Relatively high DOC values are reasonable for a site affected by anthropogenic sources such as septic systems, wastewater spills, landfills, or other sources.

The presence of relatively high nitrate-N, little or no ammonia, and relatively low DOC in water affected by septic systems suggests that oxidation of DOC and ammonia is mostly occurring in the unsaturated zone. Ground water beneath and downgradient of septic systems may be either oxic or reducing (Robertson and others, 1998). Oxic conditions facilitate conversion of ammonia to nitrate and DOC to carbon dioxide (Robertson and others, 1991). The absence of ammonia, even in UWT2-23, which had reducing conditions, was located near areas having septic systems (fig. 4), and had indicators of septic-system effects (initial $\delta^{15} \mathrm{~N}$-nitrate, and orthophosphate) (see "Major Elements"), suggests that septicsystem effluents were oxidized primarily in the unsaturated rather than the saturated zone in the local-scale TANC study area.

\section{Major Elements}

Major element concentrations in unconfined shallow urban and agricultural wells in the local-scale TANC study area were affected by anthropogenic sources, such as septic systems, sanitary sewers, and livestock waste, and geochemical reactions, such as dissolution and redox reactions. These processes are discussed in the sections below, beginning with description of water types, interpretations of anthropogenic solute sources effecting on shallow groundwater chemistry, sources of water chemistry signatures in the study PSW, and geochemical processes affecting selected major elements.

The relative abundance of major cations and anions is shown on the trilinear or piper diagram (Piper, 1953) in figure 16. The diagram shows the relative percentages of total milliequivalents per liter attributed to individual or groups of cations and anions, and can be used to infer major water types. In most wells, calcium accounted for more than $60 \%$ of the total cations, and bicarbonate accounted for more than $60 \%$ of the total anions; these samples were calcium-bicarbonate type waters. There were also many wells that were mixed cation-bicarbonate type waters, indicating that no single cation accounted for more than $60 \%$ of the total cations. Calcium was still the most abundant cation in most of these mixed cation-bicarbonate waters. The relative proportions of cations varied less between different categories of wells than the proportions of anions (fig. 16).

Most samples from confined unmixed wells were calcium-bicarbonate type waters (ig. 16). Cation proportions varied slightly more than anion proportions; proportions of sodium usually increased and calcium usually decreased as well depth increased. This pattern of increasing sodium and decreasing calcium with depth may indicate cation-exchange in the deeper parts of the confined aquifers, where dissolved calcium is adsorbed preferentially onto clays compared with sodium, which is displaced from clay surfaces by calcium and goes into solution (Appello and Postma, 1997).

Samples from unconfined shallow agricultural wells were primarily mixed cation-bicarbonate type waters, except for well NWT1-39 (fig. 16). Nitrate-N was the predominant anion at NWT1-39; this site was at the downgradient edge of a pasture used in the past for livestock waste disposal and was considered to primarily have a livestock-waste-disposal signature.

Proportions of major-ions varied most in samples from unconfined shallow urban wells; these samples were primarily mixed cation-mixed anion water types (fig. 16). Unconfined shallow urban wells generally had greater proportions of sulfate and chloride plus nitrate-N than other types of wells (fluoride concentrations were minor and are disregarded in this discussion). Bicarbonate was the most abundant anion in most of these wells. Cation proportions were relatively uniform with calcium as the most abundant cation and roughly equal amounts of sodium plus potassium and magnesium.

Confined mixed well FP3-162 and depth-dependent samples from the study PSW had anion proportions intermediate between some unconfined shallow urban and confined unmixed samples (fig. 16). These intermediate proportions are consistent with these samples being mixtures of water from the unconfined and confined aquifers.

Associations between concentrations of chloride, initial $\delta^{15} \mathrm{~N}$-nitrate, potassium, orthophosphate, sulfate, and boron suggest that the primary source of relatively high amounts of these constituents and isotopic signatures in unconfined shallow urban wells was septic system and (or) sanitary sewer leakage. These two sources cannot be distinguished on the basis of available information since both sources would be expected to have similar geochemical signatures. In wells that were upgradient of the sewer system but downgradient of septic systems (UWT2-23, FP4-28), geochemical signals did not show a difference between the effects of septic-system and sewer leakage. Therefore, these sources are lumped together in the following discussion. Septic systems have been shown to cause elevated nitrate, orthophosphate, chloride, sodium, calcium, potassium, DOC, and depressed $\mathrm{pH}$ and DO in shallow ground water (Robertson and others, 1991, 1998). 


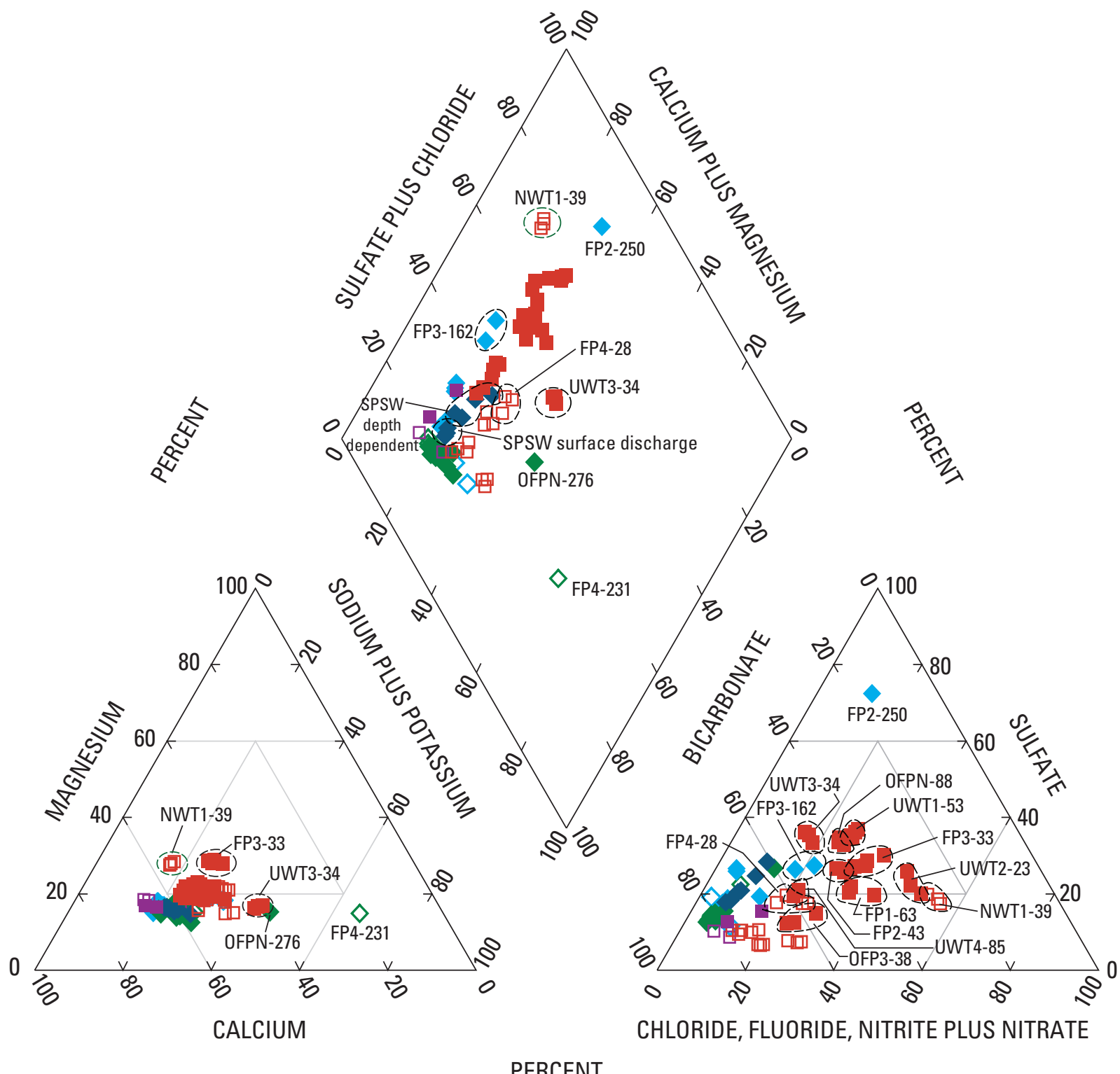

\section{EXPLANATION}

$\begin{array}{ll} & \text { Unconfined wells } \\ \square & \text { Urban shallow } \\ \square & \text { Urban deep } \\ \square & \text { Agricultural shallow } \\ \square & \text { Agricultural deep }\end{array}$

\section{Confined wells}

Urban unmixed

Urban mixed

Study public supply well (Study PSW)

$\diamond \quad$ Agricultural unmixed

$\diamond \quad$ Agricultural mixed

Figure 16. Piper diagram showing general types of ground water in the local-scale TANC study area near York, Nebraska. 
Chloride concentrations in ground water varied substantially from 6.6 to $187 \mathrm{mg} / \mathrm{L}$ (table 20 [see back of report]); concentrations $\geq 30 \mathrm{mg} / \mathrm{L}$ were in unconfined shallow urban wells, or confined urban mixed wells and the study $P S W$, indicating mixing of water from the unconfined aquifer in the urban area with water from the confined aquifer (fig. 17A,B). Concentrations of chloride $\geq 30 \mathrm{mg} / \mathrm{L}$ in unconfined shallow urban wells were associated with initial $\delta^{15} \mathrm{~N}$-nitrate values $\geq 8.6 \%$, implying that chloride has been affected by septic systems or wastewater leakage (fig. 17A). Chloride is considered to be a conservative constituent unaffected by geochemical reactions under most conditions. Chloride concentrations were largest in well UWT2-23 (138-187 mg/L, table 20; fig. 17A,B), which was located southeast of an area having many septic systems (fig. 4). Unconfined shallow agricultural well FP4-28, possibly affected by mixture of fertilizer and animal waste sources (see "Nutrients"), had chloride concentrations of 31 to $67 \mathrm{mg} / \mathrm{L}$ and an initial $\delta^{15} \mathrm{~N}$-nitrate value of 8.6\%o. Well NWT1-39, possibly affected by livestock manure disposal (see "Nutrients"), had chloride concentrations of 12 to $13 \mathrm{mg} / \mathrm{L}$, suggesting that livestock manure was not a source of elevated chloride. Consequently, the elevated chloride at FP4-28 most likely was affected by upgradient septic systems. Wastewater leakage was not expected to affect the rural location at FP4-28, since the western boundary of the sanitary sewer system did not extend upgradient of FP4-28. Chloride concentrations were $<13 \mathrm{mg} / \mathrm{L}$ in unconfined shallow agricultural wells other than FP4-28. The low chloride concentrations in most unconfined shallow agricultural wells indicate that application of potash $(\mathrm{KCl})$ fertilizers on agricultural land was not an important source of chloride to ground water. A 1996 survey of fertilizer use in the region indicated that potash was applied to only about $5 \%$ of corn acres at an average rate of about $8 \mathrm{~kg} / \mathrm{ha}$ (Franti and Dorn, 1998).

Concentrations of chloride and potassium were strongly correlated $(\rho=0.37 ; p=0.009)$ in unconfined shallow urban and agricultural wells, suggesting a common source for relatively high concentrations of these constituents (fig. 17B). The highest potassium and chloride concentrations in unconfined shallow urban wells were in UWT2-23, where effects of septic systems were considered likely (see "Nutrients"), and well FP1-63. Concentrations of potassium were $<9.5 \mathrm{mg} / \mathrm{L}$ in unconfined shallow agricultural wells (table 20). In contrast to chloride, potassium is affected by cation-exchange and sorption reactions and is not conservative (Ceazan and others, 1989; Appelo and Postma, 1999). As travel distance downgradient from septic-system or sewer leakage increases, concentrations of potassium were expected to decrease as a result of these geochemical processes and return to values representing ground water unaffected by these sources. It is possible that the high potassium concentrations (as well as chloride values) at UWT2-23 and FP1-63 may be related to proximity to septic-system or wastewater sources or particularly high source concentrations. Relatively high values of chloride and potassium were also in confined urban mixed well FP2-250. This well had unique water chemistry and may have been affected by upward movement of water from the underlying shale; lines of evidence for this interpretation, based on multiple constituents, are discussed later in the report in the section "Sources of Water and Solutes."

The positive relation of orthophosphate and chloride concentrations supports the interpretation that the most likely source of orthophosphate was septic-system or wastewater leakage. Concentrations of chloride and orthophosphate were correlated ( $\rho=0.67 ; p=<0.001)$ in unconfined shallow urban and agricultural wells (fig. 17C). High concentrations of orthophosphate at OFPS-38 may reflect reducing conditions and proximity to organic-rich stream sediments of Beaver Creek. Among unconfined shallow urban and agricultural wells other than OFPS-38, the largest concentrations of chloride and orthophosphate were in wells FP1-63 and UWT2-23 (fig. 17C). Both orthophosphate and chloride are commonly associated with septic-system effluents (Robertson and others, 1991, 1998).

Additional solutes that appeared to be elevated in unconfined shallow urban wells because of septic-system or wastewater discharge were sulfate and boron. Concentrations of sulfate in all except one of these wells and FP4-28 were 90 to $220 \mathrm{mg} / \mathrm{L}$; initial $\delta^{15} \mathrm{~N}$-nitrate values were $\geq 8.6 \%$ (fig. 17D). Well OFPS-38 was an exception; the sulfate concentration was about $50 \mathrm{mg} / \mathrm{L}$. However, this well had the largest $\mathrm{H}_{2} \mathrm{~S}$ values measured in the study (fig. 8E), possibly indicating sulfate-reducing conditions, which would decrease sulfate concentrations. Generally, values of sulfate are not always a good tracer of the effects of wastewater (Barrett and others, 1999). However, in the local-scale TANC study area, variable but high concentrations of sulfate associated with initial $\delta^{15} \mathrm{~N}$-nitrate $\geq 8.6 \%$ indicate that sulfate in unconfined shallow urban wells may be related to septic-system or wastewater sources. Concentrations of sulfate in confined unmixed wells were less than concentrations in unconfined shallow urban and agricultural wells (fig. 17E) suggesting that geologic sources of sulfate in the aquifer were absent or had little effect. Sulfate-reducing conditions were present in a few places in the confined aquifers (fig. 8E) but do not appear to have had a substantial effect on sulfate concentrations, which were similar in confined unmixed wells regardless of whether sulfate reducing conditions were present. Samples from selected wells were analyzed for sulfur isotopic values of sulfate (table 19) but the data did not clearly indicate particular sources or processes affecting sulfate concentrations.

Boron appeared to be elevated in some unconfined shallow urban wells (fig. 17E), possibly indicating septicsystem or wastewater leakage, but not in others, perhaps indicating variability in septic-system sources. Boron is typically found in wastewater because it is a component of many, but not all, detergents (Barrett and others, 1999). Concentrations of boron and sulfate were positively correlated $(\rho=0.94 ; p<0.001)$. 

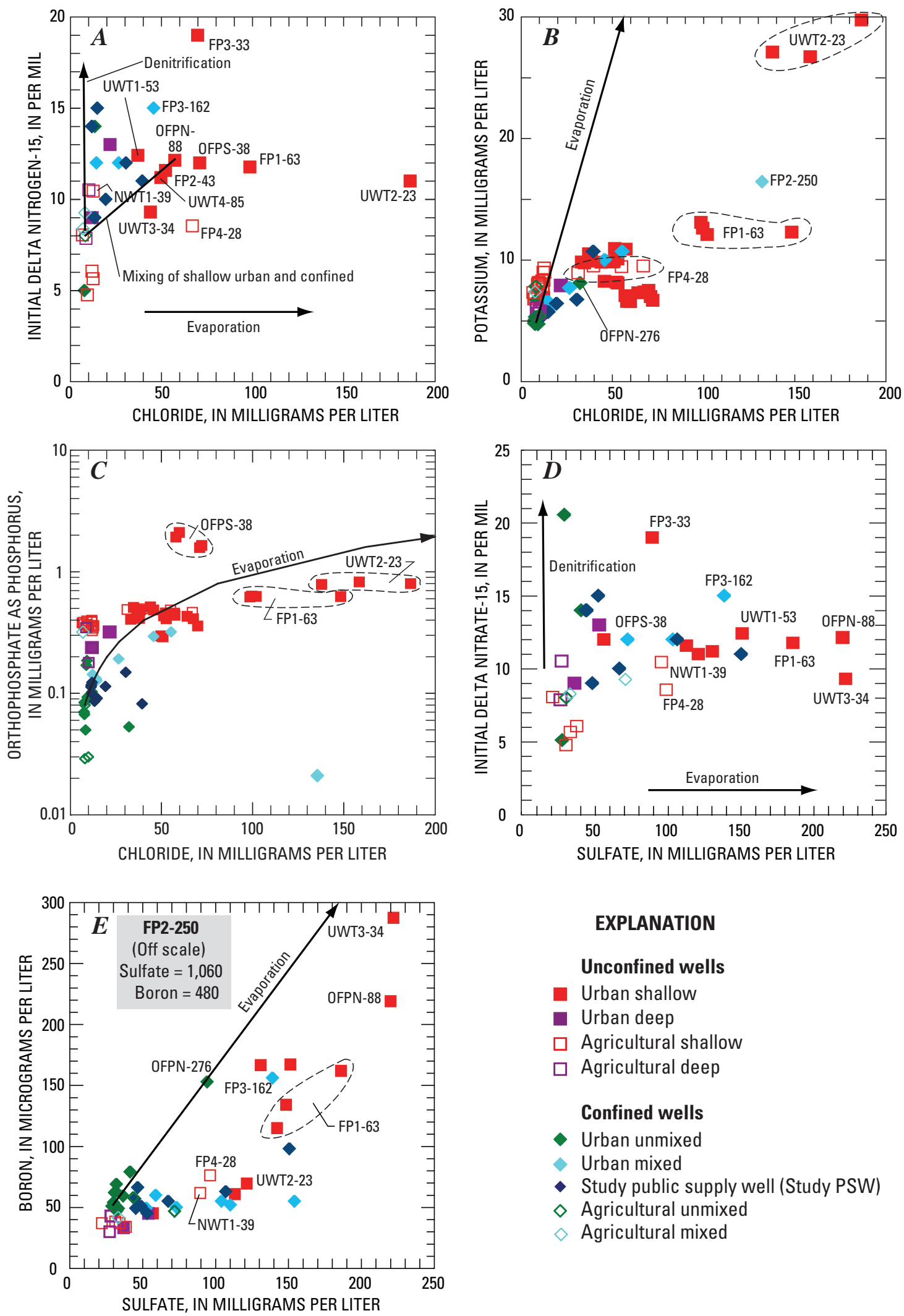

\section{EXPLANATION}

\section{Unconfined wells}

Urban shallow

Urban deep

Agricultural shallow

Agricultural deep

\section{Confined wells}

Urban unmixed

- Urban mixed

- Study public supply well (Study PSW)

$\diamond$ Agricultural unmixed

$\checkmark$ Agricultural mixed

Figure 17. Graphs showing relations between chloride and $A$. initial $\delta^{15} \mathrm{~N}$-nitrate, $B$. potassium, and $C$. orthophosphate and between sulfate and $D$. calculated initial $\delta^{15} \mathrm{~N}$-nitrate and $E$. boron in ground water from the local-scale TANC study area near York, Nebraska. Measured values of initial $\delta^{15} \mathrm{~N}$-nitrate corrected for denitrification in some samples. 
Chloride/bromide have been used to identify the sources of elevated chloride concentrations in ground water (Vengosh and Pankratov, 1998; Davis and others, 1998; Panno and others, 2006). Figure 18 shows minimum, median, and maximum values of chloride and chloride/bromide from literature sources for sewage, septic-system effluent, and animal waste source materials and ground-water affected by septic systems, animal waste, road salt, agricultural chemical application, and landfills, and background groundwater unaffected by any of these sources. The literature values provide constraints on likely chloride source material compositions. However, because the chloride and chloride/ bromide of source materials and affected ground-water can vary considerably (Davis and others, 1998; Panno and others, 2006), interpretations based comparing chloride/bromide ratios in local-scale TANC study-area ground water with those in possible sources based on literature values need to be supported by independent evidence.

Chloride/bromide are consistent with elevated chloride in unconfined shallow urban wells and unconfined shallow agricultural well FP4-28 being derived from septicsystem sources rather than a road salt application (fig. 18). Unconfined shallow urban wells and FP4-28 generally plot in a cluster having relatively high chloride concentrations of 33 to $187 \mathrm{mg} / \mathrm{L}$ and intermediate to high chloride/bromide ranging from 96 to 778 (fig. 18). These values plot close to curves for source materials and ground-water affected by septic systems and animal waste (Vengosh and Pankratov, 1998; Panno and others, 2006). Because unconfined shallow urban wells were closer to septic systems than to livestock waste areas, and because chemical composition in NWT1-39, affected by animal waste disposal, and unconfined shallow urban wells were substantially different, septic systems were likely a greater source of elevated chloride in the urban area than livestock waste areas.

Samples from well NWT1-39, affected by livestockwaste disposal, had chloride and chloride/bromide lower than the range of values in ground water affected by animal waste determined by Panno and others (2006). It is likely that livestock waste values vary as a function of local factors. Samples from unconfined shallow urban wells FP3-33 and FP1-63 plot slightly above the range of values indicated by Panno and others (2006) for ground-water affected by landfill leachate (fig. 18). However, there were no known landfills west or northwest of FP3-33 that likely affected that well. Well FP1-63 could have been affected by a former rubble wastedisposal site to the northwest (near OFPN-88, fig. 4), although there are many other land uses that could have affected this well.

Chloride concentrations in some confined mixed wells and the study PSW have intermediate values, consistent with representing mixtures, between unconfined shallow urban wells and confined unmixed wells (fig. 18). The relative uniformity of chloride concentrations in confined unmixed and unconfined shallow agricultural wells probably reflects long-term average evaporative concentration of chloride from natural precipitation. Wells FP2-250 and OFPN-276, screened in lower confined lenses (table 1), have relatively high chloride/bromide and plot close to the road-salt affected curve (fig. 18); however, these wells may be affected by interactions with water or solutes in the underlying shale (see "Sources of Water and Solutes").

Different combinations of major elements that are useful tracers of unconfined shallow urban waters, combined with isotopic and VOC data described earlier, were plotted against each other in an attempt to use geochemical signatures to identify mixing of water from the unconfined aquifer in the confined aquifers based on geochemical signatures (fig. 19). The plots shown and discussed below were the most useful for interpretations of water and solute sources.

Analysis of $\delta^{18} \mathrm{O}$ and chloride, tracers expected behave conservatively, showed a clear contrast between unconfined shallow urban, unconfined shallow agricultural, confined unmixed, and confined mixed wells that supported the interpretation that confined mixed wells contained water from the unconfined aquifer (fig. 19A). Most confined unmixed wells plotted in a tight cluster with low $\delta^{18} \mathrm{O}$ and chloride values. Most unconfined shallow agricultural wells had high $\delta^{18} \mathrm{O}$ and low chloride concentrations. Unconfined shallow agricultural wells plot along an evaporative trend such that water in these wells could have been derived from evaporative enrichment of confined unmixed water. Such a pattern could result from withdrawal and application of confined unmixed water as a source of irrigation, subsequent evaporative enrichment, and recharge of evaporatively enriched water to unconfined shallow agricultural wells. A third end-member group consisted of unconfined shallow urban wells (and including unconfined shallow agricultural well FP4-28) had intermediate $\delta^{18} \mathrm{O}$ and high chloride values. Confined urban mixed wells had intermediate values of $\delta^{18} \mathrm{O}$ and chloride along an apparent mixing line between unconfined shallow urban and confined unmixed wells. Confined urban mixed well FP3-162 overlapped with unconfined shallow urban wells. Depth-dependent samples from the study PSW also plotted between unconfined shallow urban and confined unmixed wells but along a mixing line different from that of confined urban mixed and unconfined deep urban wells (fig. 19A). These observations lead to two conclusions: (1) the water from the unconfined aquifer mixing with water from the confined aquifer in the study PSW came from an unconfined shallow urban source area and (2) the confined mixed wells and the study PSW did not have common unconfined shallow urban source areas, implying that there were multiple pathways from the unconfined aquifer source areas to zones of mixing in the confined aquifer. 


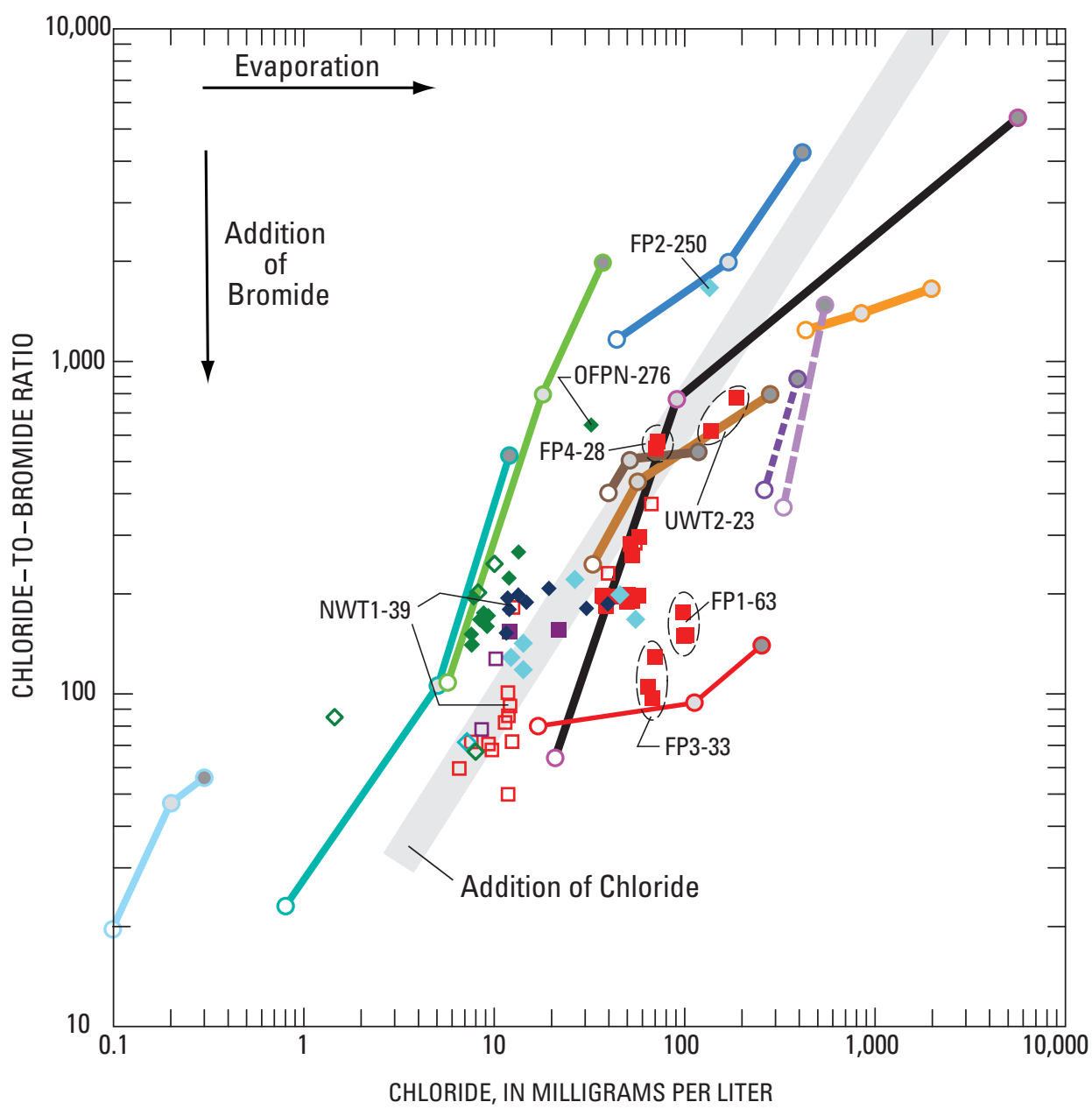

Minimum, median, and maximum shown $\begin{array}{ccc}\text { Min Median } & \text { Max } \\ \bigcirc & \bigcirc\end{array}$

\section{Unconfined wells}

- Urban shallow

- Urban deep

- Agriculture shallow

Agriculture deep

Confined wells

- Urban unmixed

- Urban mixed

- Study public supply well (Study PSW)

$\diamond$ Agriculture unmixed

$\diamond$ Agriculture mixed
Sewage (no median)
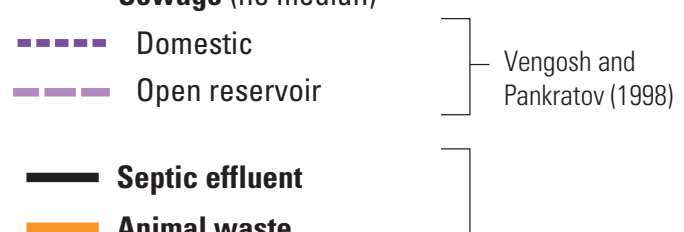

Animal waste

Ground-water affected by

Septic

Animal waste

Road salt

- Panno and others (2006)

Figure 18. Chloride and chloride/bromide in ground-water samples from the local-scale TANC study area near York, Nebraska. 

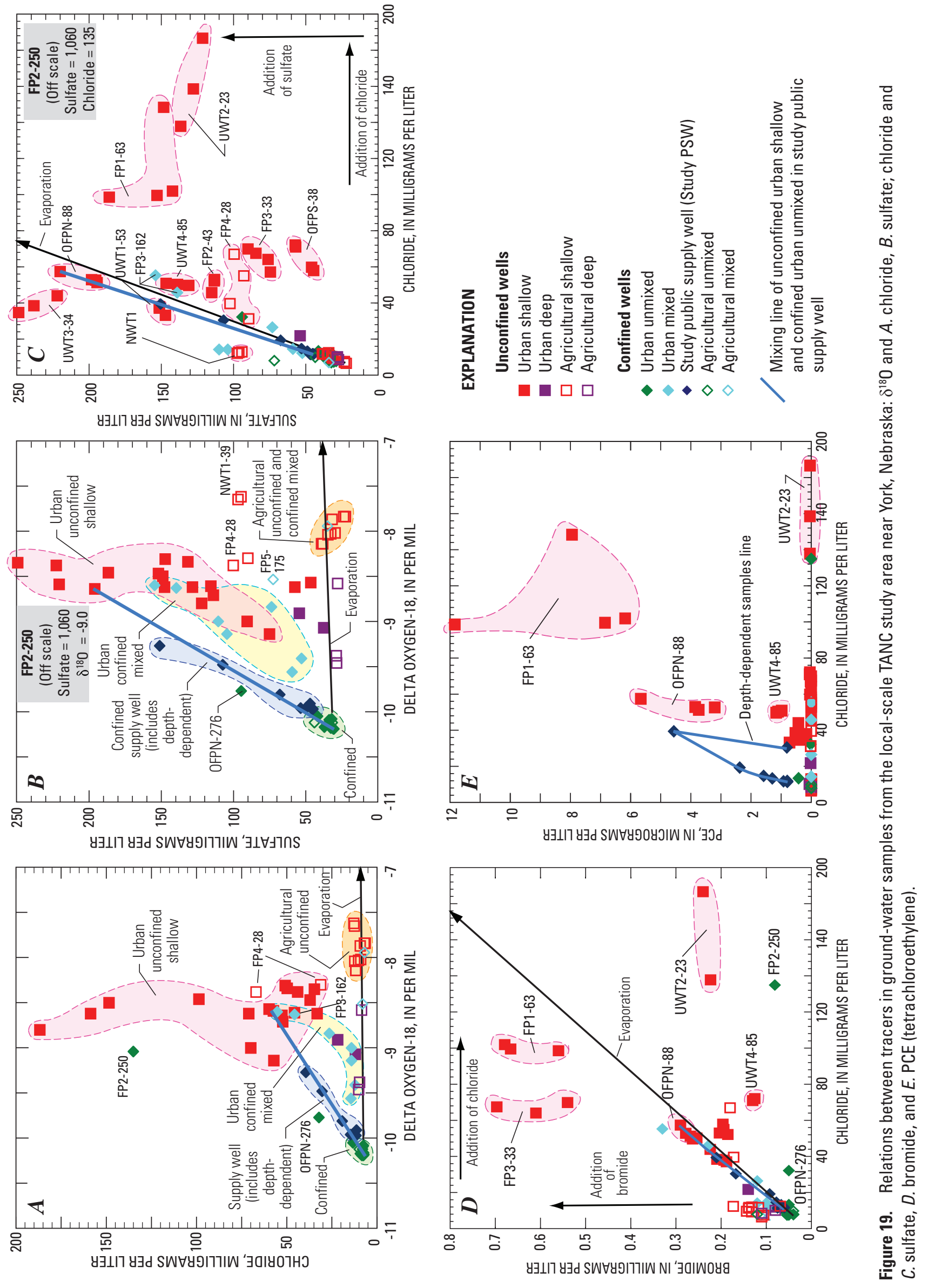
Similar interpretations were evident from a plot of $\delta^{18} \mathrm{O}$ versus sulfate (fig. 19B). Confined urban mixed wells plotted between unconfined shallow urban and confined unmixed wells, implying that the sulfate that was higher in the confined urban mixed wells than in the confined unmixed wells was derived from mixing with unconfined shallow urban wells, FP4-28, and (or) NWT1-39, rather than most unconfined shallow agricultural wells, which have lower sulfate. FP4-28 plotted similar to unconfined shallow urban wells, as with other inorganic constituents discussed earlier, and NWT1-39, interpreted to be affected by a manure source, had higher sulfate than most other unconfined shallow agricultural wells. Confined agricultural mixed well FP5-175 had higher sulfate than unconfined shallow agricultural wells other than FP4-28 and NWT1-39, which were east (downgradient) of FP5-175. The relatively high sulfate in FP5-175 was similar to concentrations in several unconfined shallow urban wells and may indicate that the sulfate was derived from a common source, either septic systems or wastewater, or from reactions of well-bore leakage with sulfur minerals in the upper confined unit, or it may indicate effects of an upgradient livestock manure source having a composition similar to that of NWT1-39.

A plot of chloride and sulfate (fig. 19C) showed low concentrations of chloride and sulfate in confined unmixed wells, causing them to plot in a tight cluster, but large variability of values among unconfined shallow urban wells, and in wells FP4-28 and NWT1-39. The wide variability of chloride and sulfate concentrations in unconfined shallow urban wells probably reflected wide variations in manure, septic system, or wastewater-source compositions and in amounts of mixing with unaffected waters.

Factors influencing calcium and bicarbonate concentrations were of particular importance because uranium concentrations were closely tied to the distribution of these constituents (see "Uranium"). Concentrations of calcium and bicarbonate were affected by equilibrium with calcite, depth to water, and possibly septic-system discharge.

Saturation indices for calcite indicated approximate thermodynamic equilibrium between the mineral calcite and all ground-water samples except those from the unconfined shallow urban wells described below. PHREEQC Interactive (version 2.12.5 [Parkhurst and Appelo, 1999]) was used to determine the saturation indices of selected mineral and gas phases, which indicate the thermodynamic state of a mineral or gas phase relative to the aqueous phase. Calcite was present in most cores analyzed for mineralogy (table 8).

Concentrations of bicarbonate were relatively low (fig. 20A) and calcite was undersaturated in unconfined shallow urban wells with $\mathrm{pH}$ less than about 6.7. The relatively low $\mathrm{pH}$ values occurred in unconfined shallow urban wells having relatively high DOC; oxidation of organic matter produces acidity, which lowers $\mathrm{pH}$ (Appelo and Postma, 1997; Robertson and others, 1998). When $\mathrm{pH}$ is low, more of the dissolved inorganic carbon exists as dissolved carbonic acid or carbon dioxide instead of bicarbonate (Appelo and
Postma, 1997). The high concentrations of DOC and low $\mathrm{pH}$ in these wells were suspected to result from a combination of factors, including shallow depths to water (FP3-33, OFPS-38, UWT1-53, UWT2-23), close proximity to stream sediments suspected to contain abundant organic matter (OFPS-38, UWT2-23, FP5-45), and livestock waste spread on overlying land (NWT1-39).

Calcium and bicarbonate concentrations in some unconfined shallow urban and confined mixed wells may have increased because of septic-system effects. Acidity generated by oxidation of organic matter and ammonia in septicsystem effluent, when reacted with calcite in the sediment, should result in increased concentrations of bicarbonate and calcium more than waters not affected by septic systems (Robertson and others, 1991). Concentrations of calcium and chloride in unconfined shallow urban and agricultural wells were correlated ( $\rho=0.32, p=0.025$ [fig. 20C]), consistent with increased dissolution of calcite in waters affected by septic systems. Concentrations of bicarbonate and chloride in unconfined shallow urban wells were not correlated (fig. 20B). However, bicarbonate concentrations can be affected by inorganic carbon speciation as a function of $\mathrm{pH}$ and soil processes generating carbon dioxide; these processes complicate interpretation of the effects of septic systems on dissolved inorganic carbon. Relatively high bicarbonate concentrations, greater than about $300 \mathrm{mg} / \mathrm{L}$, were in unconfined shallow urban wells that were oxic. Calcium and bicarbonate concentrations were greater in confined mixed wells and the study $P S W$ depth-dependent samples than in confined unmixed wells (figs. 20B,C), probably reflecting the effects of mixing of waters from the unconfined aquifer.

Constituent concentrations calculated to result from evaporative concentration of confined unmixed waters were plotted on figs 17, 18, 19, and 20 for reference. Evaporation lines usually did not uniquely fit the distribution of constituent concentrations in unconfined shallow urban and agricultural wells. The comparison of sample values to evaporation lines was inconsistent from plot to plot, making clear evaporative effects difficult to identify. Moreover, some of the constituents plotted are not conservative. These results suggest that evaporative concentration is likely to be a minor factor affecting concentrations of solutes in the unconfined aquifer. As discussed in "Stable Isotopes," unconfined aquifer $\delta^{18} \mathrm{O}$ and $\delta \mathrm{D}$ values were near MWLs, suggesting that isotopic values have been modified very little or not at all by evaporation. However, values of $\delta^{18} \mathrm{O}$ and $\delta \mathrm{D}$ are not modified by transpiration, which is a non-fractionating process (Zimmerman, 1967). Therefore, transpirative concentration could still occur and not be detectable with $\delta^{18} \mathrm{O}$ and $\delta \mathrm{D}$ values. As most of the landscape in the subhumid local-scale TANC study area has vegetation cover during the growing season, it is reasonable to consider that more water is lost through transpiration than through evaporation. Increased concentrations of dissolved constituents in unconfined shallow wells compared with confined unmixed wells could have resulted from direct evapotranspirative loss from the 

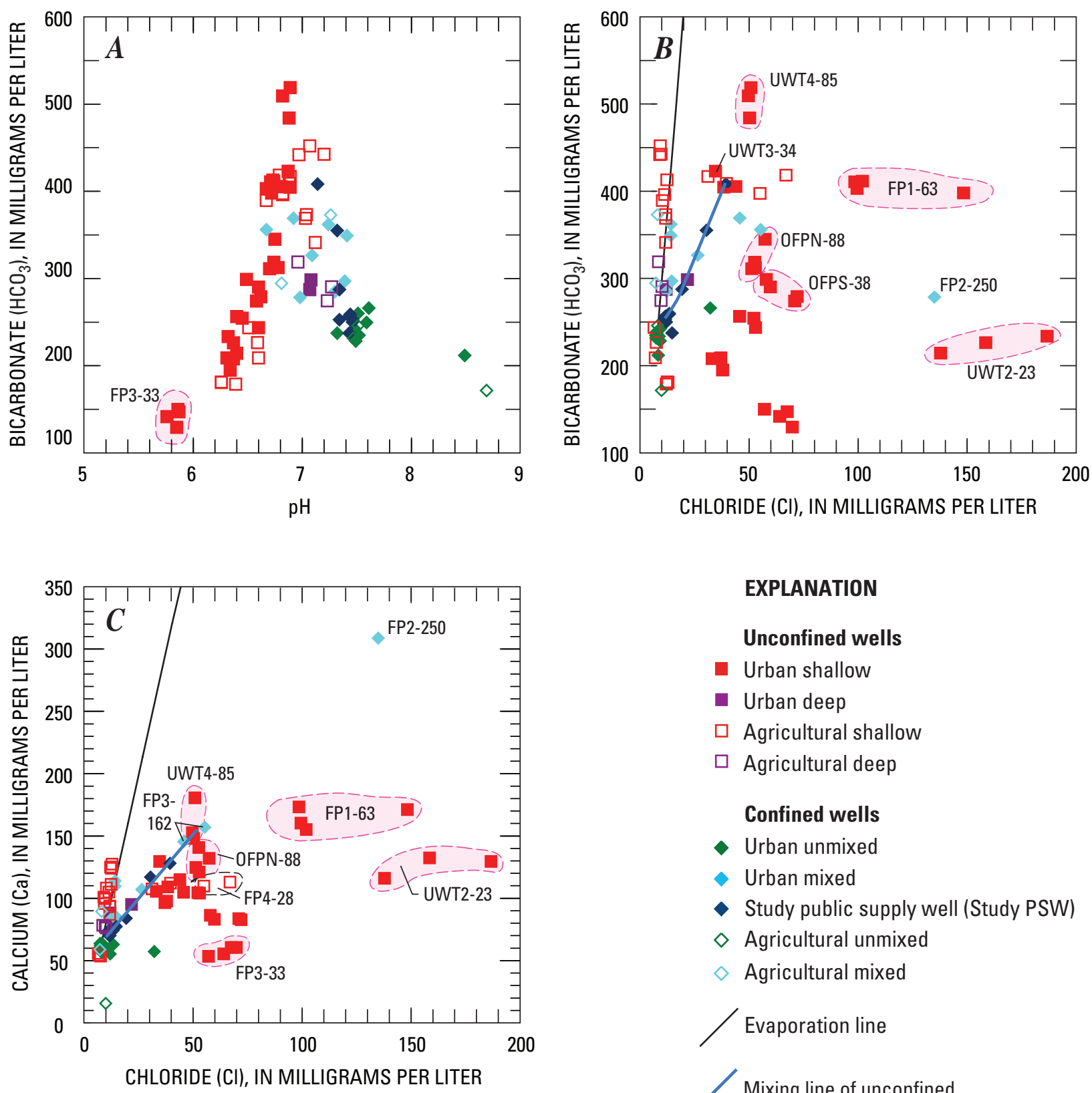

EXPLANATION
Unconfined wells
- Urban shallow
- Urban deep
$\square$ Agricultural shallow
$\square$ Agricultural deep

\section{Confined wells}

- Urban unmixed

- Urban mixed

- Study public supply well (Study PSW)

$\diamond$ Agricultural unmixed

$\diamond$ Agricultural mixed

Evaporation line

Mixing line of unconfined urban shallow and confined urban unmixed in study public supply well

Figure 20. Relations in ground-water samples from the TANC local-scale study area near York, Nebraska: $A$. pH and bicarbonate, $B$. chloride and bicarbonate, $C$. chloride and calcium.

water table or from seasonal or event-driven recharge of constituents that accumulated in the unsaturated zone during the growing season. The depth to water table $\geq 6 \mathrm{~m}$ in all but two wells, OFPS-38 and UWT2-23, (fig. 10) was greater than the maximum depth to water likely be directly affected by evapotranspirative loss on the basis of literature values for grass land cover and clay loam soil (Shah and others, 2007). Thus, direct evaporative loss from the water table is unlikely or minor. Evapotranspiration probably affects ground-water quality through evapotranspirative concentration of solutes from ground-water irrigation in the unsaturated zone. Ground water used as the source of irrigation has total dissolved solids (TDS) more than an order of magnitude higher than that in precipitation (from the nearest precipitation chemistry station at Mead, Nebraska, data from National Atmospheric Deposition Program, 2005). These processes in the unsaturated zone may affect constituent concentrations in some unconfined shallow wells, but the effects are likely to be highly variable from site to site and would be complicated by adding solutes from anthropogenic sources. 


\section{Uranium}

Uranium concentrations in ground water are of concern in the High Plains aquifer of Nebraska, as values above the U.S. EPA MCL of $30 \mu \mathrm{g} / \mathrm{L}$ for drinking water have been detected at several locations (Snow and Spalding, 1994). Uranium concentrations in the unconfined shallow urban and agricultural wells in the TANC local-scale study area ranged from 0.22 to $40 \mu \mathrm{g} / \mathrm{L}$ and were generally greater than concentrations in confined unmixed wells (fig. 21A). Uranium has several oxidation states but is only soluble in the most oxidized +6 state (Langmuir, 1997; Kraemer and Genereux, 1998). Uranium will form the soluble uranyl cation $\left(\mathrm{UO}_{2}{ }^{2+}\right)$ in the $\mathrm{pH}$ range of 6 to 9 typical of ground water. As conditions become more reducing, uranium is reduced to the +5 and +4 states, and is removed from solution as precipitating insoluble uranium minerals or by sorbing to sediment surfaces. Consequently, uranium concentrations were expected to be strongly related to the redox conditions of the aquifer. Uranium concentrations in unconfined shallow urban and agricultural wells that were oxic were 1.5 to $40 \mu \mathrm{g} / \mathrm{L}$; concentrations in the wells that were reducing were lower, ranging from 0.22 to $4.24 \mu \mathrm{g} / \mathrm{L}$ (tables 13 and 21 [see back of report]). The general decrease in uranium concentrations with increasing depth (fig. 21A), apart from relatively high concentrations in confined mixed wells discussed later in this section, primary reflected the change from oxic to reducing conditions with increasing depth (fig. 8). However, the wide range of uranium concentrations in unconfined shallow urban and agricultural wells and the relatively high concentrations of uranium in confined mixed wells suggest that controls on uranium concentrations were more complex than a simple dependence on redox conditions. The mechanisms influencing uranium concentrations in unconfined shallow urban and agricultural wells and confined mixed wells were different and are discussed separately below.

The distribution of uranium in unconfined shallow urban and agricultural wells was likely linked to the distribution of calcium and bicarbonate. For unconfined shallow urban and agricultural wells, concentrations of uranium were correlated with bicarbonate $(\rho=0.70, p=0.004$ [fig. 22A] ) and calcium $(\rho=0.77, p=0.002$ [fig. 22E]). Uranium in the +6 state forms aqueous complexes with carbonate species and calcium that reduce adsorption of uranium to sediments (Langmuir, 1997; Curtis and others, 2006). Calculations of uranium speciation with PHREEQC using a modified thermodynamic database compiled by Lawrence Livermore National Laboratory indicated that the most abundant uranium species present was a calcium-uranyl-carbonate complex $\left(\mathrm{Ca}_{2} \mathrm{UO}_{2}\left(\mathrm{CO}_{3}\right)_{3}{ }^{0}\right)$ (Bryant R. Jurgens, U.S. Geological Survey, written commun., July 29, 2006). This complex accounted for more than $90 \%$ of uranium species in all samples except one; the exception was FP3-33, having $\mathrm{pH}$ of 5.9, where calcium-uranyl-carbonate complexes accounted for about $68 \%$ of uranium species.

In unconfined shallow urban and agricultural wells, uranium concentrations were largest where the depth to water exceeded about $7 \mathrm{~m}$. Wells with depth to water of less than about $7 \mathrm{~m}$ had relatively low DO, pH, (fig. 10) and bicarbonate (figs. 20A), likely because of the effects of oxidation on soil organic matter; these wells had low concentrations of uranium also. Wells with depth to water greater than about $7 \mathrm{~m}$ generally had $\mathrm{pH}$ between 6.5 and 7.0, DO between 3 and $8.5 \mathrm{mg} / \mathrm{L}$, bicarbonate concentrations $\geq 350 \mathrm{mg} / \mathrm{L}$, and uranium concentrations $\geq 5 \mu \mathrm{g} / \mathrm{L}$.

Uranium concentrations varied considerably over a range from 5 to $40 \mu \mathrm{g} / \mathrm{L}$ in unconfined shallow urban and agricultural wells having depth to water $\geq 7 \mathrm{~m}, \mathrm{DO} \geq 3 \mathrm{mg} / \mathrm{L}$, and $\mathrm{pH} \geq 6.6$; hereinafter, these wells are referred to as high U unconfined shallow wells (FP1-63, OFPN-88, UWT3-34, UWT4-85, AWT1-83, AWT2-71, AWT3-73, FP4-28). In these high $U$ unconfined shallow wells, uranium was not correlated with bicarbonate $(\rho=-0.14 ; p=0.66$ [ fig. 22A] $)$, suggesting that once bicarbonate concentrations were above a threshold, they did not further affect uranium concentrations. In these high $U$ unconfined shallow wells, uranium was correlated with chloride $(\rho=0.92 ; p=0.004)$, potassium $(\rho=0.89 ; p=0.005)$, calcium $(\rho=0.84 ; p=0.008), \delta^{15} \mathrm{~N}$-nitrate $(\rho=0.79$; $p=0.039)$ and orthophosphate $(\rho=0.72 ; p=0.023)$ (fig. 22B-E), which were described earlier as being indicators of septic-system or wastewater influence.

The mechanism producing higher uranium concentrations in unconfined shallow urban and agricultural wells affected by septic-system leakage may have been enhanced solubility of uranium because of formation of complexes with dissolved calcium and bicarbonate in ground water affected by septic systems. Uranium can form complexes with orthophosphate that increase solubility and decrease adsorption of uranium to sediments (Sandino and Bruno, 1992). However, results of PHREEQC speciation calculations show that uranium-phosphate complexes in high $U$ unconfined shallow wells were insignificant because of the relatively low concentrations of orthophosphate compared with bicarbonate (Bryant R. Jurgens, U.S. Geological Survey, written commun., July 29, 2006). The correlation of calcium and uranium in high $U$ unconfined shallow wells was consistent with higher uranium $\left(\mathrm{Ca}_{2} \mathrm{UO}_{2}\left(\mathrm{CO}_{3}\right)_{3}{ }^{0}\right)$ concentrations in wells significantly affected by septic-system drainage caused by calcite dissolution in response to increased acidity associated with the septic-system drainage. 

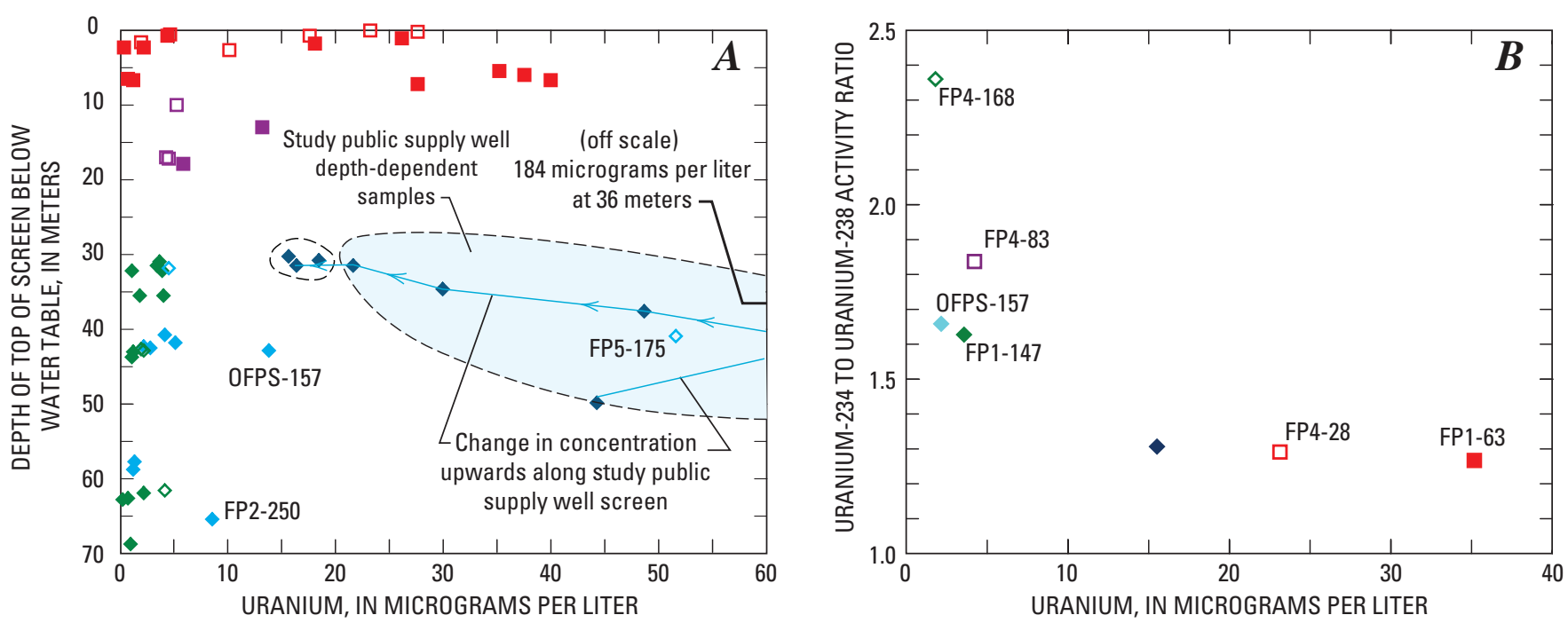

\section{EXPLANATION}

Unconfined wells
Urban shallow
Urban deep
Agricultural
shallow
Agricultural
deep

Confined wells
Urban unmixed
Urban mixed
- Study public supply well (Study PSW)
$\diamond$ Agricultural unmixed
$\diamond \begin{aligned} & \text { Agricultural } \\ & \text { mixed }\end{aligned}$

Figure 21. Relation of uranium to $A$. depth below water table and $B$. uranium isotope ratios for samples collected from the local-scale TANC study area in York, Nebraska.

Anthropogenic sources of uranium, such as phosphate fertilizers, were considered to be unlikely. Although correlations of uranium and orthophosphate have been sited as evidence to associate uranium with phosphorus fertilizers (Snow and Spalding, 1994), it was unlikely that orthophosphate concentrations in ground water in the localscale TANC study area were related to phosphorus fertilizer. The association of elevated orthophosphate with $\delta^{15} \mathrm{~N}$-nitrate values greater than 8 per mil and elevated chloride concentrations suggested that the orthophosphate was associated with ground water affected by a septic-system source. Other sources of phosphorus to ground water were considered to be minor (see "Nutrients"). Concentrations of chloride and orthophosphate were relatively low in unconfined shallow agricultural wells, suggesting that phosphorus and potash fertilizers, applied to agricultural crops in small amounts in the local-scale TANC study area, did not result in elevated concentrations in ground water.

Concentrations of uranium in some confined mixed wells were larger than would be expected from conservative mixing of water from the unconfined aquifer with water from confined unmixed wells, implying that there was an additional source of uranium to confined mixed wells. A plot of chloride versus uranium concentrations shows that depth-dependent samples from the study PSW and FP5-175 had uranium concentrations greater than those in the high $U$ unconfined shallow wells (fig. 22B); thus, the concentrations of uranium of 21 to $184 \mu \mathrm{g} / \mathrm{L}$ in the study PSW and FP5-175 could not have been generated from conservative mixing of water from the unconfined aquifer and confined unmixed wells. Welch and Lico (1998) used a similar approach to identify subsurface sources of uranium and arsenic in the Carson Desert in Nevada. Samples from the study PSW and FP5-175 that had concentrations of uranium $\geq 10 \mu \mathrm{g} / \mathrm{L}$ also had iron concentrations $\geq 100 \mu \mathrm{g} / \mathrm{L}$, consistent with iron-reducing conditions (fig. 22F). Confined mixed wells in the upper confined aquifer without iron-reducing conditions (OFPS-157, FP3-162; fig. 22F) did not have uranium concentrations larger than could be caused by mixing of water from the unconfined aquifer with water from confined unmixed wells. Conversely, confined mixed wells in the lower confined lenses (FP3-218, FP2-250) had iron-reducing conditions but did not have concentrations of uranium larger than could be caused by possible from mixing with water from the unconfined aquifer. These observations indicate that elevated uranium concentrations were in the upper confined aquifer where waters from the unconfined aquifer were mixing with water from the upper confined aquifer (represented by confined unmixed wells) under iron-reducing conditions. 

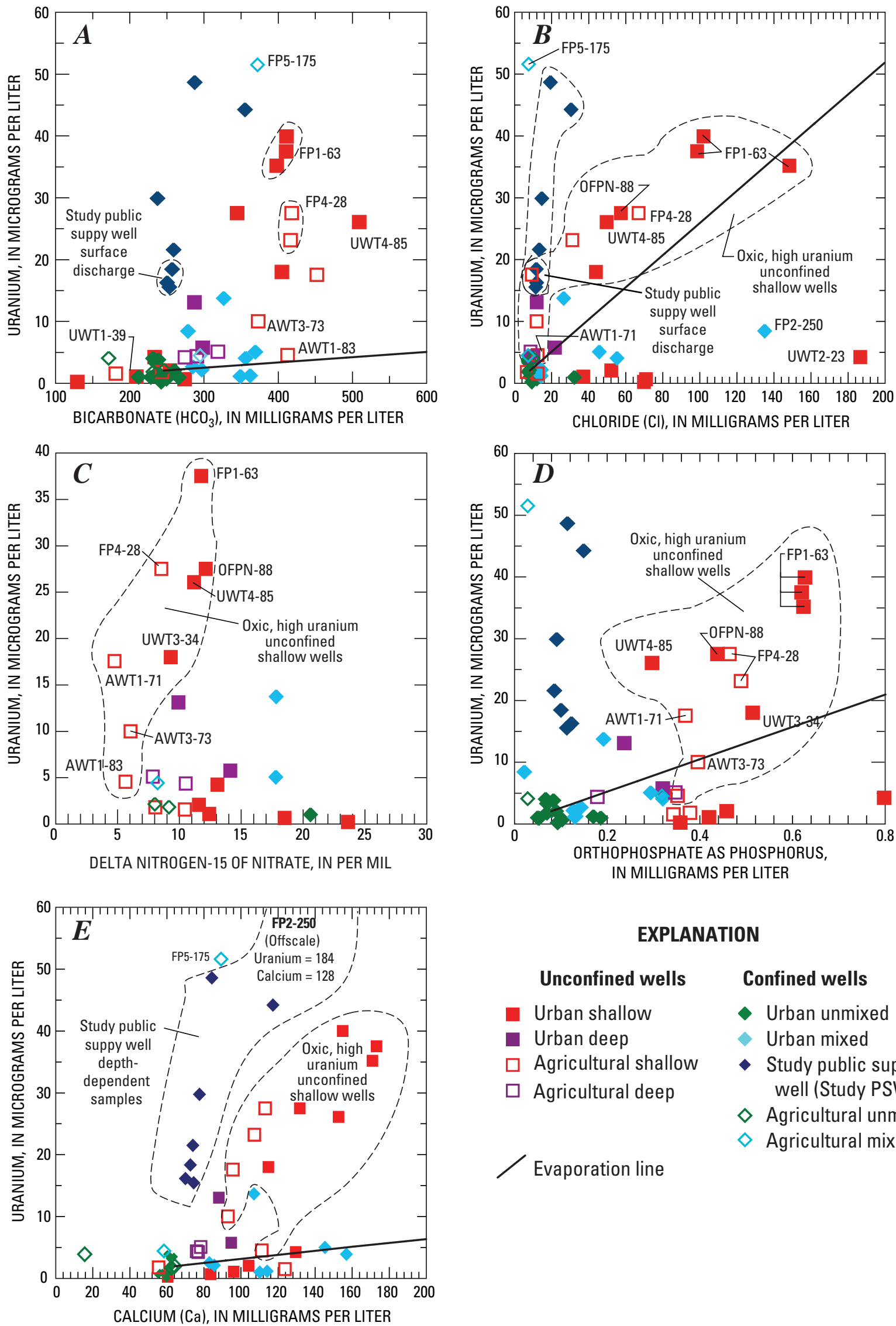

\section{EXPLANATION}

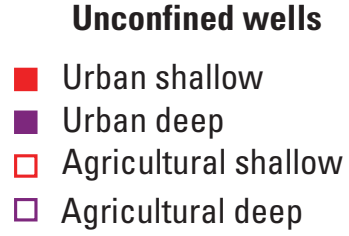

Evaporation line

\section{Confined wells \\ $\checkmark$ Urban unmixed \\ $\checkmark$ Urban mixed \\ - Study public supply well (Study PSW) \\ $\diamond$ Agricultural unmixed \\ $\diamond$ Agricultural mixed}

Figure 22. Relation of concentrations of uranium to $A$. bicarbonate, $B$. chloride, $C$. $\delta^{15} \mathrm{~N}$-nitrate, $D$. orthophosphate, $E$. calcium, and $F$. iron samples from the local-scale TANC study near York, Nebraska. 


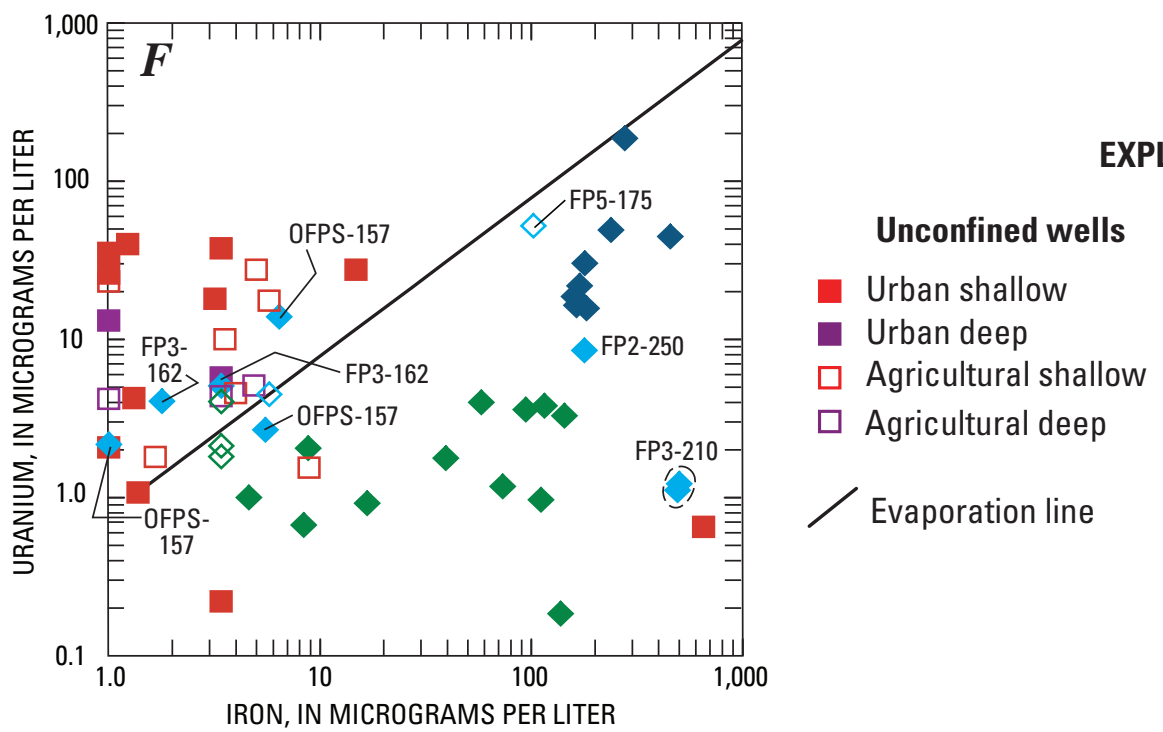

EXPLANATION

Figure 22. Continued.

Interaction of oxic well-bore leakage water from the unconfined aquifer with the reducing upper confined aquifer has the potential to mobilize uranium through redox reactions. The specific mechanism producing high uranium concentrations under these conditions was not confirmed with available data and analyses. However, a hypothesis for a mechanism is described below.

Elevated uranium concentrations in confined mixed wells with iron-reducing conditions could result from release of uranium during reduction (dissolution) of iron oxyhydroxides on colloids that moved down well bores from the unconfined aquifer into the reducing upper confined aquifer. Colloids are suspended particles typically $<1$ micrometer in diameter consisting of organic or inorganic particles, microorganisms, metal oxides, carbonates, or clay minerals (van der Lee and others, 1992). Colloids can be widespread (Kim, 1994) and can enhance transport of non-soluble phases like iron oxides (Puls and Powell, 1992) and associated adsorbed trace elements like uranium (van der Lee and others, 1992; Artinger and others, 2002; Missana and others, 2004), radionuclides (Kersting and others, 1999), and metals (Sanudo-Wilhelmy and others, 2002) under some circumstances. Laboratory column and batch reaction studies have indicated that uranium migration, especially under reducing conditions, can be substantially increased by associating uranium with colloids (Artinger and others, 2002; Missana and others, 2004). Field studies on the effect of colloidal transport on uranium are lacking, but long travel distances of radionuclides through aquifers near nuclear test sites have been attributed to colloid-driven transport (Kersting and others, 1999). Despite increasing research into the importance of colloidal transport on trace element transport (Sanudo-Wilhelmy and others, 2002), colloidal transport is not well understood. For colloidal transport of uranium to be a mechanism facilitating high uranium concentrations in confined mixed waters in the local-scale TANC study area, colloids must be present, mobile, stable, and able to adsorb the trace elements of interest irreversibly (Missana and others, 2004) in the source area-in this case, uranium in the shallow unconfined aquifer. If colloids have compositions similar to those of the core samples from the unsaturated zone and the unconfined aquifer, there would be abundant iron oxides, with associated uranium and arsenic (table 9). These colloids could move through the unconfined aquifer without losing their relatively high sorbed uranium concentrations (irreversible sorption) and flow down multi-layer well bores into the upper confined aquifer, where iron oxides on colloids would come in contact with iron-reducing conditions. The organic carbon electron donor necessary to allow iron-reduction (Welch and Lico, 1998) could be supplied by well-bore leakage water or solidphase organic carbon (table 9) present in colloidal phases. Unconfined shallow urban and agricultural wells and confined mixed wells had DOC values of 1 to $4 \mathrm{mg} / \mathrm{L}$ compared with the values 0.3 to $0.8 \mathrm{mg} / \mathrm{L}$ in most confined unmixed wells. If iron reduction was initiated under these favorable conditions, iron oxides on colloids would dissolve, releasing sorbed uranium. The uranium could then form complexes with abundant calcium and bicarbonate in the confined mixed waters to form calcium-uranyl-carbonate complexes. Bicarbonate and calcium were generally present in higher concentrations in confined mixed than in confined unmixed wells (fig. 22A,E). PHREEQC speciation calculations indicate that $99 \%$ of the uranium would be in the form of $\mathrm{Ca}_{2} \mathrm{UO}_{2}\left(\mathrm{CO}_{3}\right)_{3}{ }^{0}$ in depth-dependent samples from the study PSW and FP5-175 (Bryant R. Jurgens, U.S. Geological Survey, written commun., July 29, 2006). Complexed uranium has greater solubility, potentially allowing uranium to persist in solution even under reducing conditions where it typically would precipitate or be adsorbed to sediments. Colloid distribution was not measured in this study. Therefore, 
reporting on the effect of colloidal transport on the distribution of uranium in this study was speculative. Although the proposed mechanism required many assumptions that have not been verified, the presence of high concentrations of uranium in mixed waters in the upper confined aquifer with ironreducing conditions is consistent with the essential constraints for colloid-enhance uranium transport.

Another mechanism for the elevated uranium concentrations in confined mixed waters with iron-reducing conditions considered was uranium mobilization from the upper confining unit. A study in the Platte River valley of Nebraska, (Spalding and Druliner, 1981) suggested that aeration from pumping resulted in oxidation of previously immobilized uranium from reduced clays. However, the data were not consistent with this mechanism being the source of elevated uranium in the local-scale TANC study area. Although measurable uranium was in core samples in the upper confining unit (table 9), oxidation of reducing sediments containing uranium should result in the highest uranium concentrations associated with relatively more oxidized waters in the upper confined aquifer. Moreover, high uranium concentrations in unconfined deep wells would be expected in oxic waters at the interface of the unconfined aquifer and the upper confining aquifer. Neither of these conditions was observed. Rather, the highest uranium concentrations were in confined mixed wells with iron-reducing conditions, and uranium concentrations near the upper confining unit (FP1-147, FP3-130) were <4 $\mu \mathrm{g} / \mathrm{L}$.

Uranium isotope data $\left({ }^{234} \mathrm{U},{ }^{238} \mathrm{U}\right)$ supported the interpretation that relatively high uranium concentrations in the unconfined shallow urban and agricultural wells and the study PSW result from dissolution of uranium-bearing sediments in the unconfined aquifer. Uranium-isotope samples were collected from seven wells in March-April 2005. When uranium is leached or dissolved from a host rock, the uranium added to the water usually has ${ }^{234} \mathrm{U} /{ }^{238} \mathrm{U}$ of 1.2 to 1.5 , close to or slightly greater than typical host rock values of about 1.0 (Osmond and Cowart, 2000). Such dissolution of uranium-bearing solid phases primarily occurs in oxic waters. In contrast, uranium mobilized from a host rock by alpha recoil during radioactive decay of ${ }^{238} \mathrm{U}$ typically has ${ }^{234} \mathrm{U} /{ }^{238} \mathrm{U}$ of greater than 1.5 because ${ }^{234} \mathrm{U}$ is preferentially mobilized (Dabous and Osmond, 2001); the preferential mobilization can occur because the ${ }^{234} \mathrm{U}$ is propelled across the solidaqueous phase boundary during recoil or because the crystal lattice is weakened by recoil and the resulting ${ }^{234} \mathrm{U}$ is more vulnerable to leaching than undecayed ${ }^{238} \mathrm{U}$ (Osmond and Cowart, 2000). In reducing aquifers, uranium mobilization is typically dominated by alpha recoil (Osmond and Cowart, 2000). As water moves from oxic to reducing zones in an aquifer, the ${ }^{234} \mathrm{U} /{ }^{238} \mathrm{U}$ remains relatively unchanged even as uranium concentrations decrease; therefore, uranium isotope values can be good tracers of the source of the uranium (Dabous and Osmond, 2001). Samples from unconfined shallow urban (FP1-63) and agricultural (FP4-28) wells had uranium concentrations $\geq 20 \mu \mathrm{g} / \mathrm{L}$ and relatively low ${ }^{234} \mathrm{U} /{ }^{238} \mathrm{U}$ of about 1.2 to 1.3 (fig. $21 \mathrm{~B}$ ), consistent with values expected from dissolution of uranium from a solid-phase source. Confined unmixed wells FP1-147 and FP4-168 had uranium concentrations $<3 \mu \mathrm{g} / \mathrm{L}$ and a ${ }^{234} \mathrm{U} /{ }^{238} \mathrm{U}$ of about 1.6 to 2.4 , consistent with values for confined aquifers in many other locations (Dabous and Osmond, 2001). The relatively high ${ }^{234} \mathrm{U} /{ }^{238} \mathrm{U}$ were consistent with ${ }^{234} \mathrm{U}$ entering the aqueous phase as a result of alpha recoil processes rather than dissolution of uranium-bearing sediments in the oxic unconfined aquifer. Confined mixed well OFPS-157, which during earlier sampling periods showed greater evidence of mixing with water from the unconfined aquifer, showed only slight evidence of mixing by April 2005. The relatively high ${ }^{234} \mathrm{U} /{ }^{238} \mathrm{U}$ for OFPS-157 in April 2005 was similar to that for FP1-147 and was probably representative of confined unmixed wells. Unconfined deep well FP4-83, screened at the bottom of the unconfined aquifer, was slightly oxic, but the ${ }^{234} \mathrm{U} /{ }^{238} \mathrm{U}$ of 1.85 suggests that less dissolution of uranium occurs than in shallower parts of the unconfined aquifer. A sample of the surface discharge of the study PSW had a uranium concentration of about $16 \mu \mathrm{g} / \mathrm{L}$ and a ${ }^{234} \mathrm{U} /{ }^{238} \mathrm{U}$ of 1.35 , nearly the same ${ }^{234} \mathrm{U} / 238 \mathrm{U}$ as unconfined shallow urban (FP1-63) and agricultural (FP4-28) wells. The similarity of the ${ }^{234} \mathrm{U} /{ }^{238} \mathrm{U}$ for unconfined shallow wells and the study PSW was consistent with uranium in the study PSW being derived from leaching of uranium from the shallow unconfined aquifer. However, as described earlier, uranium concentrations in depth-dependent samples from the lower part of the screen of the study PSW were higher than in the unconfined shallow urban and agricultural wells; this result implies that the mixed waters in the upper confined aquifer were enriched with uranium. The ${ }^{234} \mathrm{U} /{ }^{238} \mathrm{U}$ in the study PSW, implying dissolved uranium derived from leaching, was also consistent with leaching of uranium from sediments or colloids dissolving during mixing of well-bore leakage and iron-reducing confined waters. 


\section{Arsenic}

Arsenic concentrations ranged from about 1.6 to $9.4 \mu \mathrm{g} / \mathrm{L}$; the median was $6.0 \mu \mathrm{g} / \mathrm{L}$, less than the USEPA MCL, $10 \mu \mathrm{g} / \mathrm{L}$ (fig. 23A; table 21). Arsenic concentrations did not vary systematically with depth, and were about the same in the generally oxic unconfined aquifer and the reducing confined aquifers. However, the speciation of arsenic differed between aquifers. In the unconfined aquifer, arsenate was the primary arsenic species; in most confined unmixed wells, arsenite was the primary arsenic species (figs. 23B-D). This distribution of arsenic species was expected, since the more oxidized arsenate is typically stable under oxic conditions and the more reduced arsenite is stable under reducing conditions (Welch and others, 2000). However, there were exceptions to the expected distribution of arsenic species on the basis of redox condition. Most confined mixed wells and the study PSW, showing evidence of mixing with unconfined waters, had more arsenate than arsenite (fig. 23D), despite having nitrate- to iron-reducing conditions. In addition, unconfined shallow urban wells with nitrate- to sulfatereducing conditions (UWT1-53, UWT2-23, FP3-33, OFPS-38; table 21) and a confined urban unmixed well (FP1-247) having manganese to sulfate reducing conditions, also had more arsenate than arsenite. Disequilibrium of arsenic speciation with redox conditions are not uncommon (Welch and others, 2000). However, these exceptions may indicate that there are factors other than redox condition influencing arsenic distribution, most likely differences in arsenic source materials. The relative uniformity of total arsenic concentrations, in spite of the different redox conditions in different aquifers, implies multiple mechanisms of arsenic mobilization and transport.

In the unconfined aquifer, mobilization of arsenic may be facilitated by two processes. First, competitive sorption processes - arsenic adsorbed onto iron- or manganese-oxide coatings on fluvial sands and gravels could be displaced by more strongly sorbing orthophosphate derived from septic systems under oxic conditions. Second, release of arsenic may occur during reductive dissolution of iron- and manganeseoxides under reducing conditions near Beaver Creek.

Septic-system drainage may facilitate higher arsenic concentrations in unconfined shallow urban wells. Arsenic and orthophosphate $(\rho=0.79 ; p=0.001$ [fig. 24A] $)$ and arsenic and chloride ( $\rho=0.55 ; p=0.024$ [fig. 24B] $)$ were correlated in unconfined shallow urban and agricultural wells. Competition between orthophosphate and arsenic for sorption sites on oxyhydroxide coatings on sediments can result in desorption of arsenic when orthophosphate is present (Welch and Stollenwerk, 2003; Kent and Fox, 2004). Among oxic unconfined shallow urban and agricultural wells, UWT2-23 and FP1-63 had the highest arsenic concentrations of 5 to $8 \mu \mathrm{g} / \mathrm{L}$ and orthophosphate concentrations of 0.6 to $0.8 \mathrm{mg} / \mathrm{L}$, and may have been influenced by septic systems on the basis of elevated chloride, potassium, orthophosphate, and $\delta^{15} \mathrm{~N}$ nitrate. Concentrations of orthophosphate in other unconfined shallow urban and agricultural wells ranged from 0.29 to $0.51 \mathrm{mg} / \mathrm{L}$; over this relatively narrow range of orthophosphate concentrations, arsenic concentrations increased from about 3 to $6 \mu \mathrm{g} / \mathrm{L}$ (fig. 24A), implying that arsenic concentrations may be sensitive to small changes in orthophosphate concentrations over this range. Correlation of concentrations of arsenic, chloride, and orthophosphate in unconfined shallow urban and agricultural wells suggests that arsenic is not related to historical application of agricultural pesticides containing arsenic (Welch and Stollenwerk, 2003).

Arsenic concentrations in the unconfined aquifer were greatest ( $8.8 \mu \mathrm{g} / \mathrm{L})$ at well OFPS-38 (fig. 24A). Because the redox conditions at this well encompass iron-reducing conditions (table 13), reductive dissolution of iron oxides containing arsenic could occur. This is a common mobilization mechanism for arsenic (Welch and others, 2000; Smedley and Kinniburgh, 2002). Solid-phase analyses indicated arsenic was present in cores collected from the unconfined aquifer (table 9). Well OFPS-38 has substantially higher arsenic concentrations than other unconfined shallow urban wells with similar chloride concentrations (fig. 24B), suggesting that the mechanism of arsenic mobilization at OFPS-38 may differ from that in other unconfined shallow urban wells. Because the distribution of organic-rich stream sediments along Beaver Creek (adjacent to OFPS-38) is limited, this mechanism for producing higher than typical arsenic concentrations in unconfined shallow urban wells may only exist near stream sediments.

In confined unmixed wells, arsenite was the dominant arsenic species present (fig. 23). The glaciofluvial sediments in the confining units and confined aquifers were deposited tens of thousands to two million years ago. When these sediments were subsequently buried and redox conditions became manganese- to sulfate-reducing, iron and manganese oxides on the sediments, in the presence of organic carbon from surficial processes, probably underwent reductive dissolution, releasing arsenate with iron and manganese (Welch and Lico, 1998). Eventually, the arsenate likely was primarily reduced to arsenite, and a quasi-equilibrium developed in the confined aquifer, with relatively slow-moving ground water during predevelopment conditions. Sorption and solubility limited arsenic concentrations in solution. Arsenite concentrations in confined unmixed waters were probably primarily influenced by these sediment/water interactions in relatively old ground water in the confined aquifer. 

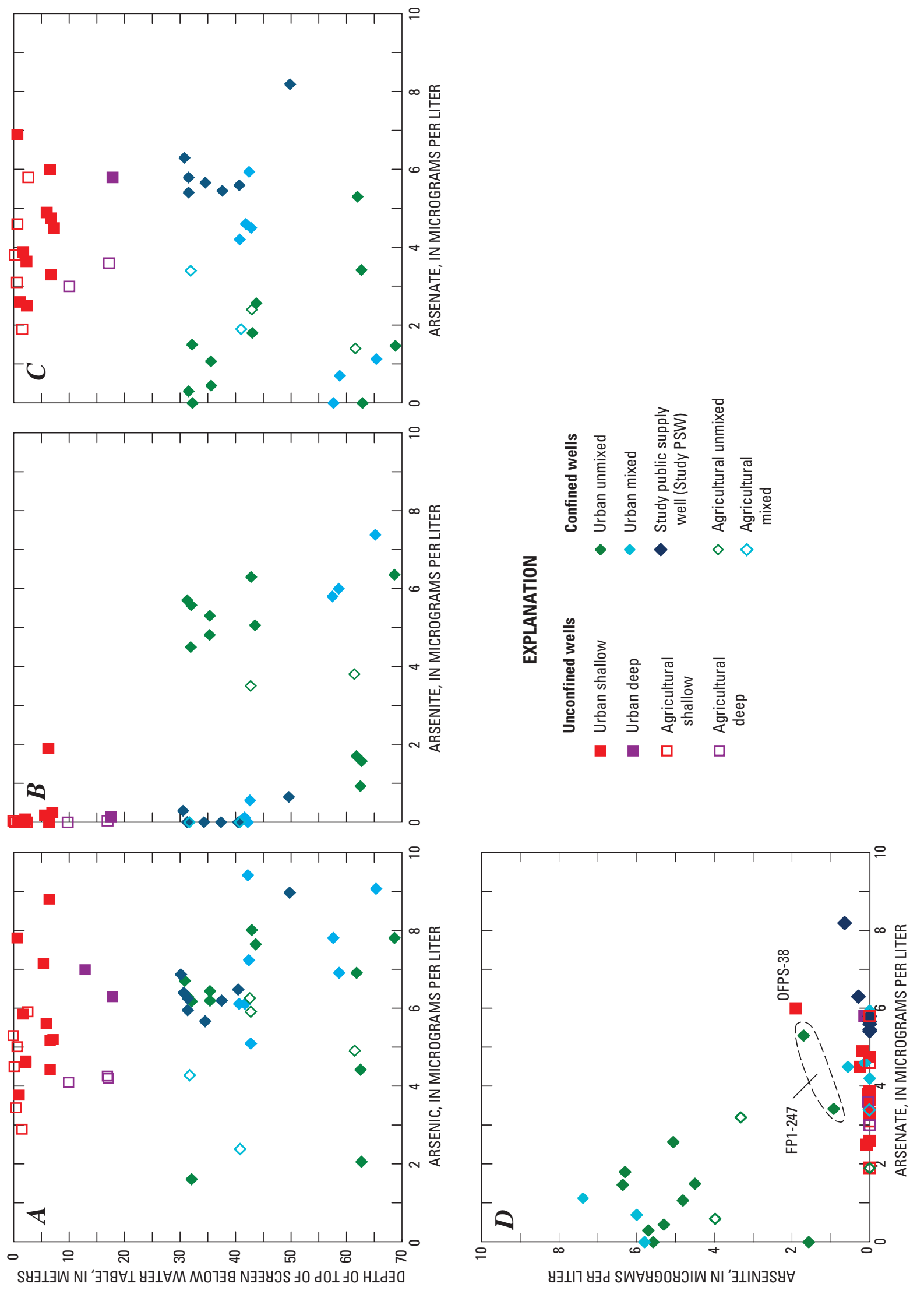

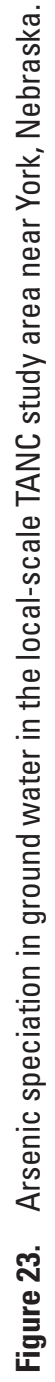



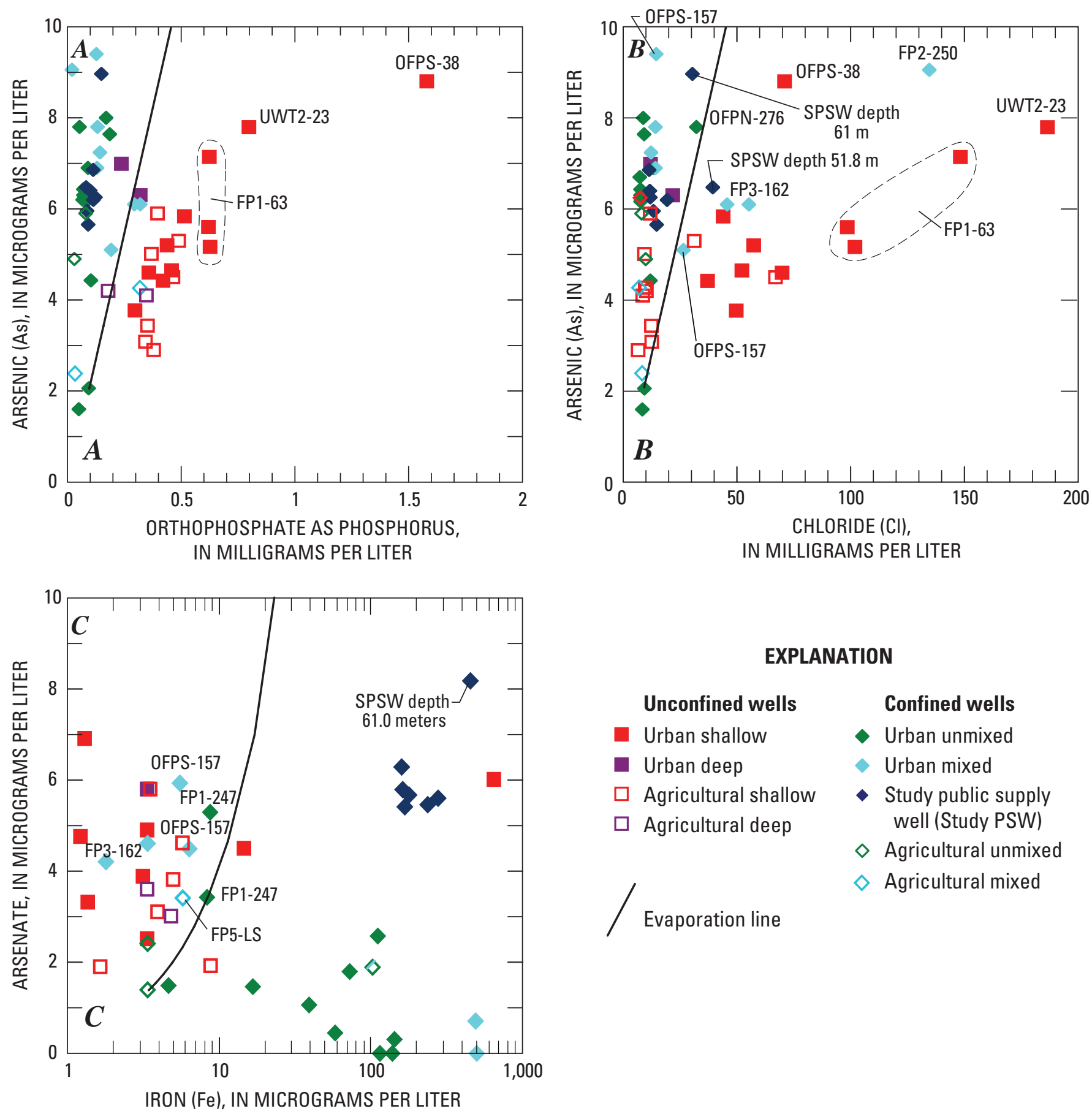

\section{EXPLANATION}

$\begin{array}{ll}\text { Unconfined wells } & \text { Confined wells } \\ \text { Urban shallow } & \diamond \text { Urban unmixed } \\ \text { Urban deep } & \text { Urban mixed } \\ \square \text { Agricultural shallow } & \diamond \text { Study public supply } \\ \square \text { Agricultural deep } & \text { well (Study PSW) } \\ & \diamond \text { Agricultural unmixed } \\ & \diamond \text { Agricultural mixed }\end{array}$

Figure 24. Arsenic and $A$. chloride and $B$. orthophosphate, and $C$. arsenate and iron concentrations in ground water in the local-scale TANC study near York, Nebraska.

Most confined mixed wells have arsenic concentrations similar to that expected from mixing of arsenic concentrations in unconfined shallow urban and agricultural wells and confined unmixed wells. In confined mixed wells in the upper confined aquifer (the study PSW, FP3-162, OFPS-157, FP5-175, FP5-LS), arsenic is predominantly arsenate (table 21). On a plot of chloride versus arsenic (fig. 24B), some confined mixed wells (FP3-162 [2 samples] and
OFPS-157 [1 sample]) and depth-dependent samples from the study PSW (depths 51.8 and $48.8 \mathrm{~m}$,) plot between unconfined shallow urban wells and confined unmixed wells such that they could indicate mixing of these waters. Mixing fractions were not calculated, as arsenate is not necessarily conservative and the unconfined and confined end-members concentrations are not well-defined. Orthophosphate concentrations were $<0.3 \mathrm{mg} / \mathrm{L}$ in confined mixed wells and $<0.2 \mathrm{mg} / \mathrm{L}$ in confined 
unmixed wells (fig. 24A), indicating that it is unlikely that interactions with orthophosphate influenced arsenic concentrations in the confined aquifer as apparently occurred in the unconfined shallow urban wells.

Interaction of relatively oxidizing well-bore leakage water with relatively reducing confined unmixed water has the potential to mobilize arsenate, as was hypothesized for uranium. The arsenic concentration in the depth-dependent sample collected from the bottom of the screen (the study PSW $61.0 \mathrm{~m}$ bls sample) was $9 \mu \mathrm{g} / \mathrm{L}$, primarily arsenate (fig. 24B). This concentration is greater than was expected from conservative mixing of water from unconfined shallow urban wells and water from confined unmixed wells (fig. 24B). Concentrations of arsenate and iron are significantly correlated $(\rho=0.539, p=0.044)$ in arsenate-dominated confined mixed (OFPS-157, FP3-162, FP5-LS) wells and samples from the study PSW (fig. 24C). Release of arsenate from reduction of iron oxyhydroxides on colloids in water from the unconfined aquifer moving down well bores into the confined aquifer may be consistent with elevated arsenate in iron reducing confined mixed wells (see "Uranium" for a more detailed description of the hypothesized mechanism). In laboratory batch and column studies, Puls and Powell (1992) found that iron-oxide colloids were highly mobile and that the rate of colloid-associated arsenate transport was more than 20 times greater than that of dissolved arsenate. However, field studies describing the role of colloidal transport of arsenate were not identified and the importance of colloidal transport for arsenate transport is speculative. Variations in arsenate concentrations were much more subtle than in uranium concentrations, and variations in arsenate concentrations in confined mixed wells and the study PSW may simply reflect mixing between unconfined aquifer and confined aquifer end-member waters that were not sampled.

The distribution of arsenate- or arsenite-dominance in the confined aquifer did not always correspond to classifications into confined mixed and confined unmixed wells on the basis of stable isotopic, major element, and VOC signatures. For example, arsenite was the dominant arsenic species in confined mixed wells from the lower confined lenses (FP2-250,

FP3-218; table 21). Arsenate was the dominant arsenic species in confined unmixed well FP1-247, from the lower confined lenses (fig. 23D). The deviation of arsenic speciation from that expected on the basis of stable isotopic and major element data may indicate that variable local sediment/water interactions influence arsenic concentrations and speciation more than other dissolved constituents.

\section{Depth-Dependent Sampling}

The results of flow measurements and sample collection from different depths in the study PSW under typical pumping conditions are presented in this section. The depth-dependent results for different constituents are discussed together in this section to determine the depths where water and solutes enter the study PSW.
Flow estimates indicated that 73 to $86 \%$ of the total flow of water, about $1,930 \mathrm{~L} / \mathrm{min}$, entering the study PSW screen came from the upper half of the screen, above $51.8 \mathrm{~m}$ bls (fig. 25A). Tracer pulse tests were done in two profiles with profile 1 consisting of measurements at 42.7, 45.7, 48.8, $51.8,54.9,57.9$, and $61.0 \mathrm{~m}$ bls, and profile 2 consisting of measurements at 44.2, 47.2, 50.3, 53.3, 56.4, and $59.4 \mathrm{~m}$ bls. Flow measurements determined using the tracer pulse method had uncertainties, particularly near the bottom part of the screen. Travel times from tracer pulse tests collected at $54.9 \mathrm{~m}$ bls or below varied considerably. For example, at $54.9 \mathrm{~m}$ bls, travel times in 6 tests varied from 172 to 181 seconds. This range in travel times resulted in flow estimates between 51.8 and $54.9 \mathrm{~m}$ bls ranging from 454 to $549 \mathrm{~L} / \mathrm{min}$, an uncertainty of about $20 \%$. Below $53.3 \mathrm{~m}$ bls, the flow measurements were not reproducible enough to be used quantitatively in mixing calculations described later in this section. Because most of the flow came from the upper half of the well screen, flow in the lower parts of the screen may have been more variable in response to subtle variations in well operation. Tracer pulse travel times were replicated within a few percent at $53.3 \mathrm{~m}$ bls or above. Several additional sources of uncertainty potentially affected the flow measurements. The tracer pulse method presumes piston movement of dye in the well bore. Dye could have been distributed non-uniformly in response to turbulence or non-vertical flow components in the well bore. Non-piston flow could have affected travel times for dye from the injection point to the fluorometer. The calculation assumes a constant screen and well diameter; variations in the actual diameter could have affected the velocity calculations. Because of the relatively moderate depth of the well $(<61 \mathrm{~m})$, stretching of the hose in the well was probably not a major factor in this study.

\section{Flow and Chemistry Profile Checks}

The depth-dependent chemistry data was used to check whether the depth-dependent flow estimates were consistent with reasonable solute concentrations in aquifer inflow. The concentration of a constituent in water that entered the well from the aquifer between sample-collection points can be calculated, assuming simple mixing within the well, according to equation 4 from Izbicki and others (1999, 2005b):

$$
\mathrm{C}_{\mathrm{a}}=\left[\mathrm{C}_{2} \mathrm{Q}_{2}-\mathrm{C}_{1} \mathrm{Q}_{1}\right] / \mathrm{Q}_{\mathrm{a}}
$$

where

$\mathrm{C}_{\mathrm{a}}$ and $\mathrm{Q}_{\mathrm{a}}$ are the constituent concentration and volumetric flux of water entering the well from the aquifer between sample-collection depths,

$\mathrm{C}_{1}$ and $\mathrm{Q}_{1}$ are the constituent concentration and the volumetric flux of water in the well at the deeper sample depth, and

$\mathrm{C}_{2}$ and $\mathrm{Q}_{2}$ are the constituent concentration and the volumetric flux of water in the well at the shallower sample depth. 

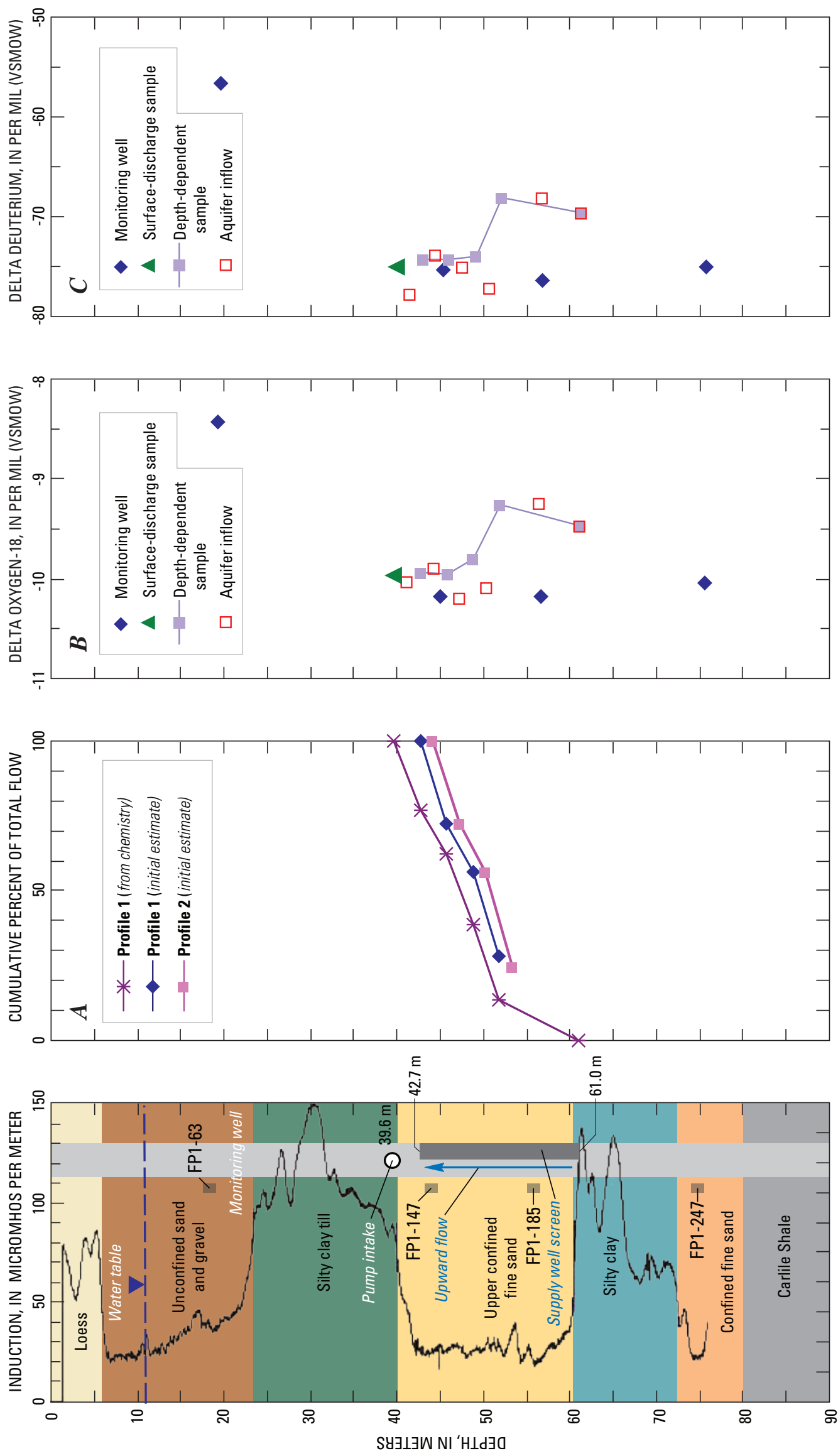

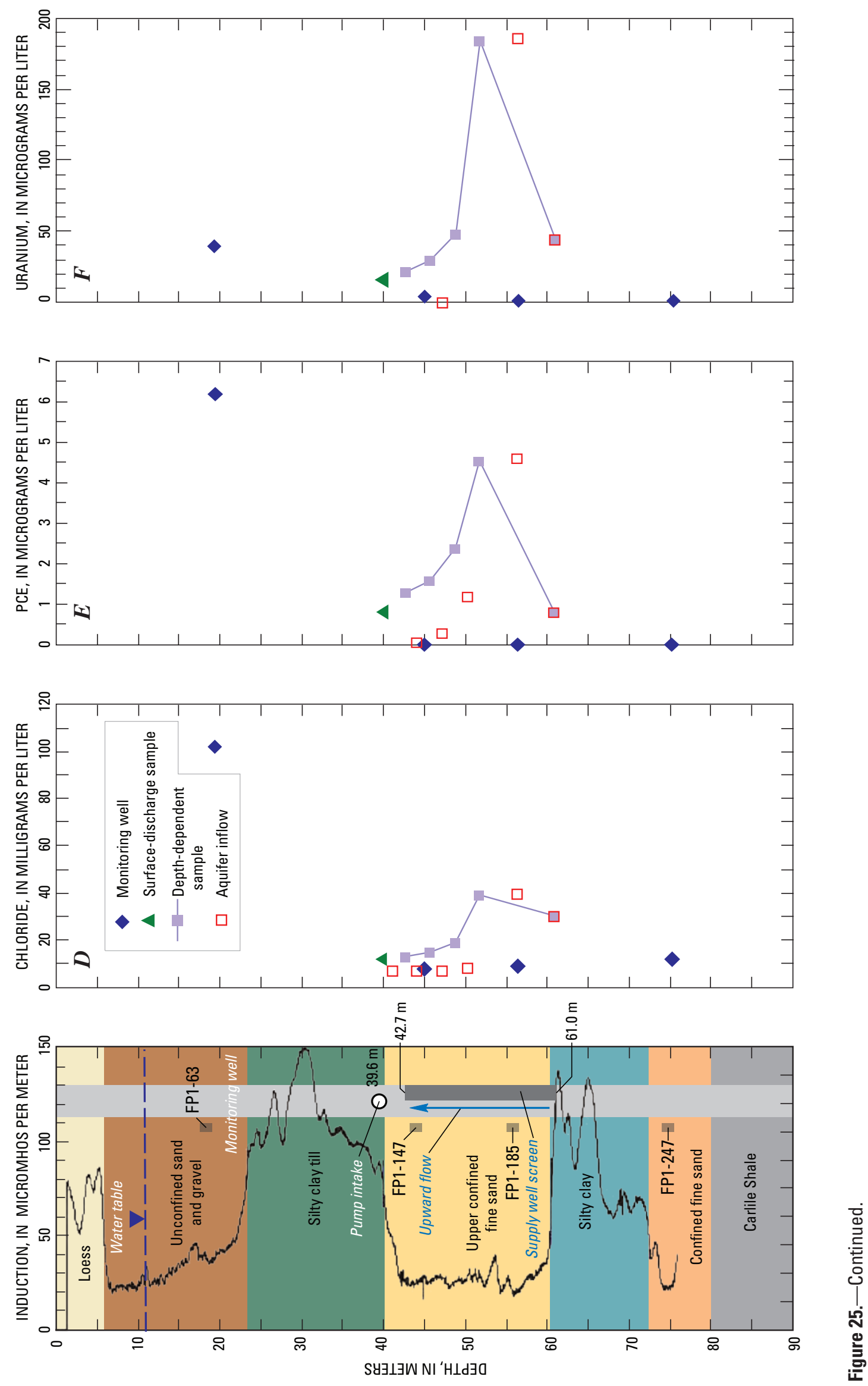

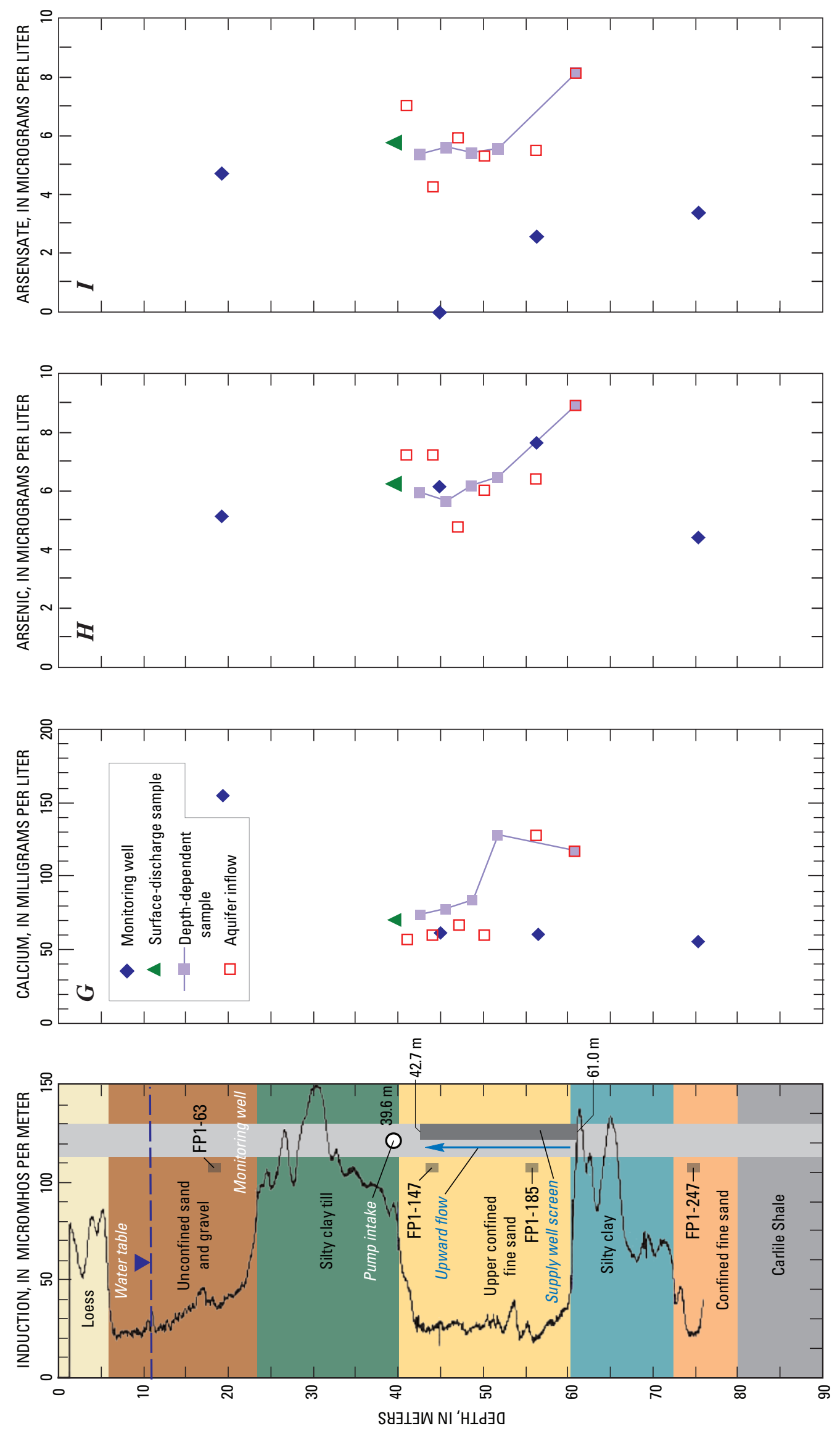
The concentration in the aquifer is calculated as a residual; the calculation assumes that the change in concentration or flow over the measurement interval must be larger than the measurement error.

Initial flow estimates calculated in the field from the tracer pulse tests in profile 1, which were collected at depths corresponding to depth-dependent sample collection, were used to calculate aquifer inflow concentrations. However, calculated inflow concentrations of many constituents were unreasonable (negative or unfeasibly small) in the intervals from 51.8 to $48.8 \mathrm{~m}$ bls, 48.8 to $45.7 \mathrm{~m}$ bls, and $42.7 \mathrm{~m}$ bls to the surface discharge. Concentrations measured in the surface discharge were assumed to represent those at the depth of the pump intake (39.6 m bls). All flow in the well was upward because the pump intake was located above the screen. Between 51.8 and $45.7 \mathrm{~m}$ bls, there was substantial inflow, yet concentrations of most analytes in depth-dependent samples decreased substantially (fig. 25C-G). The unreasonable calculated aquifer inflow concentrations implied that the initial estimates of inflows of water in the 51.8 to $45.7 \mathrm{~m}$ interval were unreasonably large or that mixing of water in the well bore was incomplete because of the large amount of water entering the well over relatively short $(3 \mathrm{~m})$ intervals. Between $42.7 \mathrm{~m}$ bls at the top of the screen and the surface discharge, concentrations decreased slightly while flow apparently changed very slightly (the initial field calculation of flow at the top of the screen was $1,824 \mathrm{~L} / \mathrm{min}$, close to $1,930 \mathrm{~L} / \mathrm{min}$, the approximate metered flow of the surface discharge). As a result, calculated concentrations in aquifer inflow between the top of the screen and the well intake were negative or unreasonably small. These results imply that the initial estimates of the change in flow between the top of the screen and the well intake were too small or that the mixing of water entering the well bore at the top of the screen was incomplete. In an attempt to reconcile these discrepancies, an alternative flow profile was estimated by re-examining the tracer pulse data and selecting the longest travel times for each of the upper intervals, which resulted in greater estimated flow in the upper part of the profile and improved estimated aquifer inflow concentrations; however, this approach did not eliminate most of the negative or unreasonable values.

For the purposes of constraining estimates of concentrations in aquifer inflow and to bound uncertainties in the well-bore flow profile, flow values were modified until aquifer inflow concentrations in the 51.8 to $45.7 \mathrm{~m}$ bls and $42.7 \mathrm{~m}$ bls to well intake intervals were reasonable for most constituents, particularly conservative constituents such as $\delta^{18} \mathrm{O}, \delta \mathrm{D}$, and chloride (fig. 25B-D). These adjusted flow values determined from chemical mixing were not unique but were constrained by maintaining flow at the pump intake within $5 \%$ of the metered flow of about $1,930 \mathrm{~L} / \mathrm{min}$ and by maintaining the flow profile as close to the original tracer pulse measurements as possible while calculating aquifer inflow concentrations that were reasonable compared with values for monitoring wells. The resulting estimated flow profile based on chemical concentrations is shown in figure
25A [Profile 1 (from chemistry)] and is not dramatically different from the flow profile estimated in the field from the tracer pulse measurements [Profile 1 (initial estimate)].

\section{Depth Intervals Contributing Solutes to the Study Public-Supply Well}

Most dissolved solutes entered the well in the bottom half of the screen, where a minority of flow enters the well. The maximum concentrations of most constituents in the depthdependent samples were from the middle of the screen (51.8 $\mathrm{m}$ bls [fig. 25B-G]). The second highest concentration in depth-dependent samples for most constituents was at the bottom of the screen $(61.0 \mathrm{~m})$. Consequently, the largest calculated concentrations in aquifer inflow were for the bottom half of the screen. Lower concentrations of constituents in the upper half of the screen indicated that water inflow in the upper part of the screen diluted constituent concentrations in water from the bottom half of the screen. These observations were true for diverse constituents, including $\delta^{18} \mathrm{O}, \delta \mathrm{D}$, chloride, PCE, uranium, and calcium (fig. 25B-G), representing similar patterns observed for most stable isotopes, major elements, VOCs, trace elements, and radiochemicals.

Values of conservative tracers $\delta^{18} \mathrm{O}, \delta \mathrm{D}$, and chloride were consistent with inflow to the bottom half of the screen below 51.8 m containing a substantial fraction of unconfined shallow urban water and inflow to the top half of the screen primarily representing confined unmixed waters (fig. 25B-D). Mixing calculations with $\delta^{18} \mathrm{O}$ and $\delta \mathrm{D}$ values suggest that the depth-dependent sample from the middle of the screen contained approximately 50\% unconfined shallow urban water (table 12; fig. 25B-C).

Minor amounts of water and solutes from the unconfined aquifer also may enter the study PSW near the top of the screen. There were minor shifts to slightly less negative $\delta^{18} \mathrm{O}$ and $\delta \mathrm{D}$ values in calculated aquifer inflow between 45.7 and $42.7 \mathrm{~m}$ bls (fig. 25B-C). Mixing calculations based on the calculated $\delta^{18} \mathrm{O}$ and $\delta \mathrm{D}$ values for this interval indicate 15 to $18 \%$ unconfined shallow urban and agricultural water. Calculated concentrations of PCE in aquifer inflow decreased upward above the middle of the screen at $51.8 \mathrm{~m}$ bls but were still greater than zero throughout the upper half of the screen (fig. 25E). A pesticide, acetochlor ESA, also was detected only in the depth-dependent sample at $42.7 \mathrm{~m}$ bls at the top of the screen (table 15; see "Pesticides"). Water from the unconfined aquifer may reach the upper parts of the study PSW screen in the confined aquifer as a result of drawdown around the well, which could induce relatively rapid flow of water through the confining unit in response to the larger downward hydraulic head gradient near the well than elsewhere. However, the amount of water from the unconfined aquifer entering the study PSW near the top of the screen was small relative to the amount of water from the unconfined aquifer entering the well along the bottom half of the screen. Moreover, the 
unconfined water entering at the top of the screen did not have elevated concentrations of solutes like that entering along the bottom part of the screen, as concentrations of chloride, PCE, uranium, and calcium decreased upward between the middle of the screen $(51.8 \mathrm{~m}$ bls $)$ and the surface discharge. These results are consistent with the interpretation that the primary mechanism permitting unconfined water to reach the bottom part of the study PSW is downward movement of unconfined water through multi-layer well bores upgradient of the study PSW and that downward movement of unconfined water through the upper confining unit near the well, possibly in response to very large drawdown induced head gradients, has a much smaller effect on study PSW water quality. These processes will be discussed further in "Water Sources and Pathways."

Concentrations of uranium in the three deepest depthdependent samples were $\geq 30 \mu \mathrm{g} / \mathrm{L}$ (the USEPA MCL for drinking water), but decreased to $17 \mu \mathrm{g} / \mathrm{L}$ in surface discharge as a result of dilution with aquifer inflow having low uranium in the upper part of the screen(fig. 25F). The uranium concentration, $184 \mu \mathrm{g} / \mathrm{L}$, measured in the $51.8 \mathrm{~m}$ bls depthdependent sample was more than 3 times greater than the next highest concentration measured in the study, including concentrations measured in the unconfined shallow urban wells. The uranium concentration of $44 \mu \mathrm{g} / \mathrm{L}$ in the lowermost depth-dependent sample indicated that uranium was present at the bottom of the well screen also. Even after adjusting the calculated flow profile to produce reasonable aquifer inflow concentration estimates for chloride and most other constituents, calculated concentrations of uranium in aquifer inflow above $51.8 \mathrm{~m}$ bls were negative. The unreasonable calculated uranium concentrations in aquifer inflow could either indicate that some uranium was lost because of reaction in the well bore or that the high concentrations of uranium entering the bottom part of the screen were incompletely mixed within the well bore. The latter is more likely. In spite of these uncertainties, the results indicate that uranium entering the bottom half of the screen appeared to account for all of the uranium entering the supply well.

Concentrations of calcium, described earlier as being correlated with uranium concentrations, also had maximum values at the mid-screen $51.8 \mathrm{~m}$ bls depth and the second highest values at the bottom of the screen (table 20). However, calculated aquifer inflow values above the middle of the screen were 57 to $67 \mathrm{mg} / \mathrm{L}$, reasonable values similar to those measured in samples from most confined unmixed wells, including those in the FP1 well nest adjacent to the supply well.

In contrast to profiles of most other constituents, depth-dependent profiles for arsenic and arsenate had maximum concentrations at the bottom of the screen and only moderate changes in concentrations upward through the well (fig. 25G-I). Most of the arsenic in the study PSW depthdependent and surface-discharge samples was arsenate. Only monitoring wells FP1-147 and FP1-185 had greater arsenite than arsenate concentrations. Concentrations of arsenate were not greatest at the middle of the screen, like other constituents, indicating that arsenate (and arsenic) distributions did not follow the distribution of unconfined water as closely as most other solutes.

For most constituents, concentrations in depth-dependent samples from the supply well and from short-screened monitoring wells located $<30 \mathrm{~m}$ away in the upper confined aquifer were different. The differences probably resulted from the three-dimensional convergence of many ground-water flow paths on the supply well as a consequence of large withdrawal rates, resulting in mixing of many waters in the supply well. In contrast, the much lower withdrawal rates and the screened intervals in the monitoring wells, even those close to a supply well, makes it likely that these wells intersected a much smaller number of ground-water flow paths moving from one direction toward the supply well. The depth-dependent samples from the supply well and the monitoring wells could be different because the supply well intersected a groundwater flow path(s) having relatively high concentrations of solutes that were not intersected by the monitoring wells.

\section{Processes Affecting Transport of Anthropogenic and Natural Contaminants to Public-Supply Wells}

In this section, results for all constituents that are useful as tracers of water sources and pathways are integrated to develop a refined conceptual model of major source, movement, and well-effect processes influencing transport of selected anthropogenic and natural constituents to PSW in the local-scale TANC study area. The "Sources of Water and Solutes" section includes a summary of sources of water and anthropogenic solutes in the shallow unconfined aquifer and sources of uranium and arsenic, natural constituents of primary interest, throughout the unconfined and confined aquifers. The section "Movement of Water and Solutes to Supply Wells" summarizes evidence that the primary mechanism permitting contamination-susceptible water from the unconfined aquifer to reach the confined aquifers where PSWs are screened is well-bore leakage. The section "Supply Well Effects on Transport of Water and Solutes" describes the effects of pumping wells on water quality in the PSW.

\section{Sources of Water and Solutes}

Precipitation is the primary source of recharge in the local-scale TANC study area, followed by return flow from irrigation or urban water use, as indicated by values of $\delta \mathrm{D}$ and $\delta^{18} \mathrm{O}$. The $\delta \mathrm{D}$ and $\delta^{18} \mathrm{O}$ values for unconfined shallow urban and agricultural wells indicate variable mixtures of these source waters. Calculated fractions of precipitation recharge varied from 47 to $78 \%$ for unconfined shallow urban wells and 66 to $81 \%$ for unconfined shallow agricultural wells. 
Anthropogenic sources influencing unconfined shallow urban and agricultural wells may include septic systems, leakage from the wastewater system, general industrial or commercial use of VOCs, livestock waste disposal, and application of fertilizers on agricultural fields. Natural sources include desorption or dissolution of uranium and arsenic from sediment. The highest concentrations of uranium and arsenate were in confined mixed wells in which water from the unconfined aquifer mixed with water in the upper confined aquifer under iron-reducing conditions. These individual sources are described more specifically in the following paragraphs.

Septic systems, having their highest density near the edge of the urban area, may be the major anthropogenic source of solutes, including nitrate-N, orthophosphate, chloride, sulfate, calcium, potassium, and boron, in unconfined shallow urban wells. These constituents, $\delta^{15} \mathrm{~N}$-nitrate, and chloride/bromide were the primary tracers of septic-system effects. Although uranium and arsenic were probably not directly derived from septic-system effluents, the association of higher uranium and arsenic concentrations with septic-system tracers implies that septic-system drainage may enhance mobilization of these "natural" contaminants. The distinction between the contributions of leakage from the municipal wastewater system and from septic-system drainage cannot be resolved on the basis of the geochemical data. Elevated values of the septic-system tracers listed above were present in samples from some wells near the western edge of the urban area where the wastewater system was absent. Alternatively, parts of the urban area that are far from areas having known or suspected septic systems may be influenced by wastewater leakage. It is possible for septic systems primarily located near the western or upgradient margin of York (fig. 4) to have a prevailing influence on ground-water chemistry downgradient underneath the York urban area. Mixing of septic-system-effected waters with other ground water dilutes high concentrations but plumes can persist for a considerable distance (Robertson and others, 1991). As the density and areal extent of septic systems increase, local dilution capacity decreases. Because recharge beneath the York urban area is estimated to be less than recharge in the upgradient agricultural area (Clark and others, 2008), septic systems would represent points of focused recharge at the edge of the urban area.

Sources of VOCs are widely distributed in or near the York urban area, as indicated by the widespread occurrence of relatively low concentrations of VOCs in unconfined shallow urban wells, but not in agricultural wells. The primary VOCs detected were the chlorinated solvents PCE and TCE. However, 23 other VOCs were detected, including chloroform, CFC-113 and CFC-12, benzene, MTBE, and the PCE and TCE degradation products cis-1,2 DCE and trans-1,2 DCE. Septic systems have been identified as likely sources of solvents in ground water (Squillace and others, 2004; Moran and others, 2007), so detections of solvents in unconfined shallow urban wells are consistent with interpretations of septic-system effects on the basis of inorganic tracers. However, other sources of VOCs, such as general industrial or commercial use of VOCs, could contribute to the concentrations of VOCs in unconfined shallow urban wells.

Livestock waste disposal areas were prevalent upgradient of York and may have affected local ground-water chemistry. The highest concentrations of nitrate- $\mathrm{N}$ measured in the study, about $80 \mathrm{mg} / \mathrm{L}$ (unconfined shallow agricultural well NWT1-39), were measured beneath a pasture historically used for manure spreading. Although manure disposal may locally impact ground-water quality, the distribution of livestock manure areas is limited and the effect on ground-water chemistry over larger areas is expected to be minor.

Application of fertilizers on cultivated fields is probably the primary source of nitrate- $\mathrm{N}$ influencing unconfined shallow agricultural wells. Nitrate is the principal constituent of concern in agricultural areas. Nitrate- $\mathrm{N}$ concentrations in unconfined shallow urban and agricultural wells were similar but derived from different sources on the basis of $\delta^{15} \mathrm{~N}$-nitrate values.

The likely source of uranium in the unconfined aquifer is desorption or dissolution from sediment under oxic conditions. Sequential extractions of core samples indicated that there was generally abundant iron and manganese oxides and uranium in aquifer sediments which were sources for uranium to oxic ground water. ${ }^{234} \mathrm{U} /{ }^{238} \mathrm{U}$ were consistent with uranium in oxic unconfined shallow urban and agricultural wells resulting from leaching from uranium-bearing sediments, oxides, or minerals. Uranium concentrations were mostly $5 \mu \mathrm{g} / \mathrm{L}$ to $40 \mu \mathrm{g} / \mathrm{L}$ in oxic unconfined shallow urban and agricultural wells and and $<5 \mu \mathrm{g} / \mathrm{L}$ in reducing wells. Where depth to water was less than about $7 \mathrm{~m}$, the unconfined shallow urban wells were usually anoxic or more reducing, had $\mathrm{pH}$ from 5.8 to 6.7 , and had low concentrations of bicarbonate. These conditions probably resulted from oxidation of soil organic matter and percolation of DOC to the water table where depth to water was shallow. Uranium concentrations in oxic unconfined shallow urban and agricultural wells were correlated with several indicators of septic-system influence, including chloride, $\delta^{15} \mathrm{~N}$-nitrate, orthophosphate, potassium, and calcium. A direct source of uranium in septic-system discharge is unlikely. Rather, higher concentrations of uranium in ground water affected by septic systems may result from complexes with high calcium and bicarbonate formed in response to additional calcite dissolving in ground water affected by relatively acidic septic-system discharge.

The highest uranium concentrations in the local-scale TANC study area, 44 to $184 \mu \mathrm{g} / \mathrm{L}$, were in confined mixed wells that were iron reducing. Uranium concentrations were low in confined unmixed wells with similar redox conditions. These results suggest that uranium can be mobilized during mixing of waters from the unconfined and confined aquifers in the upper confined aquifer having iron-reducing conditions. 
Desorption or dissolution of arsenic from sediment, enhanced in waters affected by septic-system discharges, is a plausible source for arsenic concentrations observed in oxic unconfined shallow urban and agricultural wells. In oxic unconfined shallow urban and agricultural wells, arsenic concentrations were correlated with indicators of septic-system effects, including chloride and orthophosphate. Direct sources of arsenic in septic-system effluent are not likely. Rather it is suspected that concentrations of arsenic increase in ground water affected by septic systems as a result of competitive desorption of arsenate from sediment in the presence of orthophosphate derived from septic-system effluent (Welch and Stollenwerk, 2003; Kent and Fox, 2004). In confined unmixed wells, arsenic primarily occurred as arsenite and may be present in fairly uniform concentrations as result of long-term dissolution of iron oxides in glaciofluvial sediments and redistribution of iron in the solid phase. In most confined mixed wells, arsenic concentrations are consistent with mixing of waters from the unconfined aquifer and confined aquifers. Some high concentrations of arsenic (as arsenate) in confined mixed wells may reflect mobilization of arsenic where waters from the unconfined aquifer mix with water from the confined aquifer under iron-reducing conditions.

Upward movement of water and solutes from the shale underlying the aquifer or interactions with minerals in the marine shale may locally affect the water chemistry of the lower confined lenses, but are unlikely to affect the chemistry of water reaching PSWs. The chemistry of well FP2-250 (classified as confined urban mixed well) is unique in the local-scale TANC study area, having the highest concentrations of total dissolved solids (TDS) $(2,030 \mathrm{mg} / \mathrm{L})$, sulfate (1,060 mg/L, fig. 19B,C), calcium (309 mg/L, fig. 20C), magnesium (71.8 mg/L), sodium (207mg/L), potassium (16.2 mg/L, fig. 17B), and boron $(480 \mu \mathrm{g} / \mathrm{L}$, fig. 17E), making this sample a mixed cation-sulfate type water (fig. 16). The TDS in FP2-250 was more than twice that of other samples (table 20). Phase equilibrium calculations using PHREEQC indicated that FP2-250 was the only well in the study area near equilibrium with gypsum (saturation index $(\mathrm{SI})=-0.4$; in all other wells, $\mathrm{SI}=-1.1$ to -2.5$)$. The only core sample in which gypsum was detected was from the shale (table 8). These results suggest that dissolution of gypsum in the shale has affected the chemistry of well FP2-250. The high concentrations of cations other than calcium could indicate cation exchange. Well FP2-250 had the lowest $\delta^{34} \mathrm{~S}$-sulfate $(-22.3$ per mil) of any sample (table 19). This value is in the range expected for sulfate derived from oxidation of reduced inorganic sulfur ( -30 to +5 per mil), but is outside the range of values typical for gypsum (+10 to +35 per mil) (Krouse and Mayer, 2000). One possible explanation is that the gypsum was derived from the weathering of pyrite in the shale; drilling indicated that the upper few meters of the shale was weathered. Although the shale core was not analyzed for pyrite, pyrite is a common trace mineral in marine shale (Krouse and Mayer, 2000), and iron concentrations in the core were the highest measured in the study (table 9). Under semi-arid to arid conditions, pyrite could have been oxidized, and gypsum having $\delta^{34} \mathrm{~S}$-sulfate values similar to those of the original pyrite could have been formed. This mechanism is consistent with the low $\delta^{34} \mathrm{~S}$-sulfate values and near saturation with gypsum. Well FP2-250 has relatively high chloride/bromide and plots close to literature values of waters affected by road salt (fig. 18); this could indicate dissolution of geologic halite (rather than halite or other chloride minerals applied as road salt), which was detected in the shale core (table 8). The chemistry of confined urban unmixed well OFPN-276 appeared to be intermediate between that of FP2-250 and confined unmixed wells for many analytes (figs. 16, 17B,E, 18, 19A,B,D). These results suggest that OFPN-276 may be influenced by water affected by interactions with the shale mixed with water represented by confined unmixed wells. Indicators of interactions of the shale with ground water were detected in only 2 of 7 monitoring wells (FP2-250, OFPN-276) in the lower confined lenses and none of 9 monitoring wells nor the study PSW in the upper confined aquifer.

\section{Movement of Water and Solutes to Supply Wells}

Ground water generally moves in a southeasterly direction across through the study area (fig. 3) and vertically downward due to recharge and withdrawal from pumping wells. Because storage is much greater in the unconfined aquifer, withdrawals from the confined aquifers inherently produce hydraulic head gradients downward from the unconfined to the confined aquifers (fig. 6). Because of increased recharge and discharge over several decades, simulated ground-water ages in the aquifer system became younger from the 1950 s to the 1980s (Clark and others, 2008). Historical water-level data (Landon and Turco, 2007; Clark and others, 2008), simulation results, and differences in $\delta^{18} \mathrm{O}$ and $\delta \mathrm{D}$ values between unconfined shallow wells and confined unmixed wells consistent with changes in seasonal recharge proportions all indicate that the ground-water flow system has changed substantially accompanying development of the aquifer system as a source of irrigation. These changes in the aquifer system likely cause shorter travel times and greater opportunities for contaminants to move from recharge areas to PSWs screened in the confined aquifer compared to predevelopment aquifer conditions. However, perturbations in the generalized flow pattern, including localized pumping and well-bore leakage, can cause mixing and transport of solutes in ways that are uncharacteristic of the broader ground-water system and further enhance opportunities for contaminant transport to PSW, as indicated by detailed model simulations of the local-scale TANC study area (Clark and others, 2008). 
The section summarizes geochemical, physical, and simulation evidence that well-bore leakage is the predominant process facilitating movement of constituents of concern to PSW in the confined aquifers. Alternative hypotheses are discussed in comparison with the primary hypothesis of the dominant influence of well-bore leakage. In addition, evidence for the role of reactions in attenuating movement of selected contaminants through the aquifer system are discussed.

\section{Evidence for Well-Bore Leakage}

Multiple tracers indicate water from the unconfined aquifer mixed with water in the confined aquifer at a few locations. Confined mixed wells and the study PSW had values of $\delta^{18} \mathrm{O}, \delta \mathrm{D}$, and chloride, and sometimes nitrate- $\mathrm{N}$, uranium, arsenic (arsenate), major elements, VOCs, and young groundwater age tracers intermediate between those from unconfined shallow urban and those from confined unmixed wells. These wells having intermediate composition appear to represent mixtures of waters from the unconfined and confined aquifers. Although the chemical signatures of these intermediate waters were generally consistent with those of an unconfined shallow urban recharge area, the detection of acetochlor ESA, alachlor ESA, and alachlor OA-degradation products of herbicides used only on agricultural crops-implies that at least a fraction of the water from the unconfined aquifer mixed in the confined aquifer was also derived from unconfined shallow agricultural recharge areas. On the basis of $\delta \mathrm{D}$ values, calculated fractions of unconfined water in confined mixed wells ranged from 63 to $82 \%$ (table 12; fig. 26). In study PSW depth-dependent samples, unconfined mixing fractions ranged from 15 to $46 \%$. In the study PSW surface discharge, the unconfined mixing fraction was $12 \%$ in all 3 samples collected through time (table 12). Most monitoring wells in the confined aquifers (confined unmixed wells) contained little or no water from the unconfined aquifer. Minor differences in unconfined water mixing fractions calculated using $\delta \mathrm{D}$ and $\delta^{18} \mathrm{O}$ indicated uncertainties of about $\pm 10 \%$, especially in samples containing only small amounts of water from the unconfined aquifer.

There are potentially several pathways that water from the unconfined aquifer could follow to reach the confined aquifer. Hypotheses for different pathways are conceptually illustrated in figures 27A-C and include (1) leakage down the well-bore of the supply well because of an incomplete seal of the confining unit or leakage through the confining unit adjacent to the well as a result of hydraulic head drawdown at the supply well (fig. 27A) (these two mechanisms are lumped for this discussion because they would result in a similar distribution of water from the unconfined aquifer in the confined aquifer), (2) areally uniform leakage through the confining unit (fig. 27B), and (3) leakage down well-bores in multilayer wells located upgradient of the supply well but within its ZOC (fig. 27C). Hypothetical fractions of water from the unconfined aquifer in monitoring wells and in a depth-dependent sampling profile from the supply well are shown in figures 27D,F for these three scenarios. Unconfined aquifer water fractions vary conceptually from zero (to the left on the fraction of unconfined water graph), expected in monitoring wells in the confined aquifer with no mixing with water from the unconfined aquifer, to one (to the right on the fraction of unconfined water graph) in the unconfined aquifer. These hypotheses are described in more detail in the paragraphs below.

The presence of water in the confined aquifers from the unconfined aquifer (hypothesis 1, figs. 27A,D) is not likely a result of downward flow of water between aquifers in or adjacent to the supply well itself because (1) the greatest abundance of water from the unconfined aquifer would be near the top of the screened interval under this scenario; instead, the greatest abundance of water from the unconfined aquifer was in the bottom half of the screen; (2) water from the unconfined aquifer would not be present other monitoring wells in the confined aquifers under this scenario; instead, water from the unconfined aquifer was observed in five monitoring wells in the confined aquifers away from the study PSW.

Areally uniform leakage through the confining unit (hypothesis 2, figs. 27B,E) also is not likely to be the mechanism for rapid movement of water from the unconfined aquifer to the confined aquifer. Under this scenario, the greatest abundance of water from the unconfined aquifer would be in monitoring wells near the top of the confined aquifer and near the top of the supply well. These patterns did not fit the observed data, which indicated highly variable fractions of unconfined water in a few monitoring wells in the confined aquifer unrelated to vertical position (fig. 26) and the greatest amounts of unconfined water in the bottom half of the PSW profile rather than the top (fig. 25). A hybrid of this scenario is water from the unconfined aquifer moving through the confining unit along natural preferential flowpaths unrelated to multilayer wells. This mechanism will be discussed further later in this section.

Several observations suggest that water from the unconfined aquifer moves directly to the confined aquifer within the ZOC of the study PSW through multilayer wells open to both aquifers or through unsealed well-bores connecting the aquifers (hypothesis 3 , figs. 27C,F). The evidence includes the observed distribution of tracers of water from the unconfined aquifer in the confined aquifer, the existence of physical factors that facilitate downward leakage through multilayer wells or well-bores, results of model simulations of the local-scale TANC study area (Clark and others, 2008) consistent with tracer distributions, and previous investigations that have identified well-bore leakage through multilayer wells as a mechanism capable of influencing water and chemical fluxes across confining units. These categories of supporting evidence are discussed in the paragraphs below. 

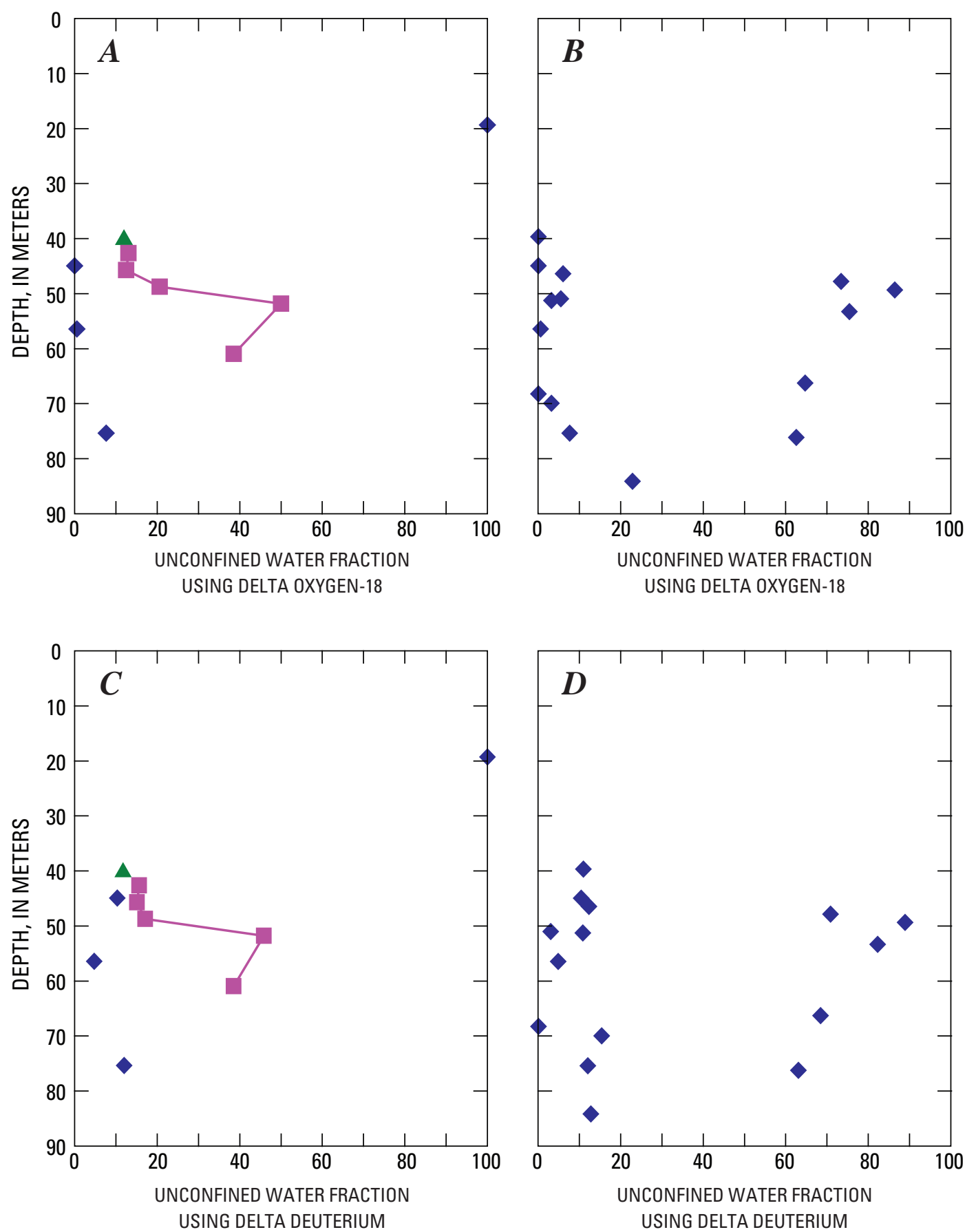

\section{EXPLANATION}

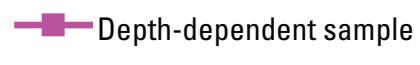

$\checkmark$ Monitoring well

- Surface-discharge sample

Figure 26. Vertical distribution of unconfined mixing fractions in samples from different depths in the confined layer in the local-scale TANC study area near York, Nebraska: $A$. values from oxygen isotopes in and adjacent to the study public-supply well, $B$. values from oxygen isotopes in other monitoring wells in confined aquifers, $C$. values from hydrogen isotopes in and adjacent to study public-supply well, $D$. values from hydrogen isotopes in other monitoring wells in confined aquifers. 

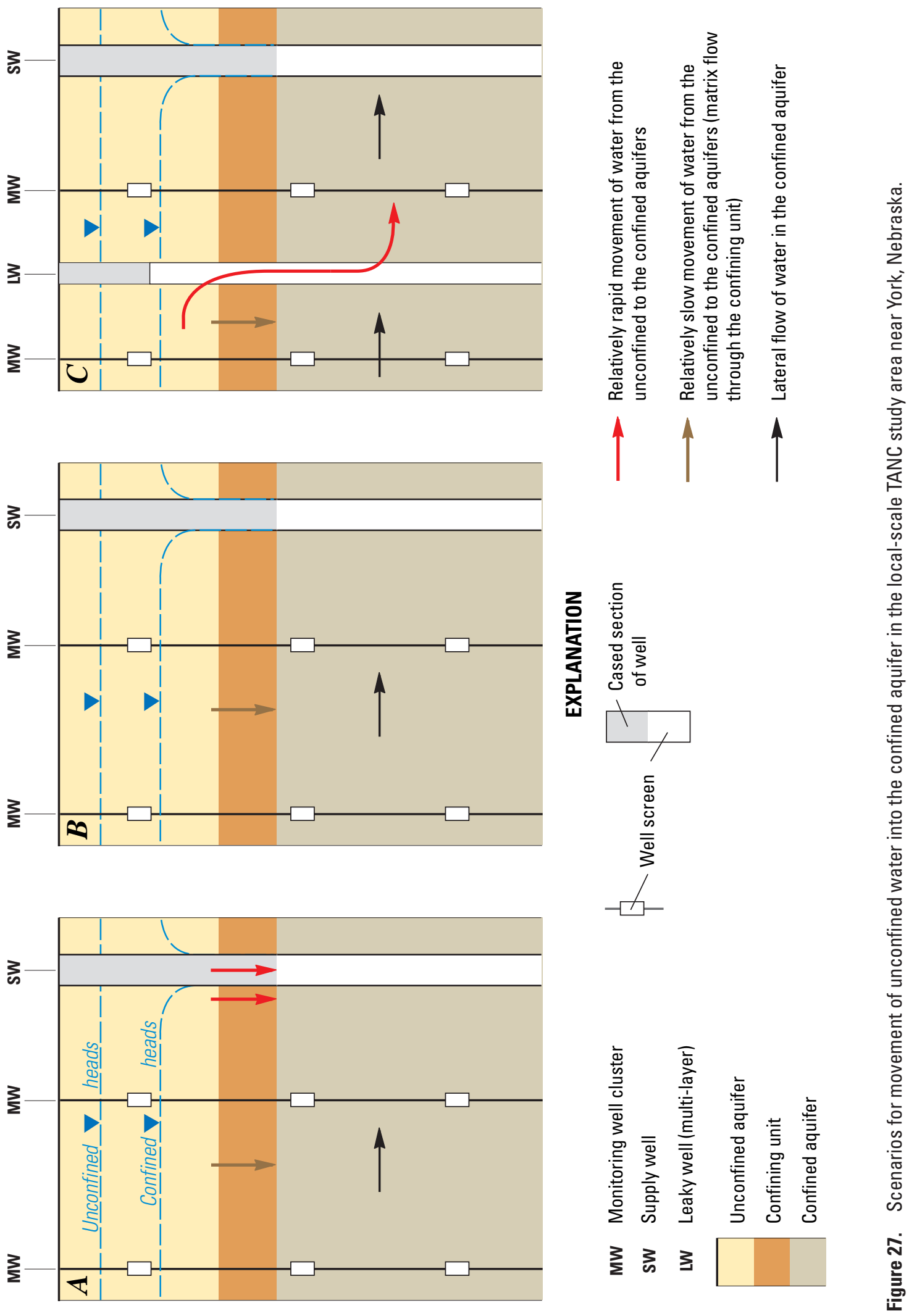

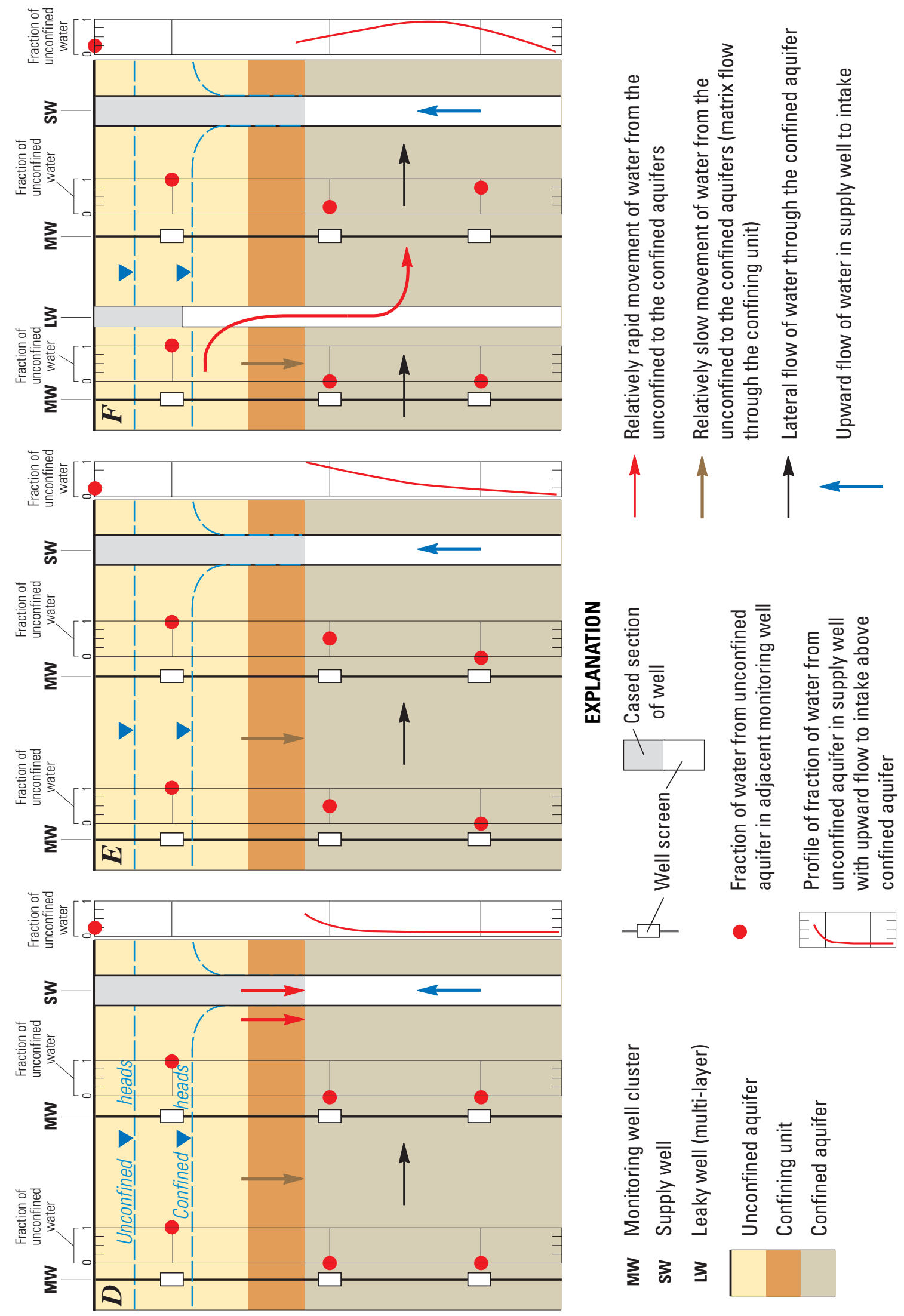
The presence of water from the unconfined aquifer in a few monitoring wells in the confined aquifer is consistent with water from the unconfined aquifer flowing down multilayer wells or leaky well-bores upgradient of the supply well (hypothesis 3, figs. 27C,F). The chemical, isotopic, and age-distribution data for confined mixed wells and depthdependent samples from the study PSW are consistent with this hypothesis. Because these multilayer wells or leaky well-bores represent discrete points where water from the unconfined aquifer can move into the confined aquifer, rather than an areally distributed source, a heterogeneous distribution of mixed waters in a few wells in the confined aquifer would be expected, and was observed (fig. 27F). Wells located near or downgradient of leaky multilayer wells or well-bores would contain mixtures of water from the unconfined and confined aquifers. Wells located away from these points would contain unmixed water from the confined aquifer. This heterogeneous distribution of mixed waters fit the observed pattern, in which highly mixed waters were in 5 of 15 monitoring wells in the confined aquifer (fig. 26). Subsequent lateral movement of the water leaked from the well-bore toward the supply well and downward displacement because of matrix flow of old water through the confining unit could allow water from the unconfined aquifer to flow to the lower part of the supply well screen, as was observed. Leakage along multilayer wells, if fully penetrating the upper confined aquifer, also could facilitate vertical distribution of water from the unconfined aquifer throughout the upper confined aquifer.

Tracer results are consistent with multiple pathways, such as multilayer well bores, between water in the unconfined aquifer and zones of mixing in the confined aquifer. The study $P S W$ and confined mixed wells did not plot along the same mixing lines on tracer-tracer plots such as $\delta^{18} \mathrm{O}$ and chloride and $\delta^{18} \mathrm{O}$ and sulfate (figs. 19A,B). These results imply that waters from the unconfined aquifer in confined mixed wells and the study PSW represent different sources.

Data collected at multilayer test well FP5-LS (classified as confined agricultural mixed well) confirm that the physical conditions of a downward hydraulic head gradient and open pipe permit flow of sufficient water such that water from the well bore in the confined aquifer has the chemical signature of the unconfined aquifer. There were downward hydraulic head gradients from the unconfined to the upper confined aquifer at the FP5 well nest (fig. 6F). A sample collected near the top of the well screen in the upper confined aquifer (sample FP5-LS) had chemistry very similar to that of unconfined shallow agricultural well FP5-45 (tables 12, 20). In addition, profiles of specific conductance measured every $3 \mathrm{~m}$ in FP5-LS indicated that, in the upper confined aquifer, values throughout the well profile were intermediate between those of FP5-45 and FP5-175. Specific conductance values were closer to that of the FP5-45 October 2004 sample than that of FP5-175 but moved closer to FP5-175 with depth. These results are consistent with downward movement of water from the unconfined aquifer to the confined aquifer down the well.
Physical conditions permitting vertical leakage through wells or well-bores in the local-scale TANC study area include

(1) large vertical downward hydraulic-head gradients between the unconfined and confined aquifers that result from withdrawals, particularly for irrigation during the summer, from the confined aquifers (fig. 6) and

(2) the presence of irrigation wells, some commercial wells, and even some older PSWs screened in both the unconfined and confined aquifers. Well construction details beyond well depth were unknown for some private wells. However, available water-level and drawdown data from well registration records (Nebraska Department of Natural Resources, 2002) were consistent with many wells with bottoms in the confined aquifer also having screens in the unconfined aquifer. Wells whose construction records indicated they were screened only in the confined aquifers had lower hydraulic heads and greater drawdowns than wells screened only the unconfined aquifer or multilayered wells screened in both the unconfined and confined aquifer. The hydraulic behavior of multilayer wells was confirmed by results from multilayer test well FP5-LS, which had hydraulic heads similar to those of adjacent wells FP5-45 and FP5-73, screened only in the unconfined aquifer (fig. 6F). Clark and others (2008) show the locations of multilayered wells and leaky well-bores where downward leakage was simulated for the local-scale TANC study area. Seasonally or perennially inactive or little used irrigation, commercial, or supply wells may be particularly important as locations of well-bore leakage because withdrawals from the confined aquifer would be less likely to withdraw vertical well-bore leakage at these locations (Clark and others, 2006).

Results of a numerical ground-water-flow and solutetransport model of the local-scale TANC study area are consistent with the interpretation that the movement of contamination-susceptible water from the unconfined aquifer to the PSWs is primarily controlled by leakage through multilayer wells and bore holes (Clark and others, 2006; Clark and others, 2008). Well-bore leakage in multilayer wells and known abandoned wells and test holes needed to be included in the model to obtain a reasonable comparison of simulated and observed age distributions and CFC concentrations in the confined aquifer (Clark and others, 2008). The simulations indicated that about $25 \%$ of the water flow through the upper confining unit moved through leaky well-bores rather than as leakage through the confining layer itself. Although multilayer well and bore-hole flow accounted for a minority of the total flow from the unconfined to the upper confined aquifer, it accounts for all of the flow of relatively young, contaminationsusceptible water to the confined aquifer in the simulations. Simulated ages of water moving through the upper confining unit are hundreds to thousands of years (Clark and others, 2008), consistent with apparent carbon-14 dates for confined unmixed wells in the lower confined lenses (FP1-247,

FP4-231; table 16). This relatively old water moving by matrix flow through the upper confining unit dilute the younger contamination-susceptible water moving from the unconfined 
aquifer into the confined aquifer through well-bores. These simulations were consistent with the tracer data discussed in this report, both indicating that well-bore leakage enables contamination-susceptible water to reach depths of the PSW. Without this well-bore leakage, the confined aquifer would have contained relatively old water that would not be expected to contain anthropogenic tracers. These old waters are represented by confined unmixed wells which contained few or no young water tracers and had a relatively uniform chemistry consisting of lower concentrations of most constituents compared with confined mixed wells.

Previous modeling investigations have identified vertical leakage through multilayer wells as a process that can influence the water balance of confined aquifers on a regional scale (Williamson and others, 1989; Hanson and others, 2004). Konikow and Hornberger (2006) ran hypothetical simulations of solute transport that considered leakage of water between unconfined and confined aquifers through multilayered wells that indicated such leakage could have a substantial local effect on solute concentrations in the confined aquifer.

Several points of evidence indicate that well-bore leakage is a critical process facilitating transport of contaminationsusceptible water to the confined aquifer. However, it is possible that other preferential flow paths through the confining unit may exist. Water and solute often move through aquitards faster than expected as a result of sediment heterogeneity, discontinuous confining layers, cracks, burrows, or other anomalous features in sediments. Although the confining unit was continuous across the local-scale TANC study area according to drilling for this study and historical drilling logs, discontinuities that have not been identified may be in the confining unit. No cracks, burrows, or other heterogeneities likely to penetrate through the 8 to $17 \mathrm{~m}$ thickness of the confining unit were observed during coring of the confining unit; however, given the small number of places where cores were collected in the confining unit, it cannot be ruled out that heterogeneities that permit water and solute movement across the confining unit exist. However, it is simpler to consider that rapid interlayer flow occurs in known preferential flow paths, multilayer wells crossing the confining unit, rather than in unknown natural preferential flow paths.

Leaky well-bores are a point-source of potential contamination to the confined aquifer. Well-bore leakage water is expected to mix with water in the confined aquifer downgradient of the leaky well-bore. The direction and rate of downgradient movement of mixed water from leaky well-bores depend upon local aquifer stresses. Changes in flow direction resulting from changing stresses can result in temporal variability of concentrations in the confined aquifer. For example, in confined urban mixed well OFPS-157, $\delta^{18} \mathrm{O}$ and $\delta \mathrm{D}$ (table 12), nitrate-N (table 18), chloride (table 20), and redox conditions (fig. 9) varied considerably. Calculated unconfined mixing fractions based on $\delta \mathrm{D}$ declined from 71 to $41 \%$ from November 2003 to April 2005 in OFPS-157 (table 12). Monitoring wells in the confined aquifer such as OFPS-157 may have chemistry that varies temporally because they are relatively far from a leaky well-bore, where considerable mixing with water from the confined aquifer would occur.

\section{Effects of Attenuation Reactions}

Reactions in reducing ground-water in the confining unit and in the confined aquifer have the potential to attenuate transport of anthropogenic nitrate, PCE, and TCE, and probably natural uranium and arsenic. Thus the reducing conditions in the confined aquifer potentially are a natural protection for the water quality of PSWs screened in the confined layer.

Values of $\delta^{15} \mathrm{~N}$ and $\delta^{18} \mathrm{O}$ of nitrate and excess $\mathrm{N}_{2}$ gas and initial $\delta^{15} \mathrm{~N}$-nitrate values derived from isotopic mass balance calculations on the basis of $\delta^{15} \mathrm{~N}-\mathrm{N}_{2}$ values indicated that nitrate was denitrified in reducing parts of the unconfined and confined aquifers (McMahon and others, 2008). Analysis of pore-water chemistry in the upper confining unit indicated that nitrate was completely denitrified across the upper 3 to $4 \mathrm{~m}$ of the aquitard (McMahon and others, 2008). In the confined aquifers, confined unmixed wells had little or no nitrate-N or excess nitrogen gas from denitrification, indicating that these "old" waters never had significant nitrate-N. Confined mixed wells had nitrate- $\mathrm{N}$ concentrations ranging from 0 to $13 \mathrm{mg} / \mathrm{L}$ and were partially to completely denitrified.

Reductive dechlorination of PCE and TCE may be occurring in the confined aquifer, and perhaps in the reducing parts of the unconfined aquifer, as evidenced by the presence of the degradation products cis- and trans-1,2 DCE. However, these reactions appear to be partial, as PCE and TCE were detected in the local-scale study PSW in addition to three other PSWs in York sampled as part of another study (SWQA) in 2002 .

However, these natural attenuation mechanisms may be bypassed by short-circuit pathways in the form of leaky wellbores through the confining layer and pumping in the confined aquifers, allowing water and contaminants to move more quickly from source areas to PSWs than would otherwise occur. The short-circuit pathways may permit contaminants in the unconfined aquifer to bypass extended contact with finetextured sediments in the confining unit, where contaminants are be expected to degrade because of the reducing conditions and low-ground-water-flow velocity through these lowpermeability sediments (McMahon and others, 1999; McMahon, 2001b; McMahon and others, 2008).

Several supply wells in the city of York have been taken off line because of nitrate- $\mathrm{N}$ concentrations greater than the USEPA MCL of $10 \mathrm{mg} / \mathrm{L}$. These results suggest that the nitrate-N can move from the unconfined aquifer to PSWs quickly enough to prevent denitrification sufficient to reduce concentrations below the MCL. 


\section{Supply-Well Effects on Transport of Water and Solutes}

The withdrawals in the study PSW probably drew contamination-susceptible water towards the well, but concentrations of constituents of concern (primarily uranium, PCE, and TCE) were diluted with unmixed water entering the well from the confined aquifer. Mixing calculations using $\delta^{18} \mathrm{O}, \delta \mathrm{D}, \mathrm{SF}_{6}$, and $\mathrm{CFC}-11$ indicated that the study PSW contained 7 to $14 \%$ water from the shallow unconfined aquifer (tables 12 and 16). Thus, most of the water reaching the study PSW was unmixed water from the confined aquifer, most of which was older than 50 to 60 years. Concentrations of uranium above of the EPA MCL of $30 \mu \mathrm{g} / \mathrm{L}$ in depthdependent samples were diluted with unmixed water from the confined aquifer so that uranium concentrations in the surface discharge were about $17 \mu \mathrm{g} / \mathrm{L}$. The occurrence of greater concentrations of VOCs and uranium in depth-dependent and surface-discharge samples from the PSW than in shortscreened monitoring wells located $<30 \mathrm{~m}$ away in the same confined aquifer suggests that contamination-susceptible water was drawn to the supply well along particular flow paths that converged on the supply well as a result of pumping but were not intersected by the monitoring wells.

Because most of the drawdown in the confined aquifer was a result of regional withdrawals for irrigation, contamination-susceptible water is expected to leak down multi-layer well bores regardless of local pumping stress caused by PSW withdrawals. Irrigation withdrawals were much greater than withdrawals for public supply and resulted in regional seasonal declines in hydraulic heads in the confined aquifer. As long as there are multi-layer wells or leaky well-bores, rapid downward movement of water from the unconfined aquifer to the confined aquifer can occur, regardless of local pumping stress from the PSW. Thus, it is expected that local pumping stress in the PSW will have little effect on the amount of well-bore water leaking from the unconfined to the confined aquifer. Pumping stress in the PSW, relative to other withdrawal wells, is expected to affect the rate and direction of movement of well-bore leakage once it is in the confined aquifer.

Although the depth-dependent results indicate that water from the unconfined aquifer primarily reached the bottom of half of the PSW screen, drawdown at the PSW may also induce movement of a small amount of water from the unconfined aquifer through the confining unit into the upper confined aquifer, where it enters the PSW near the top of the screen. Minor shifts in $\delta^{18} \mathrm{O}$ and $\delta \mathrm{D}$ values and small increases in arsenic, arsenate, bicarbonate, and excess $\mathrm{N}_{2}$ gas near the top of the screen in depth-dependent samples were consistent with a small increase in the amount of water from the unconfined aquifer near the top of the screen. However, movement of water from the unconfined aquifer to the study PSW by well-bore leakage upgradient in the ZOC is the predominant mechanism for moving contaminationsusceptible water to PSW.
Historical data from the city of York indicates that some PSWs screened only in the confined aquifers have periodically had nitrate-N concentrations above or near $10 \mathrm{mg} / \mathrm{L}$. Thus, nitrate-N was able to reach PSW in some cases without being denitrified or diluted. This may result from the combined effects of short-circuit flow paths through leaky well bores and pumping that increased ground-water velocity sufficiently to prevent denitrification or dilution from reducing nitrate-N concentrations below $10 \mathrm{mg} / \mathrm{L}$. It is likely that nitrate-N concentrations in PSWs were influenced by the number of well-bore leakage points in the ZOC, the distance from the PSW, and the relative pumping stress imposed by the PSW compared with that imposed by other withdrawal wells.

\section{Summary}

This report describes the hydrogeology and geochemistry of the local-scale TANC (Transport of Anthropogenic and Natural Contaminants) study area near York, Nebraska and discusses factors that may control transport of selected anthropogenic and natural contaminants to a PSW (publicsupply well).

The study area is 108 square kilometers in east-central Nebraska within an area containing Quaternary-age alluvial deposits of the High Plains aquifer in eastern Nebraska. Irrigated agriculture is the primary land use. Ground water is the sole source of irrigation and drinking water. Many irrigation wells, commercial wells, and some older PSWs are screened in both the unconfined and the confined aquifers, which can allow localized transfer of water from the unconfined to confined aquifer. Most York municipal wells are screened in the confined aquifers only.

A network of short-screened monitoring wells was installed throughout the zone of contribution for the selected study PSW. Criteria used to select the study PSW included representative and well-understood hydrogeologic, land use, and operational conditions, and the presence of detectable anthropogenic and natural compounds of concern. Samples were collected from monitoring wells and the study PSW, and were analyzed for a broad suite of analytes, including isotopic tracers, indicators of oxidation-reduction condition, ground-water age tracers, VOCs (volatile organic compounds), pesticides, nutrients, major elements, and trace elements, including uranium, arsenic, and species of arsenic. Core samples were collected and analyzed to characterize the chemical, mineralogical, and physical properties of the major hydrogeologic units. Flow and chemistry data were collected from different depths in the study PSW under pumping conditions to refine understanding of where water and contaminants entered the supply well. On the basis of hydrogeologic unit, land use, depth, and $\delta^{18} \mathrm{O}$ (delta oxygen-18) and $\delta \mathrm{D}$ (delta deuterium) signatures, wells were classified into categories for the purpose of relating water 
quality to hydrogeologic setting and mixing of waters from the unconfined and the confined aquifers.

Values of $\delta^{18} \mathrm{O}$ and $\delta \mathrm{D}$ in unconfined shallow urban and agricultural wells reflected differing proportions of recharge from precipitation and recharge from return flow of ground water pumped for irrigation or urban supply.

Values for confined mixed and depth-dependent and surfacedischarge samples from the study PSW reflected water from the unconfined aquifer mixed with water from the confined aquifer (represented by confined unmixed wells). More negative $\delta \mathrm{D}$ and $\delta^{18} \mathrm{O}$ values for confined unmixed wells, recharged more than sixty to thousands of years ago, to less negative values for unconfined shallow urban and agricultural wells, recharged in the last few decades, indicate historical changes in the composition of recharge water. These isotopic changes most likely result from an increase in the fraction of recharge derived from spring and summer precipitation over irrigated agricultural and urban land during the last few decades compared to seasonal recharge proportions before ground-water irrigation.

Water in most of the unconfined aquifer was oxic. There was more-reducing ground water in a few unconfined shallow urban wells where the depth to water was less than $(<) 7 \mathrm{~m}$, probably because of dissolved organic carbon leaching from natural organic matter in soils. Water in most of the confined-aquifer wells was nitrate- to iron- to sulfate-reducing. Confined mixed wells were generally less reducing than confined unmixed wells.

Interpretations of apparent ground-water age from tracer data, including CFC-12, CFC-11, CFC-113, SF $6,{ }^{3} \mathrm{H} /{ }^{3} \mathrm{He}$, and ${ }^{3} \mathrm{H}$, were complicated by mixing of waters of different ages, possible natural ( $\left.{ }^{3} \mathrm{He}, \mathrm{SF}_{6}\right)$ and anthropogenic (CFCs) contamination of ground water, and degradation of CFCs under reducing conditions in a few samples. In the unconfined aquifer, age-tracer concentrations could be reasonably interpreted using a piston-flow model. Apparent recharge ages increased from 7 to 10 years old at shallow depths, 15 to 20 years at intermediate depths, and 44 to 48 years at the bottom of the unconfined aquifer. Age-tracer data for the confined aquifers were consistent with mixing of "old" water (not containing modern tracers, recharged more than 60 years before present) with exponentially-mixed young water. Tracer results and mixing calculations indicated that confined unmixed wells contained $<3 \%$ young water mixed with a much larger fraction (greater than or equal to $[\geq]$ 97\%) of old water with no modern tracers. Mixing calculations for confined mixed wells indicated young fractions ranging from 32 to $70 \%$, with mean ages for the young fractions of 12 to 14 years.

VOCs, primarily chlorinated solvents PCE and TCE, were detected in most unconfined shallow urban wells, some confined urban mixed wells, and in the study PSW, but were generally not detected in unconfined shallow agricultural wells. Thus, the presence of VOCs in confined mixed wells indicated that the water was affected by urban land use. Sources of VOCs may have included septic systems, commercial and industrial uses, wastewater, and (or) spills along transportation corridors. Reductive dechlorination of PCE and TCE may be occurring in the confined aquifer, and perhaps in reducing parts of the unconfined aquifer, as evidenced by the presence of the degradation products $c i s$ - and trans-1,2 DCE. However, these reactions appear to be partial, as PCE and TCE were detected in the local-scale study PSW in addition to three other PSWs in York sampled as part of another study in 2002. Degradation products of agricultural pesticides acetochlor and alachlor detected in some confined mixed wells suggests that some fraction of the water in these wells was recharged in agricultural areas.

Septic systems to the west of or near the upgradient (western) edge of York appear to be a major contributor to nitrate-N concentrations, which were 13 to $26 \mathrm{mg} / \mathrm{L}$ (milligram per liter) in unconfined shallow urban wells, but sanitary-sewer leakage in the urban area also could contribute to urban nitrate loading. In the agricultural areas, the primary source of nitrate in unconfined shallow agricultural wells was probably agricultural fertilizer application. Locally, nitrate-N concentrations were high (up to $80 \mathrm{mg} / \mathrm{L}$ as nitrogen) downgradient of livestock wastedisposal areas. Combined, these multiple sources of nitrate usually resulted in concentrations of nitrate- $\mathrm{N} \geq 10 \mathrm{mg} / \mathrm{L}$ (the U.S. Environmental Protection Agency's maximum contaminant level) in unconfined shallow wells. Values of $\delta^{15} \mathrm{~N}$ and $\delta^{18} \mathrm{O}$ of nitrate and excess $\mathrm{N}_{2}$ gas and initial $\delta^{15} \mathrm{~N}$ nitrate values derived from isotopic mass balance calculations on the basis of $\delta^{15} \mathrm{~N}-\mathrm{N}_{2}$ values indicated that nitrate was denitrified in reducing parts of the unconfined and confined aquifers. Nitrate- $\mathrm{N}$ concentrations in the study PSW were $<0.2 \mathrm{mg} / \mathrm{L}$ because of denitrification and mixing with confined unmixed waters having little or no nitrate-N. Because of the widespread distribution of nitrate sources, man-made points of leakage through the confining unit, and high pumping stress in the confined aquifer, nitrate is likely to continue to be the anthropogenic compound of greatest concern in the study area.

Associations between concentrations of chloride, initial $\delta^{15} \mathrm{~N}$-nitrate, potassium, orthophosphate, sulfate, boron, and chloride/bromide suggest that the primary source of relatively high values of these constituents and isotopic signatures in unconfined shallow urban wells was septic-system and (or) sanitary-sewer leakage. These two sources cannot be distinguished on the basis of available information and geochemical signatures.

Several inorganic, isotopic, and organic constituents showed a contrast between unconfined shallow urban, unconfined shallow agricultural, and confined unmixed endmember water compositions and mixtures of these different end-members. The analyses indicated that waters from the unconfined aquifer mixing with water from the confined aquifer in the study PSW were derived from an urban source area and that waters in the confined mixed monitoring wells and the study PSW represent different sources. These results imply that there are multiple pathways for water from the unconfined aquifer to zones of mixing in the confined aquifer. 
The predominant transport process controlling movement of potential contaminants to the study PSW was well-bore leakage. Redox processes affect distributions of many constituents; however, the influence of redox processes may be lessened by pumping stress and short-circuit pathways, such as well-bore leakage that can allow water to bypass the reducing confining unit.

In oxic unconfined shallow urban and agricultural wells having concentrations of 5 to $40 \mu \mathrm{g} / \mathrm{L}$ (microgram per liter) of uranium, the predominant source of uranium was probably desorption or dissolution from sediment. Uranium concentrations were highest in oxic conditions in which $\mathrm{pH}$, dissolved oxygen, and bicarbonate are not decreased by a shallow depth to water and interactions with soil organic matter. Solubility of uranium was probably enhanced by forming complexes with dissolved calcium and bicarbonate. Although septic systems are not likely to be a source of uranium, concentrations of uranium in oxic unconfined shallow urban wells were highest in those wells more strongly affected by septic systems, possibly as a result of forming complexes with higher concentrations of calcium in ground water affected by septic systems. Uranium concentrations in confined unmixed wells were $<5 \mu \mathrm{g} / \mathrm{L}$. However, uranium concentrations of 44 to $184 \mu \mathrm{g} / \mathrm{L}$ were detected where unconfined water that entered the confined aquifer as wellbore leakage water mixed with iron-reducing water in the confined aquifer. The mechanism causing the high uranium concentrations in iron-reducing confined mixed waters is not known. A possible mechanism is iron-oxides transported with fine sediment particles or colloids from the unconfined aquifer with well-bore leakage undergoing reductive dissolution under iron-reducing conditions in the confined aquifer, releasing uranium. The uranium complexes with calcium and bicarbonate and is able to remain mobile in the reducing confined aquifer. While this hypothesis cannot be tested without additional data, it is consistent with the available data.

In oxic unconfined shallow urban wells, concentrations of arsenic (arsenate) were greatest in wells having indicators of septic-system effects such as chloride, initial $\delta^{15} \mathrm{~N}$-nitrate, chloride/bromide, potassium, and orthophosphate. The association of higher arsenic with tracers of septic-system effects could result from competitive desorption of arsenate from sediment in the presence of orthophosphate derived from septic-system effluent. In confined unmixed wells, arsenic primarily occurred as arsenite in fairly uniform concentrations of about 3 to $7 \mu \mathrm{g} / \mathrm{L}$ that may result from longterm dissolution of iron oxides deposited with the glaciofluvial sediments and redistribution of iron in the solid phase. In most confined mixed wells, the arsenic was primarily arsenate. Arsenic concentrations in most confined mixed wells are in a range where they could reflect mixing of waters from the unconfined and confined aquifers.

\section{Acknowledgements}

We wish to thank the land owners, public and private, who granted permission for wells to be installed on their property. We were greatly assisted in this study by cooperation with the city of York and the UBBNRD. We are particularly indebted to Orville Davidson and Ken Eckler with the city of York and Rod DeBuhr, Jay Bitner, Dan Leininger, and Marie Krausnick at the UBBNRD. We are indebted to the many members of the TANC study team who contributed material and intellectual assistance with this study.

\section{References}

Alexander, R.B., and Smith, R.A., 1990, County-level estimates of nitrogen and phosphorus fertilizer use in the United States, 1945 to 1985: U.S. Geological Survey OpenFile Report 90-130, available online at http://pubs.usgs.gov/ of/1990/ofr90130/report.html

Allen, H.E., Fu, G., Boothman, W., Di Toro, D.M., and Mahony, J.D., 1991, Determination of acid volatile sulfide and selected simultaneously extractable metals in sediment: U.S. Environmental Protection Agency 821-R-91-100, 18 p.

Allen, H.E., Fu, G., and Deng, B., 1993, Analysis of acidvolatile sulfide (AVS) and simultaneously extracted metals (SEM) for the estimation of potential toxicity in aquatic sediments: Environmental Toxicology and Chemistry, v. 12, p. 1441-1453.

Alley, W.M., and Emery, P.A., 1986, Groundwater model of the Blue River Basin, Nebraska-Twenty Years Later: Journal of Hydrology, v. 85, p. 225-249.

American Public Health Association, 1998, UV-Absorbing organic constituents (19 ${ }^{\text {th }}$ ed.): Standard Methods for the Examination of Water and Wastewater, p. 5-60 to 5-62

American Society of Testing and Materials, 2002, Standard Test Method for Isotopic Uranium in Water by Radiochemistry, ASTM D 3972-02.

Apodaca, L.E., Mueller, D.K., and Koterba, M.T., 2006, Review of trace element blank and replicate data collected in ground and surface water for the National Water-Quality Assessment Program, 1991-2002: U.S. Geological Survey Scientific Investigations Report 2006-5093, 32 p.

Appelo, C.A.J., and Postma, D., 1999, Geochemistry, groundwater, and pollution: Rotterdam, the Netherlands, AA. Balkema, 536 p. 
Argonne National Laboratory, 1993, Final work plan: extended site characterization demonstration, York, Nebraska, prepared for Community Credit Corporation, United States Department of Agriculture, June.

Argonne National Laboratory, 1994, Final phase I report and phase II work plan: expedited site characterization, York, Nebraska: Prepared for Community Credit Corporation, United States Department of Agriculture.

Argonne National Laboratory, 1995a, Final phase II report: expedited site characterization, York, Nebraska: Prepared for Community Credit Corporation, United States Department of Agriculture.

Argonne National Laboratory, 1995b, Final feasibility study for remedial action at York, Nebraska: Prepared for Community Credit Corporation, United States Department of Agriculture.

Artinger, R., Rabung, T., Kim, J.I., Sachs, S., Schmeide, K., Heise, K.H., Bernhard, G., and Nitsche, H., 2002, Humic colloid-borne migration of uranium in sand columns: Journal of Contaminant Hydrology, v. 58, p. 1-12.

Bailey, R.G., 1980, Description of the ecoregions of the United States: U.S. Department of Agriculture, Miscellaneous Publication 1391, Washington, D.C., 77 p.

Barrett, M.H., Hiscock, K.M., Pedley, S., Lerner, D.N., Tellam, J.H., and French, M.J., 1999, Marker species for identifying urban groundwater recharge sources: a review and case study in Nottingham, UK: Water Research, v. 33, no. 14 , p. 3083-3097.

Böhlke, J.K., 2002, Groundwater recharge and agricultural contamination: Hydrogeology Journal, v. 10, p. 153-179.

Böhlke, J.K., 2003, Sources, transport, and reaction of nitrate in ground water, in Lindsey and others, eds., Residence Times and Nitrate Transport in Ground Water Discharging to Streams in the Chesapeake Bay Watershed: U. S. Geological Survey Water-Resources Investigations Report 03-4035, p. 25-38.

Böhlke, J.K., 2006, TRACERMODEL1. Excel workbook for calculation and presentation of environmental tracer data for simple groundwater mixtures, in IAEA Guidebook on the Use of Chlorofluorocarbons in Hydrology, Publication 1238, International Atomic Energy Agency, Vienna, 291 p.

Böttcher J., Strebel, O., Voerkelius, S., and Schmidt, H-L., 1990, Using isotope fractionation of nitrate-nitrogen and nitrate-oxygen for evaluation of microbial denitrification in a sandy aquifer: Journal of Hydrology, v. 114, p. 413-424.

Bouwer, Herman, and Rice, R.C., 1976, A slug test for determining hydraulic conductivity of unconfined aquifers with completely or partially penetrating wells: Water Resources Research, v. 12, p. 423-428.
Bowles, K.C., Ernste, M.J., and Kramer, J.R., 2003, Trace sulfide determination in oxic fresh waters: Analytica Chimica Acta, v. 477, p. 113-124.

Bradley, P.M., 2000, Microbial degradation of chloroethenes in groundwater systems: Hydrogeology Journal, v. 8, no. 1, p. 104-111.

Brenton, R.W., and Arnett, T.L., 1993, Methods of analysis by the U.S. Geological Survey National Water Quality Laboratory-Determination of dissolved organic carbon by uv-promoted persulfate oxidation and infrared spectrometry: U.S. Geological Survey Open-File Report 92-480, 12 p.

Busenberg, E., and Plummer, L.N., 1992, Use of chlorofluorocarbons $\left(\mathrm{CCl}_{3} \mathrm{~F}\right.$ and $\left.\mathrm{CCl}_{2} \mathrm{~F}_{2}\right)$ as hydrologic tracers and age-dating tools: The alluvium and terrace system of central Oklahoma: Water Resources. Research, v. 28, no. 9, p. 2257-2283.

Busenberg, E., and Plummer, L.N., 2000, Dating young ground water with sulfur hexafluoride: Natural and anthropogenic sources of sulfur hexafluoride: Water Resources Research, v. 36, no.10, p. 3011-3030.

Busenberg, E., Plummer, L. N., Doughten, M. W., Wildman, P. K., and Bartholomay, R. C., 2000, Chemical, isotopic, and gas compositions of ground and surface waters from selected sites in and near the Idaho National Engineering and Environmental Laboratory, Idaho, 1994-97: U.S. Geological Survey Open-File Report 00-81, 55 p.

Busenberg, E., Weeks, E.P., Plummer, L.N., and Bartholemay, R.C., 1993, Age dating ground water by use of chlorofluorocarbons $\left(\mathrm{CCl}_{3} \mathrm{~F}\right.$ and $\left.\mathrm{CC}_{2} \mathrm{~F}_{2}\right)$, and distribution of chlorofluorocarbons in the unsaturated zone, Snake River Plain aquifer, Idaho National Engineering laboratory, Idaho: U.S. Geological Survey Water-Resources Investigations 93-4054, 47 p.

Butler, J.J., 1998, The design, performance, and analysis of slug tests: New York, Lewis Publishers, 252 p.

Butler, J.J., Garnett, E.J., and Healey, J.M., 2003, Analysis of slug tests in formations of high hydraulic conductivity: Ground Water, v. 41, no. 5, p. 620-630.

Cady, R.E., and Ginsburg, M.H., 1979, Interpretative study and numerical model of the hydrogeology of Upper Big Blue Natural Resources District: Lincoln, Nebraska, Conservation and Survey Division, University of NebraskaLincoln, 185 p.

Canfield, D.E., Raiswell, R., Westrich, J.T., Reaves, C.M., and Berner, R.A., 1986, The use of chromium reduction in the analysis of reduced inorganic sulfur in sediments and shales: Chemical Geology, v. 54, p. 149-155. 
Carmody, R.W., Plummer, L.N., Busenberg, E., and Coplen, T.B., 1997, Methods for collection of dissolved sulfate and sulfide and analysis of their sulfur isotopic composition: U.S. Geological Survey Open-File Report 97-234, 91 p.

Casciotti, K.L., Sigman, D.M., Galanter Hastings, M., Böhlke, J.K., and Hilkert, A., 2002, Measurement of the oxygen isotopic composition of nitrate in seawater and freshwater using the denitrifier method: Analytical Chemistry, v. 74, p. 4905-4912.

Ceazan, M.L., Thurman, M.E., and Smith, R.L., 1989, Retardation of ammonium and potassium transport through a contaminated sand and gravel aquifer: the role of cation exchange: Environmental Science and Technology, v. 23, no. 11, p.1402-1408.

Center for Advanced Land Management Information Technologies (CALMIT), 2000, Delineation of 1997 land use patterns for the Cooperative Hydrology Study in the Central Platte River Basin: Lincoln, Nebraska, University of Nebraska, Center for Advanced Land Management Information Technologies.

Champ, D.R., Gulens, J., and Jackson, R.E., 1979, Oxidationreduction sequences in ground water flow systems: Canadian Journal of Earth Sciences, v. 16, no. 1, p. 12-23.

Chapelle, F.H., and Lovely, D.R., 1990, Hydrogen concentrations in ground water as an indicator of bacterial processes in deep aquifer systems: First International Symposium on the Microbiology of the Deep Subsurface, U.S. Department of Energy, Orlando, Florida, January 15-19, 1990.

Chapelle, F.H., McMahon, P.B., Dubrovsky, N.M., Fujii, R.F., Oaksford, E.T., and Vroblesky, D.A., 1995, Deducing the distribution of terminal electron-accepting processes in hydrologically diverse groundwater systems: Water Resources Research, v. 31, no. 2, p. 359-371.

Chapelle, F.H., 2001, Ground-water microbiology and geochemistry ( $2^{\mathrm{d}}$ ed.): New York, John Wiley and Sons, Inc., $477 \mathrm{p}$.

Childress, C. J. O., Foreman, W. T., Connor, B. F., and Maloney, T. J., 1999, New reporting procedures based on long-term method detection levels and some considerations for interpretations of water-quality data provided by the U.S. Geological Survey National Water Quality Laboratory: U.S. Geological Survey Open-File Report 99-193, p. 99-193.

Clark, B.R., Landon, M.K., Kauffman, L.J., and Hornberger, G.Z., 2008, Simulations of ground-water flow, transport, age, and particle tracking near York, Nebraska for a study of transport of anthropogenic and natural contaminants (TANC) to public supply wells: U.S. Geological Survey Scientific Investigations Report 2007-5068, 47 p.
Clark, B.R., Landon, M.K., Kauffman, L.J., and Hornberger, G.Z., 2006, Simulation of solute movement through well bores to characterize public supply well contaminant vulnerability in the High Plains Aquifer, York, Nebraska: International Ground Water Modeling Center: Modflow and More Conference, May 22-24, 2006, Golden, Colorado.

Clark, W.B., Jenkins, W.J., and Top, Z., 1976, Determination of tritium by mass spectrometric measurement of ${ }^{3} \mathrm{He}$ : International Journal of Applied Radiation and Isotopes, v. 27 , p. $515-522$.

Clark, I.D., and Fritz, P., 1997, Environmental isotopes in hydrogeology: New York, Lewis Publishers, 328 p.

Connor, B.F. , Rose, D.L., Noriega, M.C., Murtagh, L.K., and Abney, S.R., 1998, Methods of analysis by the U.S. Geological Survey National Water Quality LaboratoryDetermination of 86 volatile organic compounds in water by gas chromatography/mass spectrometry, including detections less than reporting limits: U.S. Geological Survey Open-File Report 97-829, 78 p.

Cook, P.G., and Böhlke, J.K., 2000, Determining timescales for groundwater flow and solute transport, in Cook, P. G., and Herczeg, A., eds., Environmental tracers in subsurface hydrology: Boston, Massachusetts, Kluwer Academic Publishers, p. 1-30.

Coplen, T.B., 1993, Uses of environmental isotopes, chap. 10 of Alley, W.M., ed., Regional Ground-Water Quality: New York, Van Nostrand Reinhold, p. 227-254.

Coplen, T.B., Wildman, J.D. and Chen, J., 1991. Improvements in the gaseous hydrogen-water equilibration technique for hydrogen isotope ratio analysis: Analytical Chemistry, v. 63, p. 910-912.

Craig, H., 1961, Isotopic variations in meteoric waters: Science, v. 133, p. 1702-1703.

Curtis, G.P., Davis, J.A., and Naftz, D.L., 2006, Simulation of reactive transport of uranium (VI) in groundwater with variable chemical conditions: Water Resources Research, v. 42, W04404, doi:10.1029/2005WR003979.

Dabous, A.A., and Osmond, J.K., 2001, Uranium isotopic study of artesian and pluvial contributions to the Nubian Aquifer, Western Desert, Egypt: Journal of Hydrology, v. 243 , p. 242-253.

Darling, W.G., and Bath, A.H., 1988, A stable isotope study of recharge processes in the English Chalk: Journal of Hydrology, v. 101, p. 31-46.

Davis, S.N., Whittemore, D.O., and Fabryka-Martin, J., 1998, Uses of chloride/bromide ratios in studies of potable water: Ground Water, v. 36, no. 2, p. 338-350. 
Dennehy, K.F., 2000, High Plains regional ground-water study: U.S. Geological Survey Fact Sheet FS-091-00, 6 p.

Dennehy, K.F., Litke, D.W., and McMahon, P.B., 2002, The High Plains aquifer, USA: groundwater development and sustainability, in K.M., Hiscock, M.O., Rivett, and R.M., Davison, eds., Sustainable Groundwater Development, Geological Society: London, Special Publications, v. 193, p. 99-119.

Dreeszen, V. H., 2001, Configuration of water table, circa 1995, Lincoln 1:250,000 Quadrangle: Nebraska Conservation and Survey Division, Lincoln, Nebraska, Groundwater Map 54.5, 1 sheet.

Drimmie, R.J., Heemskerk, A.R. and Aravena, R.O., 1994. Dissolved Inorganic Carbon (DIC), Technical Procedure 5.0, Rev. 02. Environmental Isotope Laboratory: Waterloo, Ontario, Department of Earth Sciences, University of Waterloo, 7 p.

Druliner, A.D., Chen, H.H., and McGrath, T.S., 1996, Relations of nonpoint-source nitrate and atrazine concentrations in the High Plains aquifer to selected explanatory variables in six Nebraska study areas: U.S. Geological Survey Water-Resources Investigations Report 95-4202, 51 p.

Dutton, A.R., 1995, Ground water isotopic evidence for paleorecharge in US High Plains aquifers: Quaternary Research, v. 43, p. 221-231.

Eberts, S.M., Erwin, M.L., and Hamilton, P.A., 2005a, Assessing the vulnerability of public-supply wells to contamination from urban, agricultural, and natural sources: U.S. Geological Survey Fact Sheet 2005-3022. Accessed on September 1, 2006 at http://pubs.usgs.gov/fs/2005/3022

Eberts, S.M., Jones, S.A., Braun, C.L., and Harvey, G.J., 2005b, Long-term changes in ground water chemistry at a phytoremediation demonstration site: Ground Water, v. 43, no. $2,178-186$.

Emery, P.A., 1966, Use of analog model to predict streamflow depletion, Big and Little Blue River Basin, Nebraska: Ground Water, v. 4(4), p. 13-20.

Epstein, S., and Mayeda, T., 1953, Variation of O-18 content of water from natural sources: Geochimica et Cosmochimica Acta, v. 4, p. 213-224.

Fishman, M.J., ed., 1993, Methods of analysis by the U.S. Geological Survey National Water Quality LaboratoryDetermination of inorganic and organic constituents in water and fluvial sediments: U.S. Geological Survey OpenFile Report 93-125, 217 p.
Fishman, M.J., and Friedman, L.C., 1989, Methods for determination of inorganic substances in water and fluvial sediments: U.S. Geological Survey Techniques of WaterResources Investigations, book 5, chap. A1, 545 p.

Focazio, M.J., Welch, A.H., Watkins, S.A., Helsel, D.R., and Horn, M.A., 1999, A retrospective analysis on the occurrence of arsenic in ground-water resources of the United States and limitations in drinking-water-supply characterizations: U.S. Geological Survey Water-Resources Investigation Report 99-4279, 21 p.

Focazio, M.J., Reilly, T.E., Rupert, M.G., and Helsel, D.R., 2002, Assessing ground-water vulnerability to contamination: providing scientifically defensible information for decision makers: U.S. Geological Survey Circular 1224, 33 p.

Fogg, G.E., Rolston, D.E., Decker, D.L., Louie, D.T., and Grismer, M.E., 1998, Spatial variation in nitrogen isotope values beneath nitrate contamination sources: Ground Water, v. 36, no. 3, p. 418-426.

Franke, O.L., Reilly, T.E., Pollock, D.W., and LaBaugh, J.W., 1998, Estimating areas contributing recharge to wellsLessons from previous studies: U.S. Geological Survey Circular 1174, 14 p.

Franti, T.G., and Dorn, B.J., 1998, Blue River Basins agricultural survey-fertilizer use and irrigation management: Nebraska Cooperative Extension NebFacts NF98-371, Cooperative Extension, Institute of Agriculture and Natural Resources, University of Nebraska-Lincoln, 9 p. Accessed on August 5, 2002 at http://www.ianr.unl.edu/ pubs/water/nr371.htm

Freeze, R.A., and Cherry, J.A., 1979, Groundwater: Englewood Cliffs, New Jersey, Prentice-Hall Inc., 604 p.

Garbarino, J.R., Bednar, A.J., and Burkhardt, M.R., 2002, Methods of analysis by the U.S. Geological Survey National Water Quality Laboratory--Arsenic speciation in naturalwater samples using laboratory and field methods: U.S. Geological Survey Water-Resources Investigations Report 02-4144, 40 p.

Garbarino, J.R., Kanagy, L.K., and Cree, M.E., 2006, Determination of elements in natural-water, biota, sediment and soil samples using collision/reaction cell inductively coupled plasma-mass spectrometry: U.S. Geological Survey Techniques and Methods, book 5, sec. B, chap.1, 88 p.

Gilliom, R.J., Barbash, J.E., Crawford, C.G., Hamilton, P.A., Martin, J.D., Nakagaki, N., Nowell, L.H., Scott, J.C., Stackelberg, P.E., Thelin, G.P., and Wolock, D.M., 2006, Pesticides in the Nation's streams and ground water, 1992-2001: U.S. Geological Survey Circular 1291, 150 p. 
Gonfiantini, R., 1986, Environmental isotopes in lake studies, in Fritz, P. and Fontes, J-Ch., eds., Handbook of Environmental Isotope Geochemistry, v. 2, The Terrestrial Environment B: Amsterdam, The Netherlands, Elsevier, p. 113-168.

Gottula, J.J., and Link, M.L., 1992, A study of nonpoint source ground water contamination in the Western Portion of the Upper Big Blue Natural Resources District: A Special Area Report, Nebraska Department of Environmental Control, Water Quality Division, Ground Water Section, Lincoln, Nebraska, variously paged.

Gutentag, E.D., Heimes, F.J., Krothe, N.C., Luckey, R.R., and Weeks, J.B., 1984, Geohydrology of the High Plains aquifer in parts of Colorado, Kansas, Nebraska, New Mexico, Oklahoma, South Dakota, Texas, and Wyoming: U.S. Geological Survey Professional Paper 1400-B, 63 p.

Hach Company, 2002. DR/2400 Spectrophotometer Procedures Manual: Loveland, Colorado, 450 p.

Halford, K.J. and Kuniansky, E.L., 2002, Documentation of spreadsheets for the analysis of aquifer-tests and slug-test data: U.S. Geological Survey Open-File Report 02-197, $51 \mathrm{p}$.

Hanson, R.T., Li, Zhen, and Faunt, C.C., 2004, Documentation of the Santa Clara Valley regional ground-water/surfacewater flow model, Santa Clara County, California: U.S. Geological Survey Scientific Investigations Report 2004-5231, 75 p.

Harvey, F.E., 2001, Use of NADP archive samples to determine the isotope composition of precipitation: characterizing the meteoric input function for use in ground water studies: Ground Water, v. 39, no. 3, p. 380-390.

Harvey, F.E., and Welker, J.M., 2000, Stable isotopic composition of precipitation in the semi-arid north-central portion of the US Great Plains: Journal of Hydrology, v. 238 , p. $90-109$.

Helsel, D.R. and Hirsch, R.M., 1992, Statistical methods in water resources: Amsterdam, The Netherlands, Elsevier, Studies in Environmental Science, v. 49, 522 p.

High Plains Climate Center, 2003, Climate Data Archives Available: Accessed on March 11, 2003 at http://www. hprcc.unl.edu/data/

House, W.A., 2003, Geochemical cycling of phosphorus in rivers: Applied Geochemistry, v. 18, no. 5, p. 739-748.

Huntoon, P.W., 1974, Predicted water-level declines for alternative groundwater developments in the Upper Big Blue River Basin, Nebraska: Lincoln, Nebraska, Conservation and Survey Division, University of NebraskaLincoln, Resource Report no. 6, 106 p.
Izbicki, J.A., Christensen, A.H., and Hanson, R.T., 1999, U.S. Geological Survey combined well-bore flow and depthdependent water sampler: U.S. Geological Survey Fact Sheet 196-99, 2 p.

Izbicki, J.A., Christensen, A.H., Newhouse, and Aiken, G.R., 2005a, Inorganic, isotopic, and organic composition of highchloride water from wells in a coastal southern California aquifer: Applied Geochemistry, v. 20, p. 1496-1517.

Izbicki, J.A., Christensen, A.H., Newhouse, M.W., Smith, G.A., and Hanson, R.T., 2005b, Temporal changes in the vertical distribution of flow and chloride in deep wells: Ground Water, v. 43, no. 4, p. 531-544.

Johnson, C.R., and Keech, C.F., 1959, Geology and ground water resources of the Big Blue River Basin above Crete, Nebraska: U.S. Geological Survey Water-Supply Paper 1474, 94 p.

Kakiuchi, M., and Matsuo, S., 1979, Direct measurements of $\mathrm{D} / \mathrm{H}$ and ${ }^{18} \mathrm{O} /{ }^{16} \mathrm{O}$ fractionation factors between vapor and liquid water in the temperature range from $10^{\circ}$ to $40^{\circ}$ : Geochemical Journal, v. 13: p. 307-311.

Kalin, R.M., 2000, Radiocarbon dating of groundwater systems, in Cook, P. G., and Herczeg, A., eds., Environmental tracers in subsurface hydrology: Boston, Massachusetts, Kluwer Academic Publishers, p. 111-144.

Keech, C.F., Dreeszen, V.H., and Emery, P.A., 1967, Availability of ground water in York County, Nebraska: U.S. Geological Survey Water-Supply Paper 1839-F, 17 p.

Kendall, C., 1998, Tracing nitrogen sources and cycling in catchments, in Kendall, C., and McDonnell, J.J., eds., Isotope tracers in catchment hydrology: Amsterdam, The Netherlands, Elsevier Science, chap. 16, p. 519-576.

Kendall, C., and Coplen, T.B., 2001, Distribution of oxygen-18 and deuterium in river waters across the United States: Hydrological Processes, v. 15, p. 1363-1393.

Kent, D.B., and Fox, P.M., 2004, The influence of groundwater chemistry on arsenic concentrations and speciation in a quartz sand and gravel aquifer: Geochemical Transactions, v. 5, no. 1, 12 p.

Kersting, A.B., Efurd, D.W., Finnegan, D.L., Rokop, D.J., Smith, D.K., and Thompson, J.L., 1999, Migration of plutonium in ground water at the Nevada Test Site: Nature, v. $397,56-59$.

Kim, J.I., 1994, Actinide colloids in natural aquifer systems: Materials Research Society Bulletin, v. 19 (12), p. 47-53.

Kirkham Michael Consulting Engineers, 2003, Water System Master Plan, city of York, Nebraska: Prepared for city of York, Nebraska, August 28, 2003, 77 p. 
Konikow, L.F., and Hornberger, G.Z., 2006, Use of the multi-node well (MNW) package when simulating solute transport with the MODFLOW ground-water transport process: U.S. Geological Survey Techniques and Methods, chap. 6-A15, 34 p.

Koterba, M.T., Wilde, F.D., and Lapham, W.W., 1995, Ground-water data-collection protocols and procedures for the National Water-Quality Assessment ProgramCollection and documentation of water-quality samples and related data: U.S. Geological Survey Open-File Report 95-399, $113 \mathrm{p}$.

Kraemer, T.F., and Genereux, D.P., 1998, Applications of uranium- and thorium-series radionuclides in catchment hydrology studies, chap. 20, in Kendall, C. and McDonnell, J.J., eds., Isotope tracers in catchment hydrology: Amsterdam, The Netherlands, Elsevier Science, p. 679-722.

Kreitler, C.W., 1975, Determining the source of nitrate in ground water by nitrogen isotope studies: University of Texas, Bureau of Economic Geology Report of Investigations 83, $57 \mathrm{p}$.

Krouse, H.R., and Mayer, B., 2000, Sulfur and oxygen isotopes in sulfate, in Cook, P. G., and Herczeg, A., eds., Environmental tracers in subsurface hydrology: Boston, Massachusetts, Kluwer Academic Publishers, p. 195-232.

Landon, M.K., and Turco, M.J., 2007, Hydrogeologic setting and ground-water flow simulation of the Eastern High Plains Regional Study Area, Nebraska, section 8 in Paschke, S.S., ed., Hydrogeologic settings and ground-water flow simulations for regional studies of the transport of anthropogenic and natural contaminants to public-supply wells-studies begun in 2001: U.S. Geological Survey Professional Paper 1737-A, p. 8-1 to 8-28.

Langmuir, D., 1997, Aqueous environmental geochemistry: Prentice Hall, New Jersey, 600 p.

Lapham, W.W., Wilde, F.D., and Koterba, M.T., 1995, Ground-water data collection protocols and procedures for the National Water-Quality Assessment Program: selection, installation, and documentation of wells and collection of related data: U.S. Geological Survey Open-File Report 95-398, 69 p.

Lapham, W.W., Wilde, F.D., and Koterba, M.T., 1996, Guidelines and standard procedures for studies of groundwater quality: selection and installation of wells, and supporting documentation: U.S. Geological Survey WaterResources Investigations Report 96-4233, 110 p.
Lee, E.A., Strahan, A.P., and Thurman, E.M., 2002, Methods of Analysis by the U.S. Geological Survey Organic Geochemistry Research Group-Determination of glyphosate, aminomethylphosphonic acid, and glufosinate in water using online solid-phase extraction and highperformance liquid chromatography/mass spectrometry: U.S. Geological Survey Open-File Report 01-454, 13 p.

Lindberg, R. D., and Runnells, D. D., 1984, Groundwater redox reactions: Science, v. 225, p. 925-927.

Lovley, D.R., and Phillips, E.J.P., 1987, Rapid assay for microbially reducible ferric iron in aquatic sediments: Applied Environmental Microbiology, v. 53, no. 7, p. 1536-1540.

Luckey, R.R., Gutentag, E.D., Heimes, F.J., and Weeks, J.B., 1986, Digital simulation of ground-water flow in the High Plains aquifer in parts of Colorado, Kansas, Nebraska, New Mexico, Oklahoma, South Dakota, Texas, and Wyoming: U.S. Geological Survey Professional Paper 1400-D, 63 p.

Ma, Li, 1996, Impact of artificial groundwater recharge at two Nebraska sites: Lincoln, Nebraska, University of NebraskaLincoln, Ph. D. Dissertation, 209 p.

Ma, Li, and Spalding, R.F., 1997, Herbicide persistence and mobility in recharge lake watershed in York, Nebraska: Journal of Environmental Quality, v. 26, no. 1, p. 115-125.

Madsen, J.E., Sandstrom, M.W., and Zaugg, S.D., 2003, Methods of analysis by the U.S. Geological Survey National Water Quality Laboratory-A method supplement for the determination of fipronil and degradates in water by gas chromatography/mass spectrometry: U.S. Geological Survey Open-File Report 02-462, 11 p.

Maloney, T.J., ed., 2005, Quality management system, U.S. Geological Survey National Water Quality Laboratory: U.S. Geological Survey Open-File Report 2005-1263, version 1.3, accessed on January 10, 2007, at http://pubs.usgs.gov/ of/2005/1263/pdf/OFR2005-1263.pdf.

Mathieu, R., and Bariac, T., 1996, An isotopic study $\left({ }^{2} \mathrm{H}\right.$ and ${ }^{18} \mathrm{O}$ ) of water movements in clayey soils under a semiarid climate: Water Resources Research, v. 32, p. 779-789.

McCray, J.E., Kirkland, S.L., Siegrist, R.L., and Thyne, G.D., 2005, Model parameters for simulating fate and transport of on-site wastewater nutrients: Ground Water, v. 43, no. 4, p. 628-639.

McMahon, P.B., 2001a, Vertical gradients in water chemistry in the central High Plains aquifer, southwestern Kansas and Oklahoma Panhandle, 1999: U.S. Geological Survey WaterResources Investigations Report 01-4028, 35 p. 
McMahon, P.B., 2001b, Aquifer/aquitard interfaces: mixing zones that enhance biogeochemical reactions: Hydrogeology Journal, v. 9, p. 34-43.

McMahon, P.B., Böhlke, J.K., and Bruce, B.W., 1999, Denitrification in marine shales in northeastern Colorado: Water Resources Research, v. 35, no. 5, p. 1629-1642.

McMahon, P.B., Böhlke, J.K., and Christenson, S.C., 2004, Geochemistry, radiocarbon ages, and paleorecharge conditions along a transect in the central High Plains aquifer, southwestern Kansas, USA: Applied Geochemistry, v. 19 , p. $1655-1686$.

McMahon, P., Böhlke, J.K., Kauffman, L.J., Kipp, K.L., Landon, M.K., Crandall, C.A., Burow, K.R., and Brown, C.J., 2008, Source and transport controls on the movement of nitrate to public supply wells in selected principal aquifers of the United States: Water Resources Research, v. 44, W04401, doi:10.1029/2007WR006252.

Mengis, M., Schiff, S.L., Harris, M., English, M.C., Aravena, R., Elgood, R.J., MacLean, Al, 1999, Multiple geochemical and isotopic approaches for assessing ground water $\mathrm{NO}_{3}^{-}$elimination in a riparian zone: Ground Water, v. 37, no. 3, p. 448-457.

Missana, T., Garc1a-Gutierrez, M., Alonso, U., 2004, Kinetics and irreversibility of cesium and uranium sorption onto bentonite colloids in a deep granitic environment: Applied Clay Science, 26, 137-150.

Moran, M.J., Zogorski, J.S., and Squillace, P.J., 2007, Chlorinated solvents in groundwater of the United States: Environmental Science and Technology, v. 41, no. 1, p. 74-81.

Morrissey, D.J., 1989, Estimation of the recharge area contributing water to a pumped well in a glacial-drift, rivervalley aquifer: U.S Geological Survey Water-Supply Paper $2338,41 \mathrm{p}$.

Mustick, J.T., and Stewart, B.A., 1992, Irrigation technologies, in D.E. Kromm and S.E. White, eds., Groundwater Exploitation in the High Plains: Lawrence Kansas, University Press of Kansas, p. 110-144.

National Atmospheric Deposition Program, 2005, NADP/ NTN Monitoring Location NE15. Accessed on November 23, 2005 at http://nadp.sws.uiuc.edu/sites/siteinfo. asp?id=NE15\&net=NTN

Nebraska Cooperative Hydrology Study Group, 2001, Preliminary data and reports: Accessed on August 13, 2001 at http://cohyst.dnr.ne.gov/cohyst preliminarydata.html
Nebraska Conservation and Survey Division, 1980, Configuration of the water table 1979, 1:250,000 Lincoln and Nebraska City Quadrangle, Nebraska: Lincoln, Nebraska, University of Nebraska, Conservation and Survey Division, 1 sheet.

Nebraska Department of Natural Resources, 2002, Registered groundwater wells data base: Accessed on January-July 2002 at http://dnrdata.dnr.ne.gov/wellssql/

Nebraska Natural Resources Commission (NNRC), 1983, Report on the Big and Little Blue River Basins area planning study, Technical Appendix A: Groundwater resources, development, calibration, verification, and utilization of groundwater models: Lincoln, Nebraska, Nebraska Natural Resources Commission,

Nimmo, J. R. and Mello, K. A., 1991, Centrifugal techniques for measuring saturated hydraulic conductivity: Water Resources Research, v. 27, p. 1263-1269.

Nimmo, J. R., Perkins, K.S., and Lewis, A.M., 2002, Steadystate centrifuge, in Dane, J.H., and Topp, G.C., eds., Methods of soil analysis, Part 4-Physical methods: Soil Science Society of America Book Series No. 5: Madison, Wisconsin, Soil Science Society of America, p. 903-916.

Nolan, B.T., and Stoner, J.D., 2000, Nutrients in ground waters of the conterminous United States, 1992-1995: Environmental Science and Technology, v. 34, no. 7, p. 1156-1165.

Osmond, J.K., and Cowart, J.B., 2000, U-series nuclides as tracers in groundwater hydrology, in Cook, P., and Herczeg, A., eds., Environmental tracers in subsurface hydrology: Boston, Massachusetts, Kluwer Academic Publishers, p. $145-174$.

Oster, H., Sonntag, C., and Munnich, K.O., 1996, Groundwater age dating with chlorofluorocarbons: Water Resources Research, v. 32, p. 2989-3001.

Östlund, H.G., 1987, Tritium: GEOSECS Atlantic, Pacific, and Indian Ocean Expeditions, v. 7, p. 7-10.

Panno, S.V., Hackley, K.C., Hwang, H.H., Greenburg, S.E., Krapac, I.G., Landsberger, S., and O'Kelley, D.J., 2006, Characterization and identification of $\mathrm{Na}-\mathrm{Cl}$ sources in ground water: Ground Water, v. 44, no., 2, p. 176-187.

Parkhurst, D.L., and Appelo, C.A.J., 1999, User's guide to PHREEQC (Version 2) - a computer program for speciation, batch-reaction, one-dimensional transport, and inverse geochemical calculations: U.S. Geological Survey Water-Resources Investigations Report 99-4259, 312 p. 
Paschke, S.S., ed., 2007, Hydrogeologic settings and groundwater flow simulations for regional studies of the transport of anthropogenic and natural contaminants to public-supply wells - Studies begun in 2001: U.S. Geological Survey Professional Paper 1737-A, 288 p.

Patton, C.J., and Kryskalla, J.R., 2003, Methods of analysis by the U.S. Geological Survey National Water Quality Laboratory-Evaluation of alkaline persulfate digestion as an alternative to Kjeldahl digestion for determination of total and dissolved nitrogen and phosphorus in water: U.S. Geological Survey Water-Resources Investigations Report 03-4174, 33 p.

Piper, A.M., and Garrett, A.A., 1953, Native and contaminated ground waters in the Long Beach-Santa Ana area, California: U.S. Geological Survey Water Supply Paper $1136,320 \mathrm{p}$.

Plummer, L.N., Michel, R.L., Thurman, E.M., and Glynn, P.D., 1993, Environmental tracers for age dating young ground water, chap. 11, in Alley, W.M., ed., Regional Ground-Water Quality: New York, Van Nostrand Reinhold, p. 255-296.

Plummer, L.N., Busenberg, E., Drenkard, S., Schlosser, P., Ekwurzel, B., Weppernig, R., McConnell, J.B., and Michel, R.L., 1998, Flow of river water into a karstic limestone aquifer-2. Dating the young fraction in groundwater mixtures in the Upper Floridian aquifer near Valdosta, Georgia: Applied Geochemistry, v. 13(8), p. 1017-1043.

Plummer, L.N., and Busenberg, E., 2000, Chlorofluorocarbons, in Cook, P. G., and Herczeg, A., eds., Environmental Tracers in Subsurface Hydrology: Boston, Massachusetts, Kluwer Academic Publishers, p. 441-478.

Plummer, L.N., Rupert, M.G., Busenberg, E., and Schlosser, P., 2000, Age of irrigation water in ground water from the Eastern Snake River Plain aquifer, south-central Idaho. Ground Water, v. 38, no. 2, 264-283.

Prichard, H.M., and Gesell, T.F., 1977, Rapid measurements of radon-222 concentrations in water with a commercial liquid scintillation counter: Health Physics, v. 33, p. 577-581.

Puls, R.W., and Powell, R.M., 1992, Transport of inorganic colloids through natural aquifer material: implications for contaminant transport: Environmental Science and Technology, v. 26, no. 3, p. 614-621.

Reay, W.G., 2004, Septic tank impacts on ground water quality and nearshore sediment nutrient flux: Ground Water, v. 42, no. 7, p. 1079-1089.

Reilly, T.E., and Pollock, D.W., 1993, Factors affecting areas contributing recharge to wells in shallow aquifers: U.S. Geological Survey Water-Supply Paper 2412, 21 p.
Robertson, W.D., Cherry, J.A., and Sudicky, E.A., 1991, Ground-water contamination from two small septic systems on sand aquifers: Ground Water, v. 29, no. 1, p. 82-92.

Robertson, W.D., Schiff, S.L., and Ptacek, C.J., 1998, Review of phosphate mobility and persistence in 10 septic system plumes: Ground Water, v. 36, no. 6, p. 1000-1010.

Rose, D.L., and Sandstrom, M.W., 2003, Methods of analysis by the U.S. Geological Survey National Water Quality Laboratory - Determination of gasoline oxygenates, selected degradates, and BTEX in water by heated purge and trap/gas chromatography/mass spectrometry: U.S. Geological Survey Water Resources Investigations Report 03-4079, $31 \mathrm{p}$.

Sandino, Amaia, and Bruno, Jordi, 1992, The solubility of $\left(\mathrm{UO}_{2}\right)_{3}\left(\mathrm{PO}_{4}\right)_{2} \cdot 4 \mathrm{H}_{2} \mathrm{O}_{(\mathrm{s})}$ and the formation of $\mathrm{U}(\mathrm{VI})$ phosphate complexes - Their influence in uranium speciation in natural waters: Geochemica et Cosmochimica Acta, v. 56, p. 4135-4145.

Sandstrom, M.W., Stroppel, M.E., Foreman, W.T., and Schroeder, M.P., 2001, Methods of analysis by the U.S. Geological Survey National Water Quality Laboratorydetermination of moderate-use pesticides and selected degradates in water by $\mathrm{C}$ - 18 solid-phase extraction and gas chromatography/mass spectrometry: U.S. Geological Survey Water-Resources Investigations Report 01-4098, $70 \mathrm{p}$.

Sanudo-Wilhelmy, S.A., Rossi, F.K., Bokuniezicz, H., and Paulsen, R.J., 2002, Trace metal levels in uncontaminated groundwater of a coastal watershed: importance of colloidal forms: Environmental Science and Technology, v. 36, no. 7, p. 1435-1441.

Schlosser, P., Stute, M., Dorr, H., Sonntag, C., and Munnich, K.O., 1988, Tritium $/{ }^{\beta} \mathrm{He}$ dating of shallow groundwater: Earth and Planetary Science Letters, v. 89, p. 353-362.

Schlosser, P., Stute, M., Sonntag, C., and Munnich, K.O., 1989, Tritiogenic ${ }^{3} \mathrm{He}$ in shallow groundwater: Earth and Planetary Science Letters, v. 94, p. 245-256.

Shah, N., Nachabe, M., and Ross, M., 2007, Extinction depth and evapotranspiration from ground water under selected land covers: Ground Water, v. 45, no. 3, p. 329-338.

Sigman, D.M., Casciotti, K.L, Andreani, M., Barvord, C., Galanter, M., and Böhlke, J.K., 2001, A bacterial method for the nitrogen isotopic analysis of nitrate in seawater and freshwater: Analytical Chemistry, v. 73, p. 4145-4153.

Sinaj, S., Stamm, C., Toor, G.S., Condron, L.M., Hendry, T., Di, H.J., Cameron, K.C., and Frossard, E., 2002, Phosphorus exchangeability and leaching losses from two grassland soils: Journal of Environmental Quality, v. 31, p. 319-330. 
Smedley, P.L., and Kinniburgh, D.G., 2002, A review of the source, behavior, and distribution of arsenic in natural waters: Applied Geochemistry, v. 17, p. 517-568.

Snow, D.D., and Spalding, R.F., 1994, Uranium isotopes in the Platte River drainage basin of the North American High Plains Region: Applied Geochemistry, v. 9, p. 271-278.

Solomon, D.K., Poreda, R.J., Schiff, S.L., and Cherry, J.A., 1992, Tritium and Helium-3 as groundwater age tracers in the Borden Aquifer: Water Resources Research, v. 28, no. 3, p. 741-755.

Spalding, R.F., and Druliner, A.D., 1981, Groundwater uranium concentrations-how high is high?, in Van Duijvenbooden, W., Glasbergen, P., and Van Lelyveld, H., eds., Quality of Groundwater: Proceedings of an International Symposium, Noordwijkerhout, The Netherlands, Elsevier Science, Studies in Environmental Science, v. 17, p. 581-586.

Springer, R.K., and Gelhar, L.W., 1991, Characterization of large-scale aquifer heterogeneity in glacial outwash by analysis of slug tests with oscillatory responses, Cape Cod, Massachusetts, in Mallard, G.E., and Aronson, D.A., eds., U.S. Geological Survey Toxic Substance Hydrology Program, Proceedings of the technical meeting, Monterey, California, March 11-15, 1991: U.S. Geological Survey Water-Resources Investiatgion Report 91-4034, p. 34-40.

Squillace, P.J., Moran, M.J., and Price, C.V., 2004, VOCs in shallow groundwater in new residential/commercial areas of the United States: Environmental Science \& Technology, v. 38, p. $5327-5338$.

Starr, R.C., and Gillham, R.W., 1993, Denitrification and organic carbon availability in two aquifers: Ground Water, v. 31, no. 6, p. 934-946.

Stewart, M.K., and McDonnell, J.J., 1991, Modeling base flow soil water residence times from deuterium concentrations: Water Resources Research, v. 27, no. 10, p. 2681-2693.

Swinehart, J.B., Dreeszen, V.H., Richmond, G.M., Tipton, M.J., Bretz, R., Steece, F.V., Hallberg, G.R., and Goebel, J.E., 1994, Quaternary geologic map of the Platte River $4^{\circ}$ $\times 6^{\circ}$ quadrangle, United States: U.S. Geological Survey Miscellaneous Investigations Series Map I-1420 (NK-14), 1 plate.

Tamers, M.A., 1967, Radiocarbon ages of groundwater in an arid zone unconfined aquifer, in Isotope Techniques in the Hydrological Cycle: American Geophysical Union Monograph 11, p. 143-152.
Upper Big Blue Natural Resources District, 1999, A study of ground water pumping for existing uses and proposed industrial development of the Heartland Fibers Processing Plant, York County, Nebraska: Prepared by the Upper Big Blue Natural Resources District, York, Nebraska, August 3, 1999, $32 \mathrm{p}$.

U.S. Census Bureau, 2003, Nebraska: 2000-Population and housing: population and housing unit counts (PHC-3-29): Washington, D.C., U.S. Census Bureau, 57 p. [Available at http://www.census.gov/census2000/pubs/phc-3.html]

U.S. Environmental Protection Agency, 1980, Prescribed procedures for measurement of radioactivity in drinking water: U.S. Environmental Protection Agency EPA-600-4-80-032.

U.S. Environmental Protection Agency, 1995, Metolachlor, reregistration eligibility decision: EPA 738-R-95-006, April 1995. Accessed on June 29, 2006 at http://www.epa.gov/ oppsrrd1/REDs/0001.pdf

U.S. Environmental Protection Agency, 1998, Alachlor, reregistration eligibility decision: EPA-738-F-98-018, December 1998. Accessed on June 29, 2006 at http://www. epa.gov/oppsrrd1/REDs/factsheets/0063fact.pdf

U.S. Environmental Protection Agency, 2002, Guidelines for establishing procedures for the analysis of pollutants: U.S. Code of Federal Regulations, Title 40, 136 p.

U.S. Environmental Protection Agency, 2003, Atrazine Interim reregistration eligibility decision (IRED) Q\&A's - January 2003: U.S. EPA Fact Sheet. Accessed on June 29, 2006 at http://www.epa.gov/pesticides/factsheets/atrazine.htm

U.S. Environmental Protection Agency, 2006, Acetochlor Desk Statement. Accessed on June 29, 2006 at http://www. epa.gov/oppefed1/aceto/: as of June 23, 2008, available at http://www.regulations.gov/fdmspublic/component/ main?main=DocketDetail\&d=EPA-HQ-OPP-2007-0725

U.S. Geological Survey, 2000, National Land Cover Dataset: U.S. Geological Survey Fact Sheet 108-00. Accessed on June 26, 2006 at http://erg.usgs.gov/isb/pubs/factsheets/ fs10800.html

U.S. Geological Survey, variously dated, National field manual for the collection of water-quality data: U.S. Geological Survey Techniques of Water-Resources Investigations, book 9, chaps. A1-A9. Available online at http://pubs.water. usgs.gov/twri9A

U.S. Geological Survey, 2005, The Reston Chlorofluorocarbon Laboratory. Accessed on February 10, 2006 at URL http:// water.usgs.gov/lab/. 
van der Lee, J., Ledoux, E., and de Marsily, G., 1992, Modeling of colloidal uranium transport in fractured medium: Journal of Hydrology, v. 139, p. 135-158.

Vengosh, A. and Pankratov, I., 1998, Chloride/bromide and chloride/fluoride ratios of domestic sewage effluents and associated contaminated ground water: Ground Water, v. 36, no. 5 , p. $815-824$.

Verstraeten, I.M., McGuire, V.L., and Heckman, K.L., 1998, Hydrogeology and subsurface nitrate in the Upper Big Blue Natural Resources District, Central Nebraska, July 1995 through September 1997: U.S. Geological Survey WaterResources Investigations Report 98-4207, 81 p.

Vogel, J.C., Talma, A.S., and Heaton, T.H.E., 1981, Gaseous nitrogen as evidence for denitrification in groundwater: Journal of Hydrology, v. 50: p. 191-200.

Vogel, T.M., and McCarty, P.L., 1985, Biotransformation of tetrachloroethylene to trichloroethylene, dichloroethylene, vinyl chloride, and carbon dioxide under methanogenic transformation: Applied Environmental Microbiology, 49, no. 5 , p. 1080-1083.

Welch, A.H., and Lico, M.S., 1998, Factors controlling As and $\mathrm{U}$ in shallow ground water, southern Carson Desert, Nevada: Applied Geochemistry, v. 13, no. 4, p. 521-539.

Welch, A.H., Westjohn, D.B., Helsel, D.R., and Wanty, R.B., 2000, Arsenic in ground water of the United Statesoccurrence and geochemistry: Ground Water, v. 38, no. 4, p. 589-604.
Welch, A.H., and Stollenwerk, K.G., eds., 2003, Arsenic in ground water-geochemistry and occurrence: Boston, Massachusetts, Kluwer Academic Publishers, 475 p.

Wilber, W.G., and Couch, C.A., 2002, Assessing five national priorities in water resources: American Water Resources Association Water Resources IMPACT, v. 4, no. 4, p. 17-21.

Williamson, A.K., Prudic, D.E., and Swain, L.A., 1989, Ground-water flow in the Central Valley, California: U.S. Geological Survey Professional Paper 1401-D, 127 p.

Zaugg, S.D., Sandstrom, M.W., Smith, S.G., and Fehlberg, K.M., 1995, Methods of analysis by the U.S. Geological Survey National Water Quality Laboratory - Determination of pesticides in water by $\mathrm{C}-18$ solid-phase extraction and capillary-column gas chromatography/mass spectrometry with selected-ion monitoring: U.S. Geological Survey Open-File Report 95-181, 60 p.

Zimmerman, U., Ehhalt, D., and Munnich, K.O., 1967, Soilwater movement and evapotranspiration: changes in the isotopic composition of the water, in Isotopes in Hydrology, Proceedings of the Symposium, International Atomic Energy Agency, Vienna, Austria, November 14-18, 1966: p. 567-585.

Zogorski, J.S., Carter, J.M., Ivahnenko, T., Lapham, W.W., Moran, M.J., Rowe, B.L., Squillace, P.J., and Toccalino, P.L., 2006. Volatile organic compounds in the Nation's ground water and drinking-water supply wells: U.S. Geological Survey Circular 1292, 101 p. 


\section{Tables}


Table 1. Well construction information for monitoring wells installed for the local-scale TANC study near York, Nebraska.

[bls, below land surface; m, meter; NAVD 88, North American Vertical Datum of 1988; NAD 83, North American Datum of 1983; na, not applicable]

\begin{tabular}{|c|c|c|c|c|c|c|c|c|c|c|}
\hline \multirow[b]{2}{*}{ Well name } & \multirow[b]{2}{*}{$\begin{array}{c}\text { Site identification } \\
\text { number }\end{array}$} & \multirow[b]{2}{*}{$\begin{array}{l}\text { Latitude } \\
\text { NAD (83) }\end{array}$} & \multirow[b]{2}{*}{$\begin{array}{l}\text { Longitude } \\
\text { NAD (83) }\end{array}$} & \multicolumn{2}{|c|}{ Measuring point } & \multirow[b]{2}{*}{$\begin{array}{l}\text { - Altitude of } \\
\text {-land surface } \\
\text { NAVD (88) } \\
\text { (m) }\end{array}$} & \multirow[b]{2}{*}{$\begin{array}{l}\text { Depth } \\
\text { to top of } \\
\text { screen, } \\
\text { bls } \\
\text { (m) }\end{array}$} & \multirow[b]{2}{*}{$\begin{array}{l}\text { Length of } \\
\text { screen } \\
\text { (m) }\end{array}$} & \multirow[b]{2}{*}{$\begin{array}{l}\text { Depth to } \\
\text { bottom of } \\
\text { screen, } \\
\text { bls } \\
\text { (m) }\end{array}$} & \multirow[b]{2}{*}{$\begin{array}{c}\text { Length } \\
\text { of sump } \\
\text { below } \\
\text { screen, } \\
\text { (m) }\end{array}$} \\
\hline & & & & $\begin{array}{c}\text { Altitude } \\
\text { NAVD (88) } \\
(\mathrm{m})\end{array}$ & $\begin{array}{l}\text { Depth } \\
\text { bls } \\
\text { (m) }\end{array}$ & & & & & \\
\hline FP1-63 & 405130097344802 & 405130.0 & 973448.5 & 490.43 & 0.09 & 490.52 & 17.80 & 1.52 & 19.32 & 1.65 \\
\hline FP1-147 & 405130097344803 & 405129.9 & 973448.5 & 490.33 & 0.08 & 490.40 & 43.41 & 1.52 & 44.94 & 1.65 \\
\hline FP1-185 & 405130097344804 & 405129.4 & 973448.3 & 489.80 & 0.09 & 489.89 & 54.91 & 1.52 & 56.43 & 1.60 \\
\hline FP3-83 & 405146097353002 & 405146.0 & 973529.9 & 485.75 & 0.11 & 485.86 & 23.74 & 1.52 & 25.27 & 1.60 \\
\hline FP3-130 & 405146097353003 & 405145.7 & 973529.8 & 485.90 & 0.08 & 485.97 & 38.13 & 1.52 & 39.65 & 1.65 \\
\hline FP3-162 & 405146097353004 & 405145.9 & 973529.8 & 485.85 & 0.09 & 485.94 & 47.81 & 1.52 & 49.34 & 1.60 \\
\hline FP3-218 & 405146097353005 & 405145.5 & 973529.8 & 485.83 & 0.08 & 485.90 & 64.75 & 1.52 & 66.27 & 15.37 \\
\hline FP4-28 & 405205097361701 & 405204.6 & 973616.1 & 488.00 & 0.11 & 488.11 & 7.01 & 1.52 & 8.53 & 1.60 \\
\hline OFPN-167 & 405152097351402 & 405151.9 & 973513.2 & 493.54 & 0.06 & 493.60 & 49.44 & 1.52 & 50.96 & 1.60 \\
\hline OFPN-276 & 405151097350903 & 405150.7 & 973508.7 & 497.89 & 0.11 & 497.99 & 82.64 & 1.52 & 84.17 & 1.68 \\
\hline OFPS-38 & 405131097351401 & 405131.8 & 973514.1 & 482.38 & 0.06 & 482.44 & 9.98 & 1.52 & 11.51 & 1.60 \\
\hline OFPS-157 & 405131097351402 & 405131.7 & 973514.0 & 482.41 & 0.06 & 482.47 & 46.28 & 1.52 & 47.80 & 1.68 \\
\hline OFPS-225 & 405131097351403 & 405130 & 973514 & 484.18 & 0.08 & 484.25 & 66.72 & 1.52 & 68.25 & 2.32 \\
\hline OFPS-277 & 405131097351404 & 405130 & 973514 & 484.06 & 0.08 & 484.13 & 81.26 & 3.05 & 84.31 & 0.85 \\
\hline FP2-43 & 405134097355301 & 405134 & 973553 & 488.68 & 0.09 & 488.77 & 11.55 & 1.52 & 13.08 & 1.67 \\
\hline FP2-78 & 405134097355302 & 405134 & 973553 & 488.69 & 0.11 & 488.80 & 22.24 & 1.52 & 23.77 & 1.37 \\
\hline FP2-152 & 405134097355303 & 405134 & 973553 & 488.93 & 0.08 & 489.00 & 44.88 & 1.52 & 46.40 & 2.33 \\
\hline FP2-250 & 405134097355304 & 405134 & 973553 & 488.85 & 0.08 & 488.92 & 74.67 & 1.52 & 76.20 & 2.41 \\
\hline FP5-45 & 405224097382201 & 405135.0 & 973551.2 & 496.57 & -0.79 & 495.78 & 12.28 & 1.52 & 13.80 & 1.67 \\
\hline UWT1-53 & 405147097354001 & 405145.8 & 973536.7 & 486.32 & 0.06 & 486.38 & 13.30 & 3.05 & 16.35 & 1.65 \\
\hline UWT2-23 & 405149097361001 & 405149.4 & 973606.5 & 485.31 & -0.91 & 484.40 & 5.54 & 1.52 & 7.06 & 1.67 \\
\hline UWT3-34 & 405200097355101 & 405200.7 & 973549.0 & 487.42 & 0.06 & 487.48 & 8.99 & 1.52 & 10.51 & 1.37 \\
\hline UWT4-85 & 405207097345501 & 405207 & 973455 & 501.86 & 0.05 & 501.91 & 24.49 & 1.52 & 26.01 & 1.67 \\
\hline
\end{tabular}


Table 1. Well construction information for monitoring wells installed for the local-scale TANC study near York, Nebraska.-Continued

[bls, below land surface; m, meter; NAVD 88, North American Vertical Datum of 1988; NAD 83, North American Datum of 1983; na, not applicable]

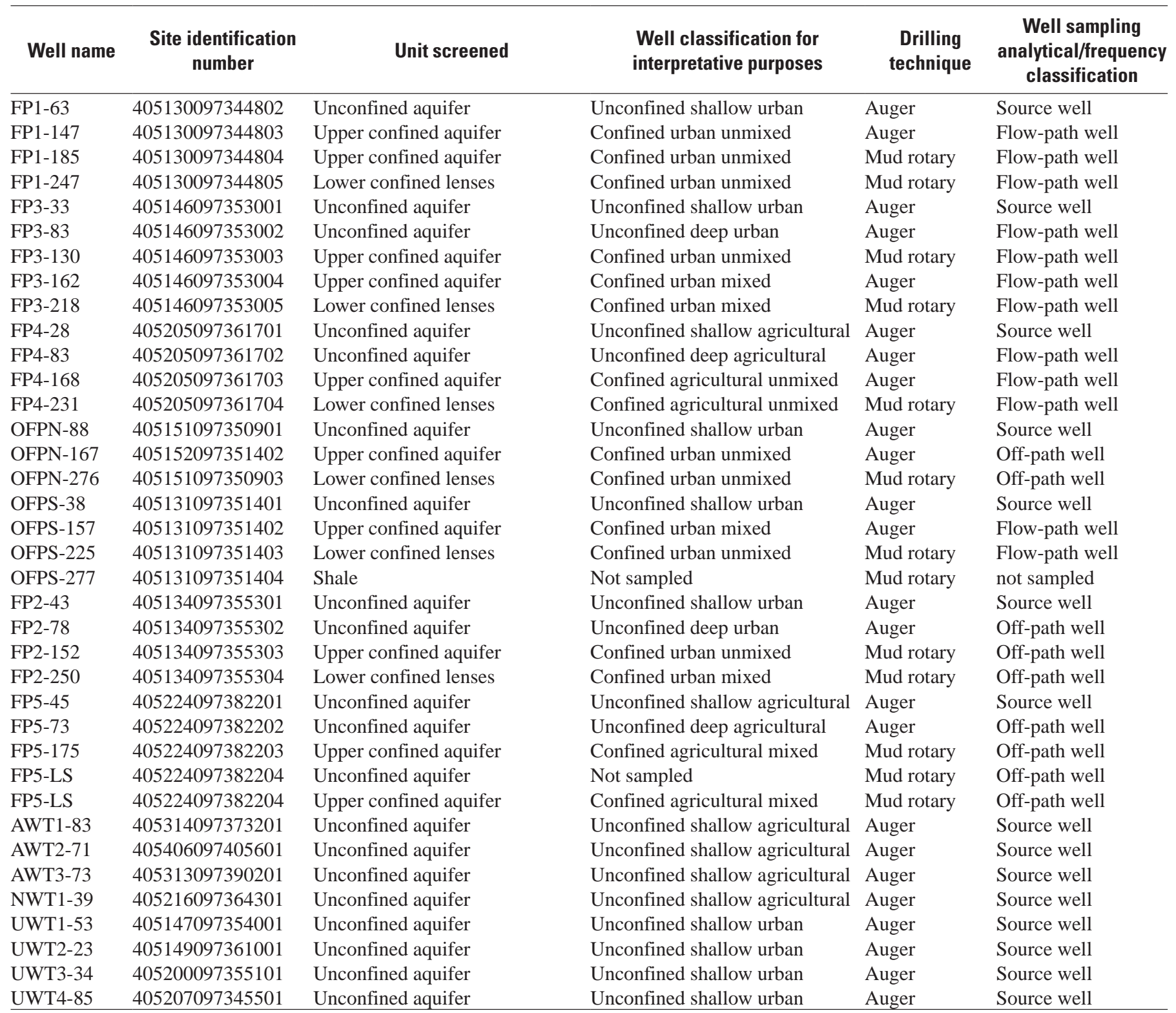




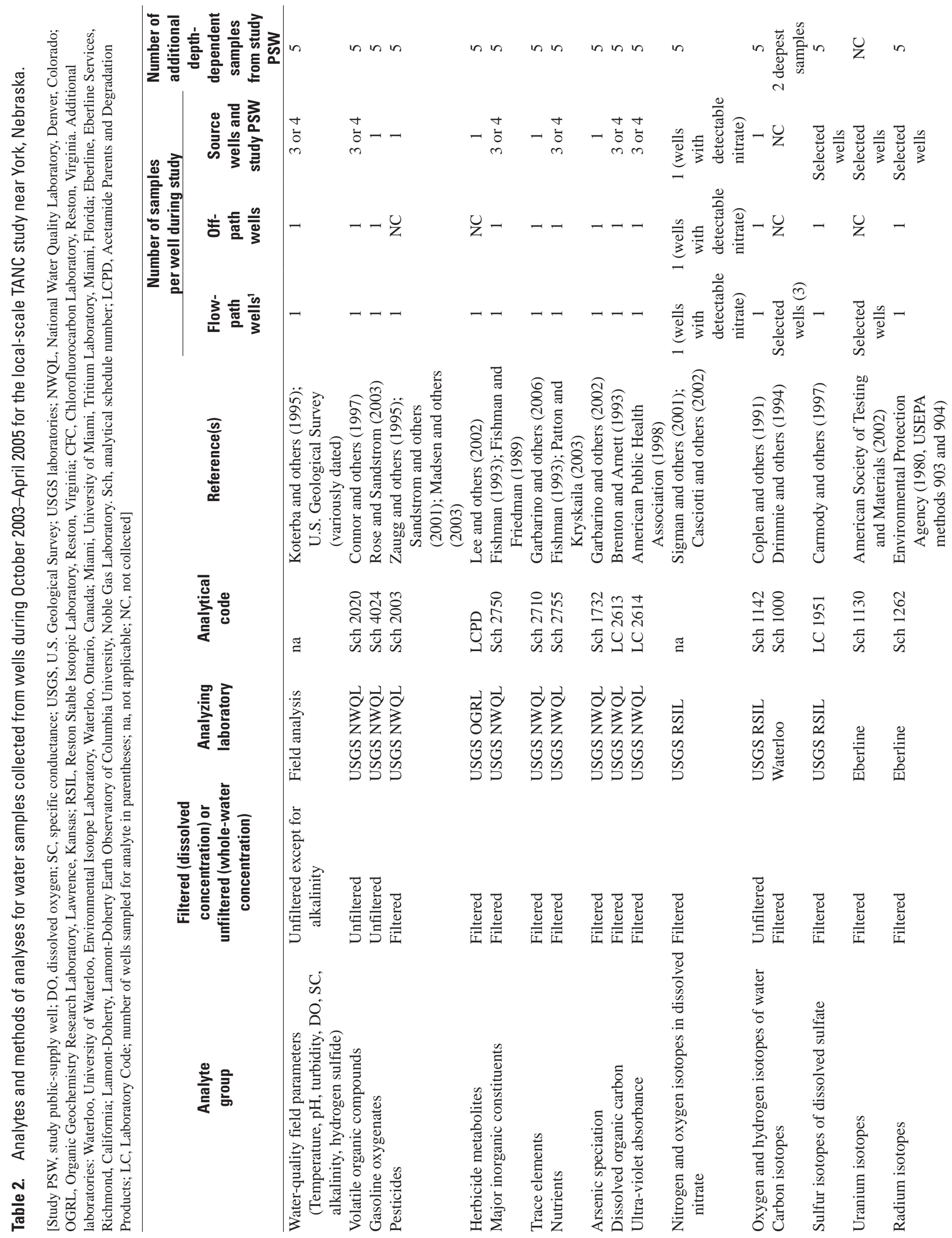




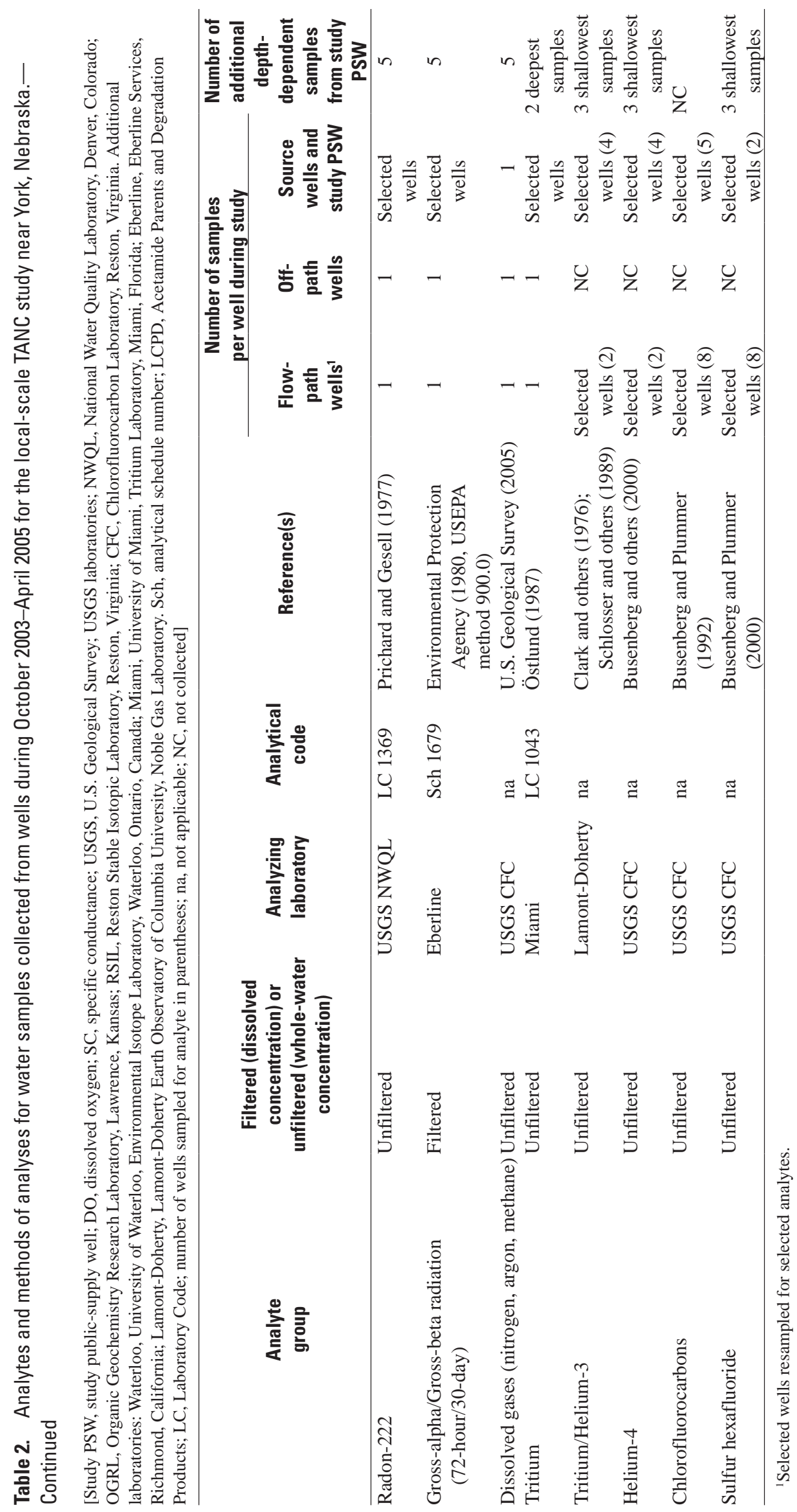


Table 3. Quality-control summary for constituents detected in field blanks and ground-water samples collected for the local-scale TANC study near York, Nebraska.

[ $\mu \mathrm{g} / \mathrm{L}$, microgram per liter; mg/L, milligram per liter; E, estimated value; <, less than; >, greater than; \%, percent; —, not detected in ground-water samples]

\begin{tabular}{|c|c|c|c|c|c|c|c|}
\hline \multirow[b]{2}{*}{ Constituent } & \multirow{2}{*}{$\begin{array}{c}\text { Number of } \\
\text { field blank } \\
\text { detections/ } \\
\text { analyses }\end{array}$} & \multirow{2}{*}{$\begin{array}{c}\text { Maximum } \\
\text { concentration } \\
\text { detected in field } \\
\text { blank samples }\end{array}$} & \multirow{2}{*}{$\begin{array}{c}\text { Long-term } \\
\text { method } \\
\text { detection level }\end{array}$} & \multirow{2}{*}{$\begin{array}{l}\text { Censoring } \\
\text { threshold }\end{array}$} & \multirow{2}{*}{$\begin{array}{c}\text { Minimum } \\
\text { concentration } \\
\text { in ground-water } \\
\text { samples }\end{array}$} & \multicolumn{2}{|c|}{$\begin{array}{l}\text { Number of ground-water } \\
\text { samples }\end{array}$} \\
\hline & & & & & & Censored & $\begin{array}{c}\text { Systematic } \\
\text { bias }>10 \% \text { of } \\
\text { concentration }\end{array}$ \\
\hline \multicolumn{8}{|c|}{ Volatile organic compounds and gasoline additives and (or) oxygenates ( $\mu \mathrm{g} / \mathrm{L}$ ) } \\
\hline Acetone $^{1}$ & $2 / 7$ & 1.54 & 3 & 4.54 & - & 0 & 0 \\
\hline Tetrahydrofuran & $1 / 9$ & 1.5 & 1.1 & 2.6 & E 0.7 & ${ }^{2} 0$ & 0 \\
\hline Toluene & $1 / 9$ & 0.03 & 0.03 & 0.06 & 0.07 & 0 & 0 \\
\hline $\begin{array}{l}\text { Trichloromethane } \\
\text { (chloroform) }\end{array}$ & $2 / 9$ & E 0.05 & 0.012 & 0.062 & E 0.01 & 4 & 0 \\
\hline \multicolumn{8}{|l|}{ Major and minor ions (mg/L) } \\
\hline \multicolumn{8}{|l|}{ Trace elements ( $\mu \mathrm{g} / \mathrm{L}$ ) } \\
\hline Barium & $1 / 6$ & E 0.11 & 0.1 & 0.21 & 17.1 & 0 & 0 \\
\hline Chromium & $1 / 6$ & 0.44 & 0.02 & 0.46 & E 0.46 & 1 & 0 \\
\hline Cobalt & $1 / 6$ & 0.04 & 0.02 & 0.06 & 0.07 & 0 & 0 \\
\hline Copper & $4 / 6$ & 1.14 & 0.2 & 1.34 & E 0.22 & 33 & 23 \\
\hline Iron & $1 / 4$ & E3.6 & 3.2 & 6.80 & E3.2 & ${ }^{3} 23$ & 0 \\
\hline Manganese & $1 / 6$ & E 0.17 & 0.1 & 0.27 & E 0.11 & 1 & 0 \\
\hline Molybdenum & $1 / 6$ & E 0.35 & 0.2 & 0.55 & E 0.89 & 0 & 0 \\
\hline Nickel & $4 / 6$ & 0.21 & 0.03 & 0.24 & 0.47 & 0 & 36 \\
\hline Vanadium & $1 / 6$ & E 0.08 & 0.05 & 0.13 & 0.10 & ${ }^{2} 0$ & 0 \\
\hline$\underline{\text { Zinc }}$ & $2 / 6$ & 1.04 & 0.3 & 1.34 & E 0.36 & 11 & 0 \\
\hline
\end{tabular}

${ }^{1}$ Constituents detected in associated source solution blanks also.

${ }^{2}$ No ground-water samples were censored because detections in field blanks occurred during a different sampling period than ground-water concentrations below the quality-control threshold. Ground-water samples and field blanks were collected during each of five sampling periods: October-November 2003, June 2004, July-August 2004, October 2004, and March-April 2005. Ground-water values were censored when most or all blanks had detections or when blank and ground-water detections below the quality-control threshold occurred during the same sampling period

${ }^{3}$ Estimated iron concentrations $(<6 \mu \mathrm{g} / \mathrm{L})$ were censored because of a detection in a field blank. This censoring is insignificant from an interpretative standpoint as these low concentrations were in oxic waters where they were expected. 
Table 4. Quality-control summary of replicate analytes with relative standard deviations greater than zero, collected for the localscale TANC study near York, Nebraska.

$[\mu \mathrm{g} / \mathrm{L}$, microgram per liter]

\begin{tabular}{|c|c|c|c|}
\hline Constituent & $\begin{array}{l}\text { Number of relative standard } \\
\text { deviations greater than } \\
20 \text { percent/replicate pairs }\end{array}$ & $\begin{array}{c}\text { Maximum relative } \\
\text { standard deviation } \\
\text { (percent) }\end{array}$ & $\begin{array}{c}\text { Median of relative } \\
\text { standard deviations } \\
\text { (percent) }\end{array}$ \\
\hline \multicolumn{4}{|c|}{$\begin{array}{l}\text { Volatile organic compounds and gasoline oxygenates/Additives (Schedules } 2020 \text { and } 4204)^{1} \\
\end{array}$} \\
\hline cis-1,2-Dichloroethylene & $0 / 4$ & 5.3 & 0.0 \\
\hline Tetrachloroethylene & $0 / 4$ & 2.8 & 0.3 \\
\hline trans-1,2-Dichloroethylene & $0 / 4$ & 14 & 1.7 \\
\hline Atrazine & $0 / 2$ & 4.7 & 2.4 \\
\hline $\begin{array}{l}\text { 2-Chloro-4-isopropylamino-6-amino-s-triazine (CIAT or } \\
\text { De-ethylatrazine) }\end{array}$ & $0 / 2$ & 10 & 4.9 \\
\hline
\end{tabular}

De-ethylatrazine)

\begin{tabular}{|c|c|c|c|}
\hline \multicolumn{4}{|c|}{ Nutrients and dissolved organic carbon } \\
\hline Dissolved organic carbon & $0 / 4$ & 13.3 & 3.4 \\
\hline Orthophosphate & $0 / 4$ & 1.6 & 1.1 \\
\hline Total nitrogen & $0 / 4$ & 5.3 & 3.3 \\
\hline Nitrate plus nitrite & $0 / 4$ & 3.3 & 0.4 \\
\hline \multicolumn{4}{|c|}{ Major and minor ions } \\
\hline Bromide & $0 / 2$ & 2.6 & 1.7 \\
\hline Calcium & $0 / 4$ & 1.2 & 0.7 \\
\hline Magnesium & $0 / 4$ & 1.2 & 0.2 \\
\hline Potassium & $0 / 4$ & 1.6 & 0.4 \\
\hline Silica & $0 / 4$ & 2.7 & 0.7 \\
\hline Sodium & $0 / 4$ & 1.7 & 0.5 \\
\hline Sulfate & $0 / 4$ & 1.6 & 0.2 \\
\hline \multicolumn{4}{|c|}{ Trace elements } \\
\hline Arsenite & $0 / 2$ & 3.1 & 0.0 \\
\hline Barium & $0 / 4$ & 1.9 & 0.5 \\
\hline Boron & $0 / 4$ & 0.9 & 0.3 \\
\hline Cadmium & $0 / 4$ & 13.3 & 1.2 \\
\hline Chromium & $0 / 4$ & 13.1 & 3.8 \\
\hline Cobalt & $0 / 4$ & 3.6 & 2.7 \\
\hline Copper & $0 / 4$ & 11 & 2 \\
\hline Lithium & $0 / 4$ & 1.3 & 0.8 \\
\hline Manganese & $1 /{ }^{2} 6$ & 46 & 0.6 \\
\hline Molybdenum & $0 / 4$ & 5.0 & 1.4 \\
\hline Nickel & $0 / 4$ & 7.8 & 2.9 \\
\hline Selenium & $0 / 4$ & 3.2 & 1.0 \\
\hline Deuterium/Protium & $0 / 1$ & 0.1 & 0.1 \\
\hline Tritium & $0 / 1$ & 2.6 & 2.6 \\
\hline Oxygen-18/Oxygen-16 & $0 / 1$ & 0.5 & 0.5 \\
\hline Sulfur-34/Sulfur-32 & $0 / 1$ & 0.2 & 0.1 \\
\hline
\end{tabular}

${ }^{1}$ Only detected constituents are shown.

${ }^{2}$ Environmental concentration $1.5 \mu \mathrm{g} / \mathrm{L}$, replicate concentration $2.9 \mu \mathrm{g} / \mathrm{L}$, laboratory reporting level $0.2 \mu \mathrm{g} / \mathrm{L}$. 
Table 5A. Quality-control summary of matrix spike recoveries for volatile organic compounds (VOC) and gasoline additives and oxygenates in samples collected for the local-scale TANC study near York, Nebraska.

[Acceptable recovery range is between 70 and 130 percent; bold font is used to identify recoveries outside of acceptable limits]

\begin{tabular}{|c|c|c|c|}
\hline Constituent (common name) & $\begin{array}{l}\text { Number } \\
\text { of spike } \\
\text { samples }\end{array}$ & $\begin{array}{l}\text { Minimum } \\
\text { recovery } \\
\text { (percent) }\end{array}$ & $\begin{array}{c}\text { Maximum } \\
\text { recovery } \\
\text { (percent) }\end{array}$ \\
\hline 1,1,1,2-Tetrachloroethane & 2 & 99 & 111 \\
\hline 1,1,1-Trichloroethane $(\mathrm{TCA})^{1}$ & 2 & 111 & 125 \\
\hline 1,1,2,2-Tetrachloroethane & 2 & 94 & 110 \\
\hline 1,1,2-Trichloroethane & 2 & 96 & 106 \\
\hline $1,1,2$-Trichlorotrifluoroethane $(\mathrm{CFC}-113)^{1}$ & 2 & 105 & 123 \\
\hline 1,1-Dichloroethane & 2 & 108 & 116 \\
\hline 1,1-Dichloroethylene (DCE) ${ }^{1}$ & 2 & 113 & 118 \\
\hline 1,1-Dichloropropene & 2 & 108 & 125 \\
\hline 1,2,3,4-Tetramethylbenzene & 2 & 101 & 108 \\
\hline 1,2,3,5-Tetramethylbenzene (isodurene) & 2 & 115 & 120 \\
\hline 1,2,3-Trichlorobenzene & 2 & 88 & 105 \\
\hline 1,2,3-Trichloropropane & 2 & 88 & 97 \\
\hline $1,2,3$-Trimethylbenzene ${ }^{1}$ & 2 & 104 & 110 \\
\hline 1,2,4-Trichlorobenzene & 2 & 89 & 98 \\
\hline $1,2,4$-Trimethylbenzene ${ }^{1}$ & 2 & 107 & 108 \\
\hline 1,2-Dibromo-3-chloropropane (DBCP) & 2 & 80 & 92 \\
\hline 1,2-Dibromoethane & 2 & 103 & 106 \\
\hline 1,2-Dichlorobenzene & 2 & 101 & 110 \\
\hline 1,2-Dichloroethane ${ }^{1}$ & 2 & 98 & 114 \\
\hline 1,2-Dichloropropane ${ }^{1}$ & 2 & 106 & 110 \\
\hline 1,3,5-Trimethylbenzene & 2 & 101 & 110 \\
\hline 1,3-Dichlorobenzene & 2 & 103 & 104 \\
\hline 1,3-Dichloropropane & 2 & 105 & 108 \\
\hline 1,4-Dichlorobenzene & 2 & 93 & 102 \\
\hline 2-Butanone & 2 & 92 & 123 \\
\hline 2,2-Dichloropropane & 2 & 99 & 110 \\
\hline 2-Chlorotoluene & 2 & 104 & 110 \\
\hline 2-Hexanone & 2 & 93 & 108 \\
\hline 2-methyl-2-butanol & 2 & 110 & 112 \\
\hline 3-Chloropropene & 2 & 75 & 85 \\
\hline 4-Chlorotoluene & 2 & 96 & 97 \\
\hline 4-Isopropyl-1-methylbenzene & 2 & 97 & 104 \\
\hline 4-Methyl-2-pentanone & 2 & 91 & 103 \\
\hline Acetone & 2 & 91 & 95 \\
\hline Acrylonitrile & 2 & 92 & 112 \\
\hline Benzene $^{1}$ & 2 & 114 & 116 \\
\hline Bromobenzene & 2 & 103 & 109 \\
\hline Bromochloromethane & 2 & 100 & 107 \\
\hline Bromodichloromethane $^{1}$ & 2 & 114 & 124 \\
\hline Bromoethene & 2 & 116 & 124 \\
\hline Bromoform (tribromomethane) & 2 & 98 & 113 \\
\hline Bromomethane & 2 & 112 & 120 \\
\hline Butylbenzene & 2 & 84 & 98 \\
\hline Carbon disulfide ${ }^{1}$ & 2 & 90 & 98 \\
\hline Chlorobenzene & 2 & 104 & 105 \\
\hline Chloroethane & 2 & 104 & 113 \\
\hline Chloroform (trichloromethane) ${ }^{1}$ & 2 & 111 & 119 \\
\hline Chloromethane & 2 & 110 & 112 \\
\hline cis-1,2-Dichloroethylene $^{1}$ & 2 & 115 & 117 \\
\hline cis-1,3-Dichloropropene & 2 & 96 & 100 \\
\hline Dibromochloromethane & 2 & 108 & 110 \\
\hline
\end{tabular}


Table 5A. Quality-control summary of matrix spike recoveries for volatile organic compounds (VOC) and gasoline additives and oxygenates in samples collected for the local-scale TANC study near York, Nebraska. —Continued

[Acceptable recovery range is between 70 and 130 percent; bold font is used to identify recoveries outside of acceptable limits]

\begin{tabular}{|c|c|c|c|}
\hline Constituent (common name) & $\begin{array}{l}\text { Number } \\
\text { of spike } \\
\text { samples }\end{array}$ & $\begin{array}{l}\text { Minimum } \\
\text { recovery } \\
\text { (percent) }\end{array}$ & $\begin{array}{c}\text { Maximum } \\
\text { recovery } \\
\text { (percent) }\end{array}$ \\
\hline Dibromomethane & 2 & 102 & 107 \\
\hline Dichlorodifluoromethane (CFC-12) ${ }^{1}$ & 2 & 80 & 112 \\
\hline Dichloromethane (methylene chloride) & 2 & 104 & 111 \\
\hline Diethyl ether & 2 & 102 & 110 \\
\hline Diisopropyl ether & 2 & 107 & 114 \\
\hline Ethyl methacrylate & 2 & 91 & 105 \\
\hline 2-Butanone (Ethyl methyl ketone) & 2 & 100 & 115 \\
\hline Ethylbenzene $^{1}$ & 2 & 107 & 111 \\
\hline Hexachlorobutadiene & 2 & 96 & 99 \\
\hline Hexachloroethane & 2 & 99 & 105 \\
\hline Isopropylbenzene & 2 & 108 & 110 \\
\hline$m$ - and $p$-Xylene ${ }^{1}$ & 2 & 102 & 106 \\
\hline Methyl acetate & 2 & 92 & 99 \\
\hline Methyl acrylate & 2 & 96 & 108 \\
\hline Methyl acrylonitrile & 2 & 85 & 114 \\
\hline Methyl iodide & 2 & 88 & 93 \\
\hline Methyl methacrylate & 2 & 83 & 104 \\
\hline Methyl tert-butyl ether (MTBE) ${ }^{1}$ & 2 & 110 & 112 \\
\hline Naphthalene & 2 & 83 & 95 \\
\hline$n$-Propylbenzene & 2 & 98 & 99 \\
\hline$o$-Ethyl toluene ${ }^{1}$ & 2 & 96 & 104 \\
\hline$o$-Xylene1 & 2 & 107 & 107 \\
\hline sec-Butylbenzene & 2 & 100 & 102 \\
\hline Styrene & 2 & 100 & 102 \\
\hline Methyl tert-pentyl ether & 2 & 100 & 108 \\
\hline tert-Amyl alcohol ${ }^{1}$ & 2 & 106 & 110 \\
\hline tert-Butyl alcohol & 2 & 106 & 110 \\
\hline tert-Butyl ethyl ether (ETBE) & 2 & 108 & 113 \\
\hline tert-Butylbenzene & 2 & 104 & 119 \\
\hline Tetrachloroethylene (PCE) $)^{1}$ & 2 & 113 & 166 \\
\hline Tetrachloromethane (carbon tetrachloride) ${ }^{1}$ & 2 & 97 & 121 \\
\hline Tetrahydrofuran ${ }^{1}$ & 2 & 100 & 121 \\
\hline Toluene $^{1}$ & 2 & 102 & 108 \\
\hline trans-1,2-Dichloroethylene $^{1}$ & 2 & 111 & 111 \\
\hline trans-1,3-Dichloropropene & 2 & 98 & 105 \\
\hline trans-1,4-Dichloro-2-butene & 2 & 105 & 129 \\
\hline Trichloroethylene (TCE) ${ }^{1}$ & 2 & 109 & 124 \\
\hline Trichlorofluoromethane (CFC-11) & 2 & 96 & 131 \\
\hline Vinyl chloride & 2 & 126 & 135 \\
\hline
\end{tabular}

${ }^{1}$ Constituents detected in ground-water samples. 
Table 5B. Quality-control summary of matrix spike recoveries for pesticides and pesticide degradates in samples collected for the local-scale TANC study near York, Nebraska.

[Acceptable recovery range is between 60 and 120 percent. Bold font is used to identify recoveries outside of acceptable limits]

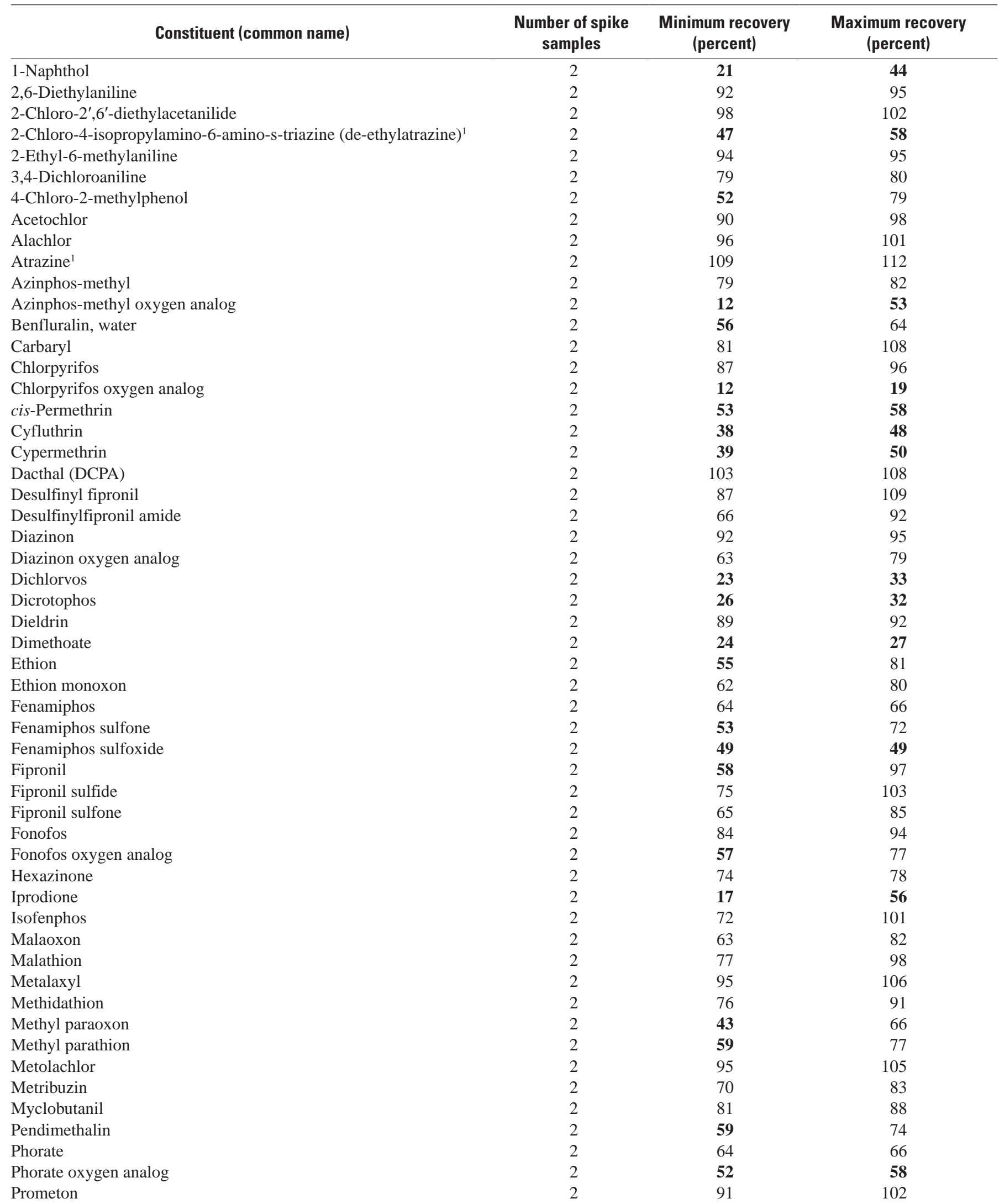


Table 5B. Quality-control summary of matrix spike recoveries for pesticides and pesticide degradates in samples collected for the local-scale TANC study near York, Nebraska.-Continued

[Acceptable recovery range is between 60 and 120 percent. Bold font is used to identify recoveries outside of acceptable limits]

\begin{tabular}{lccr}
\hline Constituent (common name) & $\begin{array}{c}\text { Number of spike } \\
\text { samples }\end{array}$ & $\begin{array}{c}\text { Minimum recovery } \\
\text { (percent) }\end{array}$ & $\begin{array}{c}\text { Maximum recovery } \\
\text { (percent) }\end{array}$ \\
\hline Prometryn & 2 & 92 & 108 \\
Pronamide & 2 & 81 & 97 \\
Simazine & 2 & 88 & 108 \\
Tebuthiuron & 2 & 89 & $\mathbf{1 2 3}$ \\
Terbufos & 2 & 65 & 77 \\
Terbufos oxygen analog sulfone & 2 & $\mathbf{5 8}$ & 77 \\
Terbuthylazine & 2 & 101 & 62 \\
Trifluralin & 2 & 62 & 66 \\
\hline
\end{tabular}

${ }^{1}$ Constituents detected in ground-water samples. 


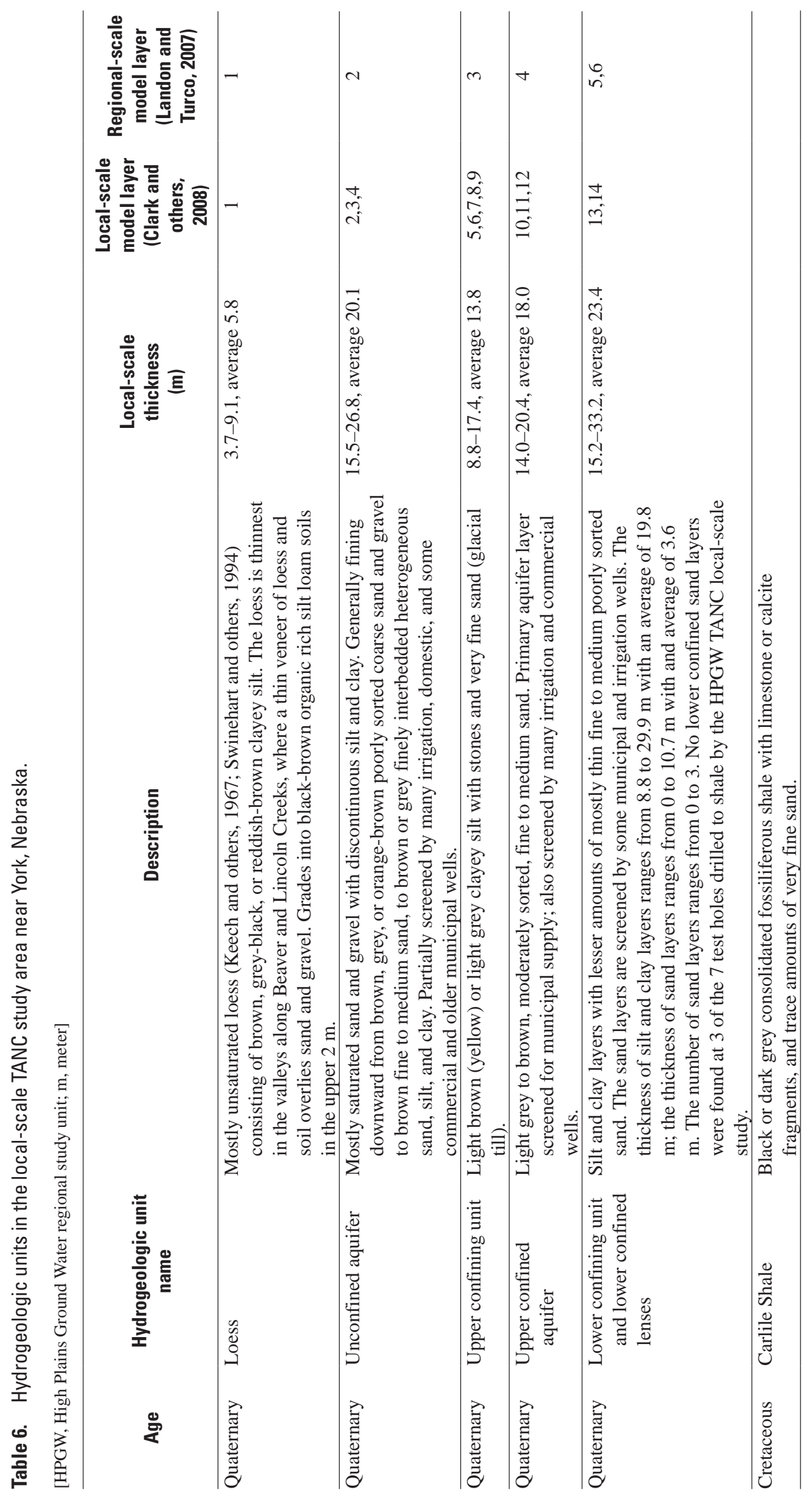


Table 7. Grain-size analyses of selected core samples collected for the local-scale TANC study near York, Nebraska.

[m, meter; mm, millimeter; >, greater than; <, less than]

\begin{tabular}{|c|c|c|c|c|c|c|c|}
\hline Well nest & $\begin{array}{l}\text { Depth to } \\
\text { top of } \\
\text { interval } \\
\text { analyzed } \\
\text { (m) }\end{array}$ & $\begin{array}{l}\text { Depth to } \\
\text { bottom of } \\
\text { interval } \\
\text { analyzed } \\
\text { (m) }\end{array}$ & $\begin{array}{l}\text { Hydrogeologic } \\
\text { unit sampled } \\
\text { (additional notes } \\
\text { on position in } \\
\text { parentheses) }\end{array}$ & $\begin{array}{l}\text { Gravel-sized } \\
\text { particles } \\
>2 \mathrm{~mm} \text { in } \\
\text { diameter, } \\
\text { (percent) }\end{array}$ & $\begin{array}{l}\text { Sand-sized } \\
\text { particles } \\
0.0625-2 \mathrm{~mm} \\
\text { in diameter, } \\
\text { (percent) }\end{array}$ & $\begin{array}{c}\text { Silt-sized } \\
\text { particles } \\
0.008-0.0625 \\
\text { mm in } \\
\text { diameter, } \\
\text { (percent) }\end{array}$ & $\begin{array}{c}\text { Clay-sized } \\
\text { particles } \\
<0.008 \mathrm{~mm} \\
\text { in diameter, } \\
\text { (percent) }\end{array}$ \\
\hline FP5 & 4.9 & 5.3 & Loess & 0.0 & 2.5 & 80.3 & 17.3 \\
\hline FP5 & 8.5 & 8.8 & $\begin{array}{l}\text { Unconfined aquifer (near } \\
\text { water table) }\end{array}$ & 53.8 & 41.2 & 4.0 & 1.1 \\
\hline OFPS & 19.8 & 20.1 & $\begin{array}{l}\text { Unconfined aquifer (near } \\
\text { bottom) }\end{array}$ & 1.0 & 90.6 & 6.8 & 1.6 \\
\hline FP5 & 28.4 & 28.6 & Upper confining unit & 0.1 & 8.4 & 72.5 & 19.0 \\
\hline FP5 & 57.9 & 58.5 & Upper confined aquifer & 0.2 & 92.6 & 5.2 & 2.1 \\
\hline OFPS & 66.7 & 66.8 & Lower confining unit & 0.0 & 0.0 & 68.2 & 31.8 \\
\hline
\end{tabular}




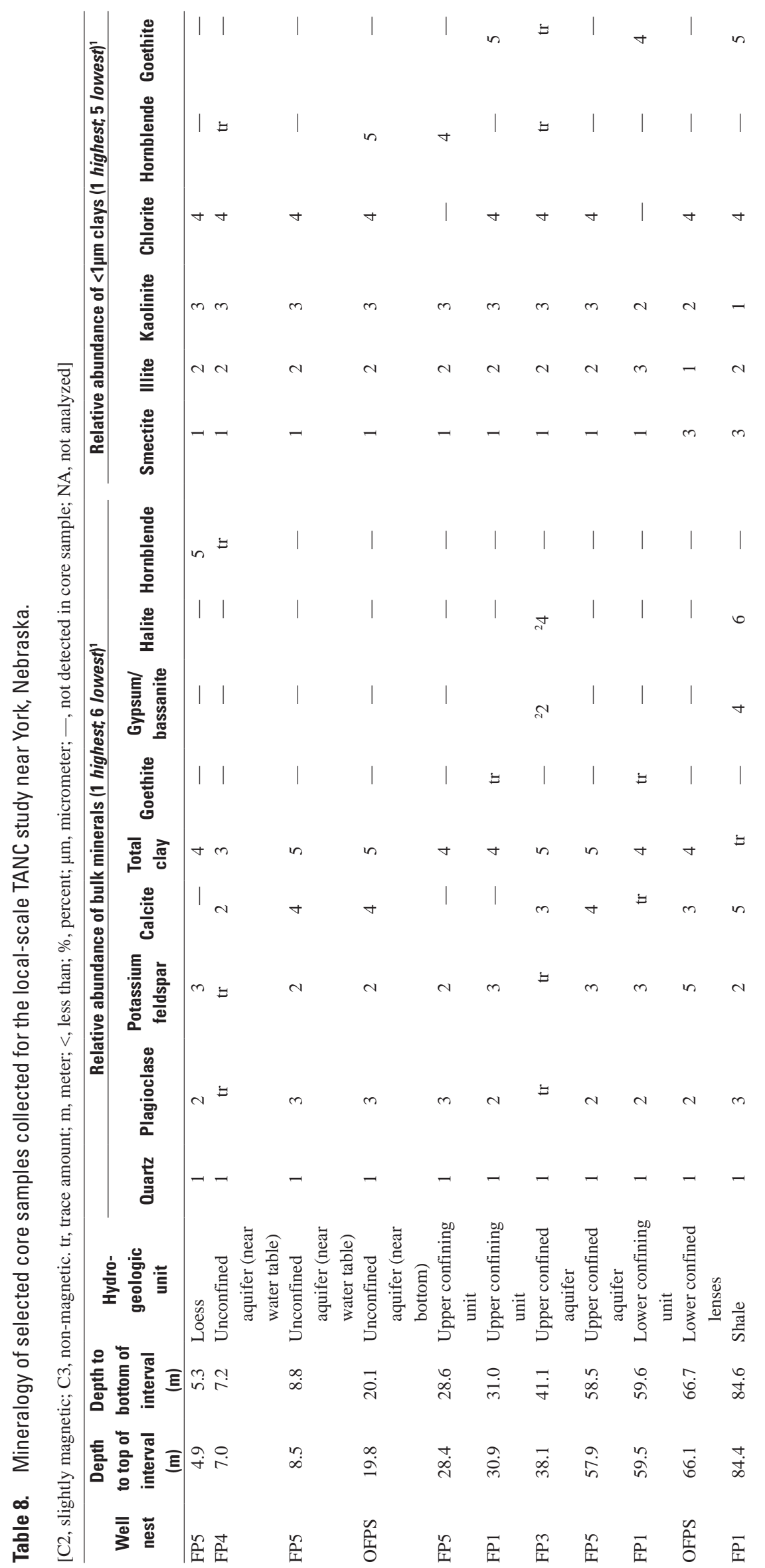


Tables 105

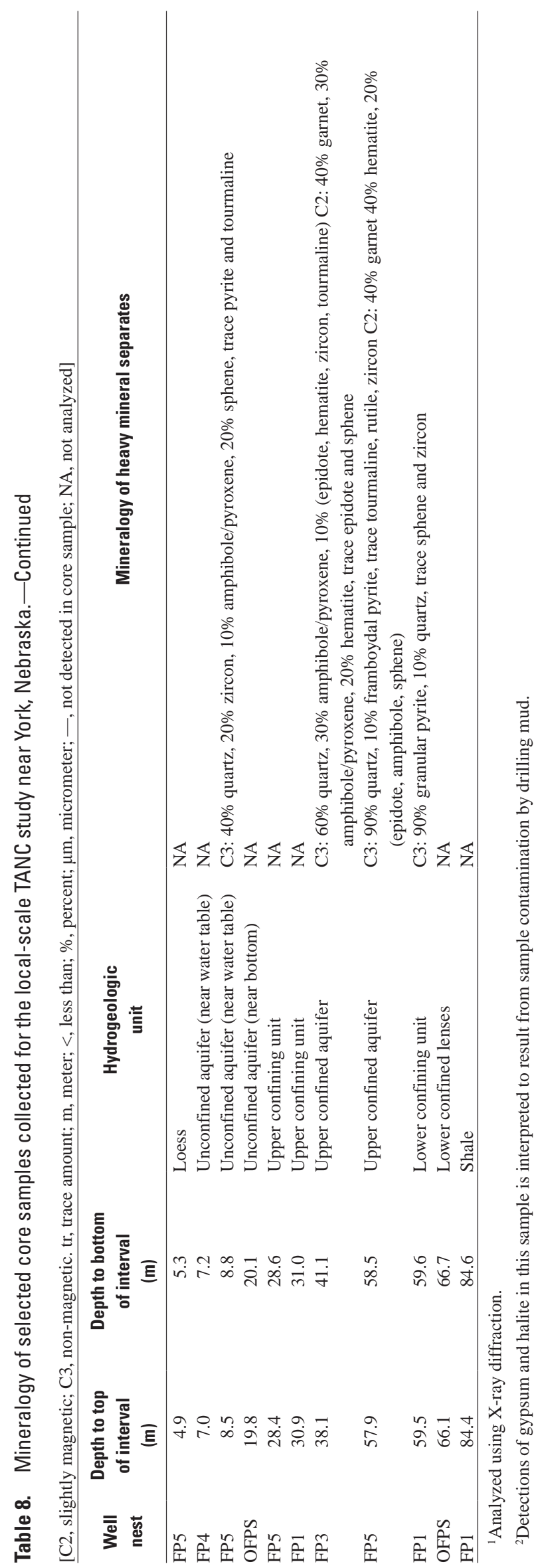




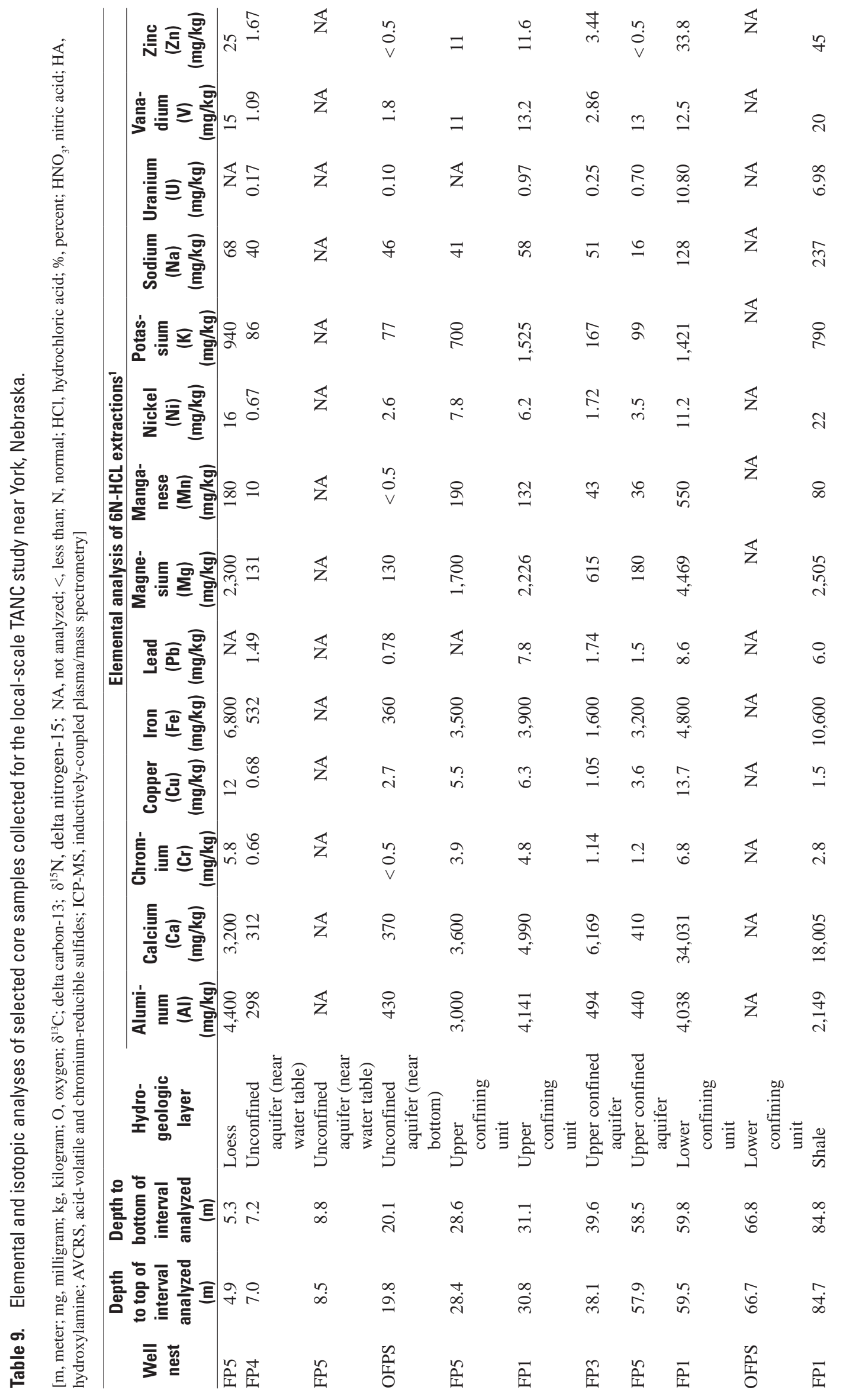




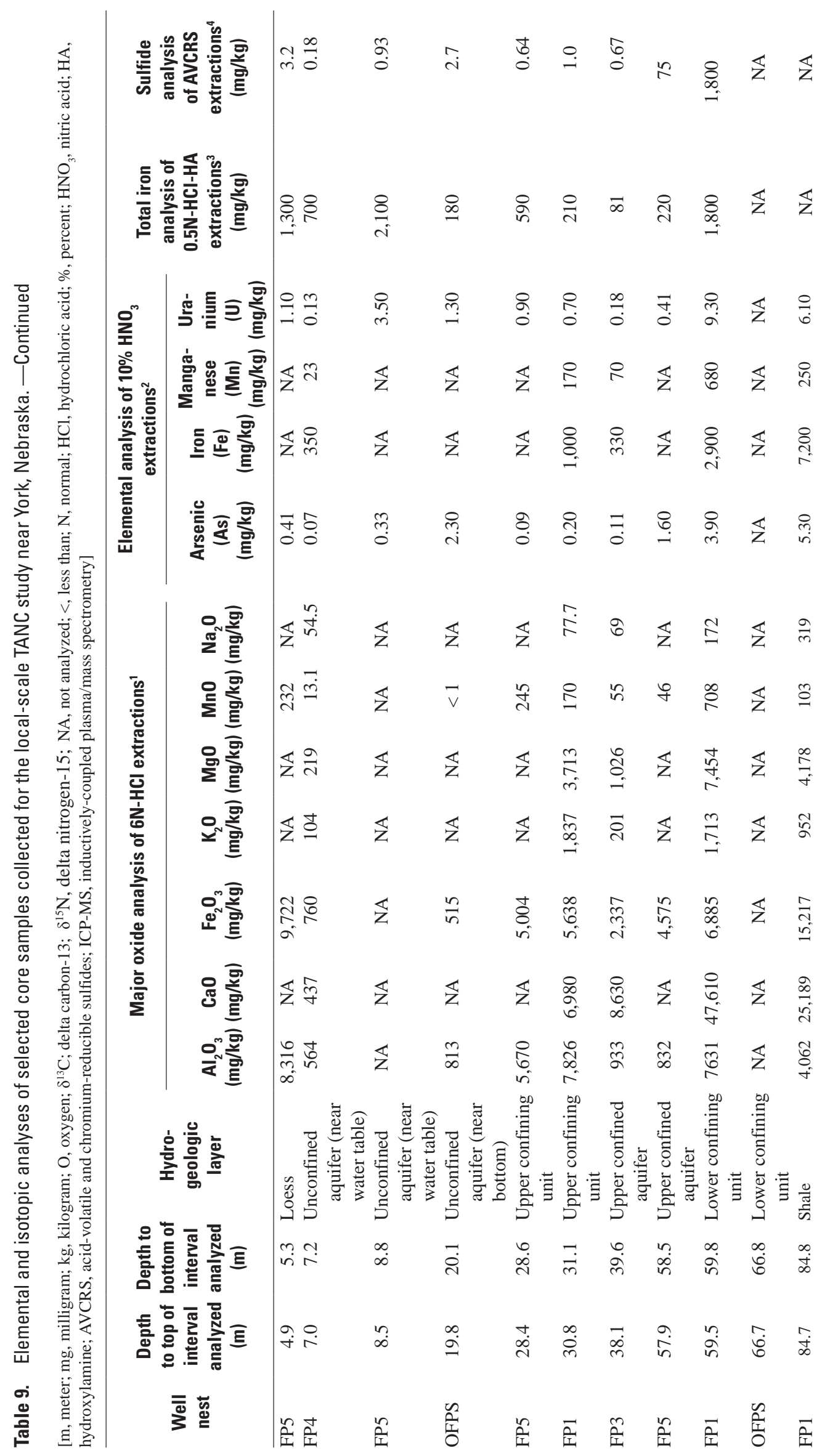




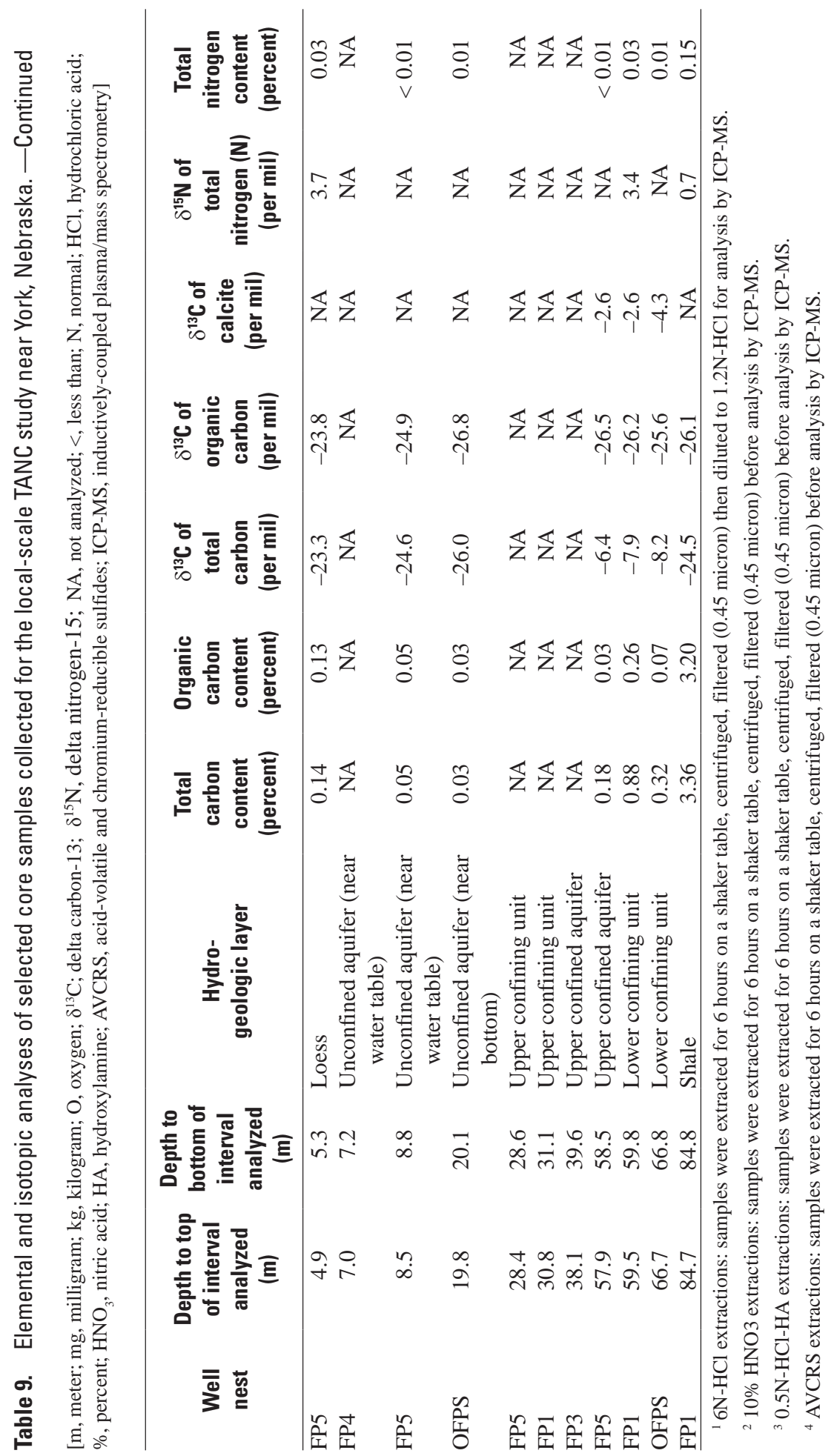




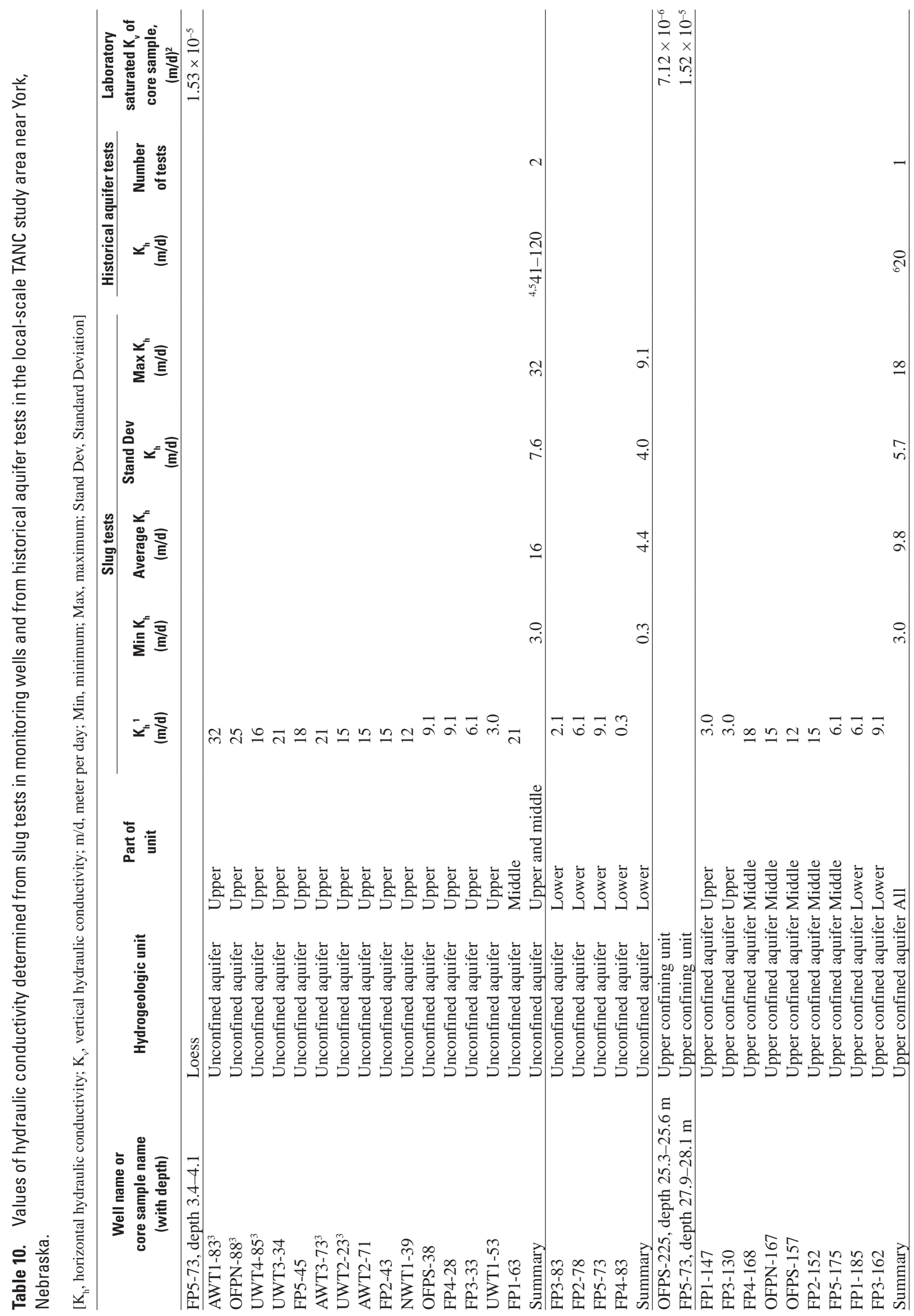




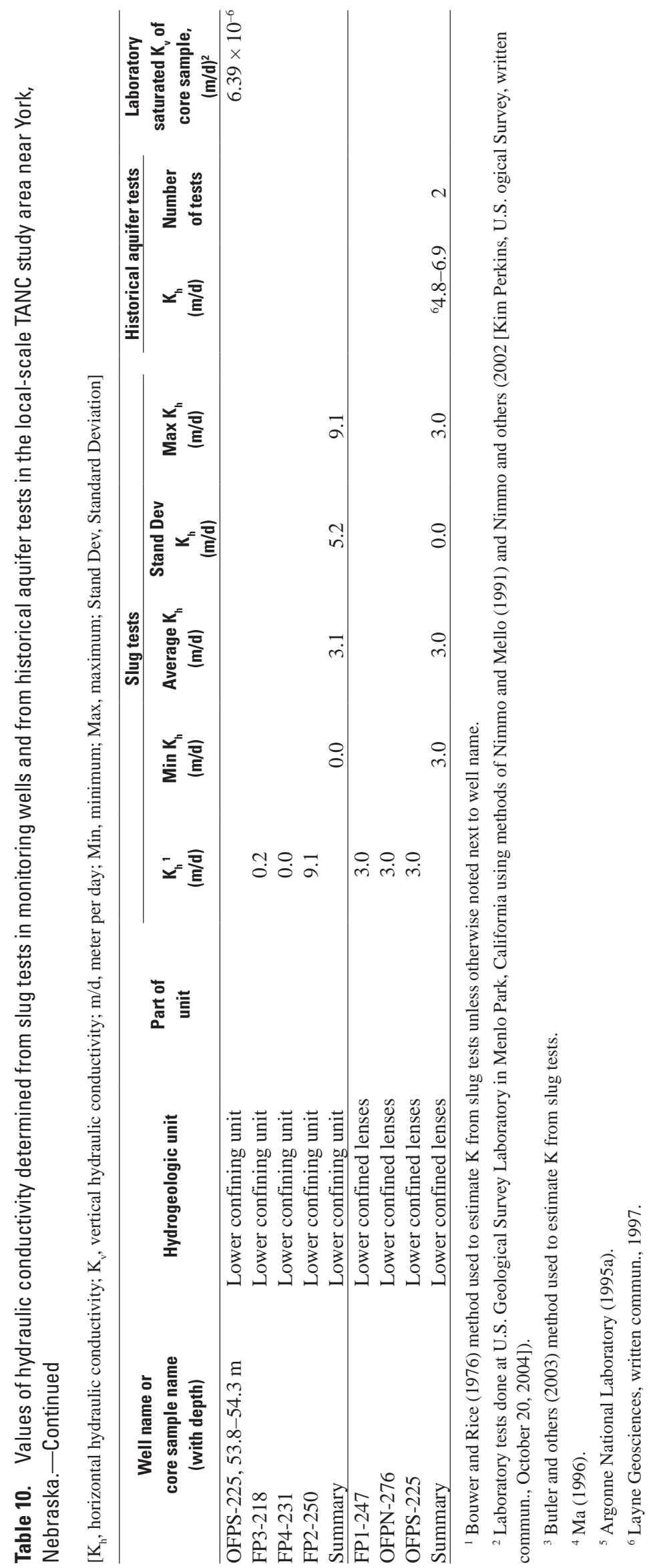




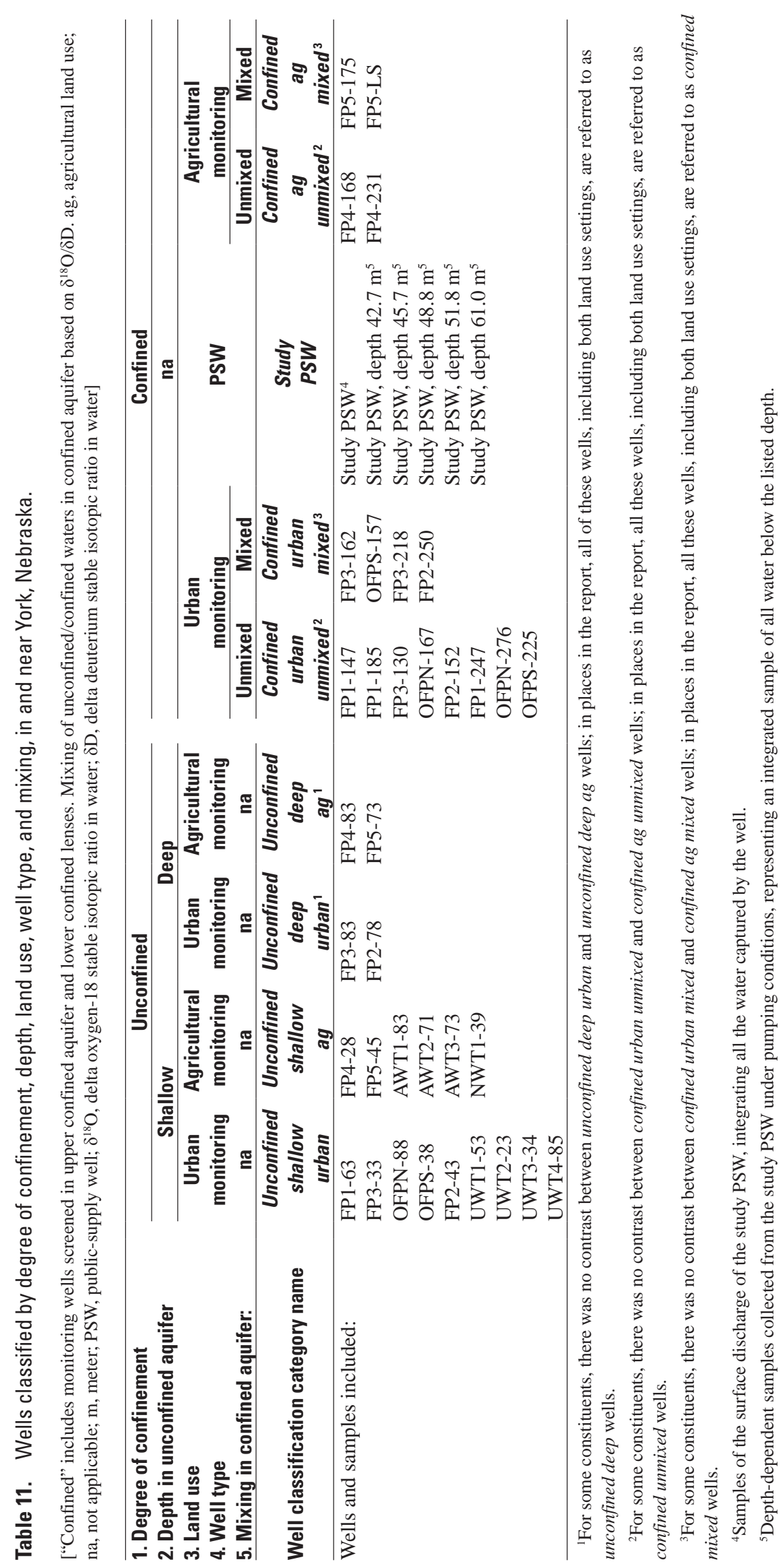




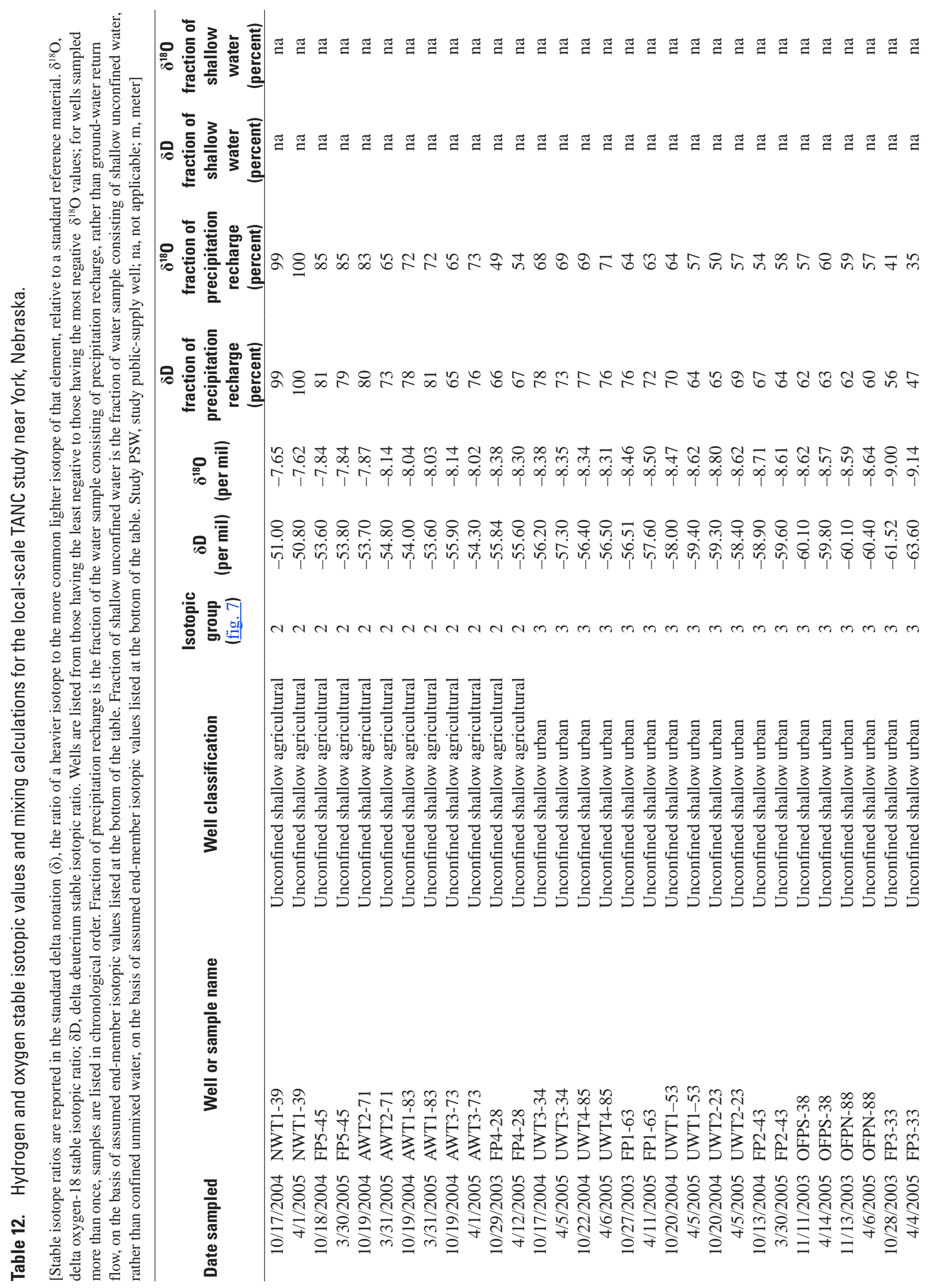




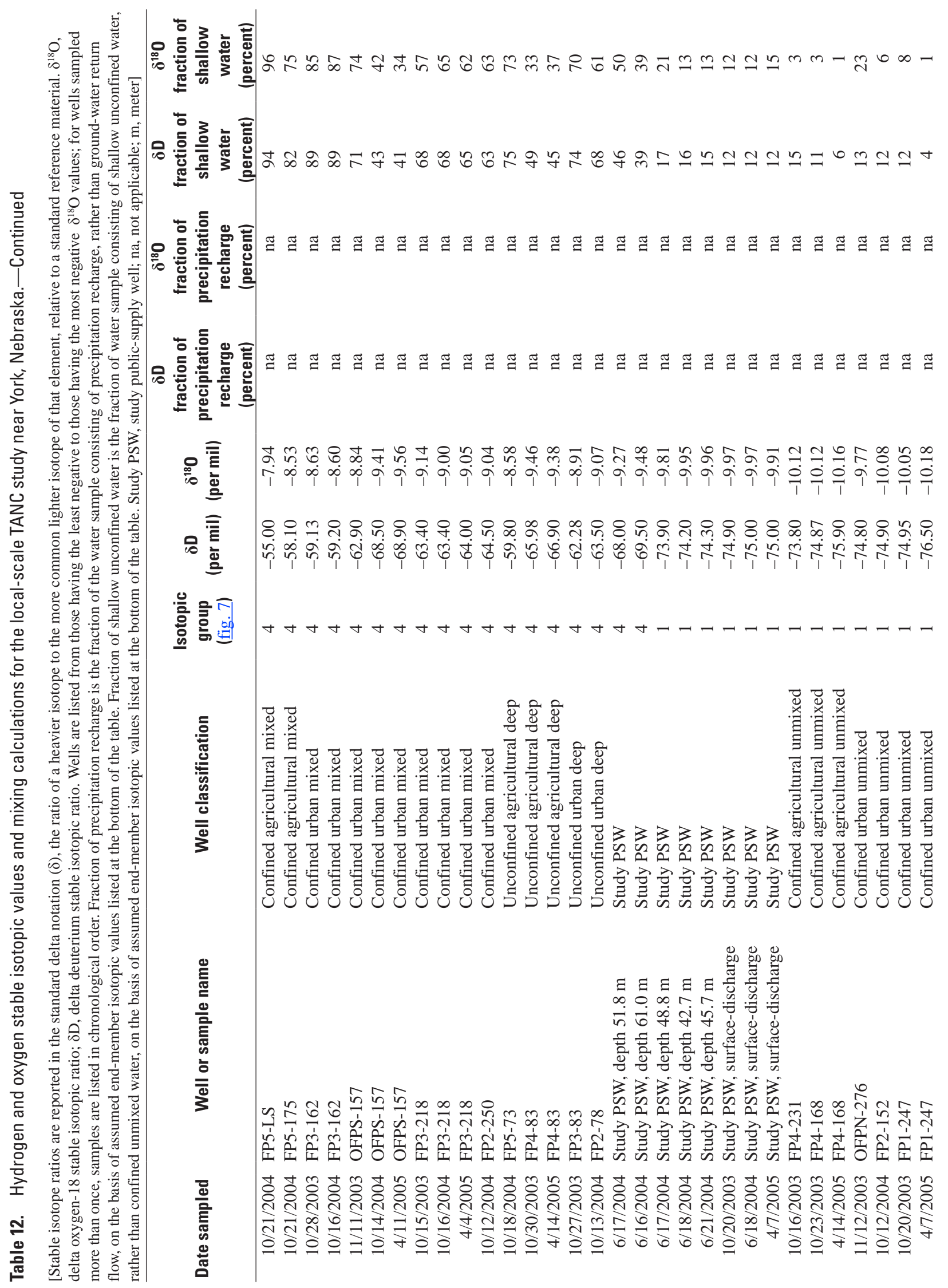




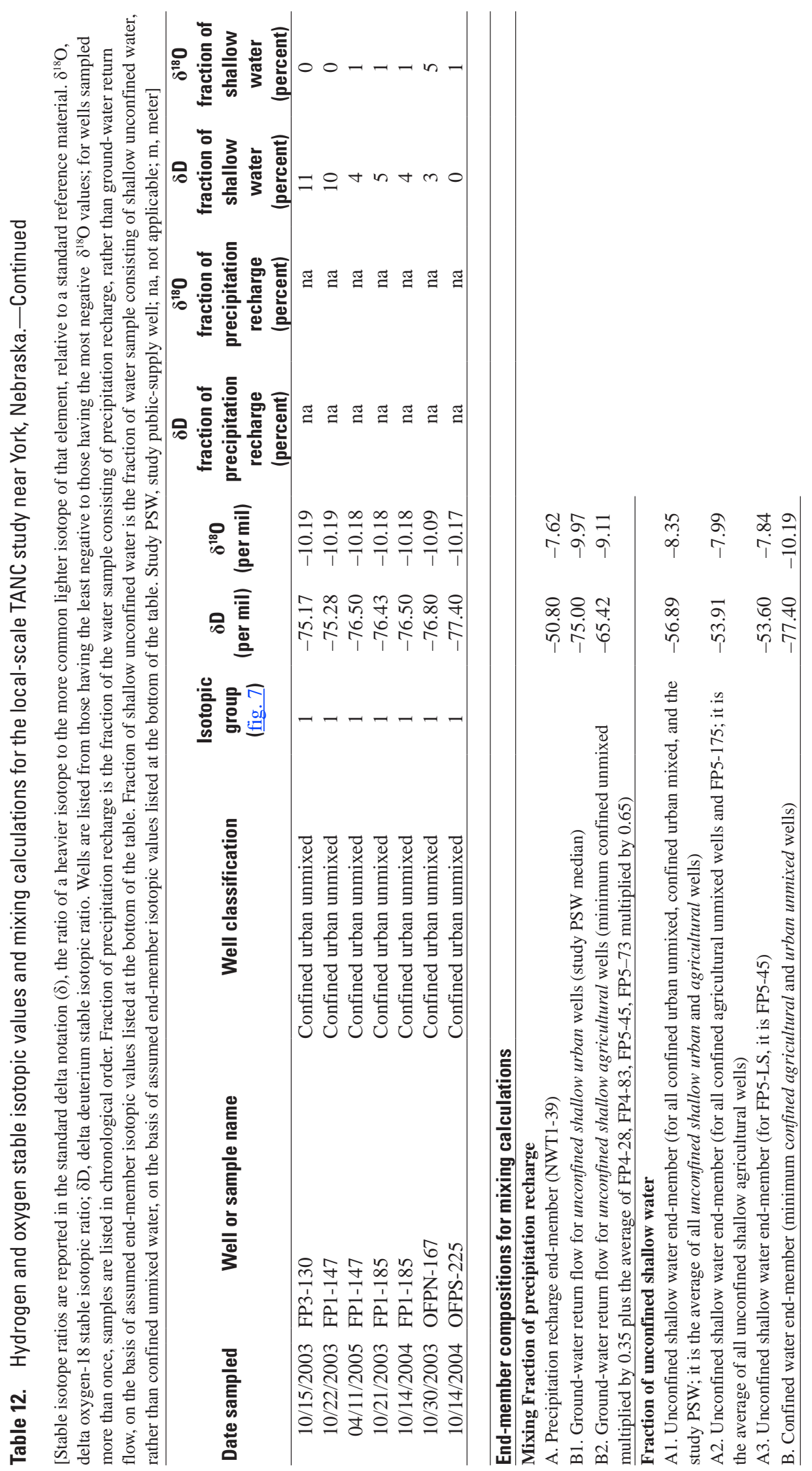




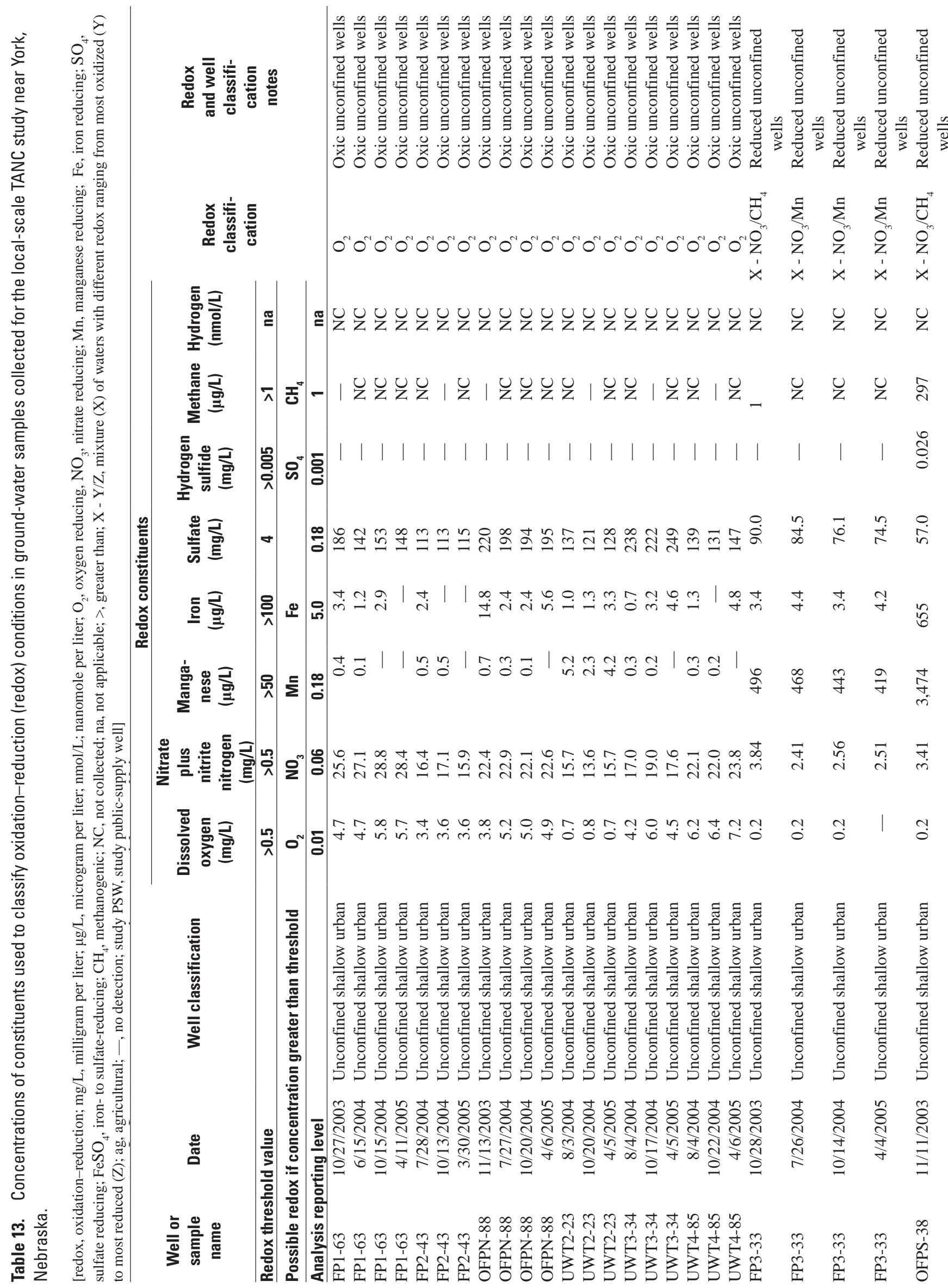




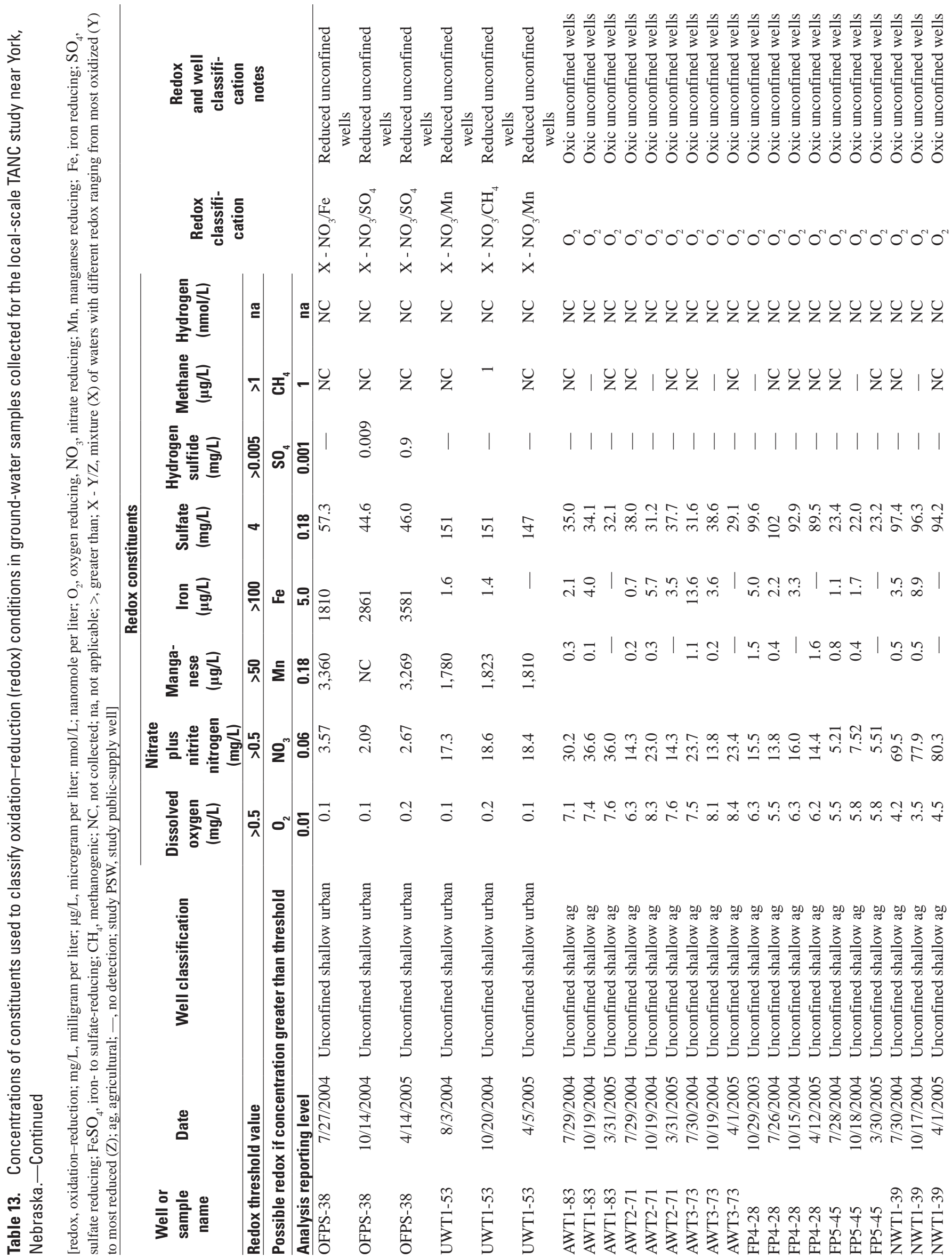




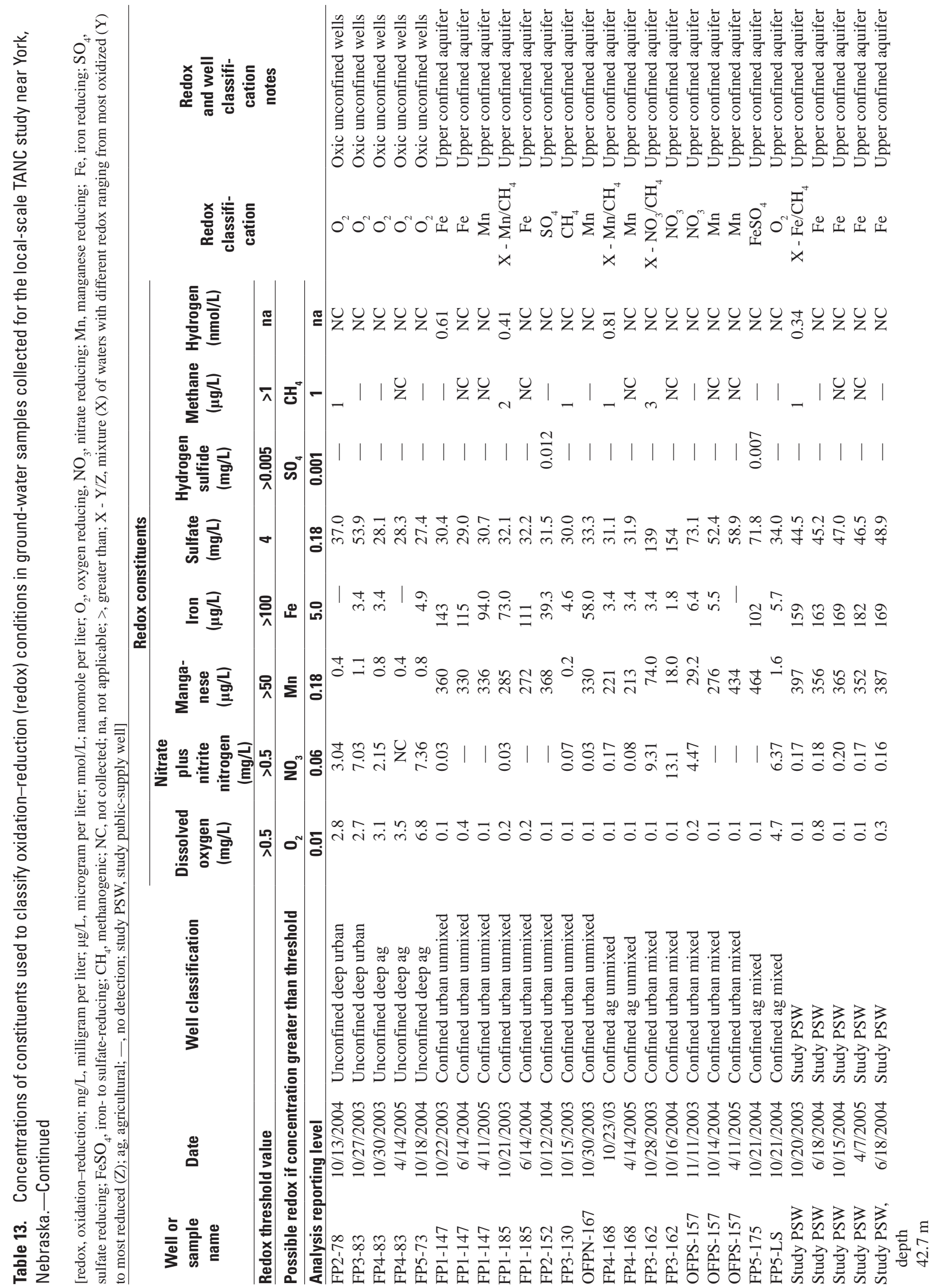




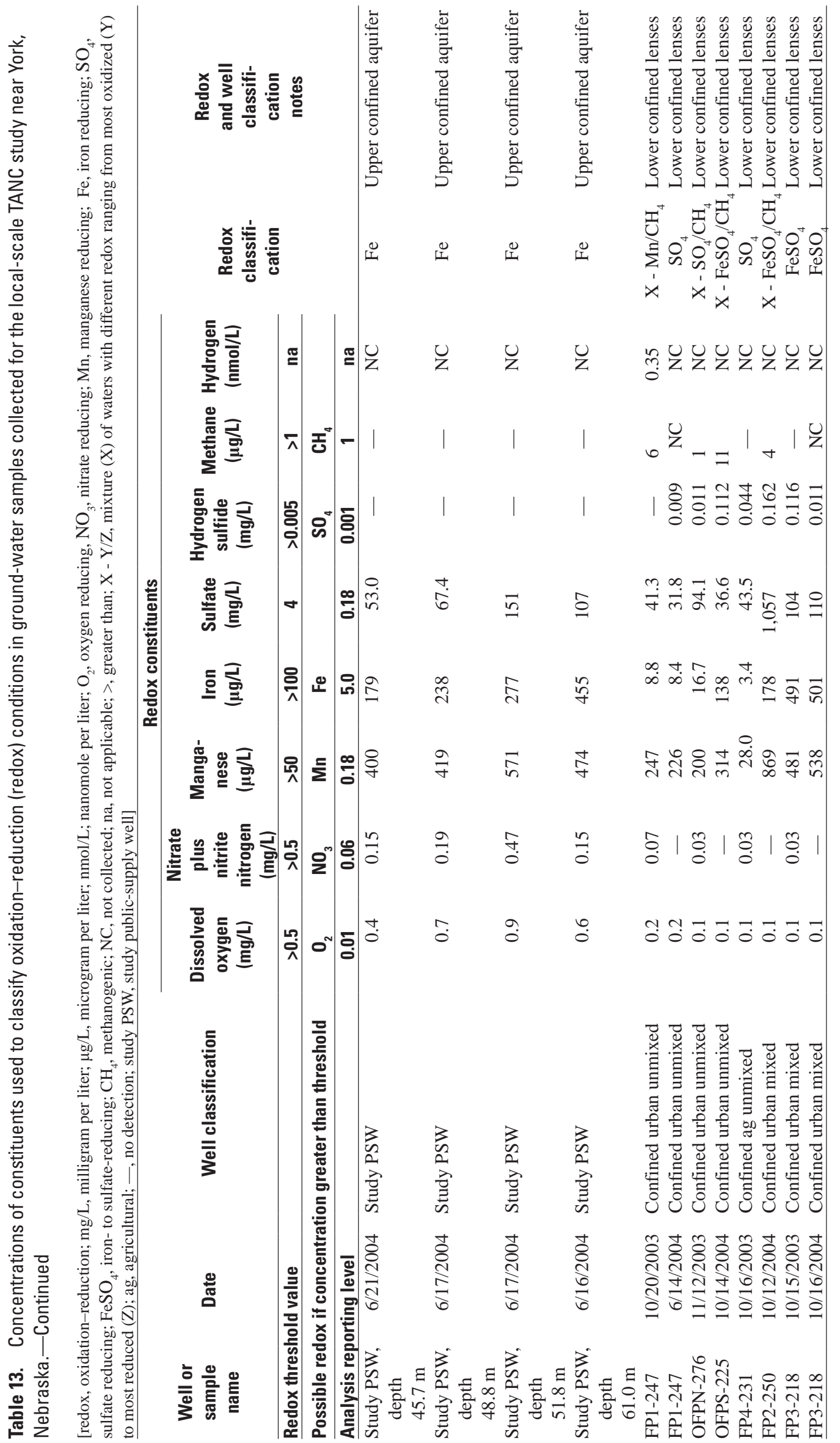




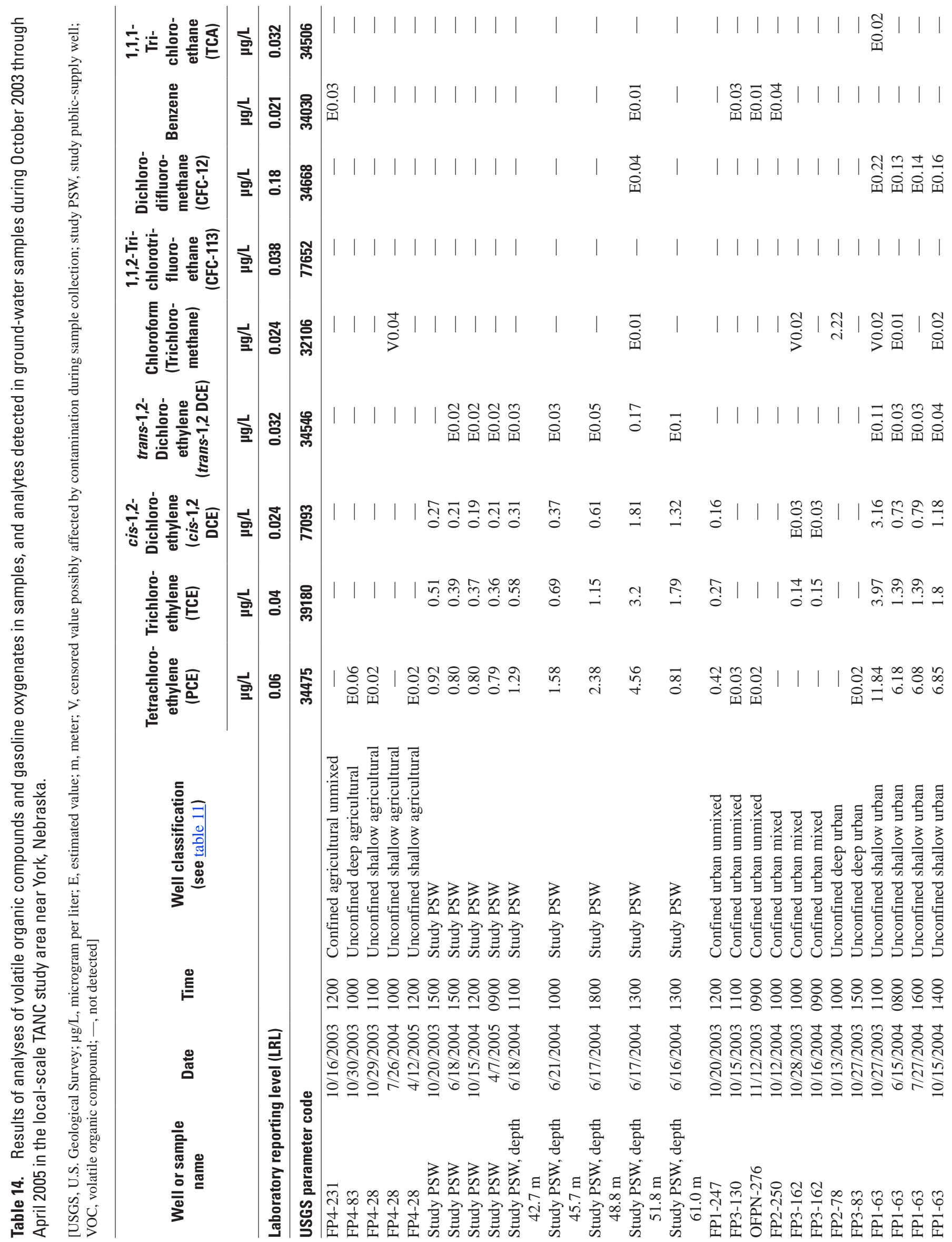




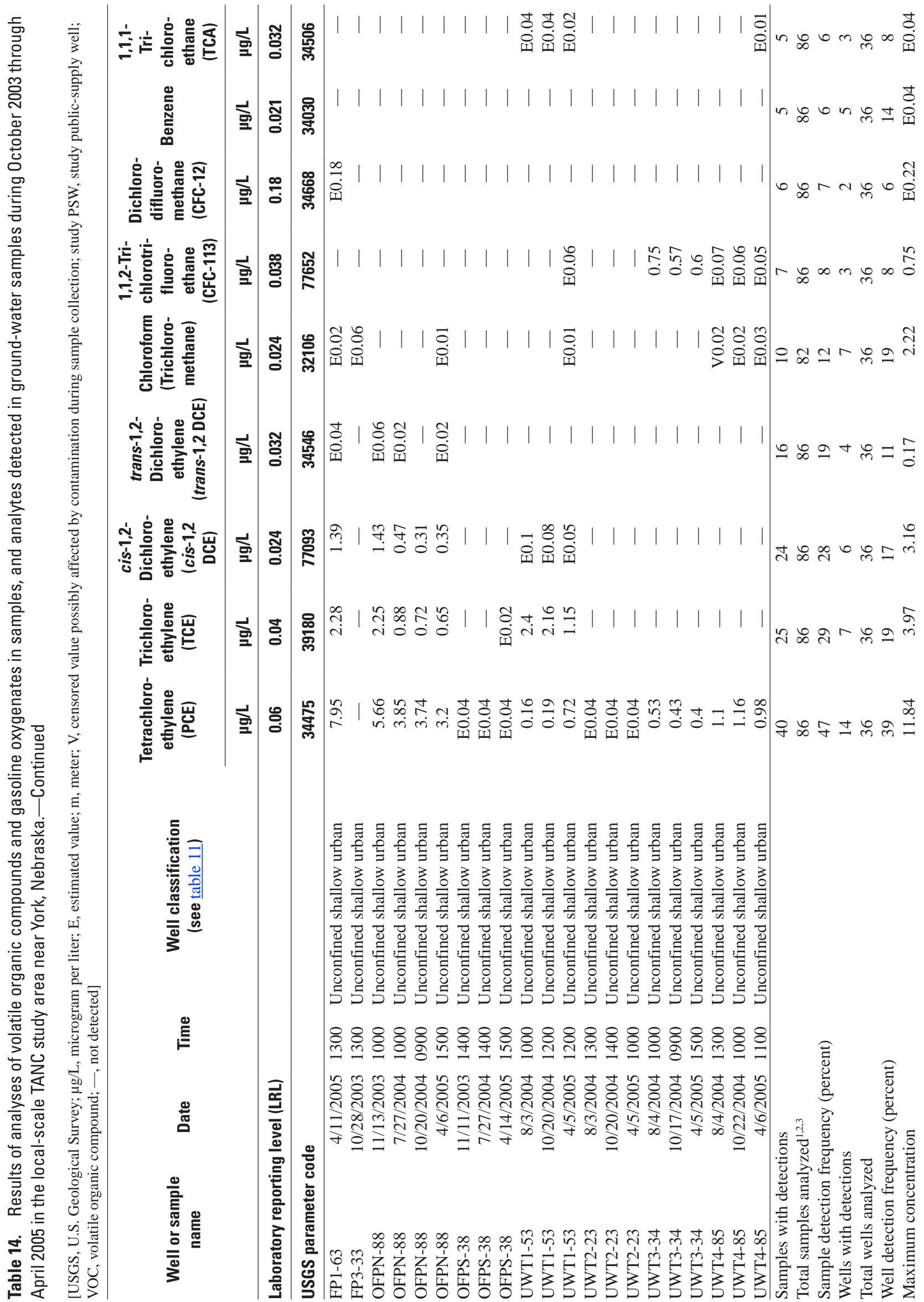




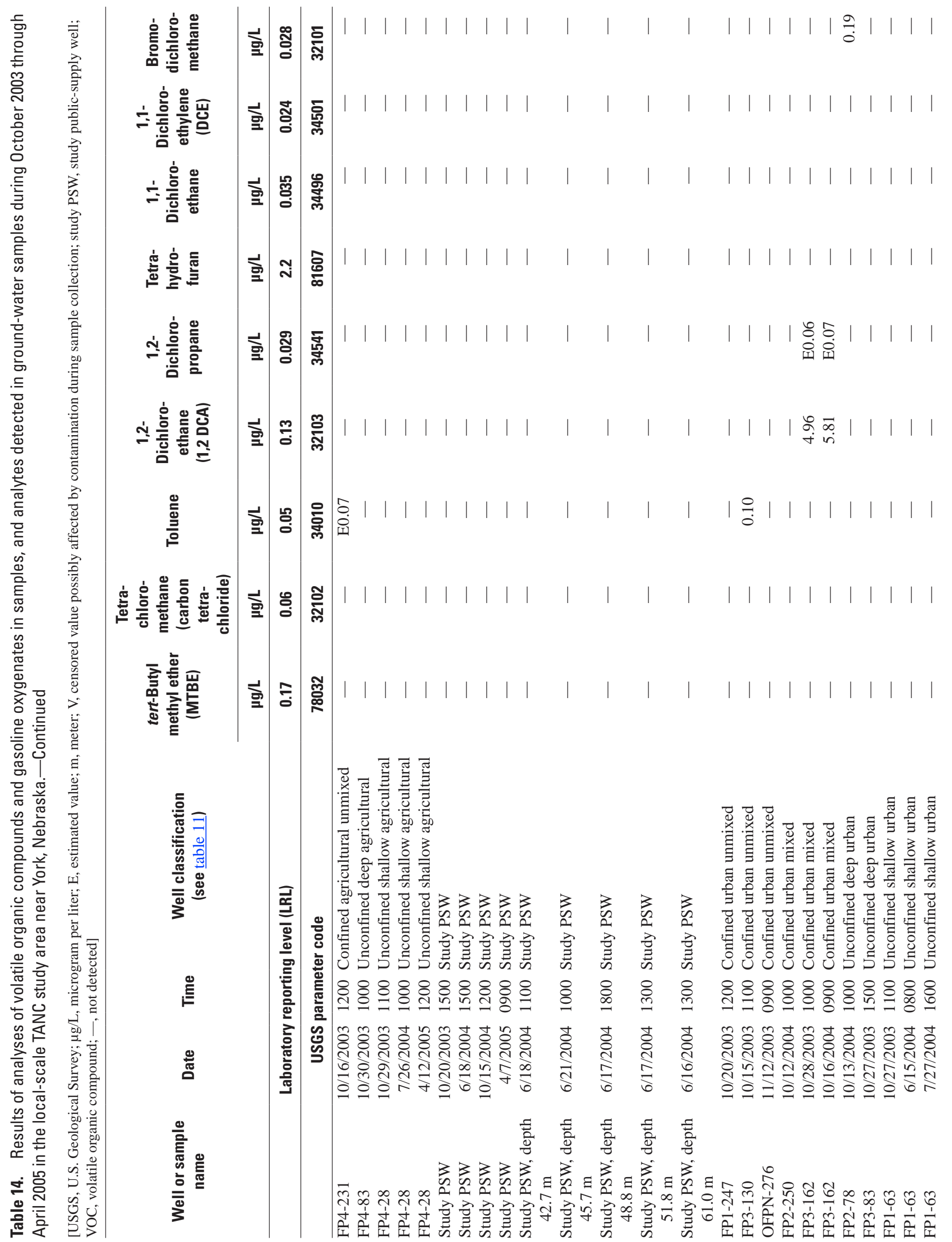




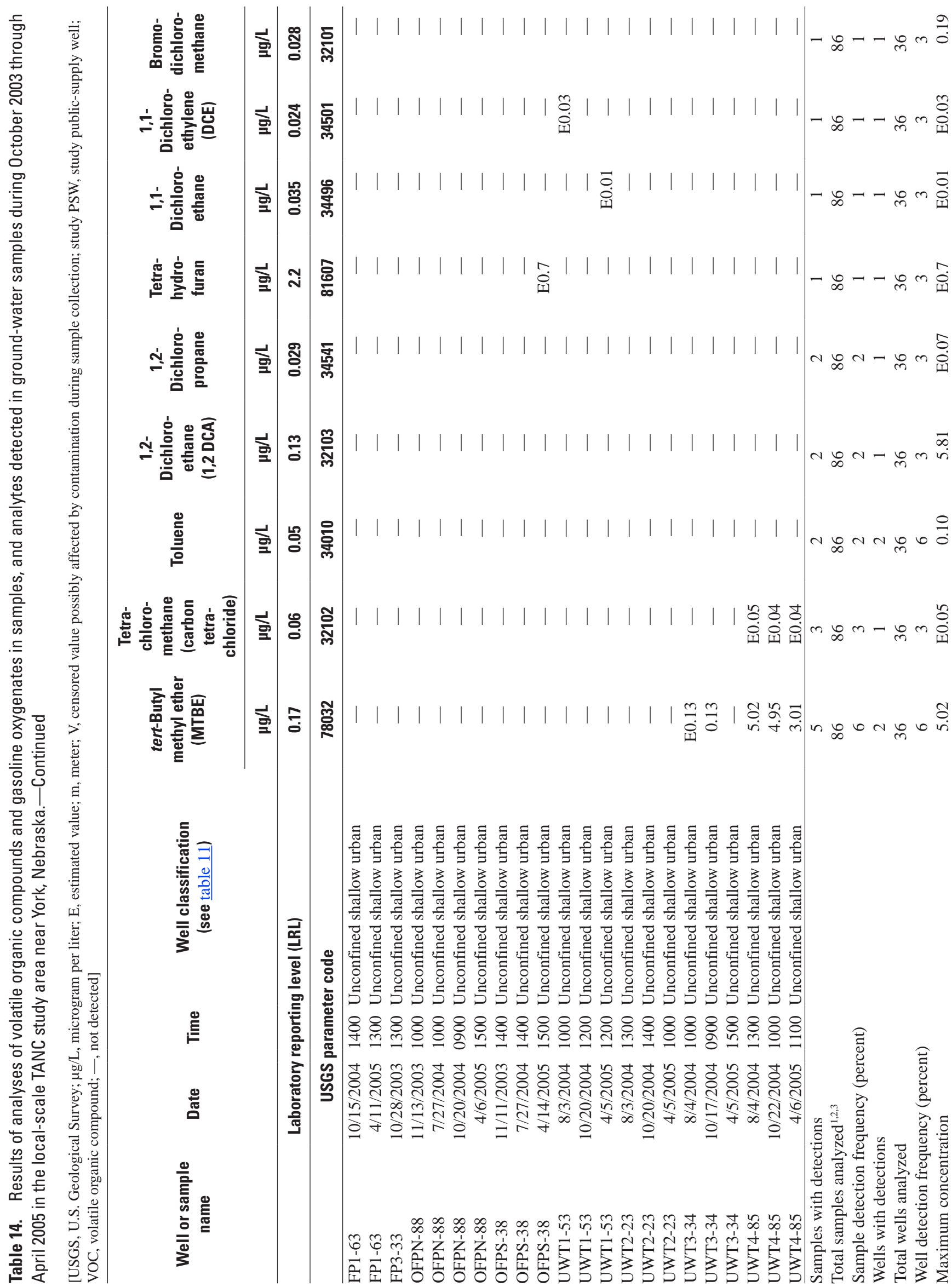




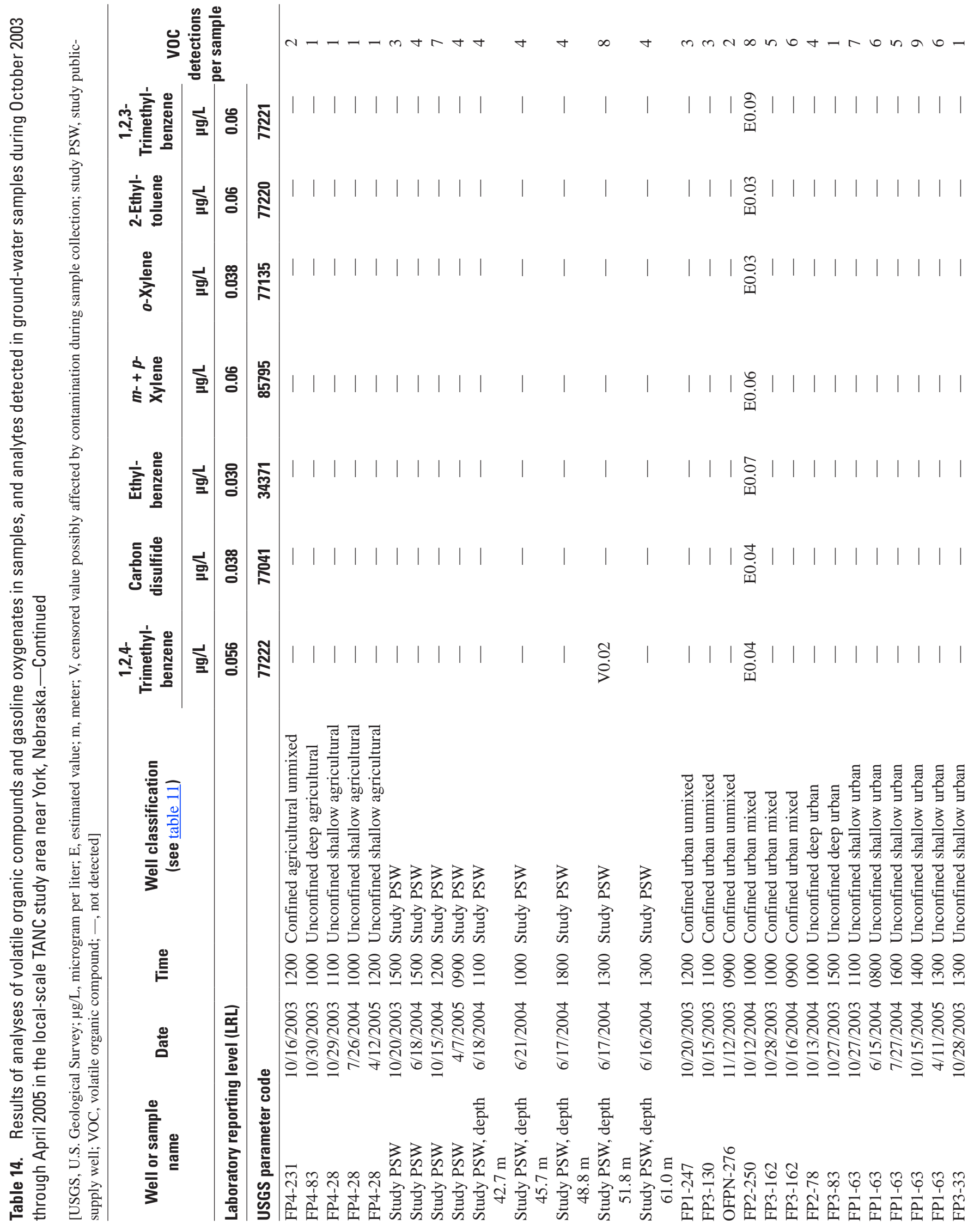




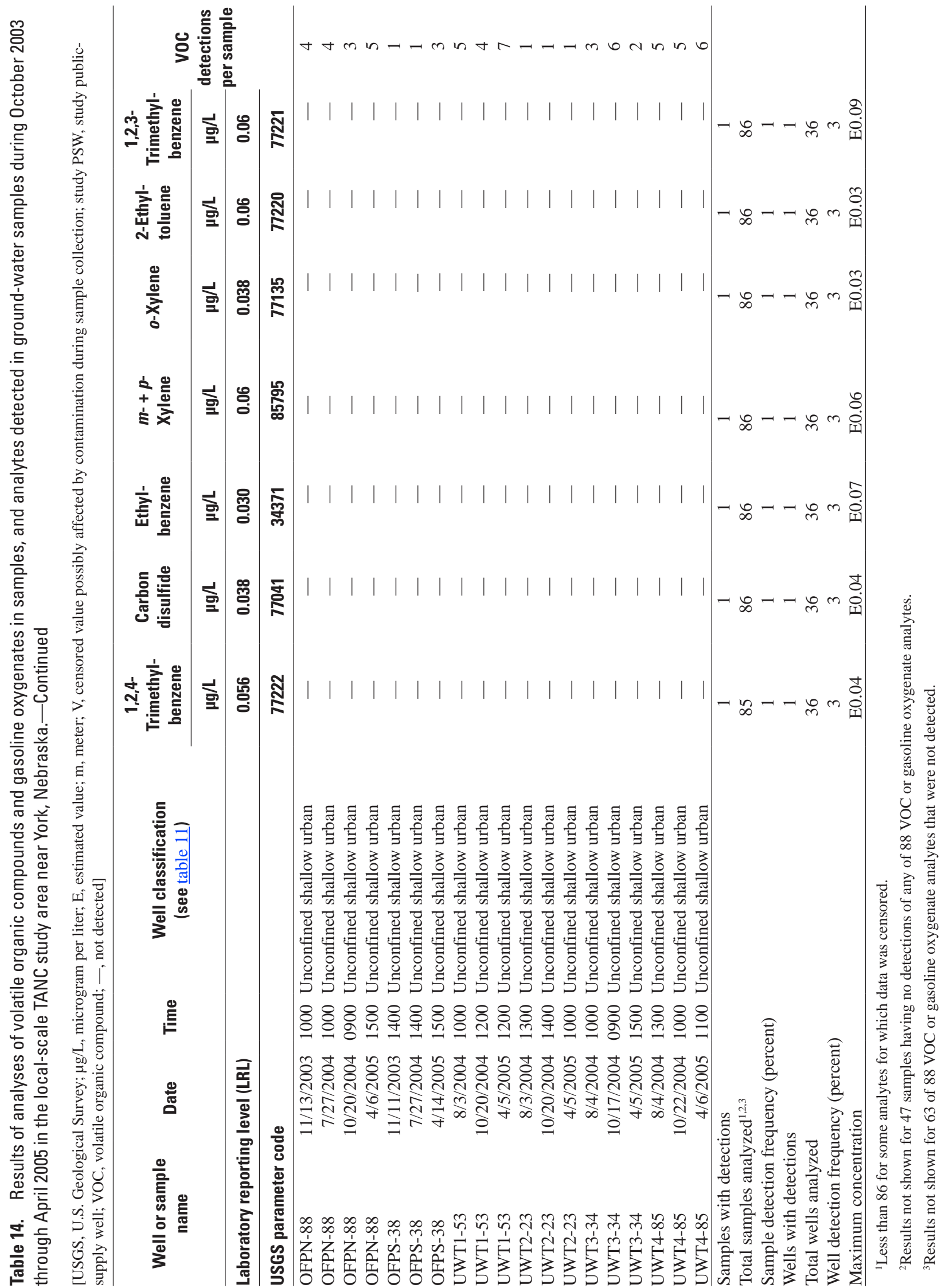




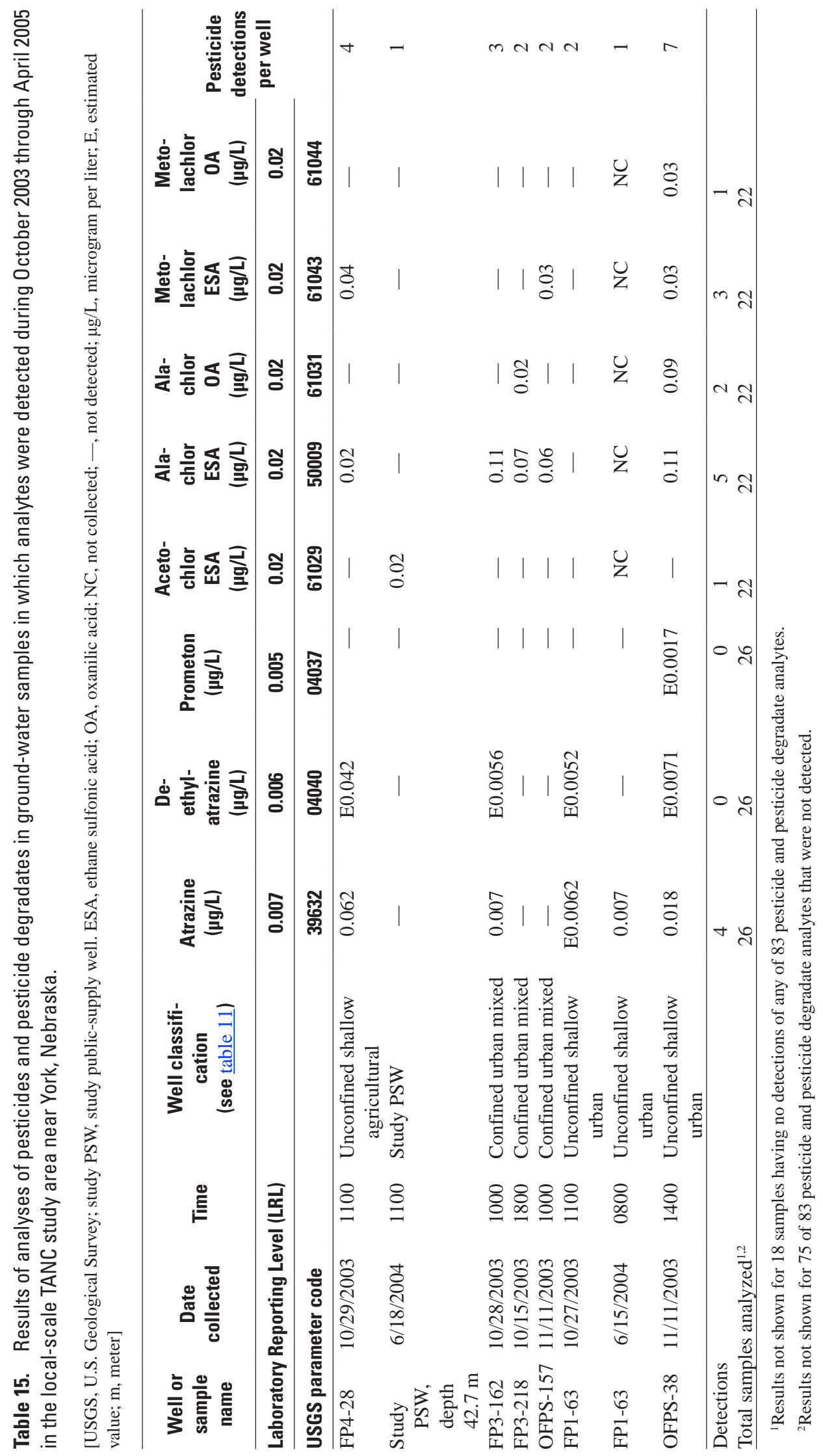


Table 16. Age tracer and supporting data for ground-water samples collected from the local-scale TANC study area near York, Nebraska.

[All apparent ages calculated based on a recharge altitude of 488 meters. He, helium; ${ }^{3} \mathrm{H}$, tritium; ${ }^{3} \mathrm{He}$, helium-3 concentration; ${ }^{4} \mathrm{He}$, helium-4 concentration; ( ${ }^{3} \mathrm{He}$ )tritium, helium-3 concentration from decay of tritium; $\delta$, isotopic ratio of light to heavy isotope relative to standard reference; B.P., before present; ${ }^{\circ} \mathrm{C}$, degree Celsius; CFC, chlorofluorocarbon; $\mathrm{cm}^{3} \mathrm{STP} / \mathrm{g}$, cubic centimeter of gas at Standard Temperature and Pressure per gram of water; contam, tracer concentrations greater than would result from atmospheric sources, indicating contamination for the purposes of age dating; italics, tracer was not detected where it was expected to be based on other tracers; $\mathrm{m}$, meter; $\mathrm{mL} / \mathrm{kg}$, milliliter per kilogram; mg/L, milligram per liter; $\mathrm{N}$, nitrogen; $\mathrm{N}_{2}$, nitrogen gas; $\mathrm{NC}$, not collected; $\mathrm{Ne}$, neon concentration; $\mathrm{P}$, phosphorus; pptv, parts per trillion by volume; $\mathrm{SF}_{6}$, sulfur hexafluoride; terrigenic, percent of ${ }^{3} \mathrm{He}$ from terrigenic sources; TU, tritium unit; USGS, U.S. Geological Survey; Study PSW, study public-supply well]

\begin{tabular}{|c|c|c|c|c|c|c|c|c|}
\hline \multirow{3}{*}{ Well or sample name } & \multirow{3}{*}{ Date } & \multirow{2}{*}{\multicolumn{3}{|c|}{$\begin{array}{c}\text { Calculated from dissolved gases } \\
\text { USGS Dissolved Gas Laboratory, } \\
\text { Reston, Virginia }\end{array}$}} & \multicolumn{4}{|c|}{$\begin{array}{c}\text { Calculated atmospheric mixing ratio corrected for } \\
\text { excess air and recharge temperature }\end{array}$} \\
\hline & & & & & \multicolumn{4}{|c|}{ USGS CFC Laboratory, Reston, Virginia } \\
\hline & & $\begin{array}{c}\text { Recharge } \\
\text { temperature } \\
\left({ }^{\circ} \mathrm{C}\right)\end{array}$ & $\begin{array}{l}\text { Excess air } \\
(\mathrm{mL} / \mathrm{kg})\end{array}$ & $\begin{array}{l}\text { Excess } \mathrm{N}_{2} \\
(\mathrm{mg} / \mathrm{L})\end{array}$ & $\begin{array}{l}\text { CFC-11 } \\
\text { (pptv) }\end{array}$ & $\begin{array}{l}\text { CFC-12 } \\
\text { (pptv) }\end{array}$ & $\begin{array}{l}\text { CFC-113 } \\
\text { (pptv) }\end{array}$ & $\begin{array}{c}\mathrm{SF}_{6} \\
\text { (pptv) }\end{array}$ \\
\hline FP1-63 & $10 / 27 / 2003$ & 8.1 & 6.1 & 0 & contam & contam & 44.0 & $\mathrm{NC}$ \\
\hline FP1-147 & $10 / 22 / 2003$ & 13.0 & 3.5 & 0 & 5.4 & 12.4 & 0.0 & 0.40 \\
\hline FP1-185 & $10 / 21 / 2003$ & 11.2 & 3.3 & 0 & 3.8 & 3.6 & 4.6 & 0.11 \\
\hline OFPS-38 & $11 / 11 / 2003$ & 13.7 & 2.9 & 4 & 12.0 & 166.7 & 0.0 & 1.26 \\
\hline OFPS-157 & $11 / 11 / 2003$ & 11.2 & 2.3 & 3.5 & contam & contam & 3.6 & 1.07 \\
\hline FP3-33 & $10 / 28 / 2003$ & 11.9 & 5.5 & 0 & 31.6 & 537.9 & 4.4 & $\mathrm{NC}$ \\
\hline FP3-83 & $10 / 27 / 2003$ & 13.3 & 2.7 & 0 & 5.7 & contam & 0.0 & $\mathrm{NC}$ \\
\hline FP3-130 & $10 / 15 / 2003$ & 11.8 & 2.6 & 0 & 19.9 & 12.0 & 3.9 & 1.23 \\
\hline FP3-162 & $10 / 28 / 2003$ & 11.6 & 5.1 & 3 & 156.7 & contam & 1.0 & 1.14 \\
\hline FP4-28 & $10 / 29 / 2003$ & 11.8 & 2.4 & 0 & contam & contam & contam & $\mathrm{NC}$ \\
\hline FP4-83 & $10 / 30 / 2005$ & 11.2 & 1.1 & 0 & 9.3 & 34.5 & contam & $\mathrm{NC}$ \\
\hline FP4-168 & $10 / 23 / 2005$ & 11.0 & 2.8 & 0 & 5.2 & 5.3 & 33.3 & 0.63 \\
\hline Study PSW & $10 / 20 / 2003$ & 11.7 & 3.7 & 1 & 38.1 & contam & 0.0 & 0.24 \\
\hline Study PSW & $6 / 18 / 2004$ & 10.9 & 6.5 & 1.5 & $\mathrm{NC}$ & $\mathrm{NC}$ & $\mathrm{NC}$ & 0.27 \\
\hline Study PSW depth $42.7 \mathrm{~m}$ & $6 / 18 / 2004$ & 11.9 & 5.7 & 2 & $\mathrm{NC}$ & $\mathrm{NC}$ & $\mathrm{NC}$ & 0.45 \\
\hline Study PSW depth $45.7 \mathrm{~m}$ & $6 / 21 / 2004$ & 11.5 & 4.0 & 1.5 & $\mathrm{NC}$ & $\mathrm{NC}$ & $\mathrm{NC}$ & 0.40 \\
\hline Study PSW depth $48.8 \mathrm{~m}$ & $6 / 17 / 2004$ & 11.7 & 3.8 & 3 & $\mathrm{NC}$ & $\mathrm{NC}$ & $\mathrm{NC}$ & 0.41 \\
\hline FP1-247 & $10 / 20 / 2003$ & 11.1 & 3.0 & 1 & $\mathrm{NC}$ & $\mathrm{NC}$ & $\mathrm{NC}$ & $\mathrm{NC}$ \\
\hline FP3-218 & $10 / 15 / 2003$ & 11.8 & 4.3 & 4 & $\mathrm{NC}$ & $\mathrm{NC}$ & $\mathrm{NC}$ & $\mathrm{NC}$ \\
\hline FP4-231 & $10 / 16 / 2003$ & 11.8 & 3.1 & 0 & $\mathrm{NC}$ & $\mathrm{NC}$ & $\mathrm{NC}$ & $\mathrm{NC}$ \\
\hline Study PSW depth $51.8 \mathrm{~m}$ & $6 / 17 / 2004$ & 11.7 & 2.6 & 7.5 & $\mathrm{NC}$ & $\mathrm{NC}$ & $\mathrm{NC}$ & $\mathrm{NC}$ \\
\hline Study PSW depth $61.0 \mathrm{~m}$ & $6 / 16 / 2004$ & 11.8 & 4.8 & 6 & $\mathrm{NC}$ & $\mathrm{NC}$ & $\mathrm{NC}$ & $\mathrm{NC}$ \\
\hline
\end{tabular}


Table 16. Age tracer and supporting data for ground-water samples collected from the local-scale TANC study area near York, Nebraska.-Continued

[All apparent ages calculated based on a recharge altitude of 488 meters. He, helium; ${ }^{3} \mathrm{H}$, tritium; ${ }^{3} \mathrm{He}$, helium-3 concentration; ${ }^{4} \mathrm{He}$, helium- 4 concentration; $\left({ }^{3} \mathrm{He}\right)$ tritium, helium- 3 concentration from decay of tritium; $\delta$, isotopic ratio of light to heavy isotope relative to standard reference; B.P., before present; ${ }^{\circ} \mathrm{C}$, degree Celsius; CFC, chlorofluorocarbon; $\mathrm{cm}^{3} \mathrm{STP} / \mathrm{g}$, cubic centimeter of gas at Standard Temperature and Pressure per gram of water; contam, tracer concentrations greater than would result from atmospheric sources, indicating contamination for the purposes of age dating; italics, tracer was not detected where it was expected to be based on other tracers; $\mathrm{m}$, meter; $\mathrm{mL} / \mathrm{kg}$, milliliter per kilogram; $\mathrm{mg} / \mathrm{L}$, milligram per liter; $\mathrm{N}$, nitrogen; $\mathrm{N}_{2}$, nitrogen gas; $\mathrm{NC}$, not collected; $\mathrm{Ne}$, neon concentration; $\mathrm{P}$, phosphorus; pptv, parts per trillion by volume; $\mathrm{SF}_{6}$, sulfur hexafluoride; terrigenic, percent of ${ }^{3} \mathrm{He}$ from terrigenic sources; TU, tritium unit; USGS, U.S. Geological Survey; Study PSW, study public-supply well]

\begin{tabular}{|c|c|c|c|c|c|c|c|c|c|c|c|}
\hline $\begin{array}{c}\text { Well or sample } \\
\text { name }\end{array}$ & Date & \multicolumn{6}{|c|}{$\begin{array}{l}\text { Lamont-Doherty Earth Observatory, Noble Gas Laboratory, } \\
\text { Palisades, New York }\end{array}$} & $\begin{array}{c}\text { Carbon-14 } \\
\text { percent } \\
\text { modern }\end{array}$ & $\begin{array}{l}\text { Uncorrected } \\
\text { carbon-14 } \\
\text { age } \\
\text { (years B.P.) }\end{array}$ & $\begin{array}{l}\delta^{13} \mathrm{C} \\
\text { (per } \\
\text { mil) }\end{array}$ & $\begin{array}{c}\text { Corrected }^{1} \\
\text { carbon-14 age } \\
\text { (years B.P.) }\end{array}$ \\
\hline FP1-63 & $10 / 27 / 2003$ & 1.04 & 0.92 & 4.38 & 19.43 & -0.16 & -3.4 & $\mathrm{NC}$ & $\mathrm{NC}$ & $\mathrm{NC}$ & $\mathrm{NC}$ \\
\hline FP1-147 & $10 / 22 / 2003$ & 1.47 & -47.07 & 17.84 & 26.35 & 42.24 & 90.5 & $\mathrm{NC}$ & $\mathrm{NC}$ & $\mathrm{NC}$ & $\mathrm{NC}$ \\
\hline FP1-185 & $10 / 21 / 2003$ & 0.4 & $\mathrm{NC}$ & $\mathrm{NC}$ & $\mathrm{NC}$ & $\mathrm{NC}$ & $\mathrm{NC}$ & 45.2 & 6,568 & -8.5 & 1,368 \\
\hline FP3-33 & $10 / 28 / 2003$ & 4.16 & $\mathrm{NC}$ & $\mathrm{NC}$ & $\mathrm{NC}$ & $\mathrm{NC}$ & $\mathrm{NC}$ & 80.1 & Not dateable & -11.7 & Not dateable \\
\hline FP3-83 & $10 / 27 / 2003$ & 2.9 & $\mathrm{NC}$ & $\mathrm{NC}$ & $\mathrm{NC}$ & $\mathrm{NC}$ & $\mathrm{NC}$ & 74.9 & Not dateable & -11.1 & Not dateable \\
\hline FP3-130 & $10 / 15 / 2003$ & 0.18 & $\mathrm{NC}$ & $\mathrm{NC}$ & $\mathrm{NC}$ & $\mathrm{NC}$ & $\mathrm{NC}$ & $\mathrm{NC}$ & $\mathrm{NC}$ & $\mathrm{NC}$ & $\mathrm{NC}$ \\
\hline FP3-162 & $10 / 28 / 2003$ & 7.72 & $\mathrm{NC}$ & $\mathrm{NC}$ & $\mathrm{NC}$ & $\mathrm{NC}$ & $\mathrm{NC}$ & $\mathrm{NC}$ & $\mathrm{NC}$ & $\mathrm{NC}$ & $\mathrm{NC}$ \\
\hline FP4-28 & $10 / 29 / 2003$ & 6.31 & -5.66 & 6.26 & 22.88 & 3.02 & 13.2 & $\mathrm{NC}$ & $\mathrm{NC}$ & $\mathrm{NC}$ & $\mathrm{NC}$ \\
\hline $\begin{array}{l}\text { Study PSW depth } \\
\quad 42.7 \mathrm{~m}\end{array}$ & $6 / 18 / 2004$ & 0.87 & -52.77 & 48.31 & 57.97 & 98.37 & 90.5 & $\mathrm{NC}$ & $\mathrm{NC}$ & $\mathrm{NC}$ & $\mathrm{NC}$ \\
\hline $\begin{array}{l}\text { Study PSW depth } \\
\quad 45.7 \mathrm{~m}\end{array}$ & $6 / 21 / 2004$ & 1.04 & 0.92 & 4.38 & 19.43 & -0.16 & -3.4 & $\mathrm{NC}$ & $\mathrm{NC}$ & $\mathrm{NC}$ & $\mathrm{NC}$ \\
\hline $\begin{array}{l}\text { Study PSW depth } \\
\quad 48.8 \mathrm{~m}\end{array}$ & $6 / 17 / 2004$ & 1.47 & -47.07 & 17.84 & 26.35 & 42.24 & 90.5 & $\mathrm{NC}$ & $\mathrm{NC}$ & $\mathrm{NC}$ & $\mathrm{NC}$ \\
\hline FP1-247 & $10 / 20 / 2003$ & 0.4 & $\mathrm{NC}$ & $\mathrm{NC}$ & $\mathrm{NC}$ & $\mathrm{NC}$ & $\mathrm{NC}$ & 45.2 & 6,568 & -8.5 & 1,368 \\
\hline FP3-218 & $10 / 15 / 2003$ & 5.5 & $\mathrm{NC}$ & $\mathrm{NC}$ & $\mathrm{NC}$ & $\mathrm{NC}$ & $\mathrm{NC}$ & 78.3 & Not dateable & -8.3 & Not dateable \\
\hline FP4-231 & $10 / 16 / 2003$ & 0.2 & $\mathrm{NC}$ & $\mathrm{NC}$ & $\mathrm{NC}$ & $\mathrm{NC}$ & $\mathrm{NC}$ & 40.6 & 7,456 & -8.8 & 1,767 \\
\hline $\begin{array}{l}\text { Study PSW depth } \\
51.8 \mathrm{~m}\end{array}$ & $6 / 17 / 2004$ & 4.16 & $\mathrm{NC}$ & $\mathrm{NC}$ & $\mathrm{NC}$ & $\mathrm{NC}$ & $\mathrm{NC}$ & 80.1 & Not dateable & -11.7 & Not dateable \\
\hline
\end{tabular}

${ }^{1}$ Ages corrected using Tamers (1967) method assuming $\delta^{13} \mathrm{C}$ of soil carbon dioxide of -23 per mil and $\delta^{13} \mathrm{C}$ of carbonates of -4 per mil, and a fractionation factor for $\delta^{13} \mathrm{C}$ between dissolved inorganic carbon and soil carbon dioxide of 10 (Clark and Fritz, 1997, fig. 5.5, table 5.3, pH $=6.8$, temperature $15^{\circ} \mathrm{C}$ ). Ages are highly sensitive to assumptions. 


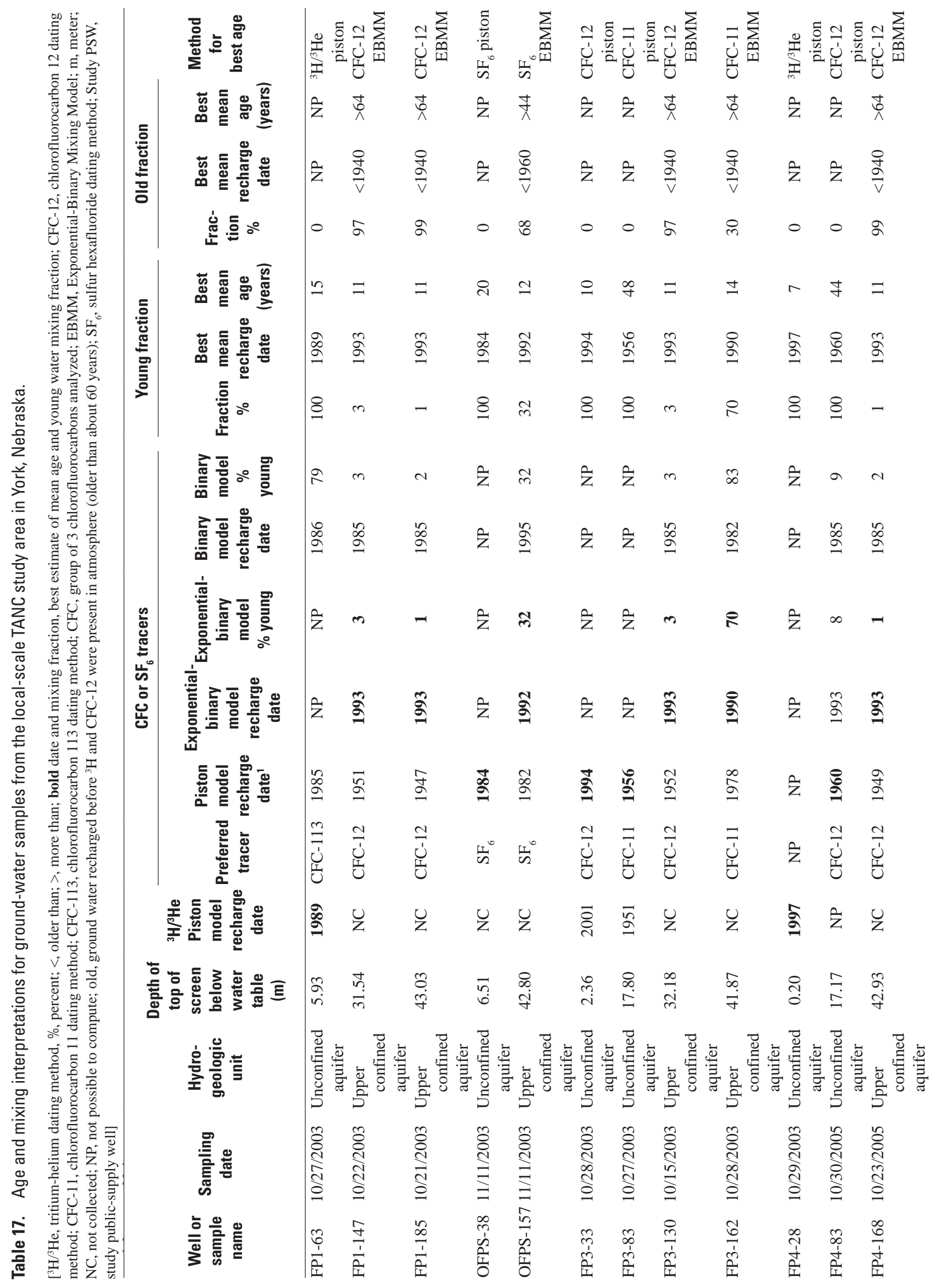




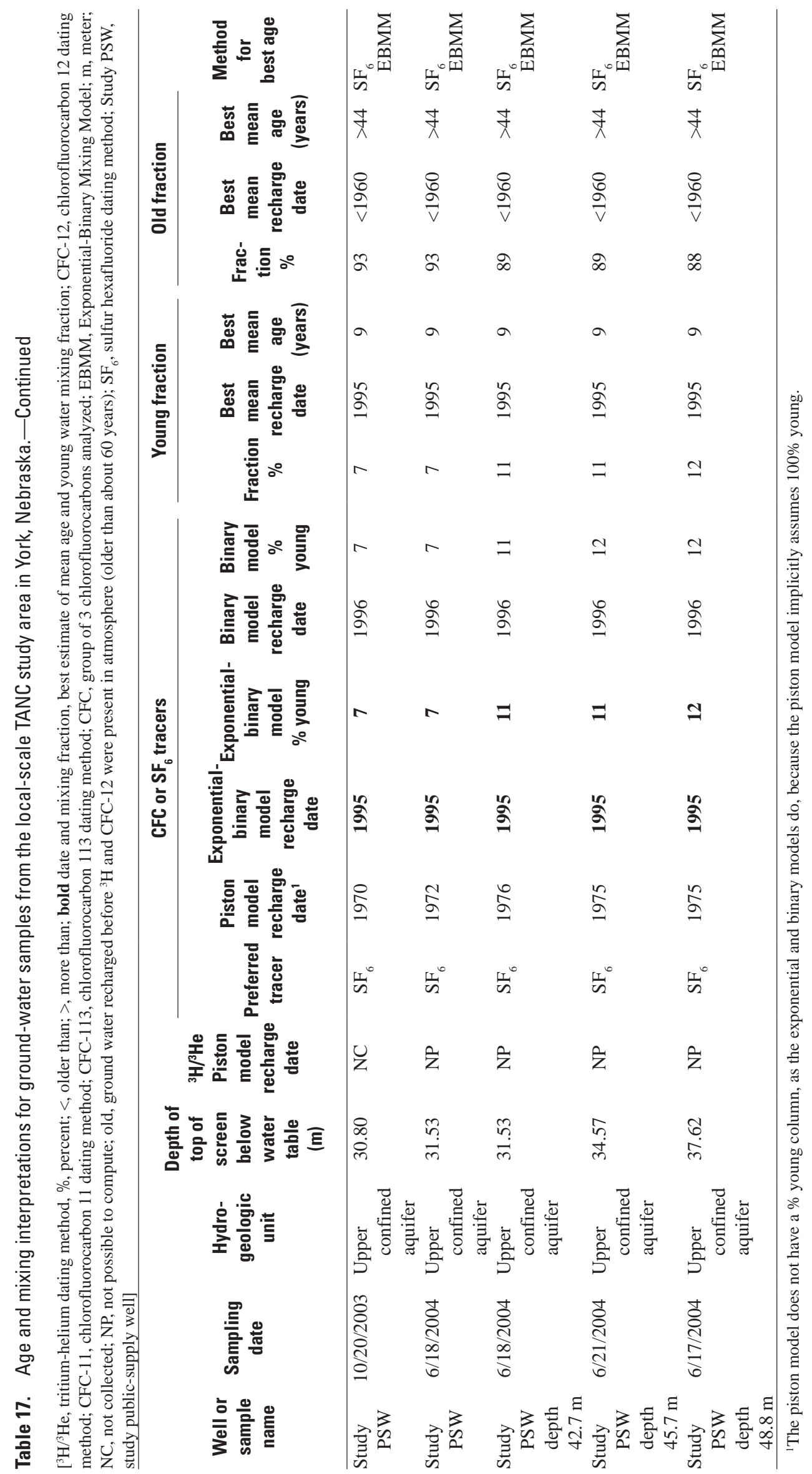


Table 18. Results of analyses of nutrients in ground-water samples collected during October 2003 through April 2005 in the local-scale TANC study area near York, Nebraska.

[USGS, U.S. Geological Survey; mg/L, milligram per liter; E, estimated value; <, less than; m, meter; study PSW, study public-supply well; N, nitrogen; P, phosphorus; —, not detected]

\begin{tabular}{|c|c|c|c|c|c|c|c|}
\hline $\begin{array}{c}\text { Well or } \\
\text { sample } \\
\text { name } \\
\end{array}$ & Date & Time & $\begin{array}{l}\text { Well classification } \\
\text { (see table 11) }\end{array}$ & $\begin{array}{l}\text { Ammonia } \\
\mathrm{mg} / \mathrm{L} \text { as } \mathrm{N}\end{array}$ & $\begin{array}{c}\text { Nitrite } \\
\mathrm{mg} / \mathrm{L} \text { as } \mathrm{N}\end{array}$ & $\begin{array}{l}\text { Nitrite plus } \\
\text { nitrate } \\
\text { mg/L as } \mathbf{N}\end{array}$ & $\begin{array}{c}\text { Orthophos- } \\
\text { phate } \\
\text { mg/L as P }\end{array}$ \\
\hline \multicolumn{4}{|c|}{ Laboratory reporting level (LRL) } & 0.04 & 0.008 & 0.06 & 0.006 \\
\hline FP4-168 & $10 / 23 / 2003$ & 1100 & Confined agricultural unmixed & 0.09 & E0.007 & 0.17 & 0.081 \\
\hline FP4-231 & $10 / 16 / 2003$ & 1200 & Confined agricultural mixed & 0.26 & E0.005 & - & 0.027 \\
\hline FP5-175 & $10 / 21 / 2004$ & 1400 & Confined agricultural mixed & 0.07 & - & - & 0.029 \\
\hline FP4-83 & $10 / 30 / 2003$ & 1000 & Unconfined deep agricultural & - & - & 2.15 & 0.179 \\
\hline FP5-73 & $10 / 18 / 2004$ & 1400 & Unconfined deep agricultural & - & - & 7.36 & 0.347 \\
\hline AWT1-83 & $7 / 29 / 2004$ & 1000 & Unconfined shallow agricultural & - & - & 30.2 & 0.362 \\
\hline AWT1-83 & $10 / 19 / 2004$ & 900 & Unconfined shallow agricultural & - & - & 36.6 & 0.352 \\
\hline AWT1-83 & $3 / 31 / 2005$ & 1000 & Unconfined shallow agricultural & - & - & 36.0 & 0.359 \\
\hline AWT2-71 & $7 / 29 / 2004$ & 1300 & Unconfined shallow agricultural & - & - & 14.3 & 0.387 \\
\hline AWT3-73 & 4/1/2005 & 1300 & Unconfined shallow agricultural & - & - & 23.4 & 0.394 \\
\hline FP4-28 & $10 / 29 / 2003$ & 1100 & Unconfined shallow agricultural & - & - & 15.5 & 0.464 \\
\hline FP4-28 & $7 / 26 / 2004$ & 1000 & Unconfined shallow agricultural & - & - & 13.8 & 0.496 \\
\hline FP4-28 & $10 / 15 / 2004$ & 900 & Unconfined shallow agricultural & - & - & 16.0 & 0.485 \\
\hline FP4-28 & $4 / 12 / 2005$ & 1200 & Unconfined shallow agricultural & - & - & 14.4 & 0.489 \\
\hline FP5-45 & $7 / 28 / 2004$ & 1000 & Unconfined shallow agricultural & - & - & 5.21 & 0.367 \\
\hline FP5-45 & $10 / 18 / 2004$ & 900 & Unconfined shallow agricultural & - & - & 7.52 & 0.379 \\
\hline FP5-45 & $3 / 30 / 2005$ & 1500 & Unconfined shallow agricultural & - & - & 5.51 & 0.384 \\
\hline NWT1-39 & $7 / 30 / 2004$ & 1000 & Unconfined shallow agricultural & - & - & 69.5 & 0.327 \\
\hline NWT1-39 & $10 / 17 / 2004$ & 1200 & Unconfined shallow agricultural & - & - & 77.9 & 0.343 \\
\hline NWT1-39 & $4 / 1 / 2005$ & 1000 & Unconfined shallow agricultural & - & - & 80.3 & 0.361 \\
\hline Study PSW, depth $61.0 \mathrm{~m}$ & $6 / 16 / 2004$ & 1300 & Study PSW & 0.20 & - & - & 0.149 \\
\hline FP1-147 & $10 / 22 / 2003$ & 1200 & Confined urban unmixed & 0.07 & - & - & 0.069 \\
\hline FP1-147 & $6 / 14 / 2004$ & 1600 & Confined urban unmixed & 0.08 & - & - & 0.084 \\
\hline FP1-185 & $10 / 21 / 2003$ & 1200 & Confined urban unmixed & 0.15 & - & - & 0.174 \\
\hline FP1-185 & $6 / 14 / 2004$ & 1200 & Confined urban unmixed & 0.15 & - & - & 0.186 \\
\hline FP1-185 & 4/7/2005 & 1500 & Confined urban unmixed & 0.15 & - & - & 0.169 \\
\hline FP1-247 & $10 / 20 / 2003$ & 1200 & Confined urban unmixed & 0.39 & - & 0.07 & 0.088 \\
\hline FP1-247 & $6 / 14 / 2004$ & 800 & Confined urban unmixed & 0.36 & - & - & 0.103 \\
\hline FP1-247 & 4/7/2005 & 1300 & Confined urban unmixed & 0.35 & - & - & 0.097 \\
\hline FP2-152 & $10 / 12 / 2004$ & 1500 & Confined urban unmixed & 0.19 & - & - & 0.070 \\
\hline FP3-130 & $10 / 15 / 2003$ & 1100 & Confined urban unmixed & 0.07 & 0.029 & 0.07 & 0.048 \\
\hline
\end{tabular}


Table 18. Results of analyses of nutrients in ground-water samples collected during October 2003 through April 2005 in the localscale TANC study area near York, Nebraska._-Continued

[USGS, U.S. Geological Survey; mg/L, milligram per liter; E, estimated value; <, less than; m, meter; study PSW, study public-supply well; N, nitrogen; P, phosphorus; - , not detected]

\begin{tabular}{|c|c|c|c|c|c|c|c|}
\hline $\begin{array}{c}\text { Well or } \\
\text { sample } \\
\text { name }\end{array}$ & Date & Time & $\begin{array}{l}\text { Well classification } \\
\text { (see table 11) }\end{array}$ & $\begin{array}{l}\text { Ammonia } \\
\mathrm{mg} / \mathrm{L} \text { as } \mathrm{N}\end{array}$ & $\begin{array}{c}\text { Nitrite } \\
\text { mg/L as } N\end{array}$ & $\begin{array}{l}\text { Nitrite plus } \\
\text { nitrate } \\
\mathrm{mg} / \mathrm{L} \text { as } \mathrm{N}\end{array}$ & $\begin{array}{c}\text { Orthophos- } \\
\text { phate } \\
\text { mg/L as } P\end{array}$ \\
\hline \multicolumn{4}{|c|}{ Laboratory reporting level (LRL) } & 0.04 & 0.008 & 0.06 & 0.006 \\
\hline OFPN-167 & $10 / 30 / 2003$ & 1400 & Confined urban unmixed & 0.09 & - & - & 0.067 \\
\hline OFPN-276 & $11 / 12 / 2003$ & 900 & Confined urban unmixed & 0.82 & - & - & 0.053 \\
\hline OFPS-225 & $10 / 14 / 2004$ & 1000 & Confined urban unmixed & 0.29 & - & - & 0.093 \\
\hline FP3-162 & $10 / 28 / 2003$ & 1000 & Confined urban mixed & - & 0.414 & 9.31 & 0.294 \\
\hline FP3-162 & $10 / 16 / 2004$ & 900 & Confined urban mixed & E0.024 & 0.045 & 13.1 & 0.320 \\
\hline FP3-218 & $10 / 15 / 2003$ & 1800 & Confined urban mixed & 0.26 & - & - & 0.130 \\
\hline FP3-218 & $10 / 16 / 2004$ & 1300 & Confined urban mixed & 0.27 & - & - & 0.132 \\
\hline FP3-218 & $4 / 4 / 2005$ & 1200 & Confined urban mixed & 0.27 & - & - & 0.136 \\
\hline OFPS-157 & $11 / 11 / 2003$ & 1000 & Confined urban mixed & - & 0.23 & 4.47 & 0.192 \\
\hline FP1-63 & $10 / 27 / 2003$ & 1100 & Unconfined shallow urban & - & - & 25.6 & 0.621 \\
\hline FP1-63 & $6 / 15 / 2004$ & 800 & Unconfined shallow urban & - & - & 27.1 & 0.627 \\
\hline FP1-63 & $10 / 15 / 2004$ & 1400 & Unconfined shallow urban & - & - & 28.8 & 0.631 \\
\hline FP1-63 & $4 / 11 / 2005$ & 1300 & Unconfined shallow urban & - & - & 28.4 & 0.624 \\
\hline FP2-43 & $7 / 28 / 2004$ & 1300 & Unconfined shallow urban & - & - & 16.4 & 0.455 \\
\hline FP2-43 & $10 / 13 / 2004$ & 1400 & Unconfined shallow urban & - & - & 17.1 & 0.458 \\
\hline FP2-43 & $3 / 30 / 2005$ & 1100 & Unconfined shallow urban & - & - & 15.9 & 0.485 \\
\hline FP3-33 & $10 / 28 / 2003$ & 1300 & Unconfined shallow urban & - & 0.009 & 3.84 & 0.358 \\
\hline FP3-33 & $7 / 26 / 2004$ & 1400 & Unconfined shallow urban & - & - & 2.41 & 0.411 \\
\hline FP3-33 & $10 / 16 / 2004$ & 1100 & Unconfined shallow urban & E0.021 & - & 2.56 & 0.430 \\
\hline FP3-33 & $4 / 4 / 2005$ & 1600 & Unconfined shallow urban & E0.027 & - & 2.51 & 0.457 \\
\hline UWT1-53 & $8 / 3 / 2004$ & 1000 & Unconfined shallow urban & - & - & 17.3 & 0.413 \\
\hline UWT1-53 & $10 / 20 / 2004$ & 1200 & Unconfined shallow urban & - & - & 18.6 & 0.420 \\
\hline UWT1-53 & $4 / 5 / 2005$ & 1200 & Unconfined shallow urban & - & - & 18.4 & 0.406 \\
\hline UWT2-23 & $8 / 3 / 2004$ & 1300 & Unconfined shallow urban & - & - & 15.7 & 0.786 \\
\hline UWT2-23 & $10 / 20 / 2004$ & 1400 & Unconfined shallow urban & - & - & 13.6 & 0.798 \\
\hline UWT2-23 & $4 / 5 / 2005$ & 1000 & Unconfined shallow urban & - & - & 15.7 & 0.824 \\
\hline UWT3-34 & $8 / 4 / 2004$ & 1000 & Unconfined shallow urban & - & - & 17.0 & 0.485 \\
\hline UWT3-34 & $10 / 17 / 2004$ & 900 & Unconfined shallow urban & - & - & 19.0 & 0.514 \\
\hline UWT3-34 & $4 / 5 / 2005$ & 1500 & Unconfined shallow urban & - & - & 17.6 & 0.509 \\
\hline UWT4-85 & $8 / 4 / 2004$ & 1300 & Unconfined shallow urban & - & - & 22.1 & 0.293 \\
\hline UWT4-85 & $10 / 22 / 2004$ & 1000 & Unconfined shallow urban & - & - & 22.0 & 0.297 \\
\hline UWT4-85 & $4 / 6 / 2005$ & 1100 & Unconfined shallow urban & - & - & 23.8 & 0.291 \\
\hline
\end{tabular}




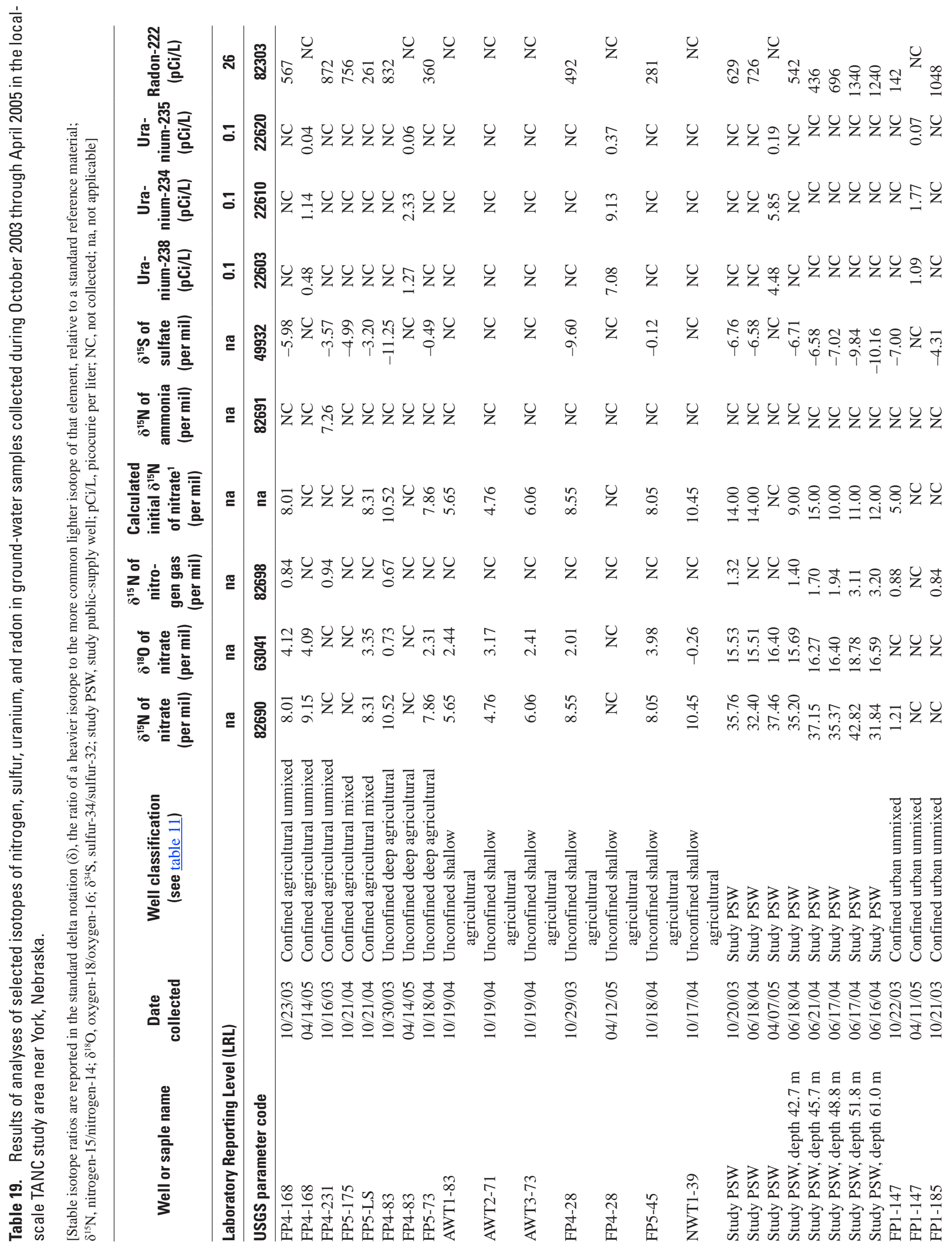




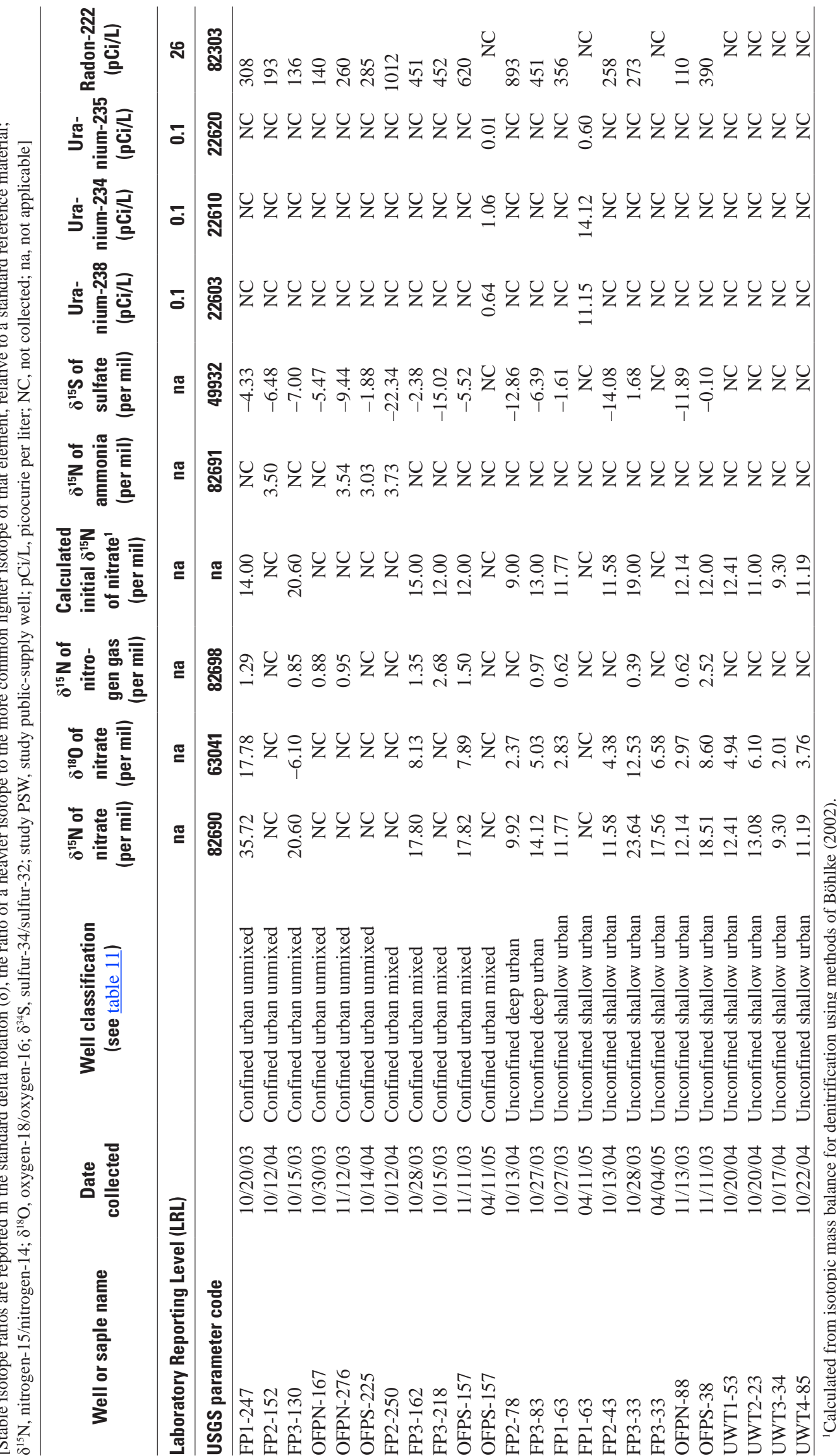




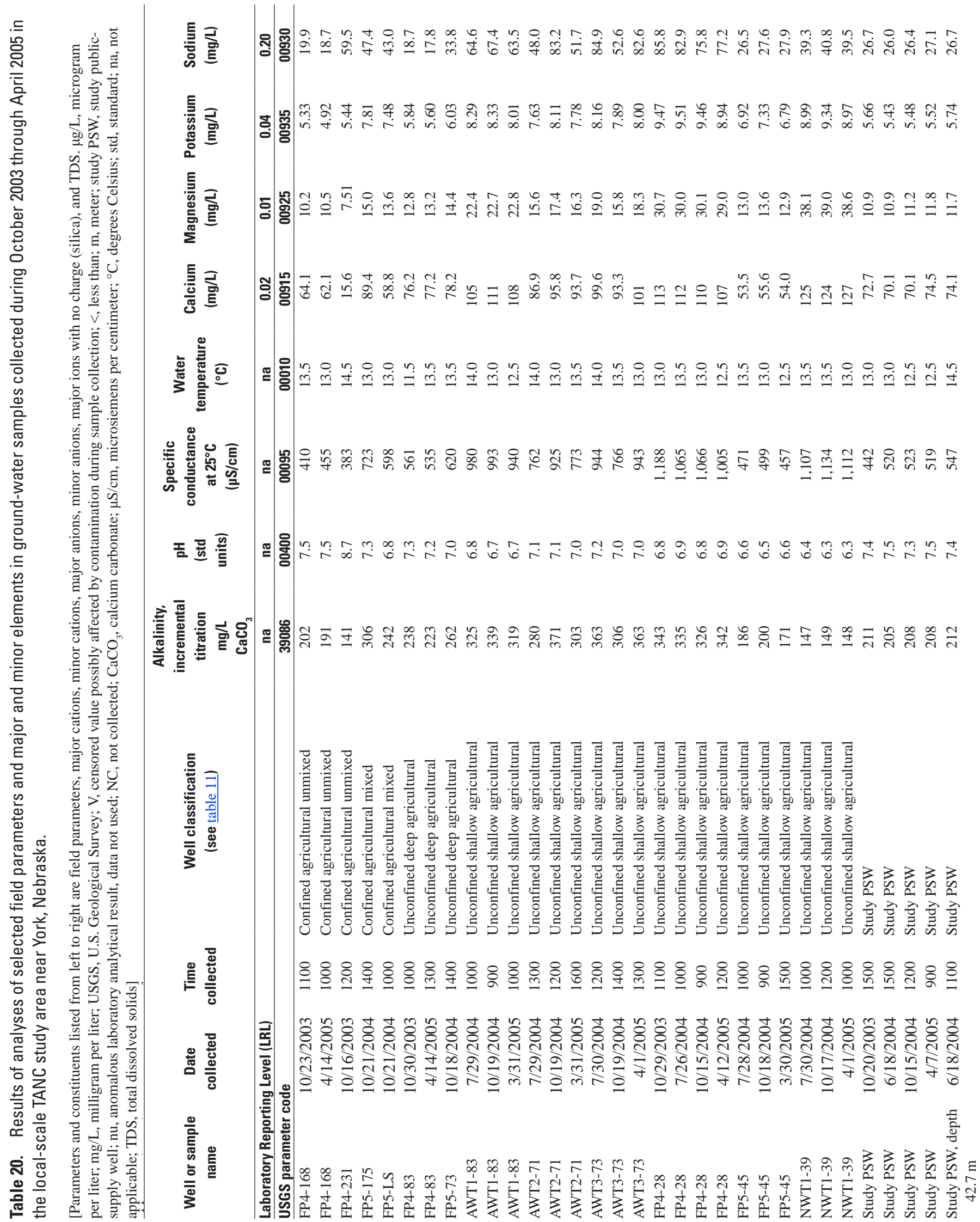




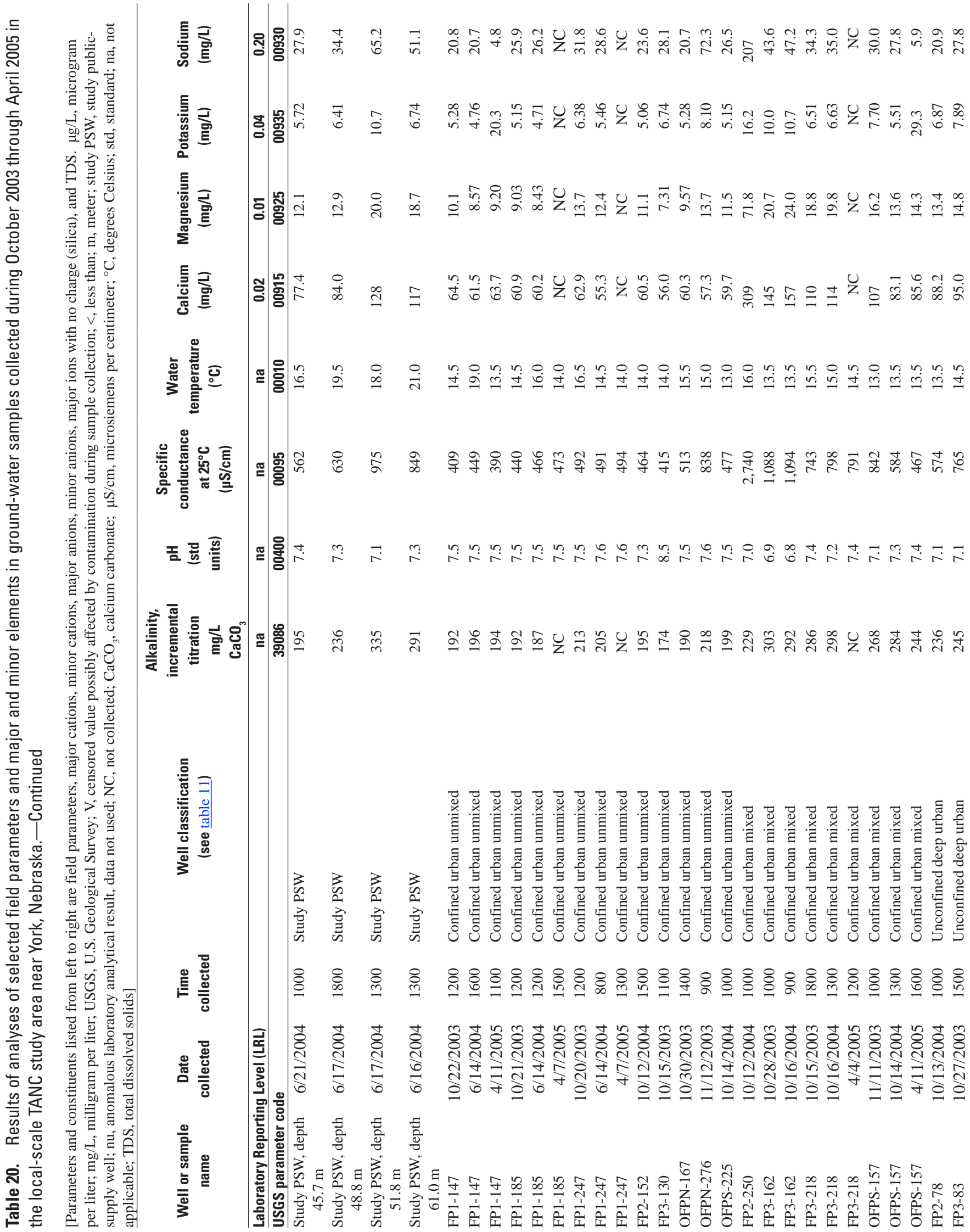




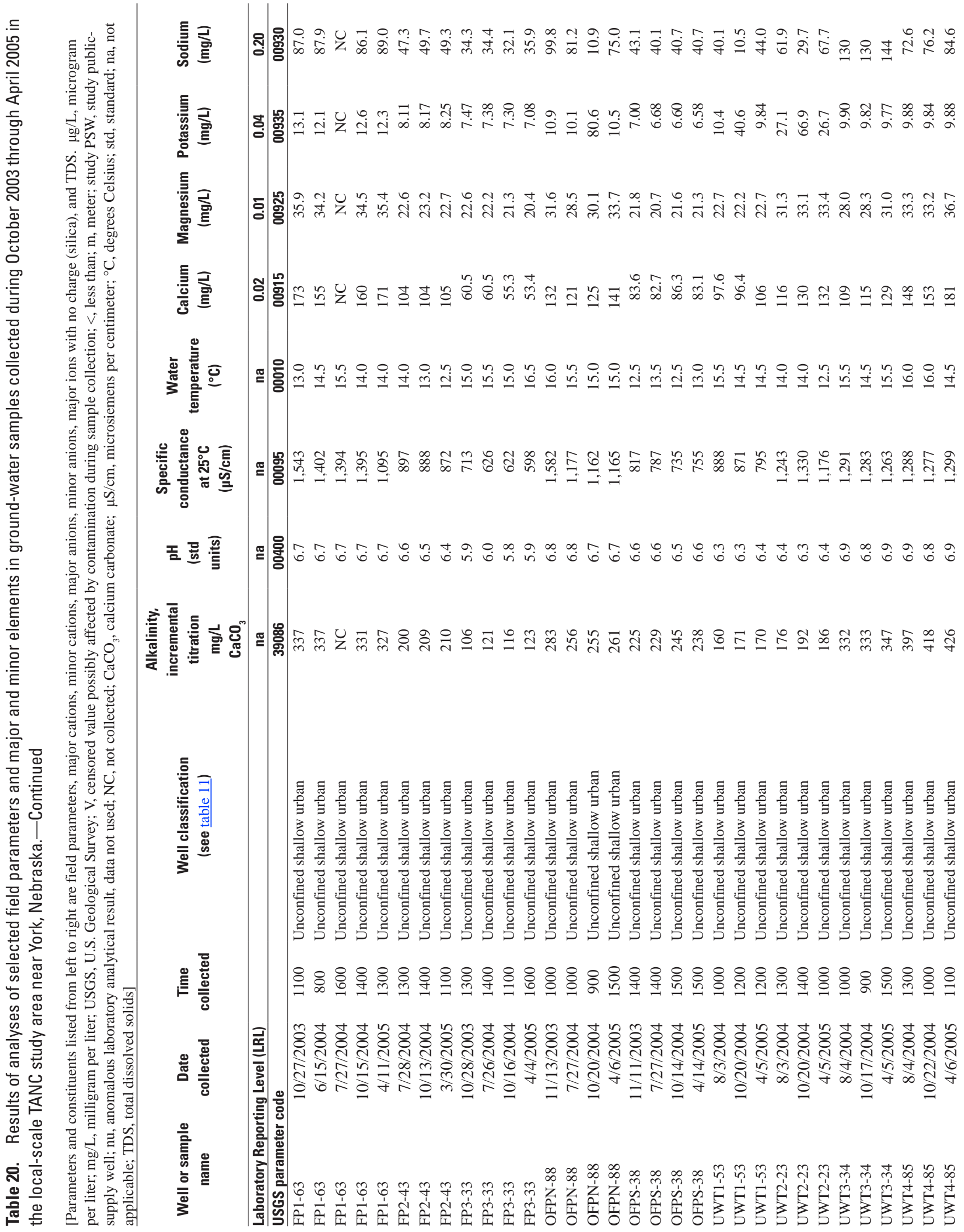




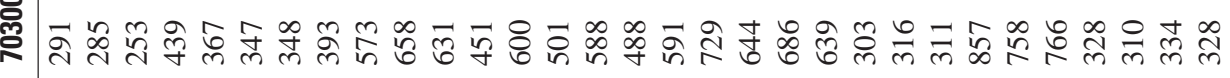

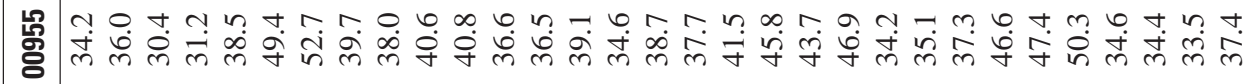

兽

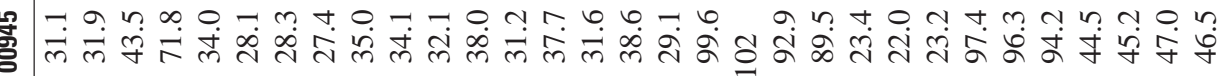

బ

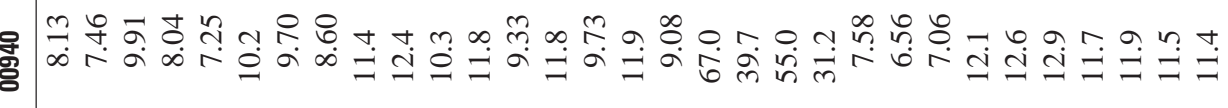

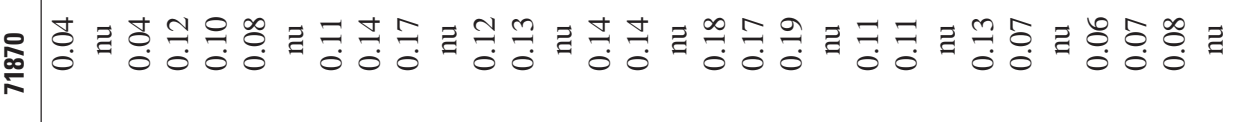

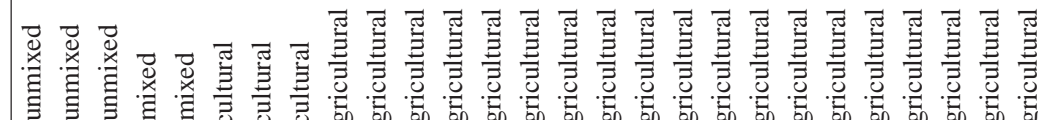

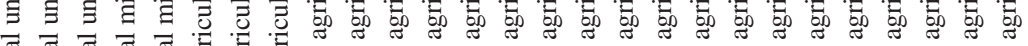

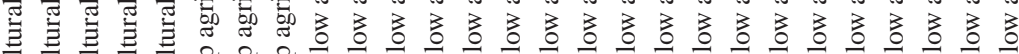

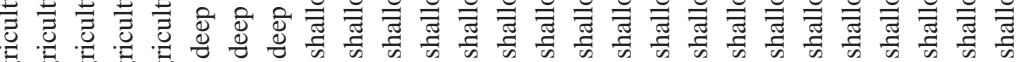

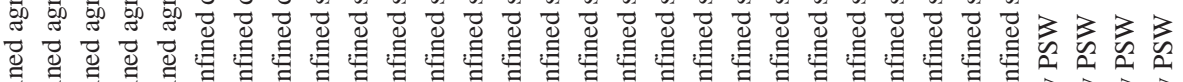

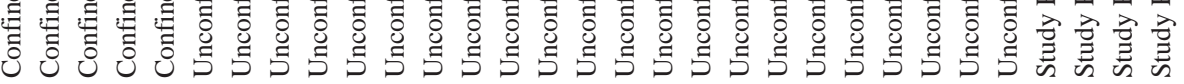

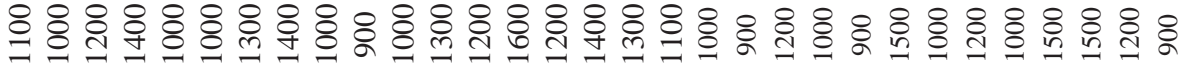

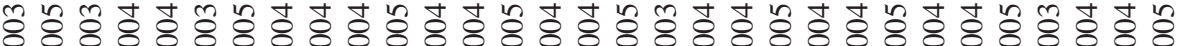

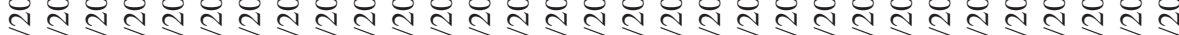

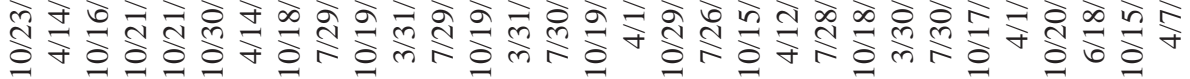

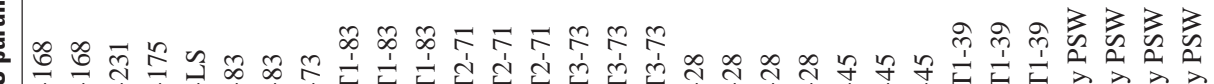

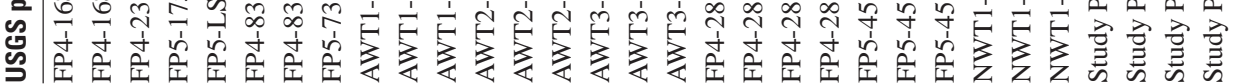




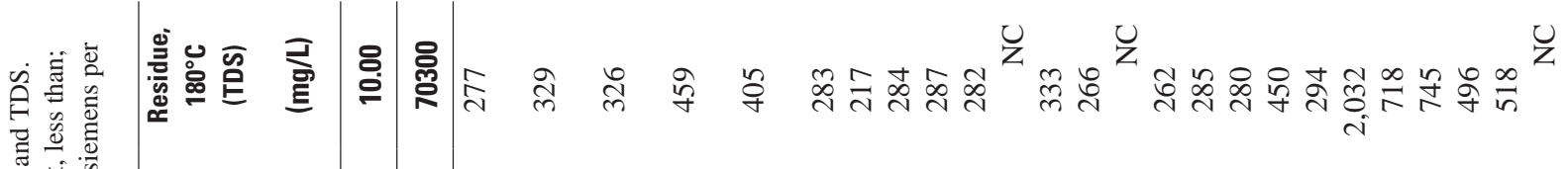

호

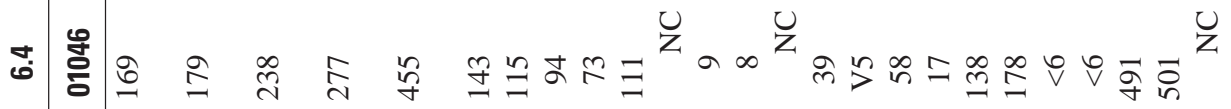

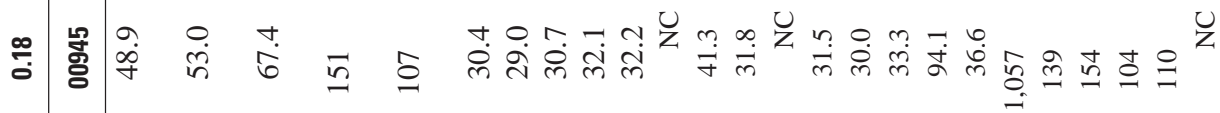

$\stackrel{n}{\infty}$

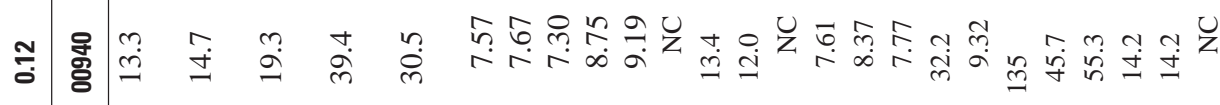

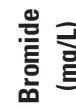

$\approx$

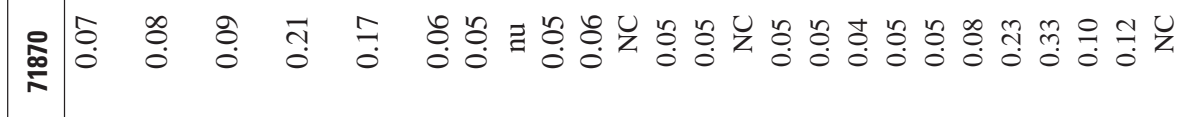

\& \& \& \& \& \& \&

¿ 


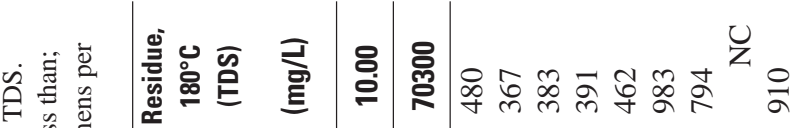

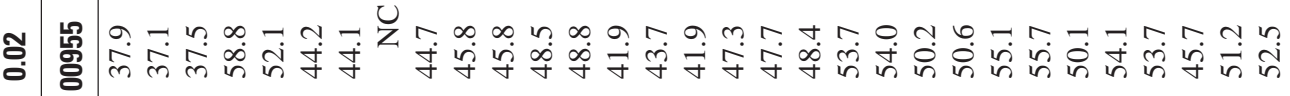

$\rightarrow+0.0 . \quad Z$

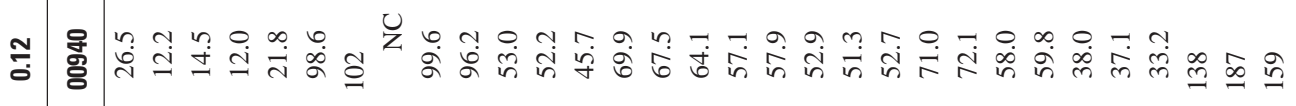

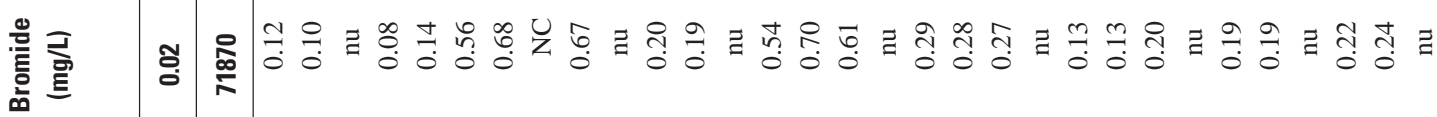

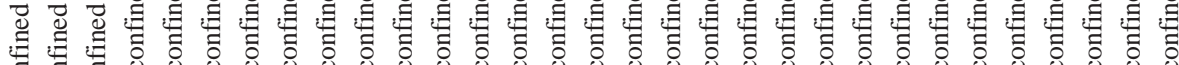

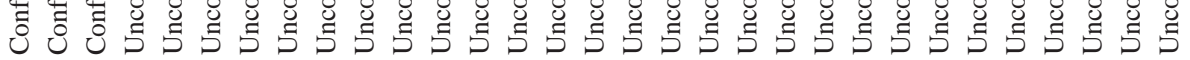

\& \& \& 응 \&

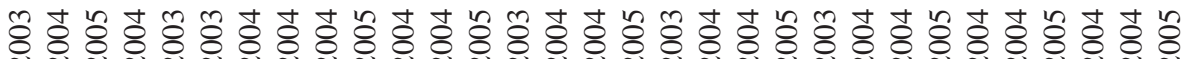

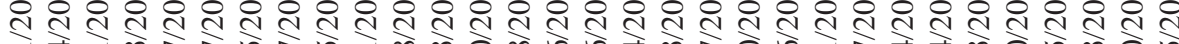

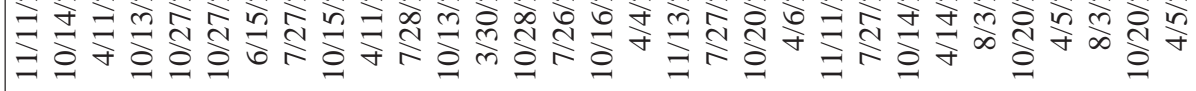




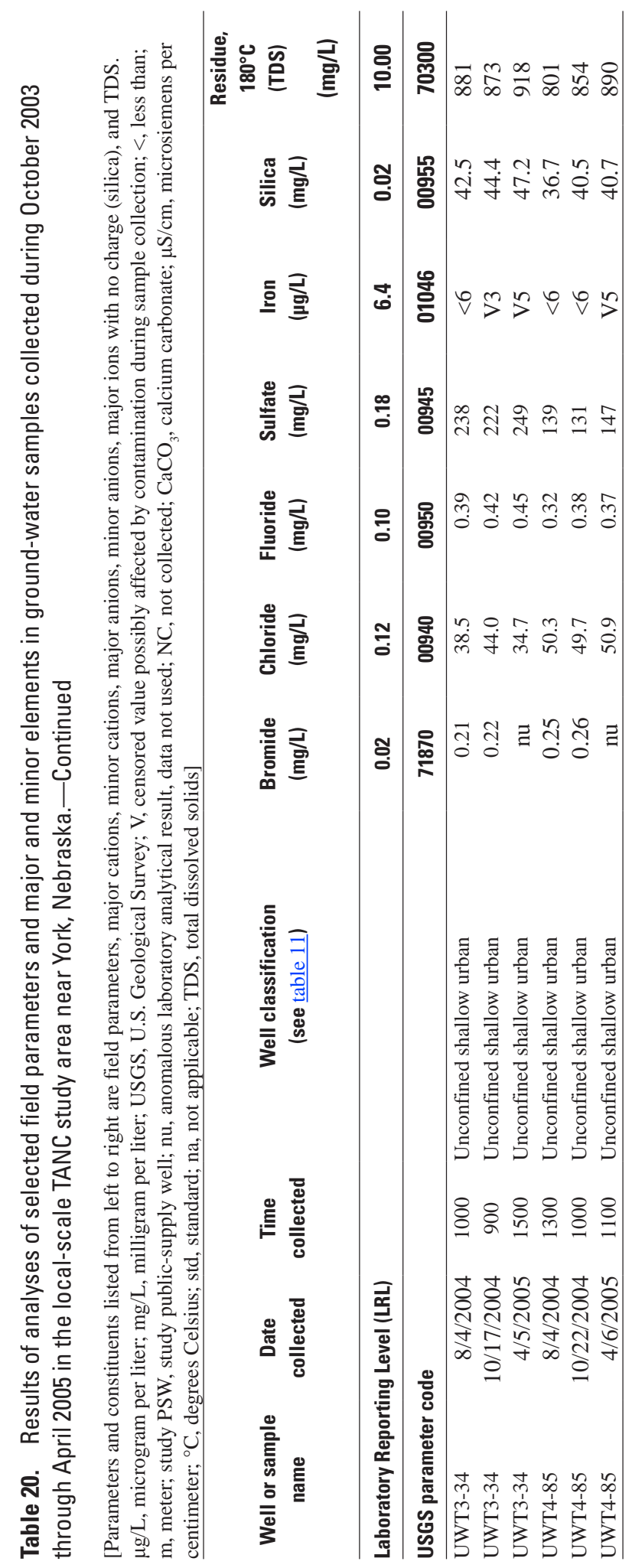




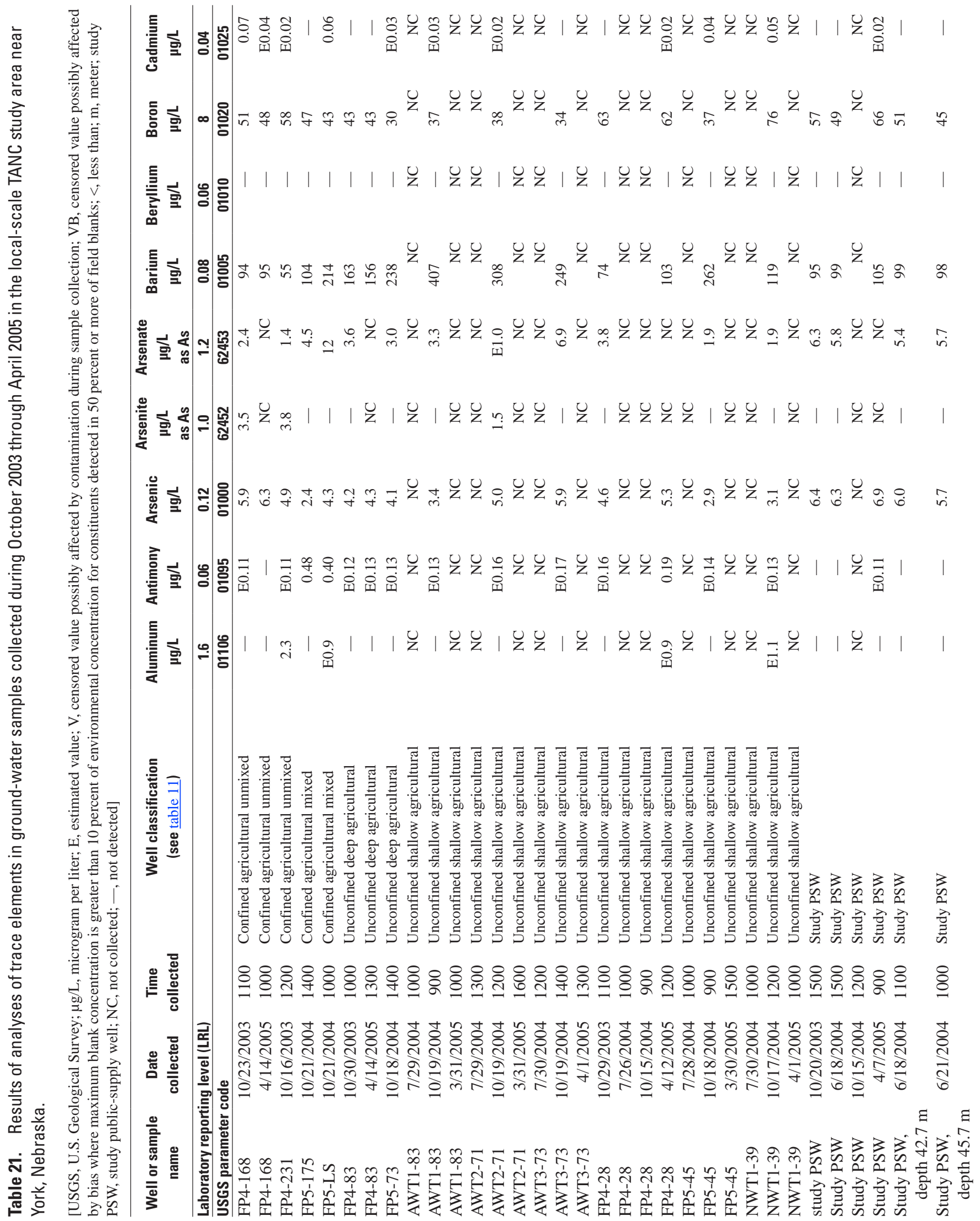




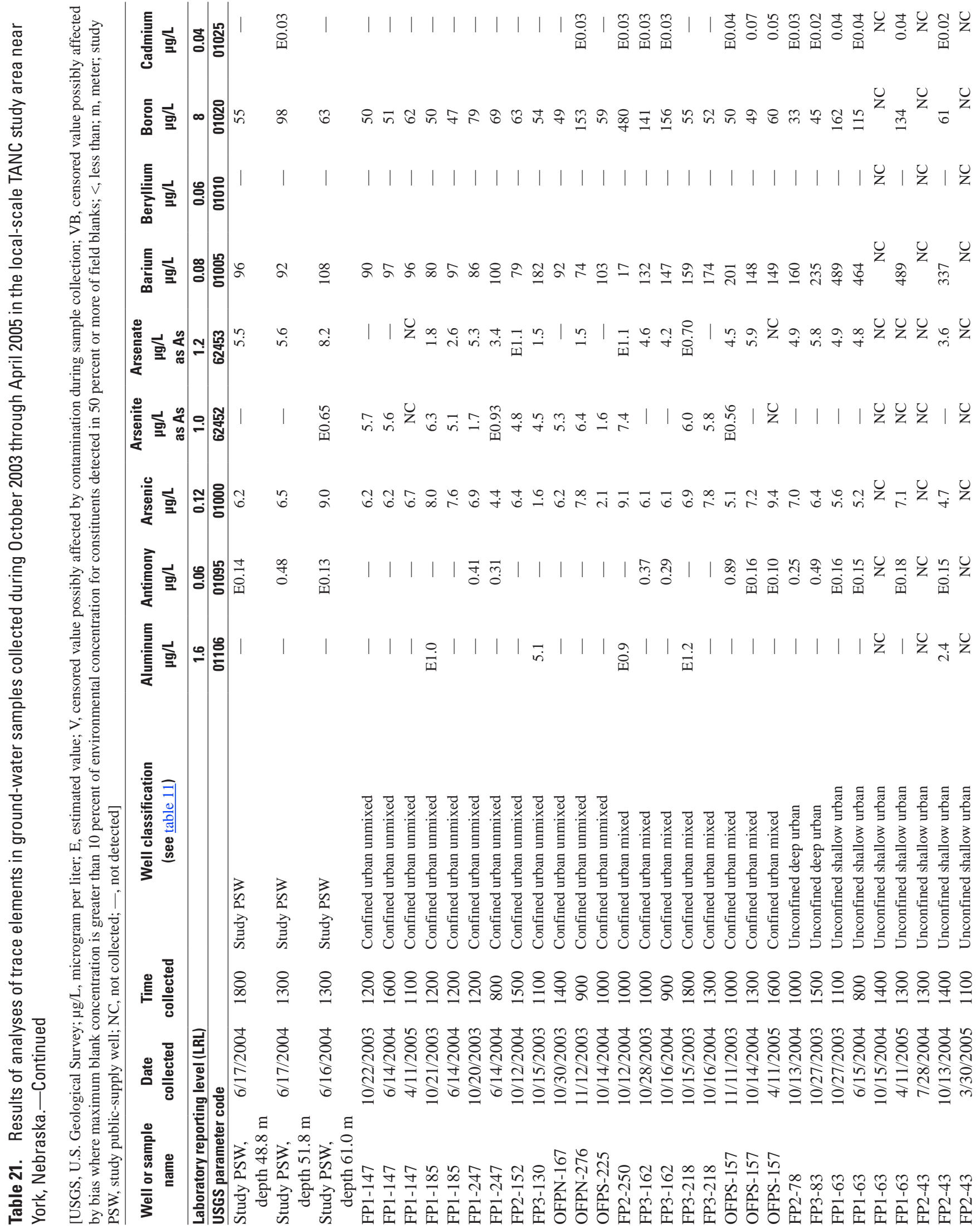




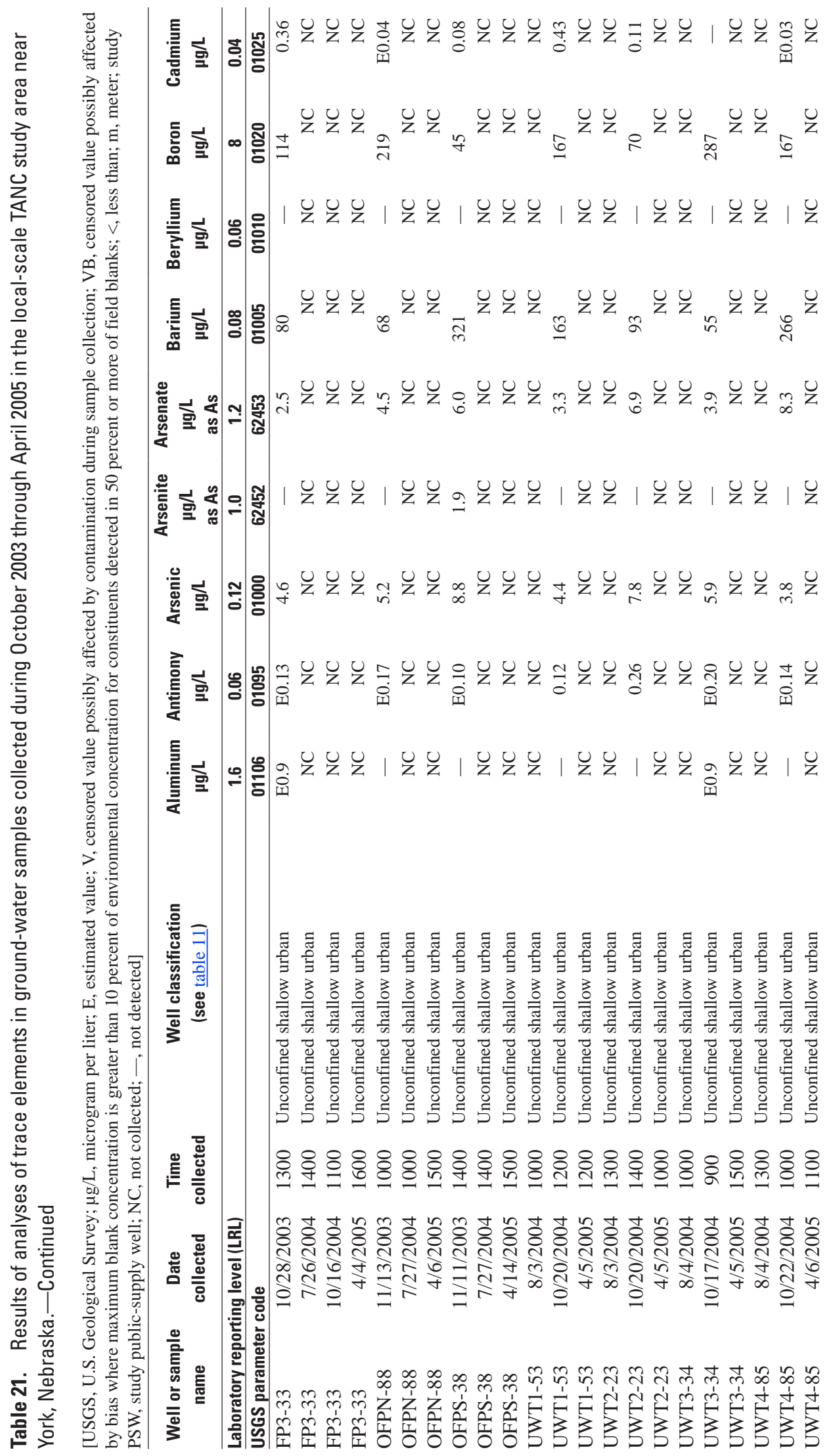




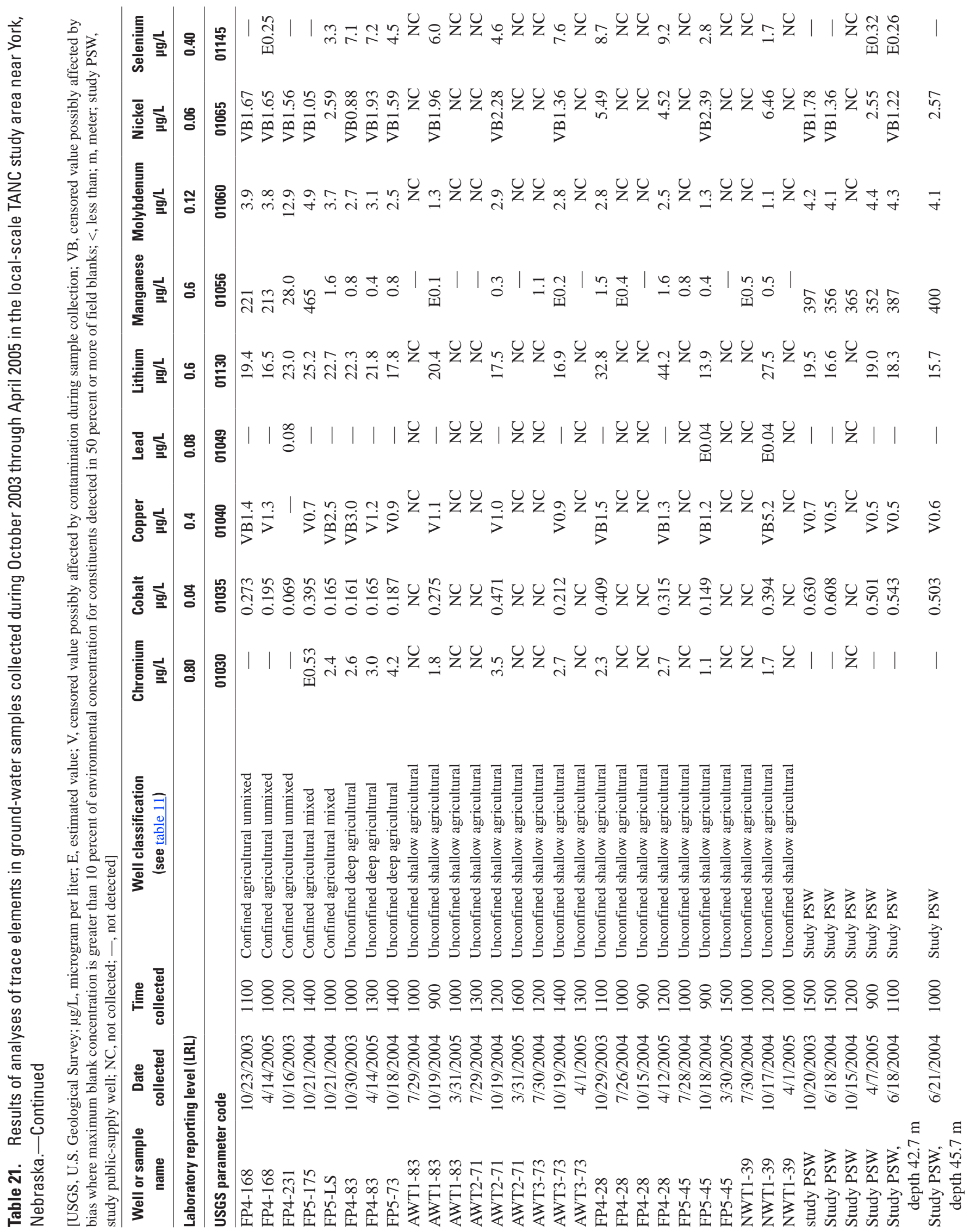




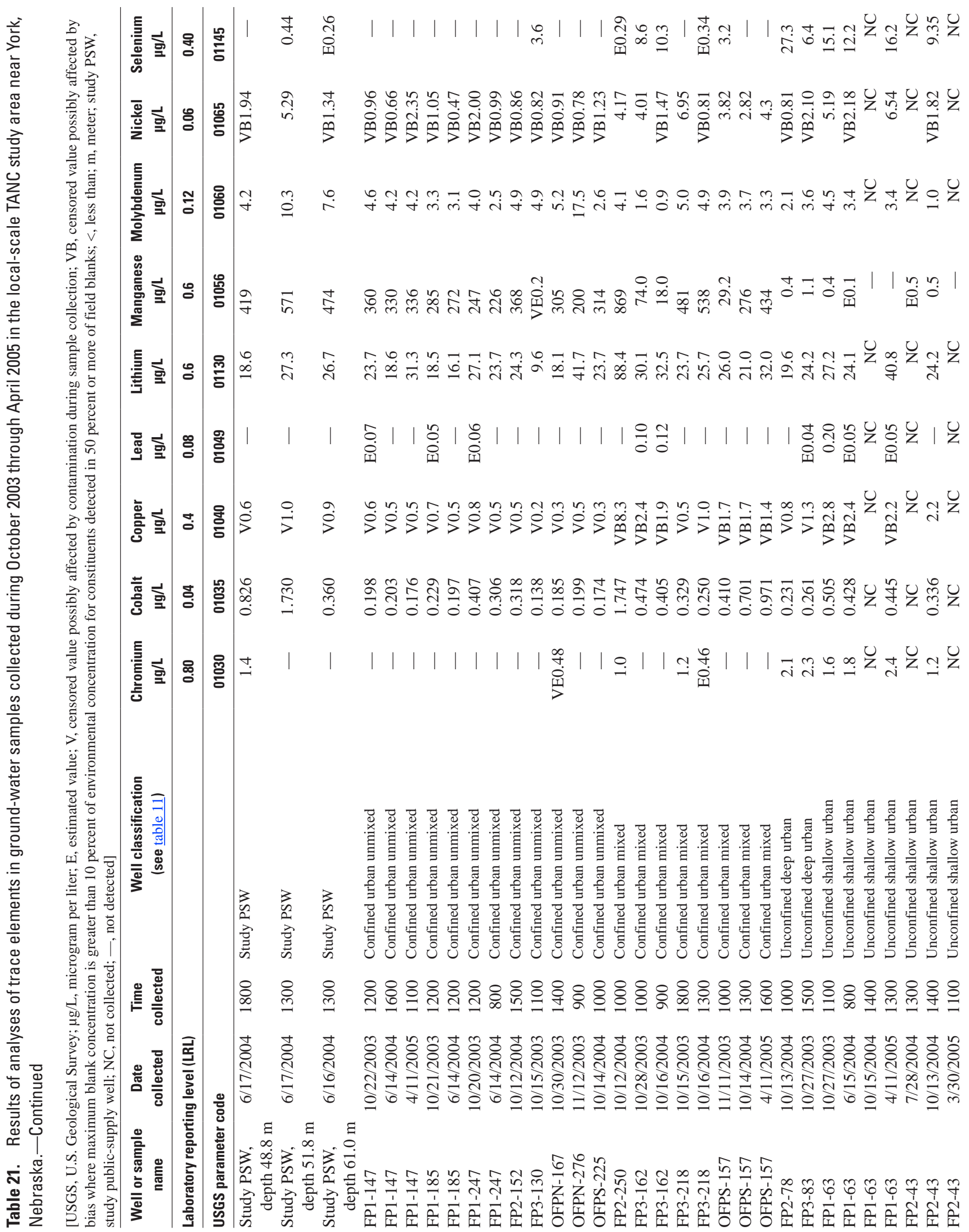




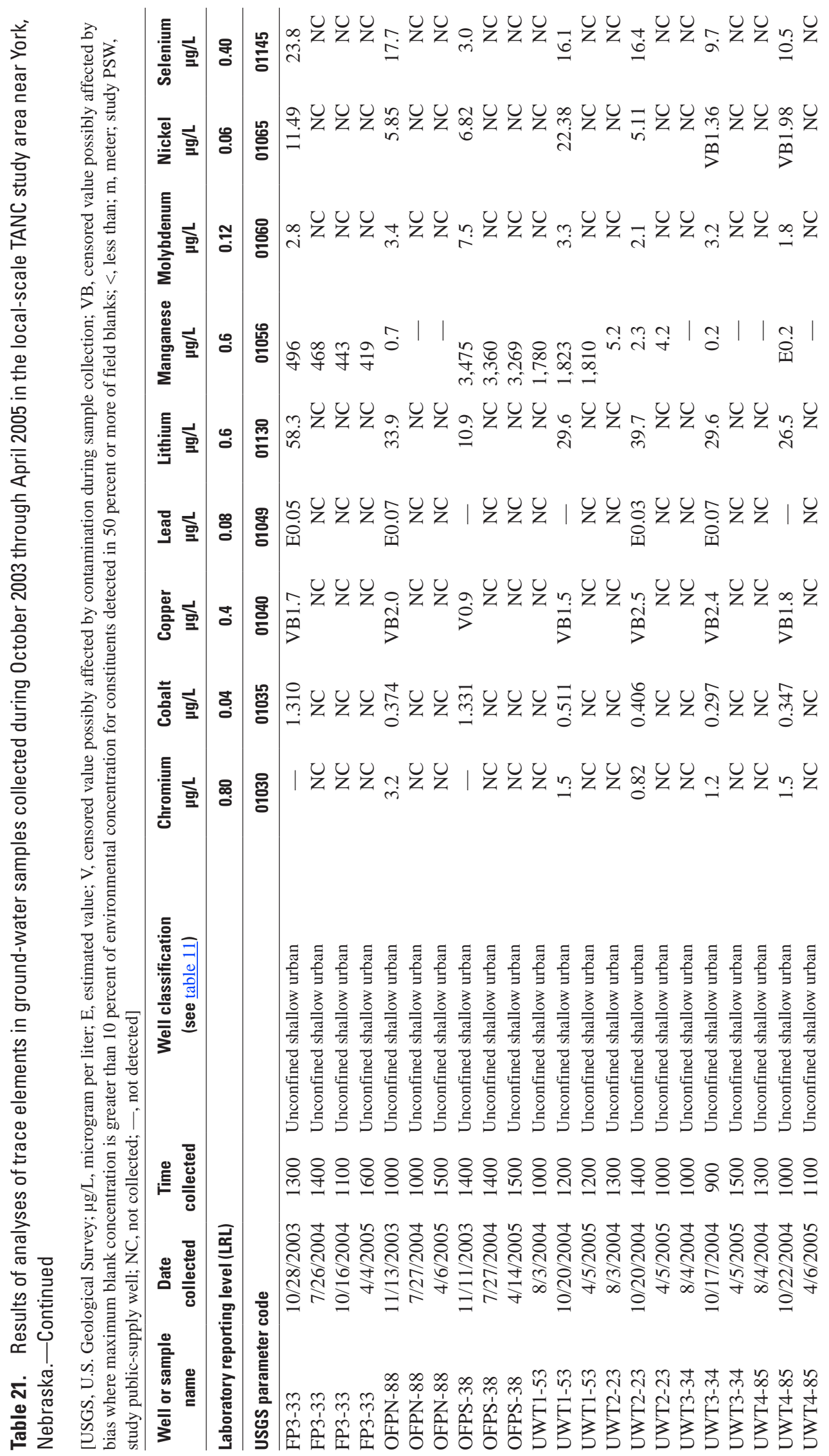




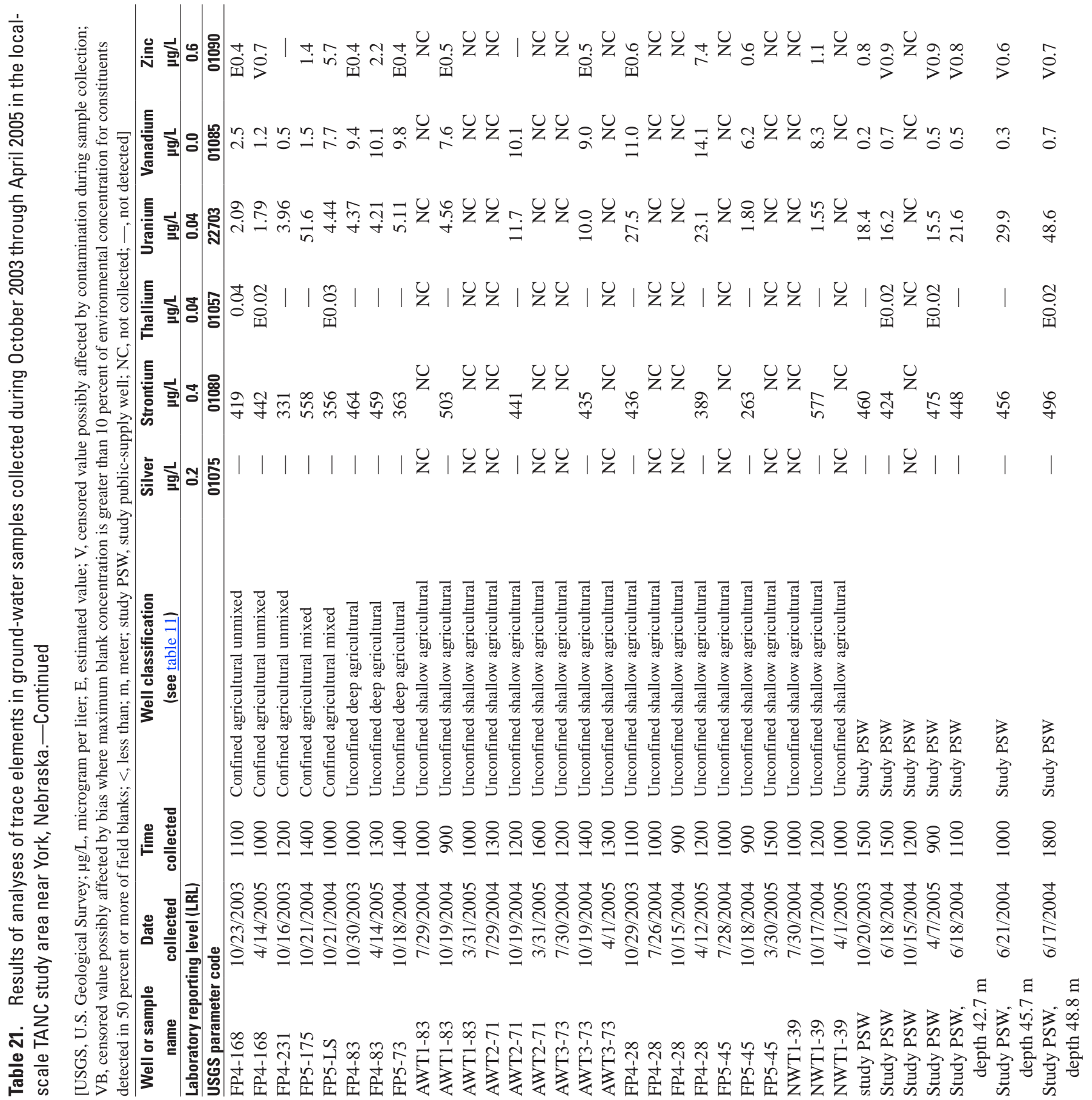




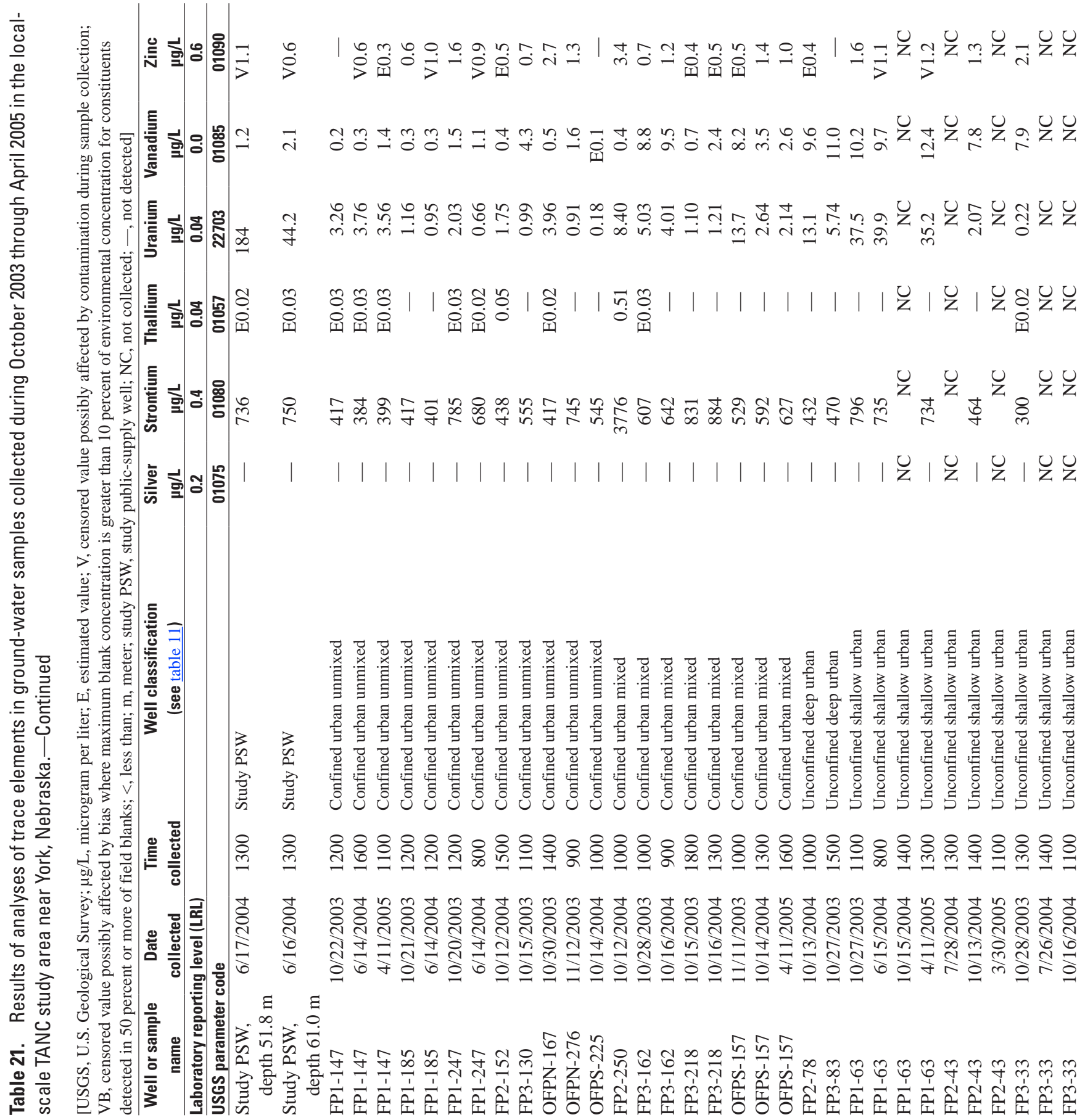




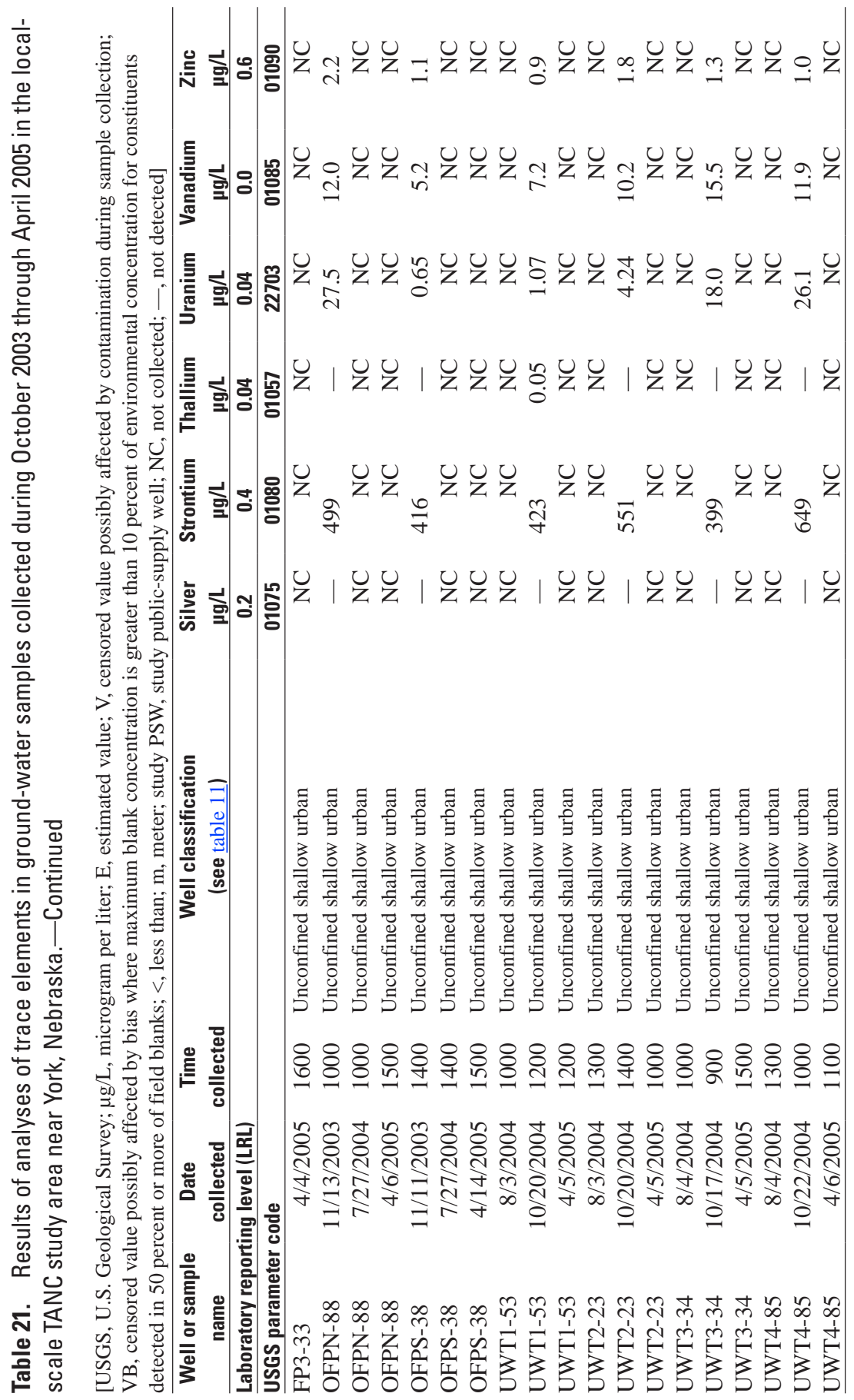





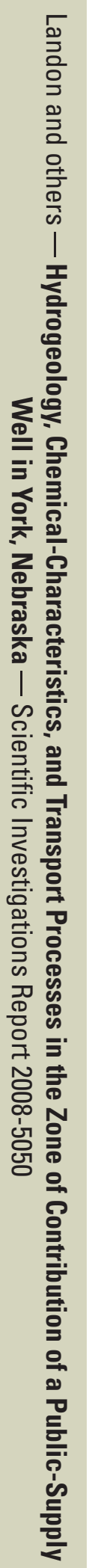

4 Printed on recycled paper 